\title{
Phosphorus nutrition of poplar
}

\author{
Dissertation \\ zur Erlangung des mathematisch-naturwissenschaftlichen \\ Doktorgrades \\ "Doctor rerum naturalium" \\ der Georg-August-Universität Göttingen \\ im Promotionsprogramm Biologie \\ der Georg-August University School of Science (GAUSS)
}

\author{
vorgelegt von \\ Mareike Jana Kavka \\ aus Hamburg
}

Göttingen, 2016 
Betreuungsausschuss

Prof. Dr. Andrea Polle, Forstbotanik und Baumphysiologie, Büsgen-Institut, Universität Göttingen

Prof. Dr. Elvira Hörandl, Systematik, Biodiversität und Evolution der Pflanzen, Albrecht-von-Haller-Institut für Pflanzenwissenschaften, Universität Göttingen

Mitglieder der Prüfungskommission

Referentin:

Prof. Dr. Andrea Polle, Forstbotanik und Baumphysiologie, Büsgen-Institut, Universität Göttingen

Korreferentin:

Prof. Dr. Elvira Hörandl, Systematik, Biodiversität und Evolution der Pflanzen, Albrecht-von-Haller-Institut für Pflanzenwissenschaften, Universität Göttingen

Weitere Mitglieder der Prüfungskommission:

Prof. Dr. Ivo Feußner, Biochemie der Pflanze, Albrecht-von-Haller-Institut für Pflanzenwissenschaften, Universität Göttingen

PD Dr. Thomas Teichmann, Zellbiologie der Pflanze, Albrecht-von-Haller-Institut für Pflanzenwissenschaften, Universität Göttingen

Prof. Dr. Konstantin Krutovsky, Forstgenetik und Forstpflanzenzüchtung, BüsgenInstitut, Universität Göttingen

Prof. Dr. Christian Ammer, Waldbau und Waldökologie der gemäßigten Zonen, Burckhardt-Institut, Universität Göttingen

Tag der mündlichen Prüfung: 15.12.2016 


\section{Table of contents}

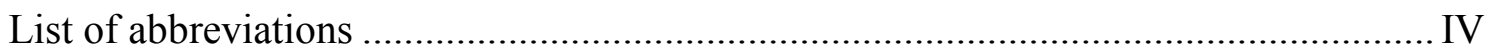

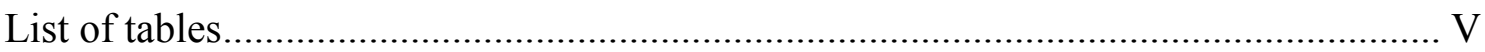

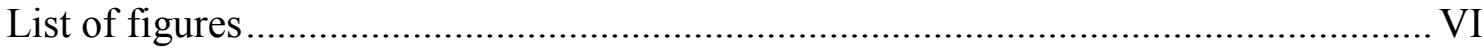

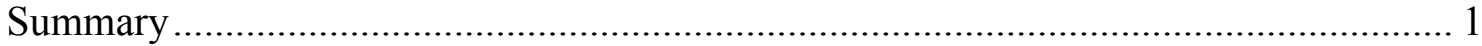

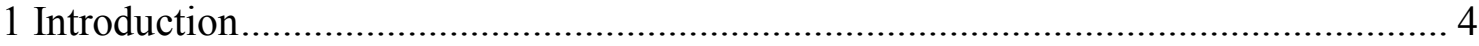

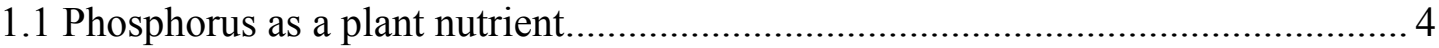

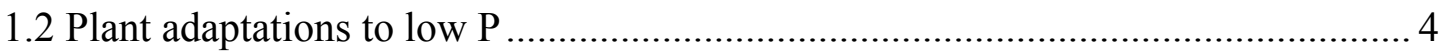

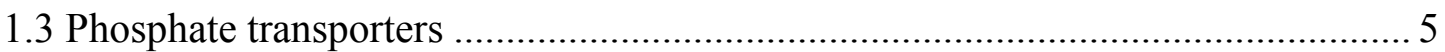

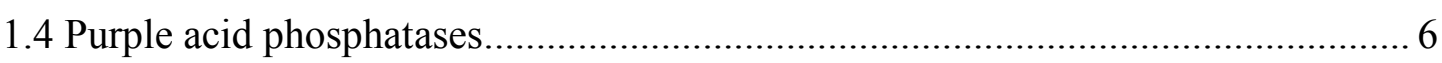

1.5 Poplar, a model to study the $\mathrm{P}$ nutrition of trees ............................................... 7

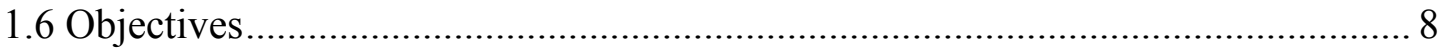

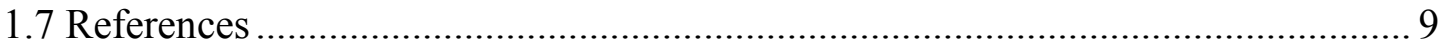

2 Dissecting nutrient-related co-expression networks in phosphate starved poplar....... 14

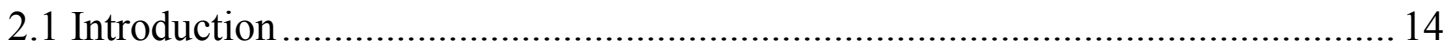

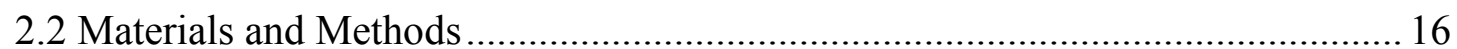

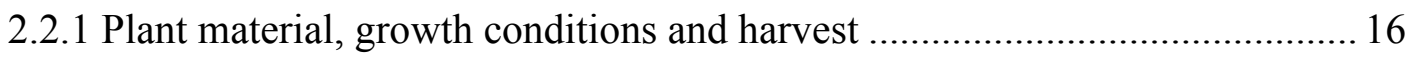

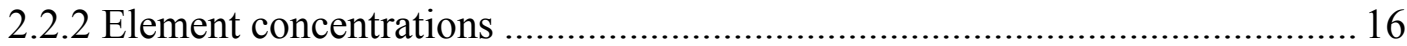

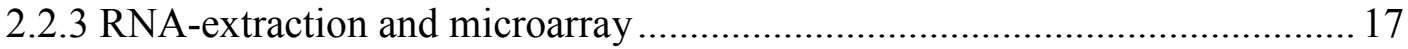

2.2.4 Statistical analyses of microarrays ......................................................... 17

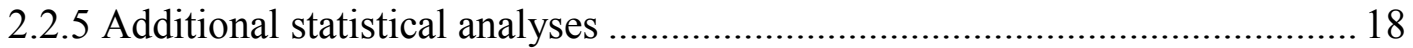

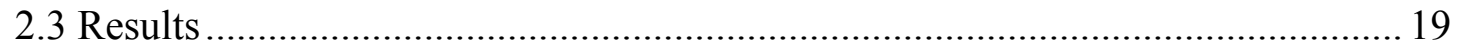

2.3.1 P deprivation affects nutrient element concentrations.................................. 19

2.3.2 $\mathrm{P}$ deprivation leads to massive transcriptional reprograming........................ 21

2.3.3 Co-expression modules are correlated with nutrient element concentrations

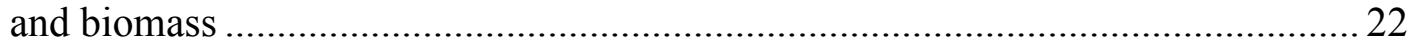

2.3.4 Network analysis reveals a hierarchy of modules ...................................... 24

2.3.5 Functional characterization of P-related and highly connected modules ....... 26

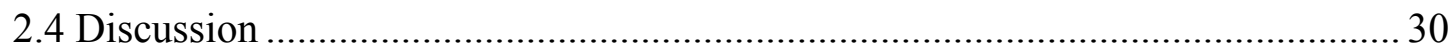

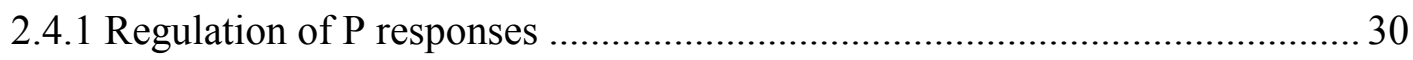

2.4.2 Transcriptional regulation of $\mathrm{P}$ acquisition and $\mathrm{P}$ uptake............................. 31 
2.4.3 Metabolism of mineral nutrients, sulfur, nitrogen and carbon upon $\mathrm{P}$ starvation

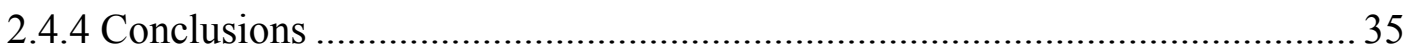

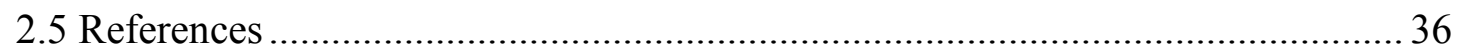

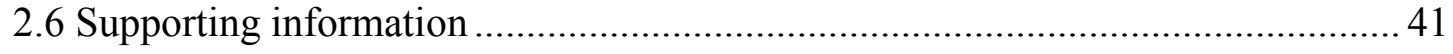

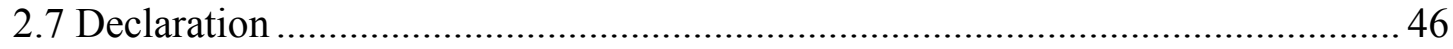

3 Phosphate uptake kinetics and tissue-specific transporter expression profiles in poplar

$($ Populus $\times$ canescens $)$ at different phosphorus availabilities..................................... 47

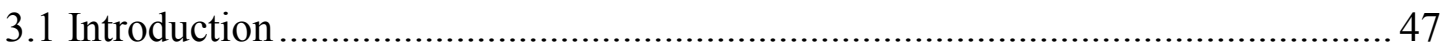

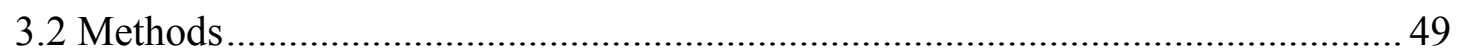

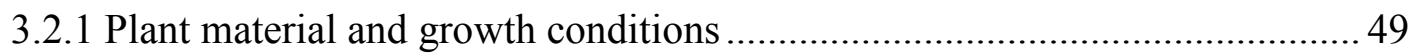

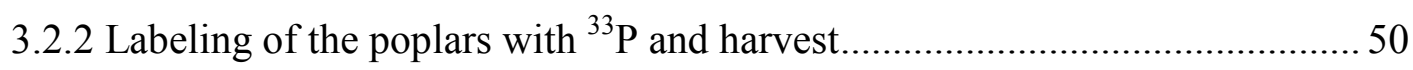

3.2.3 Phosphorus distribution at the whole-plant level ........................................5 50

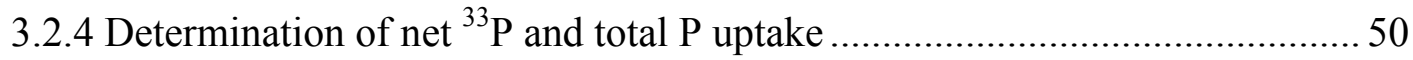

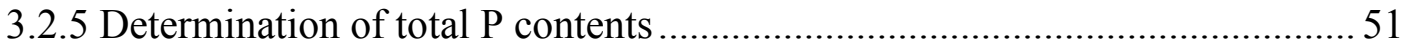

3.2.6 Phosphate uptake after glucose supply and determination of carbohydrates 52

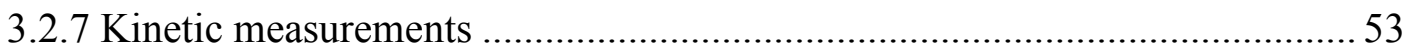

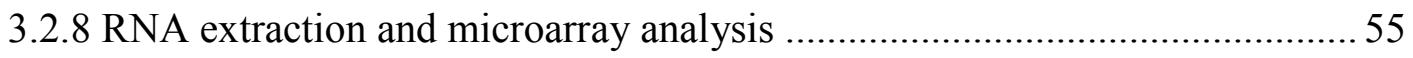

3.2.9 Quantitative Real Time PCR of P transporter genes ..................................... 57

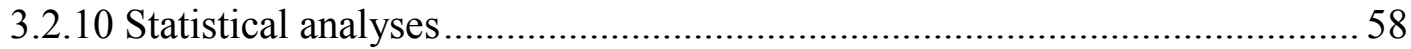

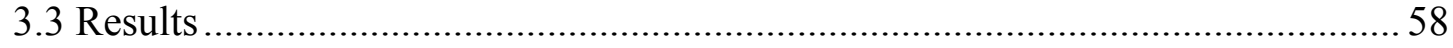

3.3.1 Plant performance, $\mathrm{P}$ uptake and allocation in response to $\mathrm{P}$ deficiency ....... 58

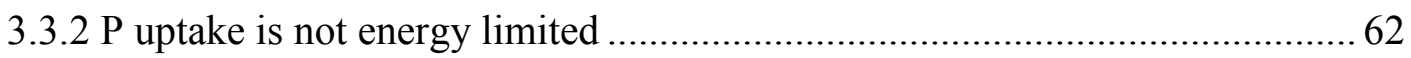

3.3.3 Low $\mathrm{P}$ concentrations in the nutrient solution limit $\mathrm{P}$ uptake .......................6 63

3.3.4 Low $\mathrm{P}$ availabilities lead to differential regulation of $\mathrm{P}$ transporters ..............65 65

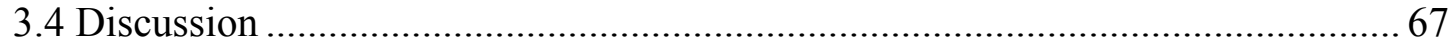

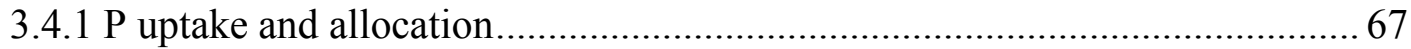

3.4.2 Regulation of the poplar PHT families in response to $\mathrm{P}$ starvation ............... 70

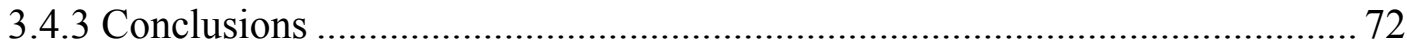

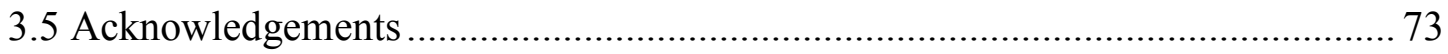

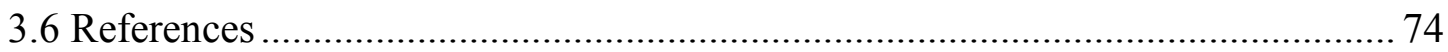

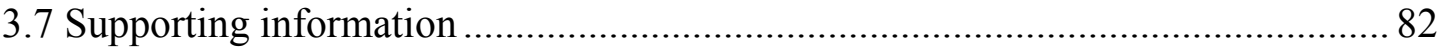

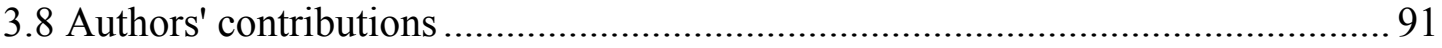


3.9 Declaration

4 Phosphate acquisition by poplar: Phylogeny, tissue-specific expression, and activity of

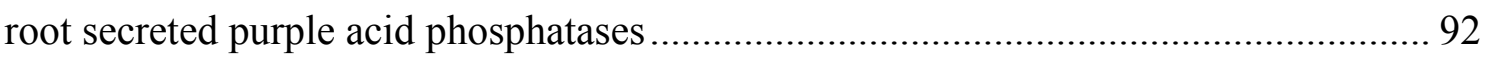

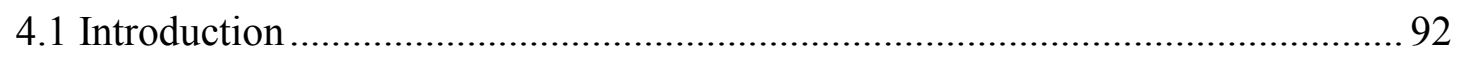

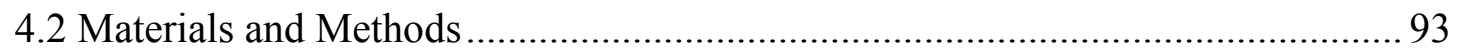

4.2.1 Measurement of root-associated acid phosphatase activity in vivo ............... 93

4.2.2 Purple acid phosphatases in apoplastic washing fluid (AWF) ..................... 95

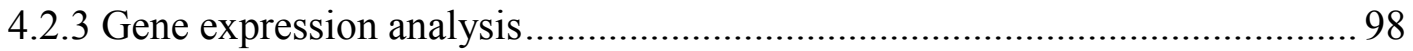

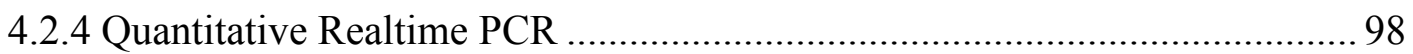

4.2.5 Assessment of root morphological parameters......................................... 101

4.2.6 Phylogeny of PAPs in poplar compared with Arabidopsis, rice and maize. 101

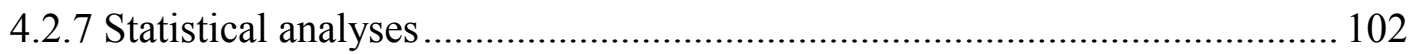

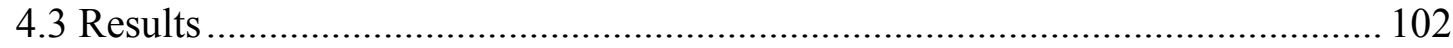

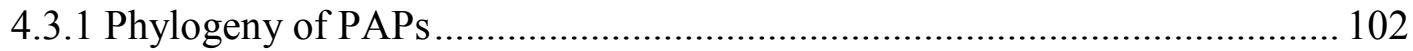

4.3.2 Expression of poplar PAPs is enhanced under phosphate deprivation in roots and leaves

4.3.3 Roots of P deprived poplar have altered root morphology and higher acid

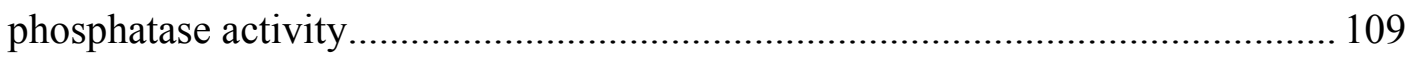

4.3.4 Roots of P deprived poplar secrete additionally PtPAP1 ............................ 112

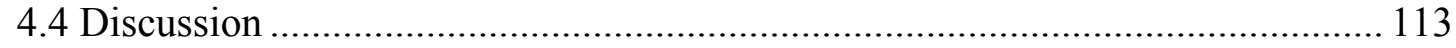

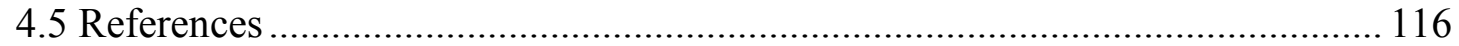

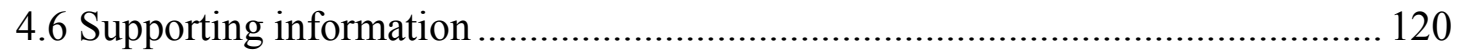

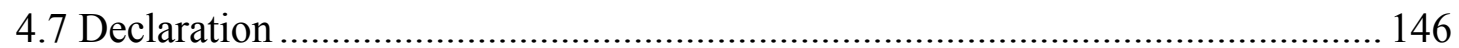

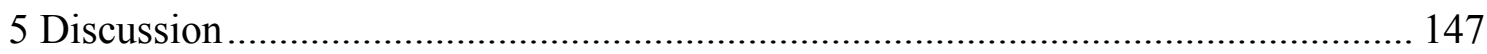

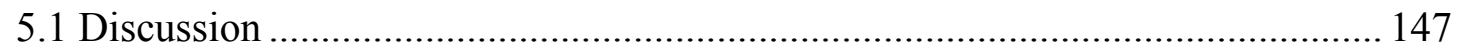

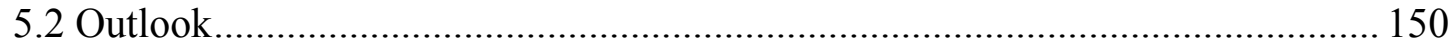

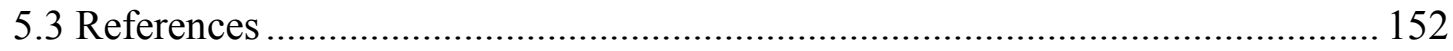

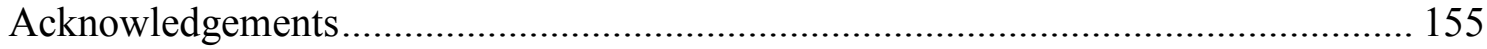

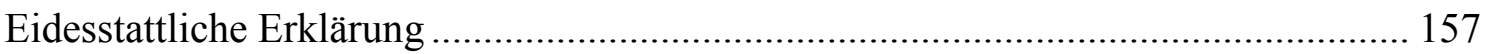

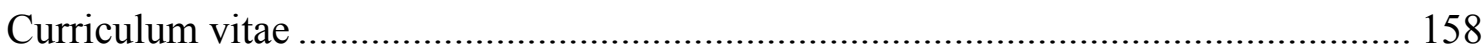




\section{List of abbreviations}

$\mathrm{Al}$

AWF

BCIP

$\mathrm{BM}$

C

$\mathrm{Ca}$

DEG

FC

$\mathrm{Fe}$

HP

ICP-OES

K

LC-ESI-MS Liquid-chromatography electrospray-ionization mass spectrometer

LP

$\mathrm{Mg}$

$\mathrm{Mn}$

MP

$\mathrm{N}$

$\mathrm{P}$

PAP

PHT

$\mathrm{Pi}$

pNPP

PUE

qRT PCR

$\mathrm{S}$

WGCNA Weighted gene co-expression network analysis

$\mathrm{Zn}$

Aluminum

Apoplastic washing fluid

5-bromo-4-chloro-3-indolyl phosphate disodium salt

Biomass

Carbon

Calcium

Differentially expressed gene

Fold change

Iron

High phosphate

Inductively coupled plasma optical emission spectrometer

Potassium

Low phosphate

Magnesium

Manganese

Medium phosphate

Nitrogen

Phosphorus

Purple acid phosphatase

Phosphate transporters

Inorganic phosphate

4-nitrophenyl phosphate disodium salt

$\mathrm{P}$ use efficiency

Quantitative Real Time PCR

Sulfur

Zinc 


\section{List of tables}

Table 2.1: ANOVA results for the main factors "treatment" and "tissue".

Table 2.2: Correlation analysis of element concentrations with $\mathrm{P}$ concentrations or biomass.

Table S2.1: Information about differentially expressed genes. (data CD)

Table S2.2: Overview about enriched GO terms in all modules. (data CD)

Table S2.3: Gene name abbreviations for Figure 2.6.

Table 3.1: In planta $P$ and $P$ uptake characteristics of $P$ deficient poplar.

Table 3.2: Kinetic parameters for $P$ uptake of $P$ deficient poplar.

Table S3.1: In silico analyses of putative poplar phosphate transporters.

Table S3.2: Primers used for qRT PCR of putative P transporter genes.

Table S3.3: Transcript abundances of phosphate transporter genes.

Table 4.1: Primers used for $\mathrm{qRT}$ PCR.

Table 4.2: Summary of in silico analyses for poplar purple acid phosphatases.

Table S4.1: Proteins in the AWF of P starved poplar. (data CD) 


\section{List of figures}

Figure 2.1. Element concentrations in leaves, stem, coarse roots and fine roots of poplars.

Figure 2.2. Venn-diagram of differentially regulated genes.

Figure 2.3. Correlation matrix between eigengenes of co-expression modules and element concentrations and biomass.

Figure 2.4. Co-expression within and between modules of DEGs.

Figure 2.5. Hierarchy of enriched GO-terms in modules "Green", "Blue" and "Brown".

Figure 2.6. Relationship of P-responsive genes in roots and leaves.

Figure S2.1. Hierarchy of enriched GO-terms in modules "Green", "Blue" and "Brown". (data CD)

Figure 3.1. Growth characteristics of $P$ deficient poplar.

Figure 3.2. ${ }^{33} \mathrm{P}$ allocation in $\mathrm{P}$ deficient poplar.

Figure 3.3. ${ }^{33} \mathrm{P}$ uptake and carbohydrate concentrations in $\mathrm{P}$ deficient poplar supplied with glucose in the nutrient solution.

Figure 3.4. Model of kinetic parameters for $\mathrm{P}$ uptake of $\mathrm{P}$ deficient poplars at different $\mathrm{P}$ concentrations.

Figure 3.5. Expression of phosphate transporters in P deficient poplars.

Figure S3.1. Biomass and performance of poplar grown with five different $P$ concentrations.

Figure S3.2. Neighbor-Joining tree (Jones-Taylor-Thornton model, 500 bootstraps) of the amino acid sequences for inorganic phosphate transporters in poplar.

Figure S3.3. Correlations of absolute microarray expression data $\left(\log _{2}\right.$-value) and qRT PCR relative expression values $\left(\log _{2}\right)$ for PtPHTs.

Figure 4.1: Experimental setup for measurement of root-associated acid phosphatase activity in vivo.

Figure 4.2. Neighbor-Joining tree (Jones-Taylor-Thornton model, 500 bootstraps) of the amino acid sequences for purple acid phosphatases in poplar.

Figure 4.3. Verification of array data by qRT PCR. 
Figure 4.4. Expression of purple acid phosphatases in P deficient poplars.

Figure 4.5. Poplar roots grown with or without Pi stained for acid phosphatase activity.

Figure 4.6. Length of roots in different root diameter classes in percent of total root length.

Figure 4.7. Roots hairs of poplars grown with differnet $P$ availabilities.

Figure 4.8. Root associated acid phosphatase activity of poplar.

Figure 4.9. In gel-assay of acid phosphatase activity from poplar root AWF.

Figure 5.1. Model for the possible contributions of PAPs and PHTs in P acquisition and P uptake in poplar $(P . \times$ canescens $)$. 


\section{Summary}

Phosphorus $(\mathrm{P})$ is a major plant nutrient required for the biosynthesis of nucleic acids, nucleotides, membrane lipids and metabolites such as organic esters. P further plays a role in enzyme regulation by phosphorylation. Plants take up $\mathrm{P}$ in its inorganic form $\mathrm{H}_{2} \mathrm{PO}_{4}{ }^{-}(\mathrm{Pi}) . \mathrm{Pi}$ is present only in low concentrations in the soil solution and therefore has to be replenished all the time to ensure sufficient plant nutrition.

In plants different strategies can be distinguished in response to $\mathrm{P}$ starvation: (i) $\mathrm{P}$ conservation by re-use of $\mathrm{P}$ from $\mathrm{P}$ containing compounds e.g. membrane lipids and avoidance of $\mathrm{P}$ requiring metabolic pathways. This results in growth reduction. (ii) Enhanced acquisition of $\mathrm{P}$ from the soil. For this purpose plants secrete purple acid phosphatases (PAPs) to mobilize Pi from organic sources and increase the activity of phosphate transporters (PHTs) for enhanced uptake capacity. Only little is known for woody plants about the molecular responses to low $\mathrm{P}$ availability because to date most of our knowledge stems from the model plant Arabidopsis.

The main aims of this thesis were to characterize molecular changes at the wholetranscriptome level in leaves and roots of Populus $\times$ canescens in response to $\mathrm{P}$ deprivation and to relate these changes to poplar growth, Pi acquisition and Pi uptake. The following questions were addressed: (a) How does P deficiency affect the nutrient states of the plant and which genes are involved in the response to $\mathrm{P}$ limitation in poplar? (b) How is the poplar Pi uptake kinetics affected by decreasing P availabilities and how are PHTs transcriptionally regulated by $\mathrm{P}$ deficiency? (c) How does low $\mathrm{P}$ availability affect the expression profile of PAPs and which members of the large PAP family are released into the medium upon P starvation?

To address these questions transcriptome analyses for poplars (Populus $\times$ canescens) grown under reduced phosphorus availabilities were conducted using microarray technology. Plant nutrient concentrations were determined by inductively coupled plasma optical emission spectrometry and uptake by use of radioactive P. The secreted proteins were determined by proteome analyses using liquid-chromatography electrospray-ionization mass spectrometry.

(a) Poplars exhibited strong growth reduction and increased P use efficiency in response to lower P availabilities. P starvation resulted also in changes of most other elements (S, 
N, K, Mg, Ca, Fe, Zn, Mn, Al) studied. A high number of genes (12068 in total) was differently expressed upon $\mathrm{P}$ starvation. These genes were clustered in eleven coexpression modules of which seven were correlated with distinct elements in the plant tissues. One module with 565 genes (4.7\% of all differentially expressed genes) was correlated with changes in the P concentration in the plant tissues and with the biomass. In this module, PAPs but no PHTs were identified among the highly upregulated Prelated genes. The functional category "galactolipid synthesis" was enriched among the P-related genes. Galactolipids substitute phospholipids in membranes under $\mathrm{P}$ limitation. Two modules, one correlated with $\mathrm{C}$ and $\mathrm{N}$ and the other with biomass, $\mathrm{S}$ and $\mathrm{Mg}$, were connected with the P-related module by co-expression. In these modules GO terms indicating DNA modification and cell division as well as defense (ethylene, respiratory burst) and RNA modification and signaling were enriched. In conclusion, most differentially expressed genes were not directly related to the tissue $\mathrm{P}$ concentrations and were, therefore, most likely regulated by downstream events of $\mathrm{P}$ starvation.

(b) Whole-plant P uptake kinetics and expression profiles of members of the phosphate transporter families were studied under high, intermediate and low $\mathrm{P}$ availability in relation to plant performance. The maximum $\mathrm{P}$ uptake rate was more than 13-times higher in P-starved than in well-supplied poplars. The $\mathrm{K}_{\mathrm{m}}$-values ranged between 20 $\mu \mathrm{M}$ and $26 \mu \mathrm{M}$ for $\mathrm{P}$ starved poplars. The minimum concentration for net $\mathrm{P}$ uptake from the nutrient solution was $1 \mu \mathrm{M}$ P. Among the PHT subfamilies, all PHTs of family 1 (PHT1) studied showed significant up-regulation upon P starvation and were higher expressed in roots than leaves, with the exception of PtPHT1;3. The transcript abundance of PtPHT1;3 was high in leaves under high P supply and increased further under P starvation. PtPHT1;1 and PtPHT1;2 showed root- and P-starvation specific expression. Expression profiles of distinct members of the PHT subfamilies, especially those of PHT1 were linked with changes in P uptake and allocation at whole-plant level. The regulation was tissue-specific with lower P-responsiveness in leaves than in roots. Because the $\mathrm{K}_{\mathrm{m}}$ for $\mathrm{P}$ uptake was higher than typical soil concentrations of Pi, nonmycorrhizal poplars are expected to suffer from $\mathrm{P}$ limitations in most environments.

(c) To study the purple acid phosphatases, transcriptome and proteome analyses were combined with phosphatase activity assays. The family of PAPs was annotated showing 33 poplar PAPs that formed three main subfamilies. Among these PAPs, 23 had a probe 
set on the microarray and showed significant transcript abundances. Ten PAPs were transcriptionally upregulated in roots and leaves of P-starved poplars. The P-starved poplars further showed higher phosphatase activity on the roots than the well P-supplied plants. The protein PtaPAP4 was secreted by poplar roots under high and low $\mathrm{P}$ conditions, whereas PtaPAP1 was secreted only under low P conditions. These results suggest that increased $\mathrm{P}$ acquisition from organic $\mathrm{P}$ sources under low $\mathrm{P}$ conditions is mediated in roots by a specific PAP enzyme.

Overall, the results of this thesis support that enhanced phosphate transporter and phosphatase activity can improve P uptake efficiency. Since poplar plantations for biomass production are often established on marginal sites where nutrients are limited, the present findings suggest that the selection of natural genotypes or molecular breeding can be used to improve tree P nutrition. 


\section{Introduction}

\subsection{Phosphorus as a plant nutrient}

Phosphorus (P) is an essential element for plant nutrition. Plants take up $\mathrm{P}$ as inorganic phosphate (Pi), mainly in the form of $\mathrm{H}_{2} \mathrm{PO}_{4}{ }^{-}$(Schachtman et al., 1998). In most soils, $\mathrm{P}$ is the least available nutrient for plants (Holford, 1997) because of the formation of precipitates with cations (calcium, iron, aluminum) and absorption to soil particles (Attiwill and Adams, 1993; Holford, 1997). The concentration of Pi in the soil solution is below $10 \mu \mathrm{M}$ under most conditions, and thus, three magnitudes lower than the concentration in the plant with 5 to $20 \mathrm{mM}$ (Bieleski, 1973). The concentration of total $\mathrm{P}$ can be up to $1 \%$ of the plant's dry weight (Bieleski, 1973). P is a constituent of nucleic acids, nucleotides, membrane lipids, proteins and organic esters as well as of ATP, an energy-rich compound. It is required for enzyme regulation by phosphorylation.

In natural ecosystems, recycling and re-use is an important basis for $\mathrm{P}$ availability to plants (Attiwill and Adams, 1993), i.e., P recycling in the plant from e.g. senescing leaves, and P storage during winter in buds and stem as phospholipids, $\mathrm{P}$ esters and nucleic acids (Chapin and Kedrowski, 1983). At the level of the ecosystem, P recycling by different organisms is an important property especially in $\mathrm{P}$ poor soils as recently reviewed by Lang et al. (2016). Up to now, only little is known about many aspects of this $\mathrm{P}$ dynamics in woody plants (Rennenberg and Herschbach, 2013), while $\mathrm{P}$ limitations increase in European forests (Braun et al., 2010; Talkner et al., 2015).

\subsection{Plant adaptations to low $P$}

Plants are able to sense the $\mathrm{P}$ availability locally at the root tips and systemically in the whole plant but a P receptor is not known until now (Baker et al., 2015; Chiou and Lin, 2011; López-Arredondo et al., 2014). Through a signaling system, plants are able to react when the $\mathrm{P}$ availability in the growth medium or the plant $\mathrm{P}$ concentration is not sufficient to maintain metabolism and growth (P starvation, $\mathrm{P}$ deprivation). Plants' responses to low $\mathrm{P}$ availability can be broadly divided into two categories: enhanced uptake capacity and acquisition of $\mathrm{P}$, and conservation and efficient use of $\mathrm{P}$ (Lajtha 
and Harrison, 1995; Vance et al., 2003). To conserve the use of P, plants decrease their growth, re-use P from membrane lipids (Nakamura, 2013; Siebers et al., 2015) and bypass $\mathrm{P}$ requiring metabolism pathways (Hammond and White, 2008; Plaxton and Carswell, 1999; Vance et al., 2003). Enhanced uptake and acquisition includes a remodeling of the root system as shown e.g. for Arabidopsis (Gruber et al., 2013). Increased activity of phosphate transporters and secretion of organic acids and phosphatases for mobilization of mineral and organic $\mathrm{P}$ under low $\mathrm{P}$ availability, respectively, are universal for plants (Vance et al., 2003). To achieve these adaptations, massive transcriptional reprogramming is required (Lan et al., 2015). For example, in long-term P starved Arabidopsis, Misson et al. (2005) found more than 700 genes with more than twofold changed transcript abundance. Arabidopsis shows a requirement of different genes during the adaptation process as only 48 regulated genes overlap with earlier time points during the starvation time (Misson et al., 2005). Across four Arabidopsis transcriptome studies with similar conditions (Lan et al., 2012; Misson et al., 2005; Morcuende et al., 2007; Woo et al., 2012) only 95 genes were commonly upregulated upon $\mathrm{P}$ starvation. Among these genes, four phosphate transporters (AtPHT1;2, AtPHT1;4, AtPHT1;8, AtPHT1;9) and five purple acid phosphatases (AtPAP1, AtPAP7, AtPAP12, AtPAP17, AtPAP22) were detected (Lan et al., 2015), emphasizing the importance of these enzymes in the $\mathrm{P}$ starvation response.

\subsection{Phosphate transporters}

To maintain a high $\mathrm{P}$ concentration in the plant against the concentration gradient to the soil and the negative membrane potential of plant cells, a high-affinity, active transport across the plasma membrane is needed (Rausch and Bucher, 2002; Smith, 2002). Kinetic measurements revealed two different $\mathrm{P}$ uptake systems for plants: a highaffinity system that responds to the $\mathrm{P}$ status of the plant and a low-affinity system that is expressed constitutively (Schachtman et al., 1998). Whole-plant P uptake that was mainly studied in agricultural crops was up to five times higher in $\mathrm{P}$ starved than in $\mathrm{P}$ sufficient plants (Bhadoria et al., 2004; Cogliatti and Clarkson, 1983; Jungk et al., 1990; Lee, 1982). 
The active $\mathrm{P}$ transport across membranes is performed by phosphate transporters (PHTs). In Arabidopsis the PHTs are divided into four families (Guo et al., 2008; Rausch and Bucher, 2002). The subcellular localization of many members of the PHT family has been studied in Arabidopsis: The members of the first family, PHT1, are located in the plasma membrane (Nussaume et al., 2011). These are responsible for the uptake of Pi from the soil, but also for the distribution and re-distribution inside the plant (Baker et al., 2015; Młodzińska and Zboińska, 2016; Nussaume et al., 2011). PHT1s have 12 transmembrane spanning domains in a ' $6+6$ ' configuration (Smith, 2002). They transport $\mathrm{H}_{2} \mathrm{PO}_{4}^{-}$ions together with protons, energized by an electrochemical gradient due to an $\mathrm{H}^{+}$-ATPase (Smith, 2002). PHT2s are located in the chloroplast envelope (Versaw and Harrison, 2002) and function as low-affinity transporters (Daram et al., 1999). Members of the third family (PHT3) have been found in mitochondria (Rausch and Bucher, 2002). The members of PHT4 are distributed in chloroplasts, heterotrophic plastids and the Golgi apparatus (Guo et al., 2008). All together, these phosphate transporters take up Pi from the soil into the plant cells, and distribute it inside the plant and between different organelles.

\subsection{Purple acid phosphatases}

Organically bound phosphate makes up 20 to $80 \%$ of the soil's P reserves, mainly as phytate and its derivatives (Schachtman et al., 1998). As PHTs transport only Pi, organic P has to be converted into inorganic P before uptake. Enzymes that cleave Pi from organic phosphate esters are ribonucleases and phosphatases. There are many different kinds of phosphatases in plants, but for most of them no specific role in the metabolism is known (Olczak et al., 2003). Purple acid phosphatases (PAPs), the largest group of phosphatases (Olczak et al., 2003), have their $\mathrm{pH}$ optimum in acidic conditions present in most soils. They are named after their purple color when concentrated in water, due to a ferric ligand in the active center of the enzyme (Vincent and Averill, 1990). Secreted acid phosphatases, associated with or bound to the root surface or released into the soil, are believed to play a role in the acquisition of phosphorus, whereas intracellular acid phosphatases are thought to recycle phosphorus from intracellular organic P reserves (Duff et al., 1994). In Arabidopsis, three out of 29 
known PAPs are responsible for about $70 \%$ of phosphatase activity in the growth medium and root-associated acid phosphatase activity under low $\mathrm{P}$ conditions: AtPAP12 and AtPAP26 are mainly secreted by roots into the growth medium and AtPAP10 is bound to the cell-wall (Wang et al., 2014).

\subsection{Poplar, a model to study the $P$ nutrition of trees}

Poplar (Populus spp.) is the model tree for forest biotechnology due to its fast growth, easy propagation and sequenced genome (Bradshaw et al., 2000; Brunner et al., 2004; Taylor, 2002; Tuskan et al., 2006). Furthermore, poplar species are important woody crops that may be suitable for growth on marginal lands, where nutrient supply is low (Polle et al., 2013; Polle and Chen, 2015).

Poplars can colonize a wide range of different environmental conditions (Polle and Chen, 2015) with riparian ecosystems being the main habitat of many poplar species. In these ecosystems flooding, sedimentation and dry periods lead to strong fluctuations in the availability of Pi (Steiger and Gurnell, 2002; Trémolières et al., 1999). Thus, these species are obviously able to cope with differences in $\mathrm{P}$ availability, but the molecular basis for $\mathrm{P}$ uptake and allocation is not yet well understood (Rennenberg and Herschbach, 2013).

The expression of selected members of poplar PHTs and PAPs under P deprivation were studied before: Similar to Arabidopsis, members of the PHT1 family are upregulated in poplar under low or the absence of $\mathrm{P}$ in the growth medium (Gan et al., 2016; Loth-Pereda et al., 2011; Zhang et al., 2016). Gan et al. (2016) demonstrated an up-regulation of one member of the poplar PAPs under P deprivation and an enhanced phosphatase activity on roots. But which PHTs and PAPs are related to increased uptake and phosphatase activity remained open. Overall, how poplars respond to low $\mathrm{P}$ at the transcriptional level is currently unknown. 


\subsection{Objectives}

The main goals of this thesis were to characterize transcriptomic changes in Populus $\times$ canescens in response to phosphate deprivation and to relate these changes to poplar $\mathrm{P}$ uptake and growth.

To address these goals, the poplar transcriptome in response to phosphate deprivation was studied (chapter 2). Nutrient-related co-expression networks were dissected in phosphate-starved poplars. To identify gene clusters and genes involved in the response to phosphorus limitation in poplar and to differentiate between P-related changes and relations to co-occurring changes in the concentration of other nutrients, co-expression gene modules were correlated with element concentrations in poplar roots and leaves.

Because increased phosphate uptake capacity is known to be a major response to phosphorus starvation in plants, chapter 3 focuses on phosphate transporters. The phosphate uptake kinetics of poplar were characterized at different phosphorus availabilities. Putative phosphate transporters were annotated, their expression profiles measured under different $\mathrm{P}$ availabilities and $\mathrm{P}$ uptake kinetic parameters determined.

Because of the low concentration of inorganic phosphate in soil solutions, plants need mechanisms for enhanced phosphate acquisition from organic sources. Therefore, purple acid phosphatases of poplar were studied in chapter 4. The family of poplar PAPs was annotated and their expression profile under different $\mathrm{P}$ availabilities measured. Upregulated and secreted purple acid phosphatases and changes in root morphology to increase the soil volume access were studied. 


\subsection{References}

Attiwill, P.M., Adams, M.A. (1993): Nutrient cycling in forests. New Phytol. 124, 561582.

Baker, A., Ceasar, S.A., Palmer, A.J., Paterson, J.B., Qi, W., Muench, S.P., Baldwin, S.A. (2015): Replace, reuse, recycle: improving the sustainable use of phosphorus by plants. J. Exp. Bot. 66, 3523-3540.

Bhadoria, P.S., Dessougi, H.E., Liebersbach, H., Claassen, N. (2004): Phosphorus uptake kinetics, size of root system and growth of maize and groundnut in solution culture. Plant Soil 262, 327-336.

Bieleski, R.L. (1973): Phosphate pools, phosphate transport, and phosphate availability. Annu. Rev. Plant Physiol. 24, 225-252.

Bradshaw, H.D., Ceulemans, R., Davis, J., Stettler, R. (2000): Emerging model systems in plant biology: Poplar (Populus) as a model forest tree. J. Plant Growth Regul. 19, 306-313.

Braun, S., Thomas, V.F.D., Quiring, R., Flückiger, W. (2010): Does nitrogen deposition increase forest production? The role of phosphorus. Environ. Pollut. 158, 2043-2052.

Brunner, A.M., Busov, V.B., Strauss, S.H. (2004): Poplar genome sequence: functional genomics in an ecologically dominant plant species. Trends Plant Sci. 9, 49-56.

Chapin, F.S., Kedrowski, R.A. (1983): Seasonal changes in nitrogen and phosphorus fractions and autumn retranslocation in evergreen and deciduous Taiga trees. Ecology 64, 376-391.

Chiou, T.-J., Lin, S.-I. (2011): Signaling network in sensing phosphate availability in plants. Annu. Rev. Plant Biol. 62, 185-206.

Cogliatti, D.H., Clarkson, D.T. (1983): Physiological changes in, and phosphate uptake by potato plants during development of, and recovery from phosphate deficiency. Physiol. Plant. 58, 287-294.

Daram, P., Brunner, S., Rausch, C., Steiner, C., Amrhein, N., Bucher, M. (1999): Pht2;1 encodes a low-affinity phosphate transporter from Arabidopsis. Plant Cell Online 11, 2153-2166.

Duff, S.M., Sarath, G., Plaxton, W.C. (1994): The role of acid phosphatases in plant phosphorus metabolism. Physiol. Plant. 90, 791-800. 
Gan, H., Jiao, Y., Jia, J., Wang, X., Li, H., Shi, W., Peng, C., Polle, A., Luo, Z.-B. (2016): Phosphorus and nitrogen physiology of two contrasting poplar genotypes when exposed to phosphorus and/or nitrogen starvation. Tree Physiol. 36, 22-38.

Gruber, B.D., Giehl, R.F.H., Friedel, S., Wirén, N. von (2013): Plasticity of the Arabidopsis root system under nutrient deficiencies. Plant Physiol. 163, 161-179.

Guo, B., Jin, Y., Wussler, C., Blancaflor, E.B., Motes, C.M., Versaw, W.K. (2008): Functional analysis of the Arabidopsis PHT4 family of intracellular phosphate transporters. New Phytol. 177, 889-898.

Hammond, J.P., White, P.J. (2008): Sucrose transport in the phloem: integrating root responses to phosphorus starvation. J. Exp. Bot. 59, 93-109.

Holford, I.C.R. (1997): Soil phosphorus: its measurement, and its uptake by plants. Soil Res. 35, 227-240.

Jungk, A., Asher, C.J., Edwards, D.G., Meyer, D. (1990): Influence of phosphate status on phosphate uptake kinetics of maize (Zea mays) and soybean (Glycine max). Plant Soil 124, 175-182.

Lajtha, K., Harrison, A.F. (1995): Strategies of phosphorus acquisition and conservation by plant species and communities, in: Tiessen, H. (ed.): Phosphorus in the global environment. John Wiley Sons Ltd, Chichester, UK, pp. 140-147.

Lan, P., Li, W., Schmidt, W. (2012): Complementary proteome and transcriptome profiling in phosphate-deficient Arabidopsis roots reveals multiple levels of gene regulation. Mol. Cell. Proteomics 11, 1156-1166.

Lan, P., Li, W., Schmidt, W. (2015): “Omics" approaches towards understanding plant phosphorus acquisition and use, in: Plaxton, W.C., Lambers, H. (eds.): Annual Plant Reviews Volume 48. John Wiley \& Sons, Inc., Hoboken, NJ, USA, pp. 65-97.

Lang, F., Bauhus, J., Frossard, E., George, E., Kaiser, K., Kaupenjohann, M., Krüger, J., Matzner, E., Polle, A., Prietzel, J., Rennenberg, H., Wellbrock, N. (2016): Phosphorus in forest ecosystems: New insights from an ecosystem nutrition perspective. J. Plant Nutr. Soil Sci. 179, 129-135.

Lee, R.B. (1982): Selectivity and kinetics of ion uptake by barley plants following nutrient deficiency. Ann. Bot. 50, 429-449.

López-Arredondo, D.L., Leyva-González, M.A., González-Morales, S.I., López-Bucio, J., Herrera-Estrella, L. (2014): Phosphate nutrition: Improving low-phosphate tolerance in crops. Annu. Rev. Plant Biol. 65, 95-123.

Loth-Pereda, V., Orsini, E., Courty, P.-E., Lota, F., Kohler, A., Diss, L., Blaudez, D., Chalot, M., Nehls, U., Bucher, M., Martin, F. (2011): Structure and expression profile 
of the phosphate Pht1 transporter gene family in mycorrhizal Populus trichocarpa. Plant Physiol. 156, 2141-2154.

Misson, J., Raghothama, K.G., Jain, A., Jouhet, J., Block, M.A., Bligny, R., Ortet, P., Creff, A., Somerville, S., Rolland, N., Doumas, P., Nacry, P., Herrerra-Estrella, L., Nussaume, L., Thibaud, M.-C. (2005): A genome-wide transcriptional analysis using Arabidopsis thaliana Affymetrix gene chips determined plant responses to phosphate deprivation. Proc. Natl. Acad. Sci. U. S. A. 102, 11934-11939.

Młodzińska, E., Zboińska, M. (2016): Phosphate uptake and allocation - A closer look at Arabidopsis thaliana L. and Oryza sativa L. Plant Traffic Transp. 7, 1198.

Morcuende, R., Bari, R., Gibon, Y., Zheng, W., Pant, B.D., Bläsing, O., Usadel, B., Czechowski, T., Udvardi, M.K., Stitt, M., Scheible, W.-R. (2007): Genome-wide reprogramming of metabolism and regulatory networks of Arabidopsis in response to phosphorus. Plant Cell Environ. 30, 85-112.

Nakamura, Y. (2013): Phosphate starvation and membrane lipid remodeling in seed plants. Prog. Lipid Res. 52, 43-50.

Nussaume, L., Kanno, S., Javot, H., Marin, E., Pochon, N., Ayadi, A., Nakanishi, T.M., Thibaud, M.-C. (2011): Phosphate import in plants: Focus on the PHT1 transporters. Front. Plant Sci. 2, 83.

Olczak, M., Morawiecka, B., Watorek, W. (2003): Plant purple acid phosphatases genes, structures and biological function. Acta Biochim. Pol. 50, 1245-1256.

Plaxton, W.C., Carswell, M.C. (1999): Metabolic aspects of the phosphate starvation response in plants, in: Lerner, H.R. (ed.): Plant responses to environmental stresses: From phytohormones to genome reorganization. Marcel Dekker, Inc., New York, NY, USA, pp. $350-372$.

Polle, A., Chen, S. (2015): On the salty side of life: molecular, physiological and anatomical adaptation and acclimation of trees to extreme habitats. Plant Cell Environ. $38,1794-1816$.

Polle, A., Janz, D., Teichmann, T., Lipka, V. (2013): Poplar genetic engineering: promoting desirable wood characteristics and pest resistance. Appl. Microbiol. Biotechnol. 97, 5669-5679.

Rausch, C., Bucher, M. (2002): Molecular mechanisms of phosphate transport in plants. Planta 216, 23-37.

Rennenberg, H., Herschbach, C. (2013): Phosphorus nutrition of woody plants: many questions - few answers. Plant Biol. 15, 785-788. 
Schachtman, D.P., Reid, R.J., Ayling, S.M. (1998): Phosphorus uptake by plants: from soil to cell. Plant Physiol. 116, 447-453.

Siebers, M., Dörmann, P., Hölzl, G. (2015): Membrane remodelling in phosphorusdeficient plants, in: Plaxton, W.C., Lambers, H. (eds.): Annual Plant Reviews Volume 48. John Wiley \& Sons, Inc., Hoboken, NJ, USA, pp. 237-263.

Smith, F.W. (2002): The phosphate uptake mechanism. Plant Soil 245, 105-114.

Steiger, J., Gurnell, A.M. (2002): Spatial hydrogeomorphological influences on sediment and nutrient deposition in riparian zones: observations from the Garonne River, France. Geomorphology 49, 1-23.

Talkner, U., Meiwes, K.J., Potočić, N., Seletković, I., Cools, N., De Vos, B., Rautio, P. (2015): Phosphorus nutrition of beech (Fagus sylvatica L.) is decreasing in Europe. Ann. For. Sci. 72, 919-928.

Taylor, G. (2002): Populus: Arabidopsis for forestry. Do we need a model tree? Ann. Bot. 90, 681-689.

Trémolières, M., Schnitzler, A., Sánchez-Pérez, J.-M., Schmitt, D. (1999): Changes in foliar nutrient content and resorption in Fraxinus excelsior L., Ulmus minor Mill. and Clematis vitalba L. after prevention of floods. Ann. For. Sci. 56, 641-650.

Tuskan, G.A., DiFazio, S., Jansson, S., Bohlmann, J., Grigoriev, I., Hellsten, U., Putnam, N., Ralph, S., Rombauts, S., Salamov, A., Schein, J., Sterck, L., Aerts, A., Bhalerao, R.R., Bhalerao, R.P., Blaudez, D., Boerjan, W., Brun, A., Brunner, A., Busov, V., Campbell, M., Carlson, J., Chalot, M., Chapman, J., Chen, G.-L., Cooper, D., Coutinho, P.M., Couturier, J., Covert, S., Cronk, Q., Cunningham, R., Davis, J., Degroeve, S., Déjardin, A., dePamphilis, C., Detter, J., Dirks, B., Dubchak, I., Duplessis, S., Ehlting, J., Ellis, B., Gendler, K., Goodstein, D., Gribskov, M., Grimwood, J., Groover, A., Gunter, L., Hamberger, B., Heinze, B., Helariutta, Y., Henrissat, B., Holligan, D., Holt, R., Huang, W., Islam-Faridi, N., Jones, S., JonesRhoades, M., Jorgensen, R., Joshi, C., Kangasjärvi, J., Karlsson, J., Kelleher, C., Kirkpatrick, R., Kirst, M., Kohler, A., Kalluri, U., Larimer, F., Leebens-Mack, J., Leplé, J.-C., Locascio, P., Lou, Y., Lucas, S., Martin, F., Montanini, B., Napoli, C., Nelson, D.R., Nelson, C., Nieminen, K., Nilsson, O., Pereda, V., Peter, G., Philippe, R., Pilate, G., Poliakov, A., Razumovskaya, J., Richardson, P., Rinaldi, C., Ritland, K., Rouzé, P., Ryaboy, D., Schmutz, J., Schrader, J., Segerman, B., Shin, H., Siddiqui, A., Sterky, F., Terry, A., Tsai, C.-J., Uberbacher, E., Unneberg, P., Vahala, J., Wall, K., Wessler, S., Yang, G., Yin, T., Douglas, C., Marra, M., Sandberg, G., Peer, Y.V. de, Rokhsar, D. (2006): The genome of black cottonwood, Populus trichocarpa (Torr. \& Gray). Science $313,1596-1604$. 
Vance, C.P., Uhde-Stone, C., Allan, D.L. (2003): Phosphorus acquisition and use: critical adaptations by plants for securing a nonrenewable resource. New Phytol. 157, $423-447$.

Versaw, W.K., Harrison, M.J. (2002): A chloroplast phosphate transporter, PHT2;1, influences allocation of phosphate within the plant and phosphate-starvation responses. Plant Cell Online 14, 1751-1766.

Vincent, J.B., Averill, B.A. (1990): An enzyme with a double identity: purple acid phosphatase and tartrate-resistant acid phosphatase. FASEB J. 4, 3009-3014.

Wang, L., Lu, S., Zhang, Y., Li, Z., Du, X., Liu, D. (2014): Comparative genetic analysis of Arabidopsis purple acid phosphatases AtPAP10, AtPAP12, and AtPAP26 provides new insights into their roles in plant adaptation to phosphate deprivation: Comparative analysis of three Arabidopsis APases. J. Integr. Plant Biol. 56, 299-314.

Woo, J., MacPherson, C.R., Liu, J., Wang, H., Kiba, T., Hannah, M.A., Wang, X.-J., Bajic, V.B., Chua, N.-H. (2012): The response and recovery of the Arabidopsis thaliana transcriptome to phosphate starvation. BMC Plant Biol. 12, 62.

Zhang, C., Meng, S., Li, M., Zhao, Z. (2016): Genomic identification and expression analysis of the phosphate transporter gene family in poplar. Front. Plant Sci. 7, 1398. 


\title{
Chapter 2
}

\section{Dissecting nutrient-related co-expression networks in phosphate starved poplar}

\author{
Published in similar form as open access article distributed \\ under the terms of the Creative Commons Attribution License \\ (http://creativecommons.org/licenses/by/4.0/). (C) 2017 Kavka, Polle. \\ Mareike Kavka and Andrea Polle \\ PLoS One (2017) 12(2):e0171958 \\ DOI 10.1371/journal.pone.0171958
}

\subsection{Introduction}

Phosphorus (P) is an important plant nutrient and essential for plant growth and metabolism. But P is also one of the least available nutrients in soil (Holford, 1997). Plants take up $\mathrm{P}$ only in its inorganic form, phosphate (Schachtman et al., 1998). Phosphate is present in very low concentrations in the soil solution $(<10 \mu \mathrm{M}$, Bieleski, 1973) due to its binding to soil particles, in organic forms, and precipitation with other soil elements like iron (Fe), aluminum (Al) and calcium (Ca) (Holford, 1997).

Responses of plants to $\mathrm{P}$ limitation have often been addressed although most studies focused on the model species Arabidopsis and only little is known for woody plants (Rennenberg and Herschbach, 2013). In poplar, the model for tree species (Bradshaw et al., 2000; Brunner et al., 2004; Taylor, 2002), most members of the plasma membrane located phosphate transporter family 1 (PHT1), responsible for the P uptake into the root (Baker et al., 2015; Nussaume et al., 2011), are upregulated upon P starvation (Gan et al., 2016; Kavka and Polle, 2016; Loth-Pereda et al., 2011). Also the expression of distinct purple acid phosphatases, that make organic $\mathrm{P}$ forms plant available, is enhanced (Gan et al., 2016). The resulting higher transport efficiency, secretion of phosphatases and, additionally, production and secretion of organic acids (Desai et al., 2014; Gan et al., 2016) lead to an enhanced P acquisition, uptake and accumulation capacity (Desai et al., 2014; Kavka and Polle, 2016). Poplars grown with low P have 
reduced growth with a higher $\mathrm{P}$ use efficiency (Gan et al., 2016; Kavka and Polle, 2016).

The genes highly regulated in four $\mathrm{P}$ deprivation studies in Arabidopsis (Lan et al., 2012; Misson et al., 2005; Morcuende et al., 2007; Woo et al., 2012) are however not only related to $\mathrm{P}$, but are also linked with other elements (e.g. SULTR1;3: sulphate transport; NAS1: iron chelating by nicotianamin (von Wirén et al., 1999)) (Lan et al., 2015). Therefore, it is to be expected that $\mathrm{P}$ limitation influences not only the $\mathrm{P}$ transport system (Kavka and Polle, 2016) and other P deficiency related acclimation responses inside the plant but also downstream processes caused by secondary deficiencies or changes of other nutrients. These effects got only little attention until now. Gan et al. (2016) showed that reduced P availability leads to higher nitrogen (N) concentrations in roots and lower $\mathrm{N}$ concentrations in leaves of poplar with higher free amino acid concentrations and reduced activity of N-related enzymes (NR, GOGAT, GDH). Wang et al. (2002) found rapid and overlapping gene regulation in response to P, potassium $(\mathrm{K})$ and $\mathrm{Fe}$ deprivation in tomato, including transporters for these nutrients. In Arabidopsis tissues, not only the $\mathrm{P}$ concentration but also other nutrient concentrations are affected by $\mathrm{P}$ starvation (Kellermeier et al., 2014; Misson et al., 2005; Ward et al., 2008). Conserved effects across all three studies with different amounts of $\mathrm{P}$ in the growth medium were a reduced concentration of $\mathrm{K}$ and an enhanced concentration of Fe in leaves of Arabidopsis plants (Kellermeier et al., 2014; Misson et al., 2005; Ward et al., 2008). Further concentration changes were a reduction of $\mathrm{Ca}$, magnesium (Mg) and manganese (Mn) (Kellermeier et al., 2014; Ward et al., 2008), thought to be an adjustment of the ionic charge (Kellermeier et al., 2014) or a result of reduced $\mathrm{P}$ availability in $\mathrm{P}$ requiring steps of metabolism and transport (Misson et al., 2005). While P-nutrient relations have been studied in Arabidopsis, only little is known for poplar.

The main goal of this study was to characterize changes in nutrient and other element concentrations ( $\mathrm{P}, \mathrm{S}, \mathrm{C}, \mathrm{N}, \mathrm{K}, \mathrm{Mg}, \mathrm{Ca}, \mathrm{Fe}, \mathrm{Zn}, \mathrm{Mn}, \mathrm{Al})$ in response to $\mathrm{P}$ starvation in poplar (Populus $\times$ canescens). A further aim was to differentiate between transcriptomic changes directly correlated with the plant $\mathrm{P}$ concentration and transcriptomic changes linked to downstream changes of other nutrient concentrations. For this purpose, we studied poplar transcriptomes under high, intermediate and low $\mathrm{P}$ availabilities, identified the weighted gene co-expression network and related gene modules to 
element concentrations. Regulated gene modules and genes and their putative functions in the poplar P starvation response are discussed.

\subsection{Materials and Methods}

\subsubsection{Plant material, growth conditions and harvest}

Populus $\times$ canescens (INRA717 1-B4) plants were grown as previously described with three different $\mathrm{P}$ availabilities (Kavka and Polle, 2016). The plants were grown in sand culture and irrigated with one of three nutrient solutions. Long Ashton nutrient solution (Hewitt and Smith, 1974) with $641 \mu \mathrm{M}$ P was used for control plants (high phosphate HP). For intermediate phosphate (MP) availability, the phosphate concentration was reduced to $6.41 \mu \mathrm{M}$ and potassium added as $\mathrm{KCl}(675.8 \mu \mathrm{M})$, for low phosphate (LP) availability to $0.0641 \mu \mathrm{M}$ (additional $682.5 \mu \mathrm{M} \mathrm{KCl}$ ).

After two months of growth with different $\mathrm{P}$ supplies, the poplars were harvested. Aliquots of the plant tissues (leaves, stem, coarse roots, fine roots $<2 \mathrm{~mm}$ diameter) were dried at $60^{\circ} \mathrm{C}$ for seven days for determination of biomass $(\mathrm{n}=10$ per treatment): tissue biomass $[\mathrm{g}]=\frac{\text { dry mass of aliquot }[\mathrm{g}] \times \text { total tissue fresh mass }[\mathrm{g}]}{\text { fresh mass of aliquot }}$.

The first three leaves from the top ( $>2 \mathrm{~cm}$ length) and aliquots of fine roots $(<2 \mathrm{~mm}$ diameter) were immediately shock frozen in liquid nitrogen and stored at $-80^{\circ} \mathrm{C}$ for RNA-extraction.

\subsubsection{Element concentrations}

Dry tissues of 2-months-old HP-, MP- and LP-poplars ( $\mathrm{n}=4$ per treatment) were milled (Retsch, type MM2, Haan, Germany) and 10 to $45 \mathrm{mg}$ of plant powder was pressureextracted in $\mathrm{HNO}_{3}$ (Heinrichs et al., 1986). Element concentrations were measured using an inductively coupled plasma optical emission spectrometer (ICP-OES; Optima 5300 DV, PerkinElmer Life and Analytical Sciences, Rodgau, Germany). For determination of carbon and nitrogen concentrations, 0.7 to $0.9 \mathrm{mg}$ dry plant powder (2month-old HP-, MP- and LP-poplars, $\mathrm{n}=5$ per treatment) was weighed into tin capsules (Hekatech, Wegberg, Germany) and analyzed in duplicates in an Elemental Analyzer 
EA1108 (Carlo Erba Strumentazione, Rodano, Italy). Acetanilide (71.09 \% C, 10.36 \% $\mathrm{N}$; Carlo Erba Strumentazione) was used as the standard.

\subsubsection{RNA-extraction and microarray}

RNA-extraction and microarray procedures at the Microarray Facility (MFT Services, Tübingen, Germany) were described in Kavka and Polle (2016). Three biological replicates (each consisting of two pooled tissue samples) were analyzed per treatment and tissue (fine roots and uppermost leaves). Raw and normalized data were uploaded into the EMBL-EBI ArrayExpress database (http://www.ebi.ac.uk/arrayexpress/) under E-MTAB-3934.

\subsubsection{Statistical analyses of microarrays}

Microarray raw data were analyzed using the free statistic software $\mathrm{R}$ (version 2.14.2, $R$ Development Core Team, 2012) after the protocol described by Janz et al. (2010). The R package "affy" (Gautier et al., 2004) was used for normalization of the array probes ("rma" function) using Bioconductor (Kauffmann et al., 2009). The $\log _{2}$ expression value of transcripts that were present ("mas5calls" function) on all replicate chips of at least one condition was used for further analyses. For the annotation of the microarrays, the best gene model for each Affymetrix ID (AffyID) in the annotation file of the Aspen Database was used (Tsai et al., 2011).

Differentially expressed genes (DEGs) were identified by two methods: (a) Significance Analysis of Microarrays (SAM) was performed with R package "siggenes" (Schwender, 2011) (FDR $\leq 0.05)$ and (b) the data were analyzed using linear models with R package "limma" (Smyth, 2005) (adjusted p-value $\leq 0.05)$. Overlapping DEGs identified by both approaches were used for further analyses. Venn diagrams of DEGs were drawn using the online tool InteractiVenn (http://www.interactivenn.net, Heberle et al., 2015). Logfold change ratios $(\log \mathrm{FCs})$ were calculated with the mean $\log _{2}$ expression values for $\mathrm{MP} / \mathrm{HP}$ and LP/HP for roots and leaves.

A weighted correlation network analysis with all DEGs was conducted using $\mathrm{R}$ package "WGCNA" (Weighted Gene Co-expression Network Analysis; Langfelder and 
Horvath, 2008). Block-wise clustering with a power of 24 was calculated and modules in the resulting dendrogram were merged at a height cut of 0.2. Pearson's correlations of eigengenes, which represent the expression profile of all genes in a given coexpression module, and mean values of element concentrations and biomass in fine roots and leaves of HP, MP and LP plants were calculated. Because the large number of DEGs did not allow a visualization of the co-expression network with the usual tools, gene numbers were reduced by using a p-value (limma) cut-off of 0.00001 . Topology was recalculated for these genes by using the same power of 24 (command "TOMsimilarityFromExpr"). Nodes (DEGs) and edges (co-expression connections between nodes, based on expression pattern) were displayed in Cytoscape (version 3.3.0, Shannon et al., 2003) in group attributes layout to show DEGs belonging to one module.

GO term enrichment analyses were conducted using Ontologizer (version2.1, Bauer et al., 2008) with Term-for-term approach and Benjamini-Hochberg-corrections. Enrichment in poplar gene lists were tested with $\mathrm{p} \leq 0.01$ against a "population" data set consisting of all genes present on the array as described above. Enriched GO terms were displayed using GOPathDrawer (version 6.0, http://coxpresdb.jp/top_draw.shtml).

\subsubsection{Additional statistical analyses}

ANOVA and Tukey's HSD were performed in R (version 2.14.2, $R$ Development Core Team, 2012) to test for differences between treatments in biomass and element concentrations with $\mathrm{p} \leq 0.05$. Residuals were tested visually for normal distribution and homogeneity of variance and data transformed logarithmically $\left(\log _{2}\right)$, by square root or by the exponent " 2 " if needed. Differences between treatments at $p \leq 0.05$ are shown with different letters in figures. Correlations of mean values were calculated using Pearson's test in R. 


\subsection{Results}

\subsubsection{P deprivation affects nutrient element concentrations}

$\mathrm{P}$ starvation resulted in strong decreases in P concentrations of MP and LP poplar tissues compared with well supplied plants and caused massive growth decline (Figure 2.1; Kavka and Polle, 2016).

The concentrations of sulfur, nitrogen, potassium, magnesium, calcium, iron, zinc, manganese and aluminum were influenced by $\mathrm{P}$ starvation (Table 2.1), but the differences were generally smaller than those for P (Figure 2.1). Sulfur, magnesium and calcium concentrations declined in all tissues except the stem in response to MP or LP treatments. Potassium was slightly reduced in all tissues except fine roots, whereas iron, manganese, zinc and aluminum concentrations increased in most tissues in response to P deficiency. Nitrogen concentrations were higher in MP than in HP poplars in all tissues. The carbon concentration did not change markedly under low P availability.

Table 2.1: ANOVA results for the main factors "treatment" and "tissue".

\begin{tabular}{cccc} 
parameter & treatment & tissue & interaction \\
\hline $\mathrm{P}$ & $<\mathbf{0 . 0 0 1}$ & 0.225 & $\mathbf{0 . 0 0 3}$ \\
$\mathrm{S}$ & $<\mathbf{0 . 0 0 1}$ & $<\mathbf{0 . 0 0 1}$ & 0.116 \\
$\mathrm{C}$ & 0.641 & $<\mathbf{0 . 0 0 1}$ & $<\mathbf{0 . 0 0 1}$ \\
$\mathrm{N}$ & $<\mathbf{0 . 0 0 1}$ & $<\mathbf{0 . 0 0 1}$ & $<\mathbf{0 . 0 0 1}$ \\
$\mathrm{K}$ & $<\mathbf{0 . 0 0 1}$ & $<\mathbf{0 . 0 0 1}$ & $\mathbf{0 . 0 0 2}$ \\
$\mathrm{Mg}$ & $\mathbf{0 . 0 0 7}$ & $<\mathbf{0 . 0 0 1}$ & $\mathbf{0 . 0 0 7}$ \\
$\mathrm{Ca}$ & $<\mathbf{0 . 0 0 1}$ & $<\mathbf{0 . 0 0 1}$ & $<\mathbf{0 . 0 0 1}$ \\
$\mathrm{Fe}$ & $\mathbf{0 . 0 0 1}$ & $<\mathbf{0 . 0 0 1}$ & $<\mathbf{0 . 0 0 1}$ \\
$\mathrm{Zn}$ & $\mathbf{0 . 0 2 6}$ & $<\mathbf{0 . 0 0 1}$ & 0.094 \\
$\mathrm{Mn}$ & $\mathbf{0 . 0 2 0}$ & $<\mathbf{0 . 0 0 1}$ & 0.593 \\
$\mathrm{Al}$ & $\mathbf{0 . 0 0 1}$ & $<\mathbf{0 . 0 0 1}$ & 0.074 \\
$\mathrm{BM}$ & $<\mathbf{0 . 0 0 1}$ & $<\mathbf{0 . 0 0 1}$ & $<\mathbf{0 . 0 0 1}$
\end{tabular}

P-values of linear models (Two-Way-ANOVA) were calculated for element concentrations and biomass (BM) (see Figure 2.1) with the factors treatment (HP, MP, LP) and tissue (leaves, stem, coarse, fine roots) and a factor of interaction. Correlations with $\mathrm{p} \leq 0.05$ are indicated in bold. 

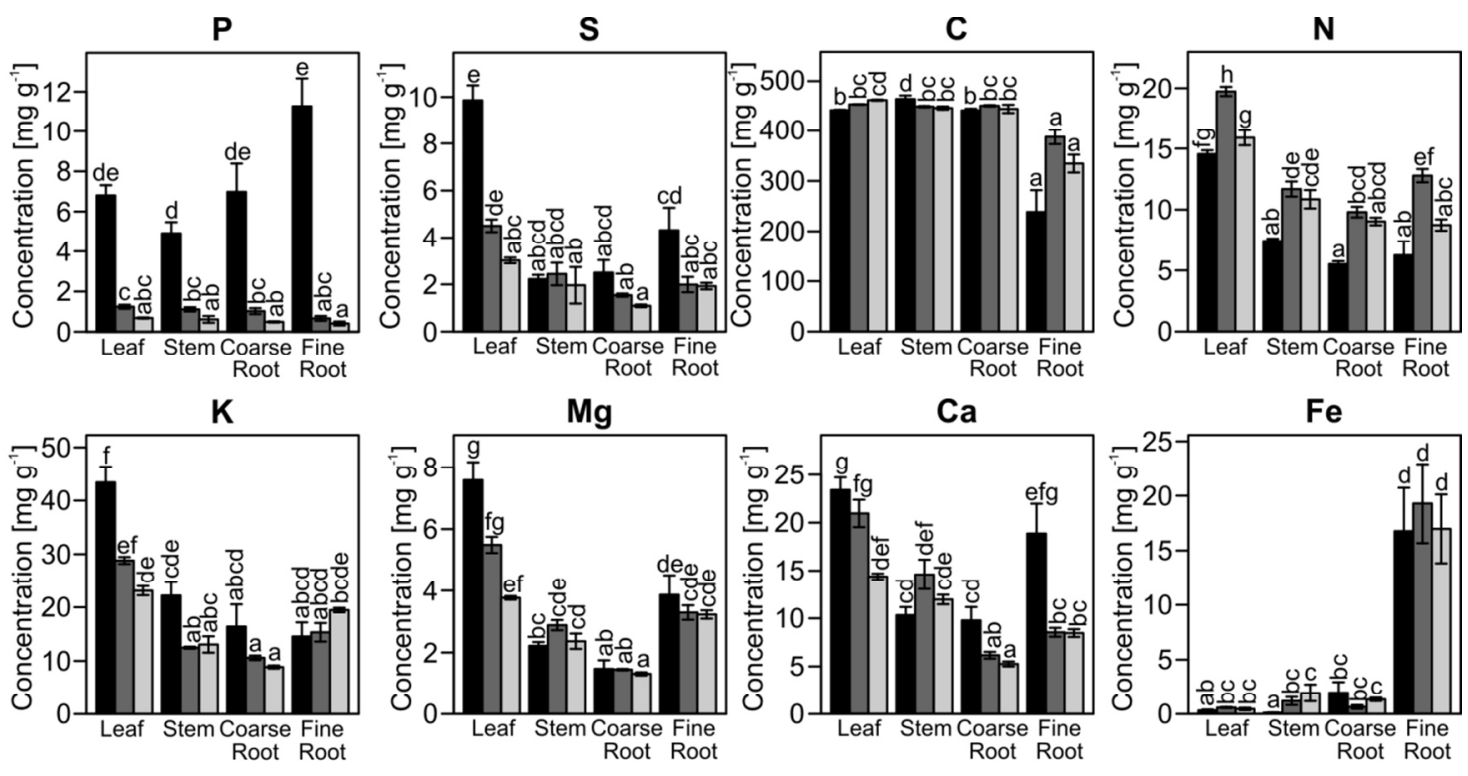

$\mathrm{Mg}$
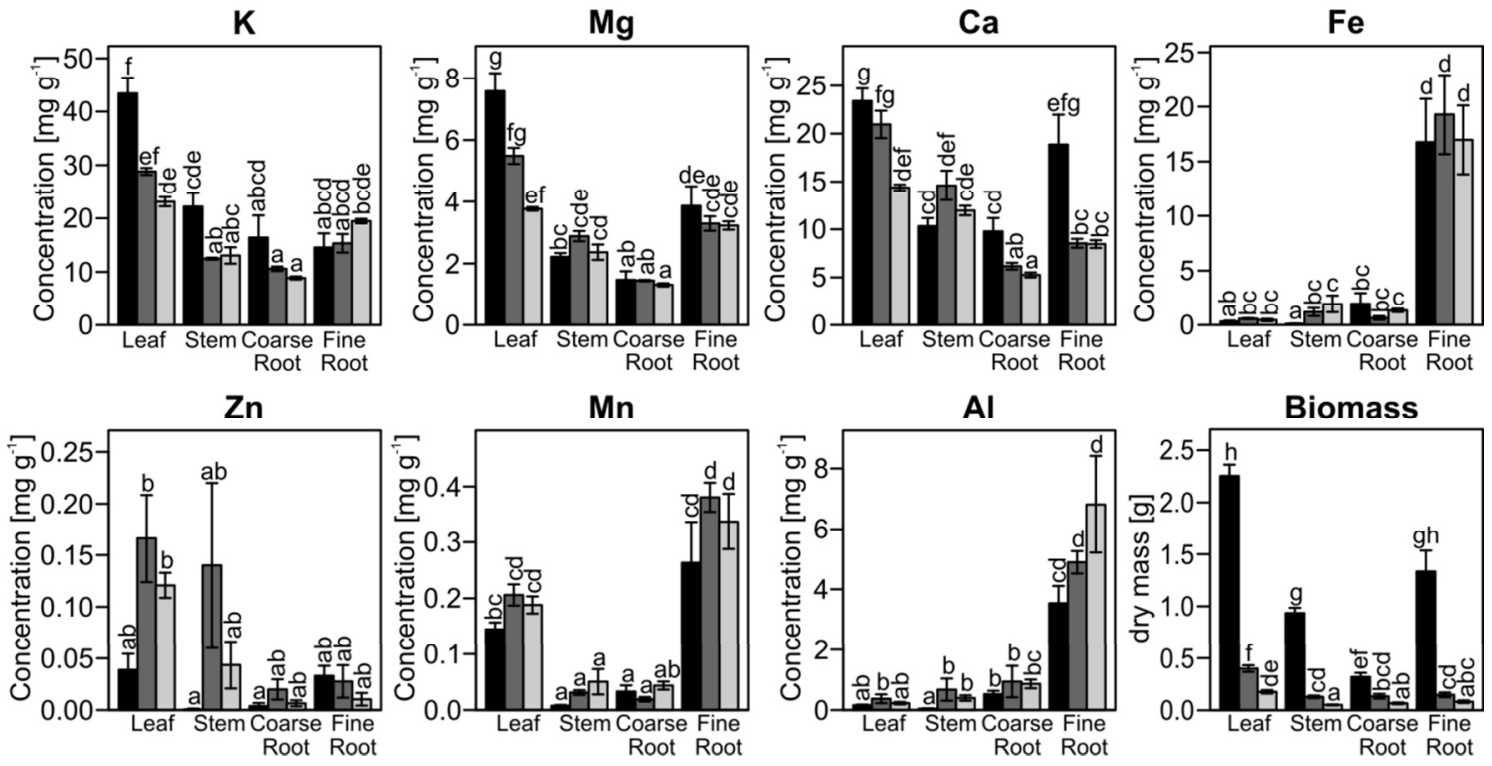

Figure 2.1. Element concentrations in leaves, stem, coarse roots and fine roots of poplars. $P . \times$ canescens was grown with high $(\mathrm{HP}, 641 \mu \mathrm{M}$, black), intermediate (MP, $6.4 \mu \mathrm{M}$, dark grey) or low (LP, $0.064 \mu \mathrm{M}$, light grey) $\mathrm{P}$ supply. Different letters indicate significant differences $(\mathrm{p} \leq 0.05$, Two-Way-ANOVA and Tukey's honest significance test, mean \pm SE, $n=4-10$. P concentration and biomass from Kavka and Polle (2016). S: sulfur, $\mathrm{C}$ : carbon, $\mathrm{N}$ : nitrogen, $\mathrm{K}$ : potassium, $\mathrm{Mg}$ : magnesium, $\mathrm{Ca}$ : calcium, Fe: iron, $\mathrm{Zn}$ : zinc, Mn: manganese, $\mathrm{Al}$ : aluminum.

Although the changes in element tissue concentrations were caused by differences in $\mathrm{P}$ availability in the growth medium, they did not correlate with the $\mathrm{P}$ concentration across all tissues and treatments (Table 2.2). However, changes in biomass were correlated with $\mathrm{P}(\mathrm{p}=0.005, \mathrm{r}=0.748)$. Also sulfur, potassium, magnesium and calcium concentrations were correlated with biomass $(\mathrm{S}: \mathrm{p}<0.001, \mathrm{r}=0.884 ; \mathrm{K}: \mathrm{p}=0.007$, $\mathrm{r}=0.731 ; \mathrm{Mg}: \mathrm{p}=0.010, \mathrm{r}=0.706$; Ca: $\mathrm{p}=0.011, \mathrm{r}=0.700)$. We also tested whether the plant contents of elements were related to the $\mathrm{P}$ content. The contents of all studied elements except iron and aluminum were significantly correlated with $\mathrm{P}$ content. However, these relationships were results of changes in biomass. 
Table 2.2: Correlation analysis of element concentrations with $P$ concentrations or biomass.

\begin{tabular}{ccc|cc} 
& \multicolumn{2}{c|}{ P concentration } & \multicolumn{2}{c}{ biomass } \\
element & $\mathrm{p}$ & $\mathrm{r}$ & $\mathrm{p}$ & $\mathrm{r}$ \\
\hline $\mathrm{P}$ & n.a. & n.a. & $\mathbf{0 . 0 0 5}$ & $\mathbf{0 . 7 4 8}$ \\
$\mathrm{S}$ & 0.094 & 0.505 & $\mathbf{0 . 0 0 0}$ & $\mathbf{0 . 8 8 4}$ \\
$\mathrm{C}$ & 0.095 & -0.504 & 0.488 & -0.222 \\
$\mathrm{~N}$ & 0.150 & -0.443 & 0.950 & 0.020 \\
$\mathrm{~K}$ & 0.404 & 0.266 & $\mathbf{0 . 0 0 7}$ & $\mathbf{0 . 7 3 1}$ \\
$\mathrm{Mg}$ & 0.420 & 0.257 & $\mathbf{0 . 0 1 0}$ & $\mathbf{0 . 7 0 6}$ \\
$\mathrm{Ca}$ & 0.128 & 0.465 & $\mathbf{0 . 0 1 1}$ & $\mathbf{0 . 7 0 0}$ \\
$\mathrm{Fe}$ & 0.648 & 0.147 & 0.908 & -0.037 \\
$\mathrm{Zn}$ & 0.361 & -0.29 & 0.677 & -0.135 \\
$\mathrm{Mn}$ & 0.979 & -0.008 & 0.876 & 0.050 \\
$\mathrm{Al}$ & 0.866 & -0.055 & 0.610 & -0.164 \\
\hline
\end{tabular}

Data for concentrations in leaves, stem, coarse and fine roots (see Figure 2.1) were used and p-value and the Pearson's correlation coefficient (r) of correlation is shown. Correlations with $\mathrm{p} \leq 0.05$ are indicated in bold. n.a.: not applicable.

\subsubsection{P deprivation leads to massive transcriptional reprograming}

A total number of 12068 genes were differentially expressed in response to MP or LP treatment compared with HP (Figure 2.2). Common to all P treatments were 766 DEGs. In general, roots contained less DEGs than leaves although the decline in $\mathrm{P}$ was more pronounced in roots than in leaves (Figures 2.1, 2.2). There were 1017 root-specific and 3347 leaf-specific DEGs in response to both MP and LP treatments (Figure 2.2). 


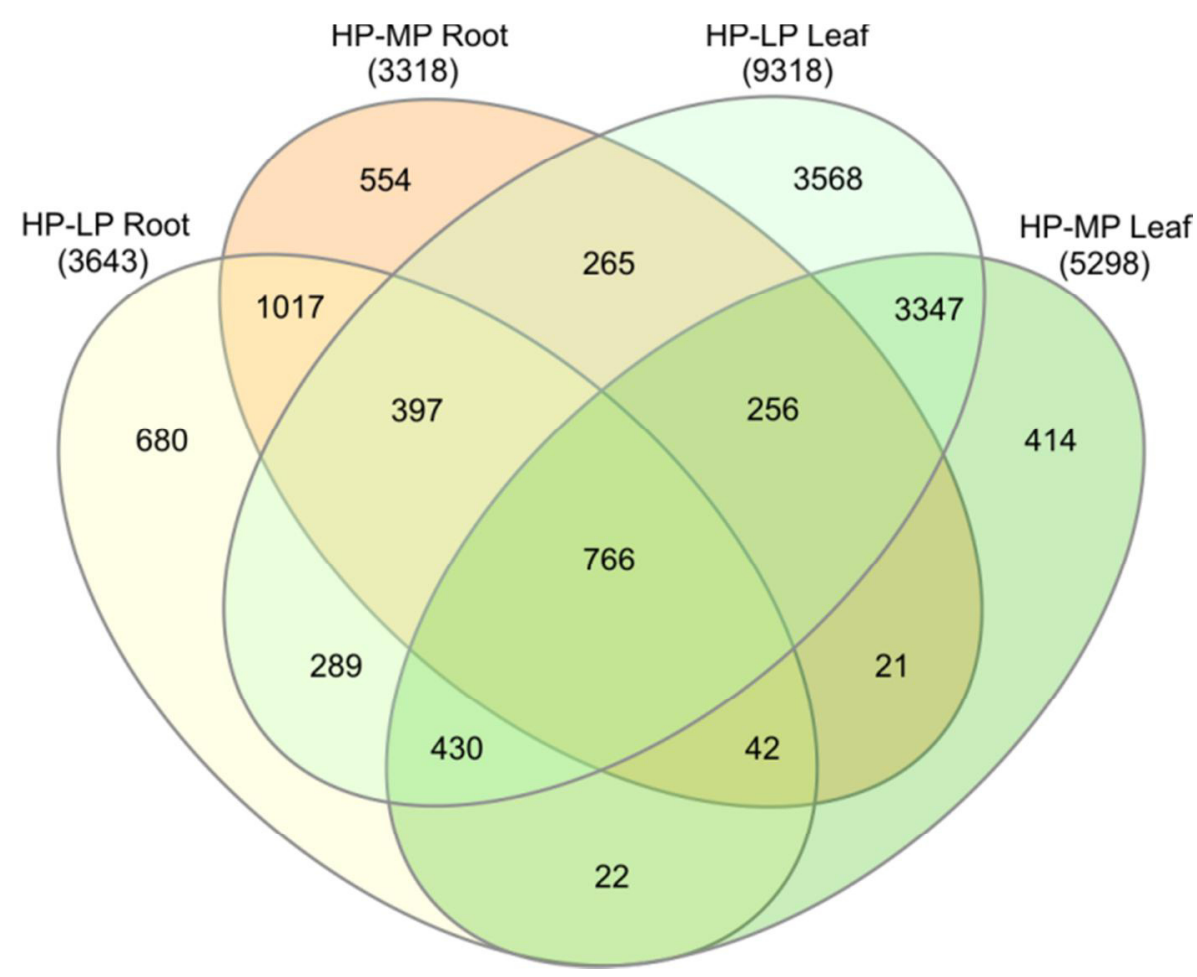

Figure 2.2. Venn-diagram of differentially regulated genes. $P . \times$ canescens was grown with high $(\mathrm{HP}, 641 \mu \mathrm{M})$, intermediate $(\mathrm{MP}, 6.4 \mu \mathrm{M})$ or low $(\mathrm{LP}, 0.064 \mu \mathrm{M}) \mathrm{P}$ supply. DEGs between HP and LP and HP and MP in roots and leaves are shown.

\subsubsection{Co-expression modules are correlated with nutrient element concentrations and biomass}

To identify genes linked to $\mathrm{P}$ nutrition, co-expression modules were calculated and the eigengenes were related to the element concentrations in roots and leaves and the biomass of these tissues. The co-expression analysis resulted in eleven modules (named after colors), which contained 5 to 3632 DEGs (Figure 2.3). The eigengenes of four modules ("Purple", "Pink", "Red", "Grey") were unrelated to any one of the examined elements or biomass (Figure 2.3) and, therefore, not considered furthermore. Eigengenes of module "Green" were strongly correlated with tissue P concentrations (pvalue: $0.0004, \mathrm{r}=0.98$ ). Module "Green" was weakly correlated with biomass ( $\mathrm{p}$ value $=0.04, \mathrm{r}=0.83$, Figure 2.3). Module "Brown" was positively related to sulfur $(\mathrm{p}=0.0005, \mathrm{r}=0.94)$, magnesium $(\mathrm{p}=0.03, \mathrm{r}=0.85)$ and biomass $(\mathrm{p}=0.0006, \mathrm{r}=0.98)$. Eigengenes of module "Blue" were negatively correlated to carbon and nitrogen concentrations (Figure 2.3). The largest module "Turquoise" (3632 genes) showed 
positive correlations with sulfur, potassium, magnesium and calcium and negative correlations with iron, manganese and aluminum concentrations (Figure 2.3). Modules "Black" showed negative correlations to potassium, manganese and sulfur concentration and "Magenta" positive correlations to manganese and aluminum and negative correlation to calcium (Figure 2.3). Module "Yellow" was negatively correlated with iron and aluminum, and positively correlated with zinc concentrations.

\begin{tabular}{|c|c|c|c|c|c|c|c|c|c|c|c|c|c|}
\hline $\begin{array}{r}\text { Green } \\
(565)\end{array}$ & $\begin{array}{c}0.98 \\
4 \times 10^{-4}\end{array}$ & $\begin{array}{l}0.62 \\
(0.2)\end{array}$ & $\begin{array}{r}-0.48 \\
(0.3)\end{array}$ & $\begin{array}{r}-0.36 \\
(0.5)\end{array}$ & $\begin{array}{c}0.2 \\
(0.7)\end{array}$ & $\begin{array}{l}0.44 \\
(0.4)\end{array}$ & $\begin{array}{l}0.72 \\
(0.1)\end{array}$ & $\begin{array}{r}-0.042 \\
(0.9)\end{array}$ & $\begin{array}{r}-0.17 \\
(0.7)\end{array}$ & $\begin{array}{r}-0.41 \\
(0.4)\end{array}$ & $\begin{array}{r}-0.27 \\
(0.6)\end{array}$ & $\begin{array}{c}0.83 \\
(0.04)\end{array}$ & \\
\hline $\begin{array}{l}\text { Brown } \\
\text { (1958) }\end{array}$ & $\begin{array}{l}0.71 \\
(0.1)\end{array}$ & $\begin{array}{c}0.94 \\
0.005\end{array}$ & $\begin{array}{r}-0.035 \\
(0.9)\end{array}$ & $\begin{array}{r}-0.046 \\
(0.9)\end{array}$ & $\begin{array}{l}0.71 \\
(0.1)\end{array}$ & $\begin{array}{r}0.85 \\
(0.03)\end{array}$ & $\begin{array}{c}0.77 \\
(0.07)\end{array}$ & $\begin{array}{l}-0.3 \\
(0.6)\end{array}$ & $\begin{array}{r}-0.22 \\
(0.7)\end{array}$ & $\begin{array}{r}-0.55 \\
(0.3)\end{array}$ & $\begin{array}{r}-0.39 \\
(0.4)\end{array}$ & $\begin{array}{r}0.98 \\
6 \times 10^{-4}\end{array}$ & \\
\hline $\begin{array}{r}\text { urquoise } \\
\text { (3632) }\end{array}$ & $\begin{array}{l}0.22 \\
(0.7)\end{array}$ & $\begin{array}{c}0.84 \\
(0.04)\end{array}$ & $\begin{array}{c}0.6 \\
(0.2)\end{array}$ & $\begin{array}{l}0.63 \\
(0.2)\end{array}$ & $\begin{array}{c}0.89 \\
(0.02)\end{array}$ & $\begin{array}{c}0.9 \\
(0.01)\end{array}$ & $\begin{array}{c}0.88 \\
(0.02)\end{array}$ & $\begin{array}{c}-0.92 \\
(0.009)\end{array}$ & $\begin{array}{l}0.54 \\
(0.3)\end{array}$ & $\begin{array}{c}-0.96 \\
0.003)\end{array}$ & $\begin{array}{l}-0.91 \\
(0.01)\end{array}$ & $\begin{array}{l}0.62 \\
(0.2)\end{array}$ & \\
\hline $\begin{array}{l}\text { Black } \\
(389)\end{array}$ & $\begin{array}{c}0.016 \\
(1)\end{array}$ & $\begin{array}{l}-0.82 \\
(0.04)\end{array}$ & $\begin{array}{r}-0.73 \\
(0.1)\end{array}$ & $\begin{array}{l}-0.7 \\
(0.1)\end{array}$ & $\begin{array}{l}-0.96 \\
0.002)\end{array}$ & $\begin{array}{c}-0.94 \\
(0.006)\end{array}$ & $\begin{array}{c}-0.68 \\
(0.1)\end{array}$ & $\begin{array}{c}0.78 \\
(0.07)\end{array}$ & $\begin{array}{r}-0.35 \\
(0.5)\end{array}$ & $\begin{array}{l}0.71 \\
(0.1)\end{array}$ & $\begin{array}{l}0.72 \\
(0.1)\end{array}$ & $\begin{array}{r}-0.56 \\
(0.3)\end{array}$ & $p$-value \\
\hline $\begin{array}{r}\text { Magenta } \\
(250)\end{array}$ & $\begin{array}{c}-0.43 \\
(0.4)\end{array}$ & $\begin{array}{r}-0.62 \\
(0.2)\end{array}$ & $\begin{array}{r}-0.36 \\
(0.5)\end{array}$ & $\begin{array}{r}-0.48 \\
(0.3)\end{array}$ & $\begin{array}{r}-0.51 \\
(0.3)\end{array}$ & $\begin{array}{r}-0.62 \\
(0.2)\end{array}$ & $\begin{array}{l}-0.87 \\
(0.02)\end{array}$ & $\begin{array}{c}0.77 \\
(0.07)\end{array}$ & $\begin{array}{r}-0.63 \\
(0.2)\end{array}$ & $\begin{array}{c}0.87 \\
(0.02)\end{array}$ & $\begin{array}{r}0.93 \\
(0.006)\end{array}$ & $\begin{array}{r}-0.53 \\
(0.3)\end{array}$ & $<0.01$ \\
\hline $\begin{array}{l}\text { Yellow } \\
(1730)\end{array}$ & $\begin{array}{r}-0.29 \\
(0.6)\end{array}$ & $\begin{array}{c}0.2 \\
(0.7)\end{array}$ & $\begin{array}{c}0.75 \\
(0.09)\end{array}$ & $\begin{array}{r}0.79 \\
(0.06)\end{array}$ & $\begin{array}{l}0.45 \\
(0.4)\end{array}$ & $\begin{array}{l}0.34 \\
(0.5)\end{array}$ & $\begin{array}{l}0.44 \\
(0.4)\end{array}$ & $\begin{array}{l}-0.91 \\
(0.01)\end{array}$ & $\begin{array}{c}0.88 \\
(0.02)\end{array}$ & $\begin{array}{l}-0.75 \\
(0.08)\end{array}$ & $\begin{array}{l}-0.84 \\
(0.04)\end{array}$ & $\begin{array}{r}-0.073 \\
(0.9)\end{array}$ & n.s. \\
\hline $\begin{array}{r}\text { Blue } \\
\text { (2562) }\end{array}$ & $\begin{array}{l}0.73 \\
(0.1)\end{array}$ & $\begin{array}{c}0.02 \\
(1)\end{array}$ & $\begin{array}{l}-0.92 \\
(0.01)\end{array}$ & $\begin{array}{l}-0.87 \\
(0.02)\end{array}$ & $\begin{array}{l}-0.4 \\
(0.4)\end{array}$ & $\begin{array}{r}-0.19 \\
(0.7)\end{array}$ & $\begin{array}{r}-0.054 \\
(0.9)\end{array}$ & $\begin{array}{c}0.74 \\
(0.09)\end{array}$ & $\begin{array}{l}-0.75 \\
(0.08)\end{array}$ & $\begin{array}{l}0.43 \\
(0.4)\end{array}$ & $\begin{array}{l}0.56 \\
(0.2)\end{array}$ & $\begin{array}{l}0.37 \\
(0.5)\end{array}$ & $\begin{array}{l}<0.05 \\
<0.01\end{array}$ \\
\hline $\begin{array}{r}\text { Purple } \\
(237)\end{array}$ & $\begin{array}{l}0.16 \\
(0.8)\end{array}$ & $\begin{array}{c}0.78 \\
(0.06)\end{array}$ & $\begin{array}{l}0.31 \\
(0.5)\end{array}$ & $\begin{array}{c}0.1 \\
(0.8)\end{array}$ & $\begin{array}{c}0.81 \\
(0.05)\end{array}$ & $\begin{array}{c}0.76 \\
(0.08)\end{array}$ & $\begin{array}{l}0.35 \\
(0.5)\end{array}$ & $\begin{array}{l}-0.3 \\
(0.6)\end{array}$ & $\begin{array}{r}-0.36 \\
(0.5)\end{array}$ & $\begin{array}{r}-0.37 \\
(0.5)\end{array}$ & $\begin{array}{l}-0.2 \\
(0.7)\end{array}$ & $\begin{array}{l}0.69 \\
(0.1)\end{array}$ & \\
\hline $\begin{array}{r}\text { Pink } \\
(294)\end{array}$ & $\begin{array}{c}0.6 \\
(0.2)\end{array}$ & $\begin{array}{r}-0.15 \\
(0.8)\end{array}$ & $\begin{array}{r}-0.55 \\
(0.3)\end{array}$ & $\begin{array}{r}-0.36 \\
(0.5)\end{array}$ & $\begin{array}{r}-0.47 \\
(0.3)\end{array}$ & $\begin{array}{r}-0.29 \\
(0.6)\end{array}$ & $\begin{array}{l}0.25 \\
(0.6)\end{array}$ & $\begin{array}{l}0.11 \\
(0.8)\end{array}$ & $\begin{array}{l}0.18 \\
(0.7)\end{array}$ & $\begin{array}{r}-0.13 \\
(0.8)\end{array}$ & $\begin{array}{c}-0.12 \\
(0.8)\end{array}$ & $\begin{array}{l}0.07 \\
(0.9)\end{array}$ & \\
\hline $\begin{array}{r}\text { Red } \\
(446)\end{array}$ & $\begin{array}{c}-0.24 \\
(0.6)\end{array}$ & $\begin{array}{c}-0.54 \\
(0.3)\end{array}$ & $\begin{array}{l}0.08 \\
(0.9)\end{array}$ & $\begin{array}{l}0.13 \\
(0.8)\end{array}$ & $\begin{array}{c}-0.44 \\
(0.4)\end{array}$ & $\begin{array}{r}-0.53 \\
(0.3)\end{array}$ & $\begin{array}{c}-0.18 \\
(0.7)\end{array}$ & $\begin{array}{r}-0.19 \\
(0.7)\end{array}$ & $\begin{array}{l}0.54 \\
(0.3)\end{array}$ & $\begin{array}{l}-0.11 \\
(0.8)\end{array}$ & $\begin{array}{l}-0.2 \\
(0.7)\end{array}$ & $\begin{array}{r}-0.56 \\
(0.3)\end{array}$ & \\
\hline $\begin{array}{r}\text { Grey } \\
(5)\end{array}$ & $\begin{array}{l}0.16 \\
(0.8)\end{array}$ & $\begin{array}{l}0.17 \\
(0.8)\end{array}$ & $\begin{array}{c}0.048 \\
(0.9)\end{array}$ & $\begin{array}{r}-0.26 \\
(0.6)\end{array}$ & $\begin{array}{r}0.095 \\
(0.9)\end{array}$ & $\begin{array}{c}-0.024 \\
(1)\end{array}$ & $\begin{array}{c}-0.11 \\
(0.8)\end{array}$ & $\begin{array}{r}-0.088 \\
(0.9)\end{array}$ & $\begin{array}{r}-0.36 \\
(0.5)\end{array}$ & $\begin{array}{c}-0.22 \\
(0.7)\end{array}$ & $\begin{array}{r}-0.12 \\
(0.8)\end{array}$ & $\begin{array}{l}0.25 \\
(0.6)\end{array}$ & \\
\hline Module & $P$ & S & C & $\mathrm{N}$ & $\mathrm{K}$ & $\mathrm{Mg}$ & $\mathrm{Ca}$ & $\mathrm{Fe}$ & $\mathrm{Zn}$ & $\mathrm{Mn}$ & $\mathrm{Al}$ & BM & \\
\hline
\end{tabular}

Figure 2.3. Correlation matrix between eigengenes of co-expression modules and element concentrations and biomass. Modules were composed of genes differentially expressed between poplars $(P . \times$ canescens $)$ grown with high $\mathrm{P}$ availability and plants grown with intermediate or low $\mathrm{P}$ availability in fine roots or leaves. Correlation coefficient and $p$-value (in brackets) are given. Significant $p$-values $(\leq 0.05)$ of correlation are color coded (red: negative correlation, blue: positive correlation). Numbers of DEGs in modules are shown below module's name. 


\subsubsection{Network analysis reveals a hierarchy of modules}

Network analysis showed that module "Green", which was strongly correlated with P concentrations, was mainly connected with "Brown" and "Blue" (Figure 2.4). Links of "Green" with other modules were rare ("Magenta", "Pink" and "Turquoise") or did not exist ("Red", "Black", "Purple" and "Yellow"). Strong co-expressions were found between genes in module "Blue" with those in modules "Yellow", "Pink" and "Brown" (Figure 2.4). Module "Brown" was further strongly connected to module "Turquoise", whose genes were co-expressed with genes in modules "Purple", "Magenta" and "Black". The network structure thus indicated co-expression of P-related genes with the $\mathrm{C}$ - and N-related genes ("Blue") on the one hand and the S-, Mg- and biomass-related genes on the other hand ("Brown", Figures 2.3, 2.4). As all other modules were apparently not strongly connected with the P-related module, also elements correlated with these genes were not strongly connected with changes in P concentrations. 


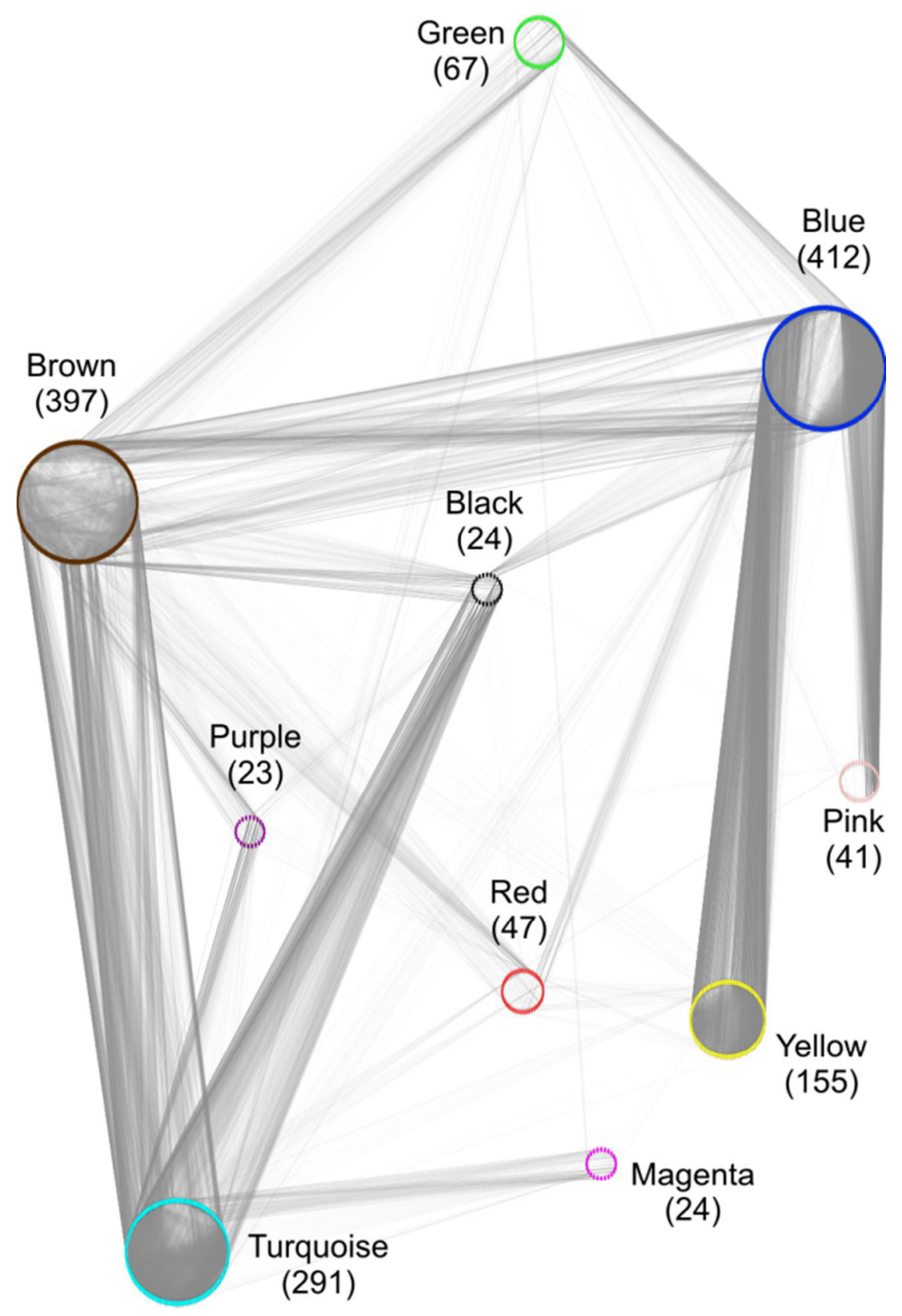

Figure 2.4. Co-expression within and between modules of DEGs. Due to computing power (about 12,000 nodes (= DEGs); about 45,000 edges (= co-expression between two DEGs) merely for module "Green"), only DEGs with $p \leq 0.00001$ (limma) were drawn. Using a fold-change cut-off resulted in a similar network picture (not shown). Nodes (= DEGs of modules) are shown by their colors. Co-expression (Weighted Gene Co-expression Network Analysis) between two nodes, is represented by grey line (edge). Higher adjacency between two DEGs is indicated by darker line color (adjacency threshold for edge drawing: 0.25). The reduced number of DEGs used to draw the network is indicated below module's name. 


\subsubsection{Functional characterization of P-related and highly connected modules}

To characterize the modules functionally, GO term enrichment analysis was performed for all modules (Supplementary Table S2.2) and presented here for module "Green" and its two most connected modules "Blue" and "Brown" (Figure 2.5). GO terms enriched in module "Green" were related to protein catabolism with terms "protein catabolic process", "proteasome assembly" and "response to misfolded protein". Further enriched GO terms in module "Green" were related to energy metabolism with "protein localization to mitochondrium", "purine nucleotide synthesis" and "photorespiration" as well as to "galactolipid synthesis" and "cellular response to phosphate starvation". The latter GO term encompassed two phosphoenolpyruvate-carboxylase kinases (Potri.013G046100, Potri.019G018100), a sulfolipid synthase (Potri.016G112600), an SPX gene (Potri.006G069500), an inorganic pyrophosphatase (Potri.003G034600) and a purple acid phosphatase (Potri.005G233400).

The genes in this GO term belonged to the genes with the strongest up-regulation under low P availability in the module "Green" in both roots and leaves (Figure 2.6a). Other highly upregulated genes in roots and leaves in module "Green" were glycerol-3-P transporters (Potri.003G109300, Potri.001G124200), the purple acid phosphatase Potri.010G158200, a phosphoenolpyruvate-carboxylase kinase (Potri.013G046100), a phosphoenolpyruvate-carboxylase (Potri.008G114200), a serine/threonine-protein kinase (Potri.006G109600) and a glycerophosphodiester phosphodiesterase (Potri.001G325200). Strongly downregulated in roots and leaves upon P starvation in module "Green" were an asparaginase (Potri.014G022900) and a choline/ethanolamine kinase (Potri.005G197500). CBL-interacting serine/threonine-protein kinases (Potri.006G062800, Potri.019G128100) and WRKY-transcription factors (Potri.001G044500, Potri.018G019800) were downregulated only in roots of the Pstarved plants. Wall-associated receptor kinase (Potri.002G075900) and a 50S ribosomal protein (Potri.005G154300) were downregulated in leaves but upregulated in roots (Figure 2.6a). 

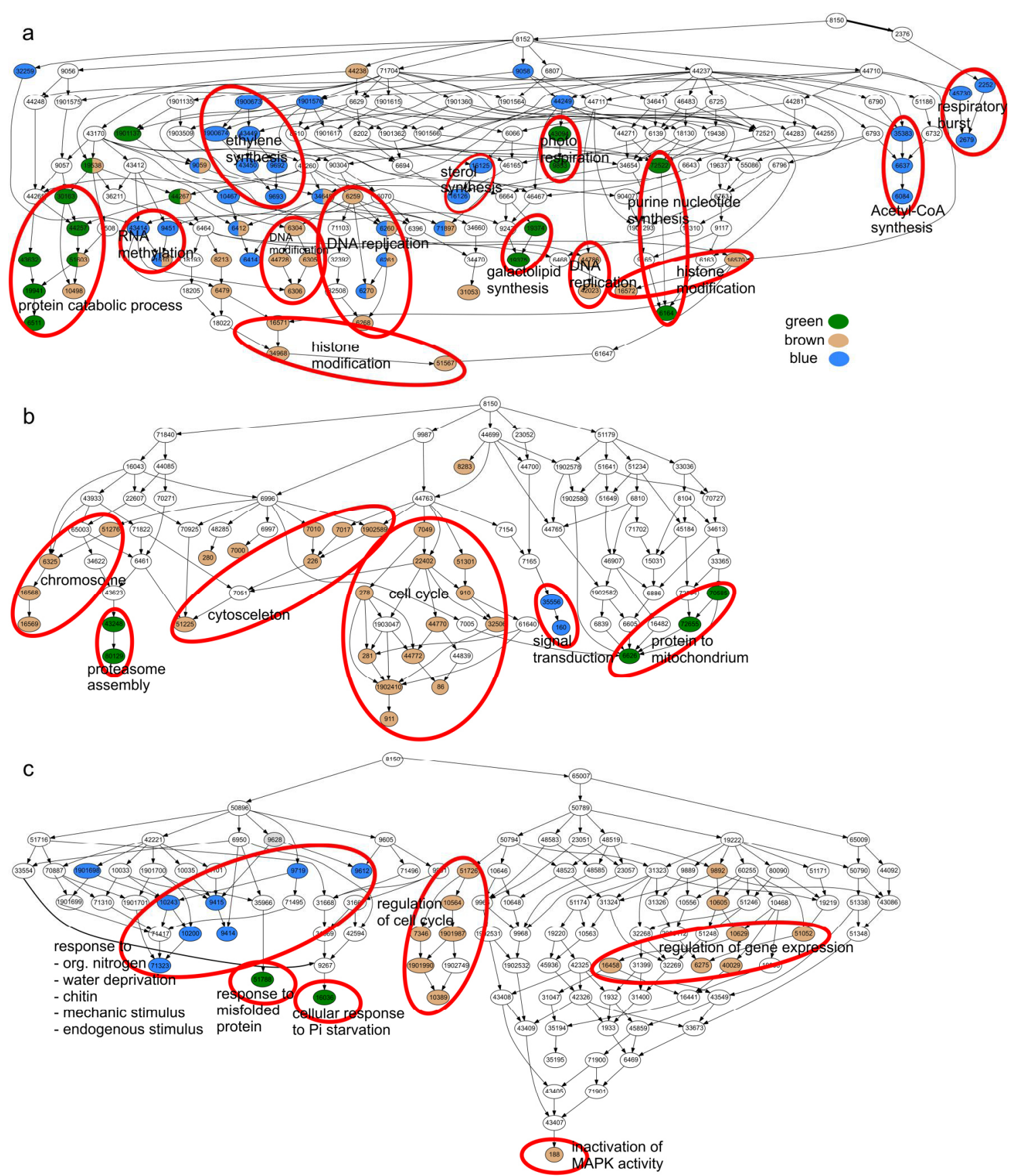

Figure 2.5. Hierarchy of enriched GO-terms in modules "Green", "Blue" and "Brown". Enriched GO terms are colored with module color, white: GO terms not enriched in modules. GO term hierarchy was drawn with GOPathDrawer. Some connections were omitted to display the figure in a page fitting format as three separated parts $(a, b, c)$. They can be found in supplementary materials Figure S2.1. 
In addition to "Biological Process" we analyzed the enrichment of GO terms for "Molecular Function" and "Cellular Component" in the co-expression modules. In agreement with "Biological Process" we found GO terms related to the respiratory chain and mitochondrium were enriched in module "Green" (Additional Table S2.2).

The P-related module "Green" was connected by 17268 edges with the biomass $/ \mathrm{S} / \mathrm{Mg}$ related module "Brown" (1958 DEGs) (cf. Figure 2.4). GO terms enriched for genes in module "Brown" were related to growth ("DNA replication", "cytoskeleton", "cell cycle" and "regulation of cell cycle"), and to the regulation of gene expression ("DNA-" and "histone modification", "chromosome" and "regulation of gene expression"). Genes encoding an SPX-domain containing protein (Potri.014G061200), the phosphate transporter PtPHT1;12 (Potri.001G318500), a chitinase (Potri.004G182000) and an NADH-dehydrogenase (Potri.011G044600) were especially highly upregulated in module "Brown" (Figure 2.6b). Genes encoding bark storage proteins (Potri.013G101000, Potri.013G100700) were highest upregulated in leaves. Phosphoethanolamine N-methyltransferases (Potri.015G039000, Potri.012G047400) were highly downregulated in both roots and leaves in module "Brown".

Genes of module "Blue" (2562 DEGs and 5330 edges with module "Green") (cf. Figure 2.4) were enriched in GO terms related to regulation and signaling ("RNA methylation", "signal transduction", "ethylene synthesis"), and to general stress responses ("respiratory burst", response to some stresses and stimuli e.g. "response to endogenous stimulus") (Figure 2.5). Further GO terms enriched in genes of module "Blue" might be related to membrane lipid degradation ("sterol-" and "Acetyl-CoA synthesis"). Notably, among the genes of module "Blue" (Figure 2.6c) purple acid phosphatases (Potri.003G030700, Potri.005G233400, Potri.010G158200, Potri.015G031400, Potri.012G042200) were highly upregulated and the ethyleneresponsive transcription factors were mostly upregulated in leaves and downregulated in roots. 

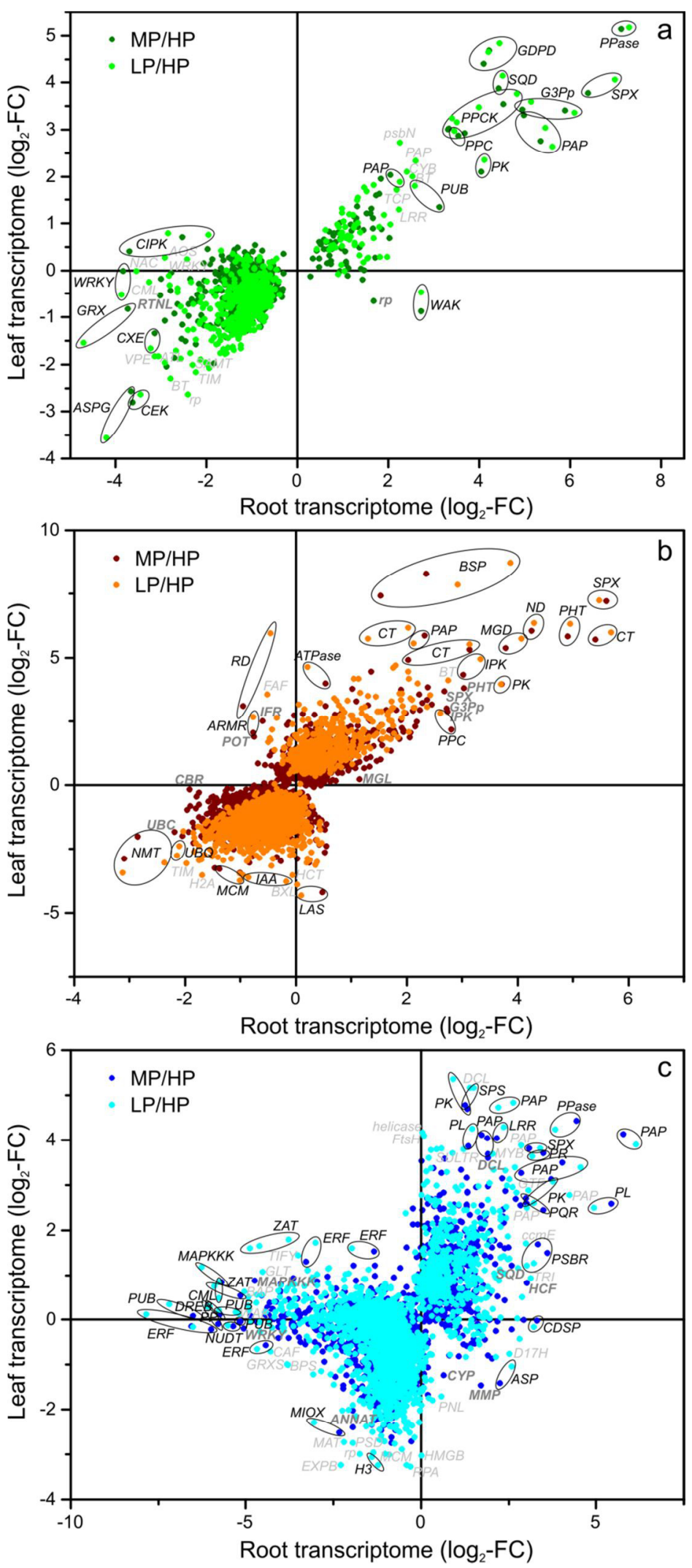

Figure 2.6. Relationship of $P$-responsive genes in roots and leaves. $\log _{2}$-fold change of $\mathrm{MP} / \mathrm{HP}$ and $\mathrm{LP} / \mathrm{HP}$ DEGs in roots were plotted to the corresponding $\log _{2}$-fold changes in leaves for module "Green" (a), "Brown" (b) and "Blue" (c). Gene abbreviations were listed in supplementary materials Table S2.3. 


\subsection{Discussion}

\subsubsection{Regulation of $P$ responses}

Here, we present the transcriptional profiles of poplar roots and leaves in response to phosphate starvation. Leaves of P-starved poplars showed more DEGs than roots. This finding agrees with the $\mathrm{P}$ starvation response in Arabidopsis (Wu et al., 2003) and suggests that the response in leaves is more complex than in roots. Among 12068 DEGs, we identified one gene cluster (module "Green") with 565 genes, which was correlated with the tissue P concentrations. Whether cause-effect-relationships exist between DEGs in module "Green" and the tissue P concentration is unknown, but the module contains homologs of Arabidopsis transcription factors known to regulate $\mathrm{P}$ sensing and signaling (Chiou and Lin, 2011; Scheible and Rojas-Triana, 2015). It is therefore likely that this module is involved in the surveillance of the P status of the cell and in crucial metabolic adjustments because it was also enriched in functions indicating enhanced degradation activities, which may be required to achieve higher $\mathrm{P}$ recycling.

Among the DEGs in roots and leaves were several members of the SPX transcription factor family (highly expressed: Potri.006G069500, Potri.006G253400, moderately enhanced: Potri.014G061200, Potri.018G028200, Potri.006G069500), which are key regulatory factors of P homeostasis in plants (Chiou and Lin, 2011; Scheible and RojasTriana, 2015). The SPX protein interacts with PHR1 (Puga et al., 2014). PHR1 enables the transcription of $\mathrm{P}$ responsive genes by binding to the P1BS element in the upstream region of those genes (Puga et al., 2014). Under high P conditions, SPX proteins bind PHR1 and thereby prevent the activation of phosphate responsive genes in a $\mathrm{P}$ dependent manner (Puga et al., 2014). Up-regulation of the expression of SPX genes under low $\mathrm{P}$ conditions further allows plants to react rapidly to $\mathrm{P}$ resupply because the binding of PHR1 stops the enhanced expression of PHR1 target genes (Puga et al., 2014). Because the poplar SPX genes in module "Green" showed P concentration related transcript abundances, it is likely that they fulfill similar functions as their homologs in Arabidopsis and rice (Puga et al., 2014; Z. Wang et al., 2014), where they link $\mathrm{P}$ perception and signaling.

Further differentially expressed transcription factors known to respond to $\mathrm{P}$ starvation were found in other co-expression modules. For example, AtWRKY75 is upregulated 
during $\mathrm{P}$ starvation and regulates $\mathrm{P}$ starvation induced genes, whereas AtWRKY6 and AtWRKY42 bind to PHO1 promoter in $\mathrm{P}$ sufficient conditions, inhibiting the transcription of PHO1 (PHOSPHATE1, involved in Pi xylem loading) (Chiou and Lin, 2011). Here, the poplar WRKY homolog Potri.001G097200 (module "Brown") is upregulated upon $\mathrm{P}$ starvation in both roots and leaves, whereas others (e.g. Potri.003G138600, Potri.006G263600, Potri.016G128300 from module "Blue", Potri.001G044500 from module "Green", Potri.003G169100, Potri.003G182200, Potri.014G096200, Potri.014G096200 from module "Pink") were downregulated especially in roots upon $\mathrm{P}$ starvation. This different expression pattern for different members of the large WRKY family emphasizes the different possible functions of distinct members. Ethylene-responsive element binding factors (ERFs) were especially abundant in the N- and C-related co-expression module with a down-regulation in roots and no or slight up-regulation in leaves upon $\mathrm{P}$ deprivation indicating an influence of ethylene signaling on root responses to low $\mathrm{P}$ conditions as for example root hair formation and primary root growth arrest (Scheible and Rojas-Triana, 2015). In Arabidopsis Zinc finger proteins (ZATs) such as AtZAT6 have functions in root development and P acquisition (Baker et al., 2015; Scheible and Rojas-Triana, 2015). Here poplar homologs from module "Blue" (Potri.009G027700, Potri.001G235800, Potri.014G017300, Potri.001G295500, Potri.008G051200, Potri.002G119300) were responsive to $\mathrm{P}$ deprivation with a strong down-regulation in roots upon $\mathrm{P}$ starvation suggesting a conserved function in poplar.

An important result of our study is that these transcription factors were assigned to different hierarchic levels of the transcriptional network: those being involved in perception and signaling were present in top level (module "Green"), while others, which control long distance transport and morphological adjustments were found in secondary positions (modules "Brown" and "Blue").

\subsubsection{Transcriptional regulation of $P$ acquisition and $P$ uptake}

Under P deficiency the expression of genes for phosphate transporters (PHTs) and purple acid phosphatases (PAPs) is upregulated increasing the P efficiency of poplar (Gan et al., 2016; Kavka and Polle, 2016; Loth-Pereda et al., 2011). Here, upregulated PAPs were present in the P-related module "Green" (Potri.005G233400, 
Potri.010G158200) but also in the secondary modules "Blue" (Potri.012G042200, Potri.015G031400, Potri.010G158200, Potri.005G233400, Potri.003G030700) and "Brown" (Potri.008G139100). In Arabidopsis, AtPAP10 and AtPAP12, which are the orthologs of the strongly P-responsive PAP Potri.005G233400 in module "Green", are secreted and root cell-wall localized phosphatases (L. Wang et al., 2014). These Arabidopsis PAPs are up-regulated under P deprivation and, thus, responsible for the $\mathrm{P}$ acquisition from organic P sources under low P conditions (L. Wang et al., 2014; Wang et al., 2011; Wang and Liu, 2012). It is therefore likely that the poplar orthologous PAP Potri.005G233400 also plays a central role in P acquisition. Since organic P source were not added to nutrient solution used in the present study, it seems that the activation of PAPs is a general response to $\mathrm{P}$ deprivation or that plants themselves release organic $\mathrm{P}$ compounds into their root surrounding, which they try to recapture or that they can even prey on bacterial debris. These suggestions are currently speculative and should be further studied. Here, other PAPs with intracellular localization might be more important because they can contribute to increase the internal P reuse of the plant. Many of those PAPs were activated in module "Blue", in which stress responses and DNA/RNA remodeling clustered as major GO terms. These results are in agreement with those found for Arabidopsis (Del Pozo et al., 1999). AtPAP17, the ortholog of the poplar PAPs Potri.012G042200 and Potri.015G031400, is highly expressed under P starvation in roots and leaves as well as in senescent leaves (Del Pozo et al., 1999). AtPAP17 has a dual function in P hydrolysis and peroxide formation (Del Pozo et al., 1999). These findings correspond to present data showing association with stress response in poplar.

An unexpected result was that none of the PHTs was assigned to module "Green", although various PHTs respond strongly to P deficiency (Kavka and Polle, 2016). Here, PtPHT1;12 and PtPHT1;9 (Potri.001G318500, Potri.002G005500) were detected in module "Brown", whose eigengenes were strongly correlated with biomass, $\mathrm{Mg}$ and S and in which GO terms for cell cycle, chromosome organization and DNA were enriched. The orthologs of PtPHT1;9 (AtPHT1;8 and AtPHT1;9) maintain high-affinity P uptake into the roots of Arabidopsis under P starvation (Remy et al., 2012) suggesting that PtPHT1;9 is also crucial for P uptake in poplar. The orthologs of PtPHT1;12 in $P$. trichocarpa and Arabidopsis $($ AtPHT1;5) show enhanced expression under P deficiency as well as in senescing leaves (Loth-Pereda et al., 2011; Mudge et al., 2002). Therefore, 
PtPHT1;12 may function in the redistribution of $\mathrm{P}$ inside the plant. Furthermore, in the module "Turquoise", which forms a tertiary level in the co-expression network, further PHTs were upregulated. Module "Turquoise" was strongly negatively correlated with Fe and Mn, which suggests links between the latter elements and $\mathrm{P}$ translocation. Earlier studies support this suggestion because enhanced $\mathrm{P}$ uptake prevented over-accumulation and toxicity of Mn (Dučić and Polle, 2007).

$\mathrm{P}$ release from plasma membranes by replacing phospholipids by galactolipids is a common adaptation to P starvation (Andersson et al., 2003; Härtel and Benning, 2000). In our study this response was evident at the transcriptome level. GO term enrichment indicated a correlation between membrane lipid remodeling and $\mathrm{P}$ concentrations in module "Green". These results agree with studies in Arabidopsis, where at least parts of membrane lipid remodeling depend on $\mathrm{P}$ signaling and auxin/cytokinin crosstalk (Kobayashi et al., 2006). For example, the Arabidopsis SQD1 (SULFOQUINOVOSYLDIACYLGLYCEROL1) is involved in sulfolipid synthesis and regulated by the phosphate content in plant tissues (Rouached et al., 2011). Here, a putative $S Q D$ (Potri.016G112600) was one of the most strongly upregulated genes in module "Green" and correlated with the P concentration supporting similar functions in the poplar and Arabidopsis P starvation response.

\subsubsection{Metabolism of mineral nutrients, sulfur, nitrogen and carbon upon P starvation}

The concentrations of basic cations declined 1.5 to 2-fold $(\mathrm{Ca}, \mathrm{Mg}, \mathrm{K})$ upon $\mathrm{P}$ starvation in poplar leaves, but did not fall below threshold values reported for sufficient nutrition in leaves of young $P$. $\times$ canescens (Ca: $15.9 \mathrm{mg} \mathrm{g}^{-1}, \mathrm{Mg}: 2 \mathrm{mg} \mathrm{g}^{-1}, \mathrm{~K}: 7.6 \mathrm{mg} \mathrm{g}^{-1}$; Burg, 1985). This was also true for sulfur, whose foliar concentrations declined 3 -fold under $P$ deficiency (threshold: $3 \mathrm{mg} \mathrm{g}^{-1}$; Burg, 1985). Together these elements were positively correlated with the co-expression module "Turquoise" in which GO terms for sulfur metabolism and organic acid biosynthesis were enriched. Production and exudation of organic acids is a known response to $\mathrm{P}$ deficiency because those metabolites can exchange anions such as Pi from soil particles, thereby increase Pi availability (Vance et al., 2003). The present data imply that the production of organic acids is not a direct 
response to declining cellular $\mathrm{P}$ concentrations but a down-stream consequence that may perhaps also require the perception of general changes in the cellular ion balance.

Cross talk exists between the $\mathrm{P}$ sensing and $\mathrm{Zn}$ as well as Fe nutrition involving the PHR1 gene regulation (Bournier et al., 2013; Khan et al., 2014). In our study the concentration of $\mathrm{Zn}$ and $\mathrm{Fe}$ were increased or relatively stable and significantly correlated with the eigengenes of module "Turquoise" (negative for Fe) and "Yellow" (positive for $\mathrm{Zn}$, negative for Fe). In contrast to poplar, in Arabidopsis and rice the $\mathrm{Zn}$ concentrations are reduced or unaffected during $\mathrm{P}$ starvation, whereas the $\mathrm{Fe}$ concentrations increase considerably upon P starvation (Gruber et al., 2013; Hirsch et al., 2006; Kellermeier et al., 2014; Rai et al., 2015; Saenchai et al., 2016; Zheng et al., 2009). In Arabidopsis, Fe as well as P homeostasis is regulated via PHR1 that induces the iron storage protein FERRITIN1 (Bournier et al., 2013). Upon P starvation, iron is stored with ferritin in chloroplasts, which prevents precipitation with Pi (Hirsch et al., 2006). But in our study, ferritin was not induced in leaves. Still, our data indicate that chloroplastic metabolism must have been massively affected because module "Yellow" was enriched in term photosynthesis, pigment biosynthesis, starch and carbohydrate metabolism. In poplar, carbohydrates accumulated in roots upon $\mathrm{P}$ starvation (Kavka and Polle, 2016) in agreement with other studies (Hammond and White, 2008) but the total tissue carbon concentrations were not significantly affected. One reason for this observation is a shift in metabolic use of carbon-bearing compounds. For example, in $\mathrm{P}$ starved poplars, we found a very high up-regulation of PPC (phosphoenolpyruvatcarboxylase) and the PPC activating kinase PPCK. PPC catalyzes the production of oxaloacetate from phosphoenolpyruvate and bicarbonate releasing Pi. Oxaloacetate can then be secreted or further metabolized into other organic acids and used for energy production.

Furthermore, $\mathrm{P}$ starvation has consequences for $\mathrm{N}$ nutrition. Both carbon and nitrogen clustered with module "Blue", which is characterized by defense responses including respiratory burst (ethylene, phosphorelay signal transduction system) and histone modification suggesting massive transcriptional reprogramming. Unlike most of the mineral nutrients, tissue $\mathrm{N}$ concentrations increased, which may happen when growth is inhibited but $\mathrm{N}$ uptake continues. Here we noted a strong induction of BSP (Bark Storage Protein) gene expression. In poplar, BSP expression increases in fall resulting in BSP protein accumulation and $\mathrm{N}$ storage during winter (Coleman et al., 1991; 
Wildhagen et al., 2010). Our result suggest that the strong growth reduction imposed by $\mathrm{P}$ deficiency led to $\mathrm{N}$ accumulation and as a further consequence induced the formation of BSPs to store N. This speculation is supported by earlier results showing that shoot growth influenced BSP promoter activity (Zhu and Coleman, 2001). Seasonal N cycling in perennial species also involves protein degradation (Rennenberg et al., 2010). BSP induction may, thus, be related to protein degradation, which was found here among the directly P correlated transcriptional responses.

\subsubsection{Conclusions}

Surprisingly few regulated gene expression patterns were directly correlated with the total tissue $\mathrm{P}$ concentrations. Whether these genes are regulated by the $\mathrm{P}$ concentration is not known, but homologs of some of them are known to regulate $\mathrm{P}$ sensing and signaling in Arabidopsis. All other P starvation responsive genes were most likely regulated by downstream events of $\mathrm{P}$ starvation, by free phosphate concentrations or by co-occurring changes in e.g. other nutrient concentrations and not directly by the $\mathrm{P}$ concentration. Cross talk between the signaling pathways of different elements are beginning to be unraveled, but further research is needed. 


\subsection{References}

Andersson, M.X., Stridh, M.H., Larsson, K.E., Liljenberg, C., Sandelius, A.S. (2003): Phosphate-deficient oat replaces a major portion of the plasma membrane phospholipids with the galactolipid digalactosyldiacylglycerol. FEBS Lett. 537, 128-132.

Baker, A., Ceasar, S.A., Palmer, A.J., Paterson, J.B., Qi, W., Muench, S.P., Baldwin, S.A. (2015): Replace, reuse, recycle: improving the sustainable use of phosphorus by plants. J. Exp. Bot. 66, 3523-3540.

Bauer, S., Grossmann, S., Vingron, M., Robinson, P.N. (2008): Ontologizer 2.0--a multifunctional tool for GO term enrichment analysis and data exploration. Bioinformatics 24, 1650-1651.

Bieleski, R.L. (1973): Phosphate pools, phosphate transport, and phosphate availability. Annu. Rev. Plant Physiol. 24, 225-252.

Bournier, M., Tissot, N., Mari, S., Boucherez, J., Lacombe, E., Briat, J.-F., Gaymard, F. (2013): Arabidopsis Ferritin 1 (AtFer1) Gene regulation by the Phosphate Starvation Response 1 (AtPHR1) transcription factor reveals a direct molecular link between iron and phosphate homeostasis. J. Biol. Chem. 288, 22670-22680.

Bradshaw, H.D., Ceulemans, R., Davis, J., Stettler, R. (2000): Emerging model systems in plant biology: Poplar (Populus) as a model forest tree. J. Plant Growth Regul. 19, 306-313.

Brunner, A.M., Busov, V.B., Strauss, S.H. (2004): Poplar genome sequence: functional genomics in an ecologically dominant plant species. Trends Plant Sci. 9, 49-56.

Burg, J. van den (1985): Foliar analysis for determination of tree nutrient status- a compilation of literature data. Rapp. Rijksinst. Voor Onderz. Bos- En Landschapsbouw Dorschkamp Neth.

Chiou, T.-J., Lin, S.-I. (2011): Signaling network in sensing phosphate availability in plants. Annu. Rev. Plant Biol. 62, 185-206.

Coleman, G.D., Chen, T.H.H., Ernst, S.G., Fuchigami, L. (1991): Photoperiod control of poplar Bark Storage Protein accumulation. Plant Physiol. 96, 686-692.

Del Pozo, J.C., Allona, I., Rubio, V., Leyva, A., De La Peña, A., Aragoncillo, C., PazAres, J. (1999): A type 5 acid phosphatase gene from Arabidopsis thaliana is induced by phosphate starvation and by some other types of phosphate mobilising/oxidative stress conditions. Plant J. 19, 579-589.

Desai, S., Naik, D., Cumming, J.R. (2014): The influence of phosphorus availability and Laccaria bicolor symbiosis on phosphate acquisition, antioxidant enzyme activity, and rhizospheric carbon flux in Populus tremuloides. Mycorrhiza 24, 369-382.

Dučić, T., Polle, A. (2007): Manganese toxicity in two varieties of Douglas fir (Pseudotsuga menziesii var. viridis and glauca) seedlings as affected by phosphorus supply. Funct. Plant Biol. 34, 31-40. 
Gan, H., Jiao, Y., Jia, J., Wang, X., Li, H., Shi, W., Peng, C., Polle, A., Luo, Z.-B. (2016): Phosphorus and nitrogen physiology of two contrasting poplar genotypes when exposed to phosphorus and/or nitrogen starvation. Tree Physiol. 36, 22-38.

Gautier, L., Cope, L., Bolstad, B.M., Irizarry, R.A. (2004): affy-analysis of Affymetrix GeneChip data at the probe level. Bioinformatics 20, 307-315.

Gruber, B.D., Giehl, R.F.H., Friedel, S., Wirén, N. von (2013): Plasticity of the Arabidopsis root system under nutrient deficiencies. Plant Physiol. 163, 161-179.

Hammond, J.P., White, P.J. (2008): Sucrose transport in the phloem: integrating root responses to phosphorus starvation. J. Exp. Bot. 59, 93-109.

Härtel, H., Benning, C. (2000): Can digalactosyldiacylglycerol substitute for phosphatidylcholine upon phosphate deprivation in leaves and roots of Arabidopsis? Biochem. Soc. Trans. 28, 729-732.

Heberle, H., Meirelles, G.V., da Silva, F.R., Telles, G.P., Minghim, R. (2015): InteractiVenn: a web-based tool for the analysis of sets through Venn diagrams. $B M C$ Bioinformatics 16.

Heinrichs, H., Brumsack, H.-J., Loftfield, N., König, N. (1986): Verbessertes Druckaufschlußsystem für biologische und anorganische Materialien. Z. Für Pflanzenernähr. Bodenkd. 149, 350-353.

Hewitt, E.J., Smith, T.A. (1974): Plant mineral nutrition. English University Press, London, 298 pp.

Hirsch, J., Marin, E., Floriani, M., Chiarenza, S., Richaud, P., Nussaume, L., Thibaud, M.C. (2006): Phosphate deficiency promotes modification of iron distribution in Arabidopsis plants. Biochimie 88, 1767-1771.

Holford, I.C.R. (1997): Soil phosphorus: its measurement, and its uptake by plants. Soil Res. 35, 227-240.

Janz, D., Behnke, K., Schnitzler, J.-P., Kanawati, B., Schmitt-Kopplin, P., Polle, A. (2010): Pathway analysis of the transcriptome and metabolome of salt sensitive and tolerant poplar species reveals evolutionary adaption of stress tolerance mechanisms. BMC Plant Biol. 10, 150.

Kauffmann, A., Rayner, T.F., Parkinson, H., Kapushesky, M., Lukk, M., Brazma, A., Huber, $W$. (2009): Importing ArrayExpress datasets into R/Bioconductor. Bioinformatics 25, 2092-2094.

Kavka, M., Polle, A. (2016): Phosphate uptake kinetics and tissue-specific transporter expression profiles in poplar (Populus $\times$ canescens) at different phosphorus availabilities. BMC Plant Biol. 16, 206.

Kellermeier, F., Armengaud, P., Seditas, T.J., Danku, J., Salt, D.E., Amtmann, A. (2014): Analysis of the root system architecture of Arabidopsis provides a quantitative readout of crosstalk between nutritional signals. Plant Cell 26, 1480-1496. 
Khan, G.A., Bouraine, S., Wege, S., Li, Y., de Carbonnel, M., Berthomieu, P., Poirier, Y., Rouached, H. (2014): Coordination between zinc and phosphate homeostasis involves the transcription factor PHR1, the phosphate exporter PHO1, and its homologue PHO1;H3 in Arabidopsis. J. Exp. Bot. 65, 871-884.

Kobayashi, K., Masuda, T., Takamiya, K., Ohta, H. (2006): Membrane lipid alteration during phosphate starvation is regulated by phosphate signaling and auxin/cytokinin cross-talk. Plant J. 47, 238-248.

Lan, P., Li, W., Schmidt, W. (2012): Complementary proteome and transcriptome profiling in phosphate-deficient Arabidopsis roots reveals multiple levels of gene regulation. Mol. Cell. Proteomics 11, 1156-1166.

Lan, $P$., Li, $W$., Schmidt, $W$. (2015): “Omics" approaches towards understanding plant phosphorus acquisition and use, in: Plaxton, W.C., Lambers, H. (eds.): Annual Plant Reviews Volume 48. John Wiley \& Sons, Inc., Hoboken, NJ, USA, pp. 65-97.

Langfelder, P., Horvath, S. (2008): WGCNA: an R package for weighted correlation network analysis. BMC Bioinformatics 9, 1-13.

Loth-Pereda, V., Orsini, E., Courty, P.-E., Lota, F., Kohler, A., Diss, L., Blaudez, D., Chalot, M., Nehls, U., Bucher, M., Martin, F. (2011): Structure and expression profile of the phosphate Pht1 transporter gene family in mycorrhizal Populus trichocarpa. Plant Physiol. 156, 2141-2154.

Misson, J., Raghothama, K.G., Jain, A., Jouhet, J., Block, M.A., Bligny, R., Ortet, P., Creff, A., Somerville, S., Rolland, N., Doumas, P., Nacry, P., Herrerra-Estrella, L., Nussaume, L., Thibaud, M.-C. (2005): A genome-wide transcriptional analysis using Arabidopsis thaliana Affymetrix gene chips determined plant responses to phosphate deprivation. Proc. Natl. Acad. Sci. U. S. A. 102, 11934-11939.

Morcuende, R., Bari, R., Gibon, Y., Zheng, W., Pant, B.D., Bläsing, O., Usadel, B., Czechowski, T., Udvardi, M.K., Stitt, M., Scheible, W.-R. (2007): Genome-wide reprogramming of metabolism and regulatory networks of Arabidopsis in response to phosphorus. Plant Cell Environ. 30, 85-112.

Mudge, S.R., Rae, A.L., Diatloff, E., Smith, F.W. (2002): Expression analysis suggests novel roles for members of the Pht1 family of phosphate transporters in Arabidopsis. Plant J. 31, 341-353.

Nussaume, L., Kanno, S., Javot, H., Marin, E., Pochon, N., Ayadi, A., Nakanishi, T.M., Thibaud, M.-C. (2011): Phosphate import in plants: Focus on the PHT1 transporters. Front. Plant Sci. 2, 83.

Puga, M.I., Mateos, I., Charukesi, R., Wang, Z., Franco-Zorrilla, J.M., de Lorenzo, L., Irigoyen, M.L., Masiero, S., Bustos, R., Rodriguez, J., Leyva, A., Rubio, V., Sommer, H., Paz-Ares, J. (2014): SPX1 is a phosphate-dependent inhibitor of PHOSPHATE STARVATION RESPONSE 1 in Arabidopsis. Proc. Natl. Acad. Sci. 111, 1494714952.

$R$ Development Core Team (2012): R: a language and environment for statistical computing. R Foundation for Statistical Computing, Vienna, Austria. 
Rai, V., Sanagala, R., Sinilal, B., Yadav, S., Sarkar, A.K., Dantu, P.K., Jain, A. (2015): Iron availability affects phosphate deficiency-mediated responses, and evidence of cross-talk with auxin and zinc in Arabidopsis. Plant Cell Physiol. 56, 1107-1123.

Rennenberg, H., Herschbach, C. (2013): Phosphorus nutrition of woody plants: many questions - few answers. Plant Biol. 15, 785-788.

Rennenberg, H., Wildhagen, H., Ehlting, B. (2010): Nitrogen nutrition of poplar trees. Plant Biol. 12, 275-291.

Rouached, H., Secco, D., Arpat, B., Poirier, Y. (2011): The transcription factor PHR1 plays a key role in the regulation of sulfate shoot-to-root flux upon phosphate starvation in Arabidopsis. BMC Plant Biol. 11, 19.

Saenchai, C., Bouain, N., Kisko, M., Prom-u-thai, C., Doumas, P., Rouached, H. (2016): The involvement of OsPHO1;1 in the regulation of iron transport through integration of phosphate and zinc deficiency signaling. Front. Plant Sci. 7, 396.

Schachtman, D.P., Reid, R.J., Ayling, S.M. (1998): Phosphorus uptake by plants: from soil to cell. Plant Physiol. 116, 447-453.

Scheible, W.-R., Rojas-Triana, M. (2015): Sensing, signalling, and control of phosphate starvation in plants: molecular players and applications, in: Plaxton, W.C., Lambers, H. (eds.): Annual Plant Reviews Volume 48. John Wiley \& Sons, Inc., Hoboken, NJ, USA, pp. 23-63.

Schwender, H. (2011): siggenes: Multiple testing using SAM and Efron's empirical Bayes approaches. R package version 1.28.0.

Shannon, P., Markiel, A., Ozier, O., Baliga, N.S., Wang, J.T., Ramage, D., Amin, N., Schwikowski, B., Ideker, T. (2003): Cytoscape: a software environment for integrated models of biomolecular interaction networks. Genome Res. 13, 2498-2504.

Smyth, G.K. (2005): limma: Linear Models for Microarray Data, in: Gentleman, R., Carey, V.J., Huber, W., Irizarry, R.A., Dudoit, S. (eds.): Bioinformatics and computational biology solutions using $\mathrm{R}$ and Bioconductor. Springer New York, pp. $397-420$.

Taylor, G. (2002): Populus: Arabidopsis for forestry. Do we need a model tree? Ann. Bot. 90, 681-689.

Tsai, C.-J., Ranjan, P., DiFazio, S., Tuskan, G., Johnson, V. (2011): Poplar genome microarrays, in: Joshi, C., DiFazio, S., Kole, C. (eds.): Genetics, genomics and breeding of poplars. Science Publishers, Enfield, NH, pp. 112-127.

Vance, C.P., Uhde-Stone, C., Allan, D.L. (2003): Phosphorus acquisition and use: critical adaptations by plants for securing a nonrenewable resource. New Phytol. 157, 423-447.

von Wirén, N., Klair, S., Bansal, S., Briat, J.-F., Khodr, H., Shioiri, T., Leigh, R.A., Hider, R.C. (1999): Nicotianamine chelates both FeIII and FeII. Implications for metal transport in plants. Plant Physiol. 119, 1107-1114. 
Wang, L., Li, Z., Qian, W., Guo, W., Gao, X., Huang, L., Wang, H., Zhu, H., Wu, J.-W., Wang, D., Liu, D. (2011): The Arabidopsis purple acid phosphatase AtPAP10 is predominantly associated with the root surface and plays an important role in plant tolerance to phosphate limitation. Plant Physiol. 157, 1283-1299.

Wang, L., Liu, D. (2012): Arabidopsis purple acid phosphatase 10 is a component of plant adaptive mechanism to phosphate limitation. Plant Signal. Behav. 7, 306-310.

Wang, L., Lu, S., Zhang, Y., Li, Z., Du, X., Liu, D. (2014): Comparative genetic analysis of Arabidopsis purple acid phosphatases AtPAP10, AtPAP12, and AtPAP26 provides new insights into their roles in plant adaptation to phosphate deprivation: Comparative analysis of three Arabidopsis APases. J. Integr. Plant Biol. 56, 299-314.

Wang, Y.-H., Garvin, D.F., Kochian, L.V. (2002): Rapid induction of regulatory and transporter genes in response to phosphorus, potassium, and iron deficiencies in tomato roots. Evidence for cross talk and root/rhizosphere-mediated signals. Plant Physiol. 130, 1361-1370.

Wang, Z., Ruan, W., Shi, J., Zhang, L., Xiang, D., Yang, C., Li, C., Wu, Z., Liu, Y., Yu, $Y$., Shou, H., Mo, X., Mao, C., Wu, P. (2014): Rice SPX1 and SPX2 inhibit phosphate starvation responses through interacting with PHR2 in a phosphate-dependent manner. Proc. Natl. Acad. Sci. 111, 14953-14958.

Ward, J.T., Lahner, B., Yakubova, E., Salt, D.E., Raghothama, K.G. (2008): The effect of iron on the primary root elongation of Arabidopsis during phosphate deficiency. PLANT Physiol. 147, 1181-1191.

Wildhagen, H., Dürr, J., Ehlting, B., Rennenberg, H. (2010): Seasonal nitrogen cycling in the bark of field-grown Grey poplar is correlated with meteorological factors and gene expression of bark storage proteins. Tree Physiol. 30, 1096-1110.

Woo, J., MacPherson, C.R., Liu, J., Wang, H., Kiba, T., Hannah, M.A., Wang, X.-J., Bajic, V.B., Chua, N.-H. (2012): The response and recovery of the Arabidopsis thaliana transcriptome to phosphate starvation. BMC Plant Biol. 12, 62.

Wu, P., Ma, L., Hou, X., Wang, M., Wu, Y., Liu, F., Deng, X.W. (2003): Phosphate starvation triggers distinct alterations of genome expression in Arabidopsis roots and leaves. Plant Physiol. 132, 1260-1271.

Zheng, L., Huang, F., Narsai, R., Wu, J., Giraud, E., He, F., Cheng, L., Wang, F., Wu, P., Whelan, J., Shou, H. (2009): Physiological and transcriptome analysis of iron and phosphorus interaction in rice seedlings. Plant Physiol. 151, 262-274.

Zhu, B., Coleman, G.D. (2001): Phytochrome-mediated photoperiod perception, shoot growth, glutamine, calcium, and protein phosphorylation influence the activity of the poplar Bark Storage Protein gene promoter (bspA). Plant Physiol. 126, 342-351. 


\subsection{Supporting information}

Table S2.1: Information about differentially expressed genes. (data CD)

Table S2.2: Overview about enriched GO terms in all modules. (data CD)

Table S2.3: Gene name abbreviations for Figure 2.6.

Figure S2.1. Hierarchy of enriched GO-terms in modules "Green", "Blue" and "Brown". (data CD) 
Table S2.3: Gene name abbreviations for Figure 2.6.

\begin{tabular}{|c|c|c|}
\hline $\begin{array}{l}\text { Gene } \\
\text { abbreviations }\end{array}$ & gene name & $\begin{array}{l}\text { Potri.IDs (labeled } \\
\text { in figure) }\end{array}$ \\
\hline \multicolumn{3}{|l|}{ (a) } \\
\hline AOS & allene oxide synthase & Potri.014G038700 \\
\hline ASPG & asparaginase & Potri.014G022900 \\
\hline ATL & RING-H2 zinc finger protein & Potri.001G162000 \\
\hline BT & $\begin{array}{l}\mathrm{BTB} / \mathrm{POZ} \text { domain-containing } \\
\text { protein }\end{array}$ & $\begin{array}{l}\text { Potri.001G468700 } \\
\text { Potri.007G140400 }\end{array}$ \\
\hline CEK & choline/ethanolamine kinase & Potri.005G197500 \\
\hline CIPK & CBL-interacting protein kinase & $\begin{array}{l}\text { Potri.006G062800 } \\
\text { Potri.019G128100 }\end{array}$ \\
\hline CML & calcium-binding protein & Potri.016G142000 \\
\hline CXE & carboxylesterase & Potri.009G104400 \\
\hline CYB & cytochrome b & Potri.013G136800 \\
\hline G3Pp & $\begin{array}{l}\text { Glycerol-3-phosphate } \\
\text { transporter }\end{array}$ & $\begin{array}{l}\text { Potri.001G124200 } \\
\text { Potri.003G109300 }\end{array}$ \\
\hline GDPD & $\begin{array}{l}\text { glycerophosphodiester } \\
\text { phosphodiesterase }\end{array}$ & Potri.001G325200 \\
\hline GRX & glutaredoxin & Potri.017G017300 \\
\hline LRR & leucine rich repeat protein & Potri.001G425500 \\
\hline NAC & $\begin{array}{l}\text { NAC-domain containing } \\
\text { protein }\end{array}$ & Potri.007G099400 \\
\hline PAP & purple acid phosphatase & $\begin{array}{l}\text { Potri.002G243900 } \\
\text { Potri.010G158200 } \\
\text { Potri.005G233400 }\end{array}$ \\
\hline PK & serine/threonine-protein kinase & Potri.006G109600 \\
\hline PPase & pyrophosphatase & Potri.003G034600 \\
\hline PPC & \multicolumn{2}{|l|}{ phosphoenolpyruvatcarboxylase } \\
\hline PPCK & $\begin{array}{l}\text { phosphoenolpyruvatcarboxylase } \\
\text { kinase }\end{array}$ & $\begin{array}{l}\text { Potri.013G046100 } \\
\text { Potri.019G018100 }\end{array}$ \\
\hline $\mathrm{psbN}$ & $\begin{array}{l}\text { photosystem II reaction centre } \\
\text { N protein }\end{array}$ & Potri.019G028300 \\
\hline PUB & $\begin{array}{l}\text { U-box domain containing } \\
\text { protein }\end{array}$ & Potri.014G084900 \\
\hline $\mathrm{rp}$ & ribosomal protein & $\begin{array}{l}\text { Potri.009G064100 } \\
\text { Potri.005G154300 }\end{array}$ \\
\hline RTNL & reticulon-like protein & Potri.015G027300 \\
\hline SAMT & $\begin{array}{l}\text { S-adenosyl-L-methionine- } \\
\text { dependent methyltransferase }\end{array}$ & Potri.007G021400 \\
\hline SPX & SPX domain containing protein & Potri.006G069500 \\
\hline SQD & $\begin{array}{l}\text { sulfoquinovosyldiacylglycerol / } \\
\text { UDP-sulfoquinovose synthase }\end{array}$ & Potri.016G112600 \\
\hline TCP & TCP transcription factor & Potri.002G152200 \\
\hline
\end{tabular}


Table S2.3 (continued)

\begin{tabular}{lll}
\hline $\begin{array}{l}\text { Gene } \\
\text { abbreviations }\end{array}$ & gene name & $\begin{array}{l}\text { Potri.IDs (labeled } \\
\text { in figure) }\end{array}$ \\
\hline TIM & $\begin{array}{l}\text { mitochondrial import inner } \\
\text { membrane translocase } \\
\text { vacuolar processing enzyme }\end{array}$ & Potri.015G102000 \\
VPE & Potri.006G232900 \\
WAK & Wall-associated kinase & $\begin{array}{l}\text { Potri.002G075900 } \\
\text { WRKY }\end{array}$ \\
& & $\begin{array}{l}\text { Potri.001G044500 } \\
\text { Potri.018G019800 }\end{array}$
\end{tabular}

(b)

ARMR Armadillo repeat-containing Potri.002G118800 protein

ATPase ATP synthase Potri.014G168000

BSP bark storage protein Potri.013G100700

BT S. (a)

Potri.013G101000

Potri.014G122200

CBR NADH-cytochrome B5 Potri.013G067300

CT chitinase Potri.009G142200

reductase

FAF Fantastic Four meristem $\quad$ Potri.001G216000

regulator

G3Pp s. (a) Potri.003G109300

H2A histone H2A Potri.005G040700

HCT shikimate O- Potri.005G028000

hydroxycinnamoyltransferase

IAA auxin responsive protein Potri.001G177500

IFR isoflavone reductase Potri.005G228700

IPK inositol-tetrakis/trisphosphate Potri.009G084600

kinase

LAS ribosome biogenesis factor Potri.009G067800

MCM DNA replication licensing Potri.018G112800 factor

MGD monogalactosyldiacylglycerol Potri.006G063300

synthase

MGL methionine gamma-lyase Potri.003G190600

ND NADH:ubiquinone reductase Potri.011G044600 (none-electrogenic)

NMT phosphoethanolamine N- Potri.015G039000 methyltransferase Potri.012G047400

PAP s. (a) Potri.008G139100

PHT phosphate transporter Potri.001G318500

PK s. (a) Potri.002G005500

POT proton-dependent oligopeptide Potri.006G096800 transporter 
Table S2.3 (continued)

\begin{tabular}{|c|c|c|}
\hline $\begin{array}{l}\text { Gene } \\
\text { abbreviations }\end{array}$ & gene name & $\begin{array}{l}\text { Potri.IDs (labeled } \\
\text { in figure) }\end{array}$ \\
\hline PPC & s. (a) & Potri.011G110700 \\
\hline $\mathrm{RD}$ & dehydration-responsive protein & Potri.004G136000 \\
\hline SPX & s. (a) & Potri.014G061200 \\
\hline TIM & s. (a) & Potri.012G039100 \\
\hline UBC & ubiquitin-conjugating enzyme & Potri.001G254500 \\
\hline UBQ & ubiquitin extension protein & Potri.016G077200 \\
\hline
\end{tabular}

(c)

\begin{tabular}{|c|c|c|}
\hline ANNAT & annexin & Potri.001G024900 \\
\hline ASP & aspartyl protease & Potri.018G014800 \\
\hline BAP & $\mathrm{BON}$ association protein & Potri.002G155300 \\
\hline BPS & bypass 1-related protein-related & Potri.010G171000 \\
\hline CAF & CCR4-associated factor & Potri.009G161500 \\
\hline $\operatorname{ccmE}$ & heme-binding protein-related & Potri.001G379000 \\
\hline CDSP & thioredoxin-like protein & Potri.005G245700 \\
\hline \multirow[t]{2}{*}{ CML } & calmodulin like / EF-hand & Potri.002G001400 \\
\hline & $\begin{array}{l}\text { calcium-binding domain } \\
\text { containing protein }\end{array}$ & Potri.005G259900 \\
\hline CYP & cytochrome P450 CYP2 & Potri.004G106600 \\
\hline D17H & $\begin{array}{l}\text { desacetyoxyvindoline-17- } \\
\text { hydroxylase }\end{array}$ & Potri.005G222300 \\
\hline DCL & $\begin{array}{l}\text { endoribonuclease dicer } \\
\text { homolog }\end{array}$ & Potri.002G181400 \\
\hline DREB & $\begin{array}{l}\text { dehydration-responsive } \\
\text { element-binding protein }\end{array}$ & Potri.001G110800 \\
\hline \multirow[t]{5}{*}{ ERF } & ethylene responsive factor & Potri.006G138800 \\
\hline & & Potri.006G138700 \\
\hline & & Potri.009G101900 \\
\hline & & Potri.001G154200 \\
\hline & & Potri.007G138100 \\
\hline EXPB & beta-expansin precursor & Potri.014G066300 \\
\hline FtsH & FtsH protease & Potri.017G084000 \\
\hline GLT & $\begin{array}{l}\text { glycosyltransferase domain- } \\
\text { containing protein }\end{array}$ & Potri.008G192600 \\
\hline GRXS & monothiol glutaredoxin & Potri.007G134800 \\
\hline GTF & glycosyltransferase & Potri.006G097600 \\
\hline \multirow[t]{2}{*}{ H3 } & histone $\mathrm{H} 3$ & Potri.014G096900 \\
\hline & & Potri.002G028800 \\
\hline $\mathrm{HCF}$ & $\begin{array}{l}\text { photosystem II } \\
\text { stability/assembly factor }\end{array}$ & Potri.007G071300 \\
\hline helicase & DNA helicase & Potri.012G114100 \\
\hline HMGB & HMG-box-containing protein & Potri.007G000900 \\
\hline LRR & s. (a) & Potri.017G152500 \\
\hline
\end{tabular}


Table S2.3 (continued)

\begin{tabular}{|c|c|c|}
\hline $\begin{array}{l}\text { Gene } \\
\text { abbreviations }\end{array}$ & gene name & $\begin{array}{l}\text { Potri.IDs (labeled } \\
\text { in figure) }\end{array}$ \\
\hline \multirow[t]{2}{*}{ MAPKKK } & mitogen-activated protein & Potri.005G139300 \\
\hline & kinase kinase kinase & Potri.007G044800 \\
\hline MAT & $\begin{array}{l}\text { S-adenosylmethionine } \\
\text { synthetase }\end{array}$ & Potri.006G123200 \\
\hline MCM & s. (b) & Potri.001G070500 \\
\hline MIOX & myo-inositol oxygenase & Potri.018G069700 \\
\hline MMP & $\begin{array}{l}\text { matrix metalloproteinase / } \\
\text { interstitial collagenase }\end{array}$ & Potri.013G033200 \\
\hline MYB & MYB transcription factor & Potri.010G128900 \\
\hline NUDT & nudix hydrolase & Potri.008G134000 \\
\hline \multirow[t]{6}{*}{ PAP } & s. (a) & Potri.001G023400 \\
\hline & & Potri.003G030700 \\
\hline & & Potri.005G233400 \\
\hline & & Potri.010G158200 \\
\hline & & Potri.015G031400 \\
\hline & & Potri.012G042200 \\
\hline \multirow[t]{2}{*}{ PK } & s. (a) & Potri.001G014700 \\
\hline & & Potri.016G123300 \\
\hline \multirow[t]{2}{*}{ PL } & phospholipase & Potri.013G012300 \\
\hline & & Potri.001G250500 \\
\hline PNL & pectin lyase-like & Potri.010G042100 \\
\hline PP & protein phosphatase $2 \mathrm{C}$ & Potri.001G381000 \\
\hline PPase & s. (a) & Potri.008G196800 \\
\hline PQR & PQ-loop repeat protein & Potri.007G031800 \\
\hline PR & pathogenesis related protein & Potri.009G083300 \\
\hline PSBR & $\begin{array}{l}\text { photosystem II } 10 \mathrm{kDa} \\
\text { polypeptide }\end{array}$ & Potri.011G142300 \\
\hline PSD & $\begin{array}{l}\text { phosphatidylserine } \\
\text { decarboxylase }\end{array}$ & Potri.003G061700 \\
\hline \multirow[t]{3}{*}{ PUB } & s. (a) & Potri.017G135000 \\
\hline & & Potri.006G202600 \\
\hline & & Potri.008G137700 \\
\hline $\mathrm{rp}$ & s. (a) & Potri.006G192900 \\
\hline RPA & replication protein & Potri.006G275700 \\
\hline SPS & sucrose phosphate synthase & Potri.013G095500 \\
\hline SPX & s. (a) & Potri.006G069500 \\
\hline SQD & s. (a) & Potri.006G228000 \\
\hline SULTR & sulfate transporter & Potri.005G169300 \\
\hline TIFY & TIFY domain protein & Potri.003G165000 \\
\hline TRI & tropinone reductase & Potri.005G039300 \\
\hline WAK & s. (a) & Potri.005G021300 \\
\hline WRKY & & Potri.003G138600 \\
\hline \multirow[t]{3}{*}{ ZAT } & zinc finger protein & Potri.001G235800 \\
\hline & & Potri.014G017300 \\
\hline & & Potri.002G1 19300 \\
\hline
\end{tabular}




\subsection{Declaration}

The following data shown in this chapter have been provided:

- ICP-OES and calculations were conducted by members of the Department of Plant Ecology and Ecosystems Research (Albrecht-von-Haller-Institute for Plant Sciences, Georg-August University Göttingen).

- All laboratory steps for microarray analyses (from RNA quality determinations to raw data) were provided by the Microarray Facility (MFT Services, Tübingen, Germany). 


\title{
Chapter 3
}

\section{Phosphate uptake kinetics and tissue-specific transporter expression profiles in poplar (Populus $\times$ canescens) at different phosphorus availabilities}

\author{
Published in similar form as open access article distributed under the terms of \\ the Creative Commons Attribution 4.0 International License \\ (http://creativecommons.org/licenses/by/4.0/). (C) The Author(s). 2016. \\ Mareike Kavka and Andrea Polle \\ BMC Plant Biology (2016) 16:206 \\ DOI 10.1186/s12870-016-0892-3
}

\subsection{Introduction}

Phosphorus $(\mathrm{P})$ is a major nutrient, required for growth and metabolism, but often is the least plant-available compound in soil (Holford, 1997). Plants take up phosphorus in the form of inorganic phosphate $(\mathrm{Pi})$, whose concentration is usually low $(<10 \mu \mathrm{M})$ in soil solutions (Bieleski, 1973). P uptake and translocation is achieved by a diverse group of phosphate transporters (PHTs), which cluster in four families (Guo et al., 2008; Rausch and Bucher, 2002). Most members of family 1 (PHT1) are localized in the plasma membrane (Nussaume et al., 2011), of PHT2 in chloroplasts (Versaw and Harrison, 2002), of PHT3 in the mitochondria (Rausch and Bucher, 2002) and of PHT4 in various subcellular compartments, including heterotrophic plastids and the Golgi apparatus (Guo et al., 2008). In Arabidopsis, members of the PHT1 family exhibit strong expression in roots, are responsible for $\mathrm{P}$ uptake from soil and for the distribution and remobilization within the plant (Baker et al., 2015; Nussaume et al., 2011), whereas the members of the other PHT families are required for intracellular P distribution (Guo et al., 2008; Takabatake et al., 1999; Versaw and Harrison, 2002).

Kinetic measurements showed that plants possess two different P uptake systems: high affinity systems that respond to the $\mathrm{P}$ status of the plant, and low affinity systems that 
are expressed constitutively (Schachtman et al., 1998). Low affinity P uptake systems are operational under high $\mathrm{P}$ availabilities and exhibit $\mathrm{K}_{\mathrm{m}}$ values of 50 to several hundred $\mu \mathrm{M}$ (Schachtman et al., 1998). In Arabidopsis, PHT2;1 (Daram et al., 1999; Versaw and Harrison, 2002) and all transporters of family 4 (Guo et al., 2008) were shown to be low affinity transporters. But also family 1 may contain low affinity transporters (rice: OsPHT1;2 (Ai et al., 2009), barley: HvPHT1;6 (Rae et al., 2003)). The expression of high affinity transporters is induced when $\mathrm{P}$ availability is low (Zhang et al., 2014). Their $\mathrm{K}_{\mathrm{m}}$ values are in the lower micro-molar range (LópezArredondo et al., 2014). For example, Arabidopsis AtPHT1;1 exhibited a $\mathrm{K}_{\mathrm{m}}$ of $3 \mu \mathrm{M}$ (Mitsukawa et al., 1997) and transported together with AtPHT1;4 the highest proportion of phosphate into the roots under low P conditions (Shin et al., 2004).

At the whole-plant level, $\mathrm{P}$ uptake is driven by the interplay of multiple $\mathrm{P}$ transporters and internal resource allocation. Whole-plant $\mathrm{P}$ uptake has mainly been determined for agricultural crops such as barley, maize, potato and soybean, and was about 1.8 to 5.2 times higher in P starved than in P sufficient plants (Bhadoria et al., 2004; Cogliatti and Clarkson, 1983; Jungk et al., 1990; Lee, 1982), but information on the involved transport systems is lacking.

Populus species are important woody crops (Polle et al., 2013; Polle and Chen, 2015). With an increasing demand for woody biomass, an extension of poplar plantations is expected, especially on marginal soils where nutrients are often limited (Polle et al., 2013; Polle and Chen, 2015). Previous studies on selected members of the PHT1 family in poplar demonstrated up-regulation when the trees were exposed to low or no $\mathrm{P}$ in the growth medium (Gan et al., 2016; Loth-Pereda et al., 2011). It was further shown that the $\mathrm{K}_{\mathrm{m}}$ for $\mathrm{P}$ accumulation in roots of $\mathrm{P}$ starved poplars (P. tremuloides) was $32 \mu \mathrm{M}$ (Desai et al., 2014). P uptake kinetics that link changes in $\mathrm{P}$ uptake with changes in the expression profiles in different PHT families, are still missing. Furthermore, it is not known whether modulation in $\mathrm{P}$ availability affects $\mathrm{P}$ acquisition, internal allocation and P use efficiency in poplar.

The goal of the present study was to characterize whole-plant $\mathrm{P}$ uptake kinetics and expression profiles of the PHT transporter families 1, 2, 3, and 4 in roots and leaves under high, intermediate and low $\mathrm{P}$ availability in poplar $(P . \times$ canescens $)$. As prerequisite for these studies we annotated the poplar PHT families 2, 3, and 4 in addition to the known PHT1 family (Loth-Pereda et al., 2011). We further determined P 
acquisition and allocation in response to different $\mathrm{P}$ availabilities. Our results show that intermediate $\mathrm{P}$ concentrations of about $6 \mu \mathrm{M}$, which are often present in environments, led to a tissue-specific regulation of PHTs, a relative increase in P uptake with low $\mathrm{K}_{\mathrm{m}}$ and high $\mathrm{v}_{\max }$, increased $\mathrm{P}$ use efficiency, but strong growth reduction.

\subsection{Methods}

\subsubsection{Plant material and growth conditions}

In vitro micropropagated (Leple et al., 1992) Populus $\times$ canescens (INRA717 1-B4) plantlets were grown on half-strength Murashige and Skoog medium for three weeks to develop roots. Afterwards, they were planted singly into PVC tubes $(5 \mathrm{~cm}$ diameter; 40 cm length) with one drain (Jentschke et al., 1999; Müller et al., 2013) filled with autoclaved sand (Ø 0.4-3.15 mm particle size, Melo, Göttingen, Germany) and grown in a greenhouse at an air humidity of about $65 \%$. The plants were supplemented with additional light (EYE Clean Ace MT400DL/BH, EYE Lighting Europe, Uxbridge, UK; 50-100 $\mu \mathrm{mol}$ quanta $\mathrm{m}^{-2} \mathrm{~s}^{-1}$ of photosynthetically active radiation, depending on poplar height and natural light condition) for $14 \mathrm{~h}$ a day from 7 am to $9 \mathrm{pm}$. The plants were automatically irrigated as described by Müller et al. (2013) every 4 hours (ca. $6.5 \mathrm{~mL}$, after 45 days ca. $9 \mathrm{~mL}$ ) with Long Ashton nutrient solution (Hewitt and Smith, 1974) containing either high phosphate (HP) supply $\left(200 \mu \mathrm{M} \mathrm{KNO}_{3}, 900 \mu \mathrm{M} \mathrm{Ca}\left(\mathrm{NO}_{3}\right)_{2}, 300.2\right.$ $\mu \mathrm{M} \mathrm{MgSO}_{4}, 599.9 \mu \mathrm{M} \mathrm{KH}_{2} \mathrm{PO}_{4}, 41.3 \mu \mathrm{M} \mathrm{K}_{2} \mathrm{HPO}_{4}, 10 \mu \mathrm{M} \mathrm{H}_{3} \mathrm{BO}_{3}, 2 \mu \mathrm{M} \mathrm{MnSO}_{4}, 7 \mu \mathrm{M}$ $\mathrm{Na}_{2} \mathrm{MoO}_{4}, 40 \mathrm{nM} \mathrm{CoSO}, 200 \mathrm{nM} \mathrm{ZnSO}_{4}, 128 \mathrm{nM} \mathrm{CuSO}_{4}, 10 \mu \mathrm{M}$ EDTA-Fe, in total: $641 \mu \mathrm{M} \mathrm{P}_{\mathrm{i}}$ ) or reduced Pi concentrations. Mildly Pi starved (medium phosphate, MP)

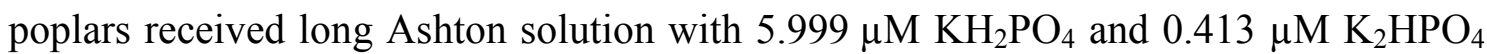
and additionally $675.8 \mu \mathrm{M} \mathrm{KCl}$ and Pi starved (low phosphate, LP) plants $0.060 \mu \mathrm{M}$ $\mathrm{KH}_{2} \mathrm{PO}_{4}$ and $0.004 \mu \mathrm{M} \mathrm{K}_{2} \mathrm{HPO}_{4}$ and additionally $682.5 \mu \mathrm{M} \mathrm{KCl}$. Plant height was measured weekly from the stem base to the apex. This experiment was repeated four times for different measurements with twelve biological replicates each time. 


\subsubsection{Labeling of the poplars with ${ }^{33} \mathrm{P}$ and harvest}

Sixty-day-old HP, MP and LP poplars ( $n=5$ per treatment, experiment 2 ) were watered by hand at 7 am and 10 am with the respective nutrient solution (16 and $14 \mathrm{~mL}$ for HP, $4 \mathrm{~mL}$ for $\mathrm{MP}$ and $2 \mathrm{~mL}$ for $\mathrm{LP}$ ) and labeled with $\mathrm{H}_{3}{ }^{33} \mathrm{PO}_{4}$ (Hartmann Analytic, Braunschweig, Germany) at $11 \mathrm{am}: 20.25 \mu \mathrm{L}$ of the $\mathrm{H}_{3}{ }^{33} \mathrm{PO}_{4}$ stock solution were mixed with $5.5 \mathrm{~mL}$ of each of the respective nutrient solutions and $1 \mathrm{~mL}$ of each labeling solution was applied once to the poplars. This treatment resulted in $1.2( \pm 0.013$ resp. 0.002) $\mathrm{MBq}$ for the HP and MP plants and $1.12( \pm 0.034) \mathrm{MBq}$ for the LP plants (mean $\pm \mathrm{SE}, n=3)$. The specific radioactivity was $1.88 \times 10^{3} \mathrm{~Bq} \mathrm{nmol}^{-1} \mathrm{P}$ for $\mathrm{HP}, 1.87 \times 10^{5} \mathrm{~Bq}$ $\mathrm{nmol}^{-1} \mathrm{P}$ for MP and $1.46 \times 10^{7} \mathrm{~Bq} \mathrm{nmol}^{-1} \mathrm{P}$ for LP poplars.

The automatic irrigation was stopped during the chase period of two days. During this time the poplars were irrigated by hand with unlabeled nutrient solution avoiding through-flow. Two days after label application, the plants were harvested. The roots were briefly washed with tap water. Each plant was divided into fine roots, coarse roots, stem and leaves. The biomass of the tissues was determined immediately after harvest and after drying at $60^{\circ} \mathrm{C}$ for 7 days.

\subsubsection{Phosphorus distribution at the whole-plant level}

To visualize the distribution of radioactivity, the poplars were dried at $60^{\circ} \mathrm{C}$ for one day pressed between paper and two glass plates. Autoradiographs were taken with a Phosphorimager (FLA 5100, Fuji, Japan) after exposure for $30 \mathrm{~min}$ on imaging plates (Imaging Plate BAS-MS 2040, $20 \times 40 \mathrm{~cm}$, Fuji, Japan). The image was taken with the program Image Reader FLA-5000 (version 3.0, Fuji Film, Japan) with $100 \mu \mathrm{m}$ resolution and analyzed with AIDA Image Analyzer (version 4.27, raytest Isotopenmeßgeräte, Straubenhardt, Germany).

\subsubsection{Determination of net ${ }^{33} \mathrm{P}$ and total $P$ uptake}

Dried plant tissues were milled (Retsch, type MM2, Haan, Germany) to a fine powder. About $25 \mathrm{mg}$ of leaf or stem powder and $10 \mathrm{mg}$ of fine or coarse root powder were 
weighed into glass vials $(20 \mathrm{~mL}$, PerkinElmer Life and Analytical Sciences, Rodgau, Germany) and incinerated for $4 \mathrm{~h}$ at $500^{\circ} \mathrm{C}$ (M104, Heraeus Holding, Hanau, Germany). The residual material was mixed with $10 \mathrm{~mL}$ of scintillation liquid (Rotiszint ${ }^{\circledR}$ eco plus [Carl Roth, Karlsruhe, Germany]) and the radioactivity was measured by liquidscintillation technique (Tri-Carb® 2800TR [PerkinElmer Life and Analytical Sciences, Rodgau, Germany]). The maximum count time was $10 \mathrm{~min}$ in normal count mode calculated against a quench set of ${ }^{33} \mathrm{P}$. All values were corrected for the half-life of ${ }^{33} \mathrm{P}$. ${ }^{33} \mathrm{P}$-activity in plants and proportion of ${ }^{33} \mathrm{P}$-uptake was calculated using following equations:

Radioactivity in plant tissue $[\mathrm{Bq}]=$

(activity in vial $[\mathrm{Bq}]$-background $[\mathrm{Bq}]) \times 0.5^{\frac{\text { date of harvest-date of measurement }}{25.3}} \times \frac{\text { dry mass tissue }[\mathrm{g}]}{\text { sample in vial }[\mathrm{g}]}$

${ }^{33}$ P-recovery $[\%]=\frac{\text { radioactivity in plant }[\mathrm{Bq}]}{\text { given radioactivity }[\mathrm{Bq}]} \times 100$

To determine total $\mathrm{P}$ uptake the specific radioactivity of the nutrient solution was used:

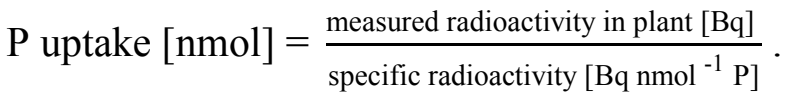

\subsubsection{Determination of total $P$ contents}

Dry fine root, coarse root, leaf and stem of 63-day-old HP, MP and LP poplars ( $n=4$ per treatment, experiment 1) were powdered and pressure-extracted in $\mathrm{HNO}_{3}$ (Heinrichs et al., 1986). Total phosphorus concentration was measured using an inductively coupled plasma optical emission spectrometer (ICP-OES; Optima 5300 DV, PerkinElmer Life and Analytical Sciences, Rodgau, Germany). P use efficiency (PUE) was calculated as dry mass per total P content. The equation for the whole plant PUE was

$$
\mathrm{PUE}\left[\mathrm{g} \mathrm{mg}^{-1}\right]=\frac{\mathrm{DM}_{\text {total }}}{\mathrm{P}_{\mathrm{conc}} \times \mathrm{DM}_{\mathrm{L}}+\mathrm{P} \operatorname{conc}_{\mathrm{S}} \times \mathrm{DM}_{\mathrm{S}}+\mathrm{P} \operatorname{conc}_{\mathrm{FR}} \times \mathrm{DM}_{\mathrm{FR}}+\mathrm{P} \operatorname{conc}_{\mathrm{CR}} \times \mathrm{DM}_{\mathrm{CR}}}
$$

with DM: dry mass [g], P conc: total P concentration in fraction $\left[\mathrm{mg} \mathrm{g}^{-1}\right], \mathrm{L}$ : leaves, $\mathrm{S}$ : stem, FR: fine roots, CR: coarse roots. 


\subsubsection{Phosphate uptake after glucose supply and determination of carbohydrates}

Seventy-seven-day-old HP, MP and LP poplars ( $n=5$ per treatment, experiment 3 ) were irrigated with $80 \mathrm{~mL}$ HP, MP or LP Long Ashton medium with or without $400 \mathrm{mM}$ glucose at $5 \mathrm{am}$. Along with turning on the additional light at $7 \mathrm{am}$, they were labeled with $\mathrm{H}_{3}{ }^{33} \mathrm{PO}_{4}$ (Hartmann Analytic, Braunschweig, Germany) in $1 \mathrm{~mL}$ of HP, MP or LP Long Ashton medium to yielding $1.08( \pm 0.006) \mathrm{MBq}$ in the growth medium of HP poplars and $1.09 \mathrm{MBq}( \pm 0.0008$ resp. 0.003$)$ in the growth medium of MP and LP poplars (mean $\pm \mathrm{SE}, n=2)$. At the end of the light period $(9 \mathrm{pm})$, the poplars were harvested to determine biomass, ${ }^{33} \mathrm{P}$ activity (as above), and the carbohydrate concentrations. Leaves (half of each leaf) and fine roots for carbohydrate determination were immediately shock frozen in liquid nitrogen and stored at $-80^{\circ} \mathrm{C}$. The tissues were freeze-dried at $-80^{\circ} \mathrm{C}$ for three days (BETA1, Martin Christ Gefriertrocknungsanlagen, Osterode am Harz, Germany) and milled (as above). About $25 \mathrm{mg}$ tissue powder was extracted in $1.5 \mathrm{ml}$ dimethyl sulfoxide / hydrochloric acid (80:20 (v:v)) at $60^{\circ} \mathrm{C}$ for $30 \mathrm{~min}$. After centrifugation, $200 \mu \mathrm{L}$ of the supernatant were mixed with $1250 \mu \mathrm{L} 0.2 \mathrm{M}$ citrate buffer ( $\mathrm{pH}$ 10.6). After an additional centrifugation, $400 \mu \mathrm{L}$ of the supernatant were mixed with $400 \mu \mathrm{L}$ citrate buffer $(50 \mu \mathrm{M}, \mathrm{pH} 4.6)$. Two hundred $\mu \mathrm{L}$ were mixed with $250 \mu \mathrm{L}$ reaction solution (4 mM NADP, $10 \mathrm{mM}$ ATP, $9 \mathrm{mM} \mathrm{MgSO}_{4}, 0.75 \mathrm{M}$ triethanolamine, $\mathrm{pH}$ 7.6) and $300 \mu \mathrm{L} \mathrm{H}_{2} \mathrm{O}$. The reaction was started by subsequent addition of enzymes and the production of NADPH was determined photometrically at a wavelength of $340 \mathrm{~nm}$ and $25^{\circ} \mathrm{C}$ until no further increase was observed. For glucose determination $10 \mu \mathrm{L}$ (ca. $3.4 \mathrm{U} ; 1.7 \mathrm{U}$ ) of hexokinase; glucose-6-phosphatedehydrogenase (Roche Diognostics Deutschland, Mannheim, Germany), and subsequently for fructose $5 \mu \mathrm{L}$ (ca. $17.5 \mathrm{U}$ ) of phosphoglucose-isomerase (Roche Diognostics, Deutschland, Mannheim, Germany) were added. To determine the amount of sucrose $400 \mu \mathrm{L}$ (ca. $12 \mathrm{U}$ ) invertase (Sigma-Aldrich Chemie, Steinheim, Germany) solution $(0.1 \mathrm{mg}$ invertase in $1 \mathrm{~mL} 0.32 \mathrm{M}$ citrate buffer, $\mathrm{pH} 4.6)$ were mixed with $400 \mu \mathrm{L}$ of supernatant and then glucose was determined as above. Free glucose was subtracted. The concentration of glucose (fructose) was calculated for $\Delta \mathrm{E}=\mathrm{E} 1-\mathrm{E} 0$ with E1 and E0 being the extinction of assay after and before addition of glucose-6phosphate-dehydrogenase (after and before addition of phosphoglucose-isomerase) and 
the extinction coefficient $\varepsilon=6.3 \mathrm{~L} \times \mathrm{mmol}^{-1} \mathrm{~cm}^{-1}$ for NADPH. Sucrose concentration was below the detection limit in most of the samples. Each sample was measured in triplicate.

\subsubsection{Kinetic measurements}

Roots of nine-week-old HP, MP and LP poplars (experiment 4) were washed carefully with tap water to remove the sand. The plants were transferred to aerated nutrient solution with HP, MP and LP Long Ashton nutrient solution and acclimated to this and lab conditions under continuous light (about $10 \mu \mathrm{mol}$ quanta $\mathrm{m}^{-2} \mathrm{~s}^{-1}$ of photosynthetically active radiation, TLD18W/840, Philips Lighting, Hamburg, Germany) for 1 day. Phosphate uptake was determined with the method of Claassen and Barber (1974). The plants were removed from the nutrient solutions, the roots were cautiously surface-dried between tissue papers, washed with the experimental solution (see below), surface-dried again and placed in plastic beakers. An appropriate volume (5 to $45 \mathrm{ml}$ ) of Long Ashton nutrient solution which contained $213.7 \mu \mathrm{M}$ Pi for all plants and ${ }^{33} \mathrm{P}$-phosphoric acid (Hartmann Analytic, Braunschweig, Germany) (to about $5375 \mathrm{~Bq} \mathrm{~mL} L^{-1}$ of experimental solution) was added. During the time course of the experiment of up to $14 \mathrm{~h}$, the nutrient solution was stirred and aerated with compressed air and water loss by plant transpiration was replaced by adding deionized water up to the marked original level. Uptake of $\mathrm{P}$ was calculated by the decrease in ${ }^{33} \mathrm{P}$ in the experimental solution. For this purpose, $40 \mu \mathrm{L}$ of experimental nutrient solution was removed at distinct time intervals and mixed with $0.5 \mathrm{~mL}$ inactive nutrient solution and $4 \mathrm{~mL}$ of Rotiszint ${ }^{\circledR}$ eco plus scintillation liquid (Carl Roth, Karlsruhe, Germany). Radioactivity was measured by liquid scintillation counting (Tri-Carb ${ }^{\circledR}$ 2800TR, PerkinElmer Life and Analytical Sciences, Rodgau, Germany). Samples were taken at min 0 (immediately after addition to the plants), 2.5, 5, 7.5, 10, 15, 20, 30, 45, 60 and 75 after addition to the plants, then every 30 min until 5 hours, thereafter every hour and after 8 hours every 2 hours, if needed. The experiment lasted until the LP plants showed no further uptake, but at least 7 hours. The experiment was conducted with 6 plants per $\mathrm{P}$ nutrient level. The plants were harvested at the end of the experiment and the biomass of the root system was measured. 
The uptake rate $\left(\mathrm{I}_{\mathrm{k}, \mathrm{k}+1}\right)$ was calculated between two time points ( $\mathrm{k}$ and $\left.\mathrm{k}+1\right)$ with the following equations. Because the measured radioactivity fluctuated strongly in samples of the first minutes of the experiment, only the values after stabilization were used for calculations and models.

$\mathrm{C}_{\mathrm{k}}=\mathrm{C}_{0} \times \frac{\mathrm{A}_{\mathrm{k}}}{\mathrm{A}_{0}}$

$\mathrm{C}_{\mathrm{k}}$ : $\mathrm{P}$ concentration in the nutrient solution at time point $\mathrm{k}[\mu \mathrm{M}]$

$\mathrm{A}_{\mathrm{k}}$ : activity in nutrient solution at time point $\mathrm{k}\left[\mathrm{Bq} \mu \mathrm{L}^{-1}\right]$

$\mathrm{C}_{0}$ : $\mathrm{P}$ concentration at time point 0 (start of experiment) $[\mu \mathrm{M}]$

$\mathrm{A}_{0}$ : activity in nutrient solution at time point 0 (start of experiment) $\left[\mathrm{Bq} \mu \mathrm{L}^{-1}\right]$

$\mathrm{I}_{\mathrm{k}, \mathrm{k}+1}=\frac{\mathrm{C}_{\mathrm{k}+1} \times \mathrm{V}-\mathrm{C}_{\mathrm{k}} \times \mathrm{V}}{\frac{\mathrm{t}_{\mathrm{k}+1}-\mathrm{t}_{\mathrm{k}}}{\mathrm{FM}}}$

$\mathrm{I}_{\mathrm{k}, \mathrm{k}+1}$ : $\mathrm{P}$ uptake rate between time point $\mathrm{k}$ and $\mathrm{k}+1\left[\mu \mathrm{mol} \min ^{-1} \mathrm{~g}^{-1}\right]$

$\mathrm{V}$ : volume of experimental solution [L]

$\mathrm{t}_{\mathrm{k},} \mathrm{t}_{\mathrm{k}+1}:$ time point $\mathrm{k}$ and $\mathrm{k}+1[\mathrm{~min}]$

FM: fresh mass of fine roots $[\mathrm{g}]$.

Due to plant uptake, the $\mathrm{P}$ concentration in the nutrient solution declined during the experiment. Therefore, the $\mathrm{P}$ concentration $\left(\mathrm{C}_{\mathrm{k}, \mathrm{k}+1}\right)$ at each uptake rate $\left(\mathrm{I}_{\mathrm{k}, \mathrm{k}+1}\right)$ was calculated as:

$\mathrm{C}_{\mathrm{k}, \mathrm{k}+1}=\frac{\mathrm{C}_{\mathrm{k}}+\mathrm{C}_{\mathrm{k}+1}}{2}$

To model the change in uptake rate in relation to the concentration in the nutrient solution, $\mathrm{I}_{\mathrm{k}, \mathrm{k}+1}$ and the corresponding $\mathrm{C}_{\mathrm{k}, \mathrm{k}+1}$ were plotted und a curve was fitted to determine $\mathrm{v}_{\max }$ (the maximum uptake rate), $\mathrm{C}_{\min }$ (the minimum concentration at which the plants can take up phosphate) and $\mathrm{K}_{\mathrm{m}}$ (the Michaelis-Menten constant) using the following equation in a non-linear model (R-package "nlme", Pinheiro et al., 2012):

$\mathrm{I}_{\mathrm{k}, \mathrm{k}+1}=\frac{\mathrm{v}_{\max } \times\left(\mathrm{C}_{\mathrm{k}, \mathrm{k}+1}-\mathrm{C}_{\min }\right)}{\mathrm{K}_{\mathrm{m}}+\mathrm{C}_{\mathrm{k}, \mathrm{k}+1}-\mathrm{C}_{\min }}$

The fitted curve for these parameters was drawn; the standard errors of the predictions were used for calculation of the 95\%-prediction interval (R-package "emdbook", Bolker, 2013). Because the uptake rate of the control plants (HP) was slow, a linear fit without slope was defined as $\mathrm{v}_{\max }$. Outliers $(>1.5$ interquartile ranges below first and above third quartile) were excluded from the linear fit. 


\subsubsection{RNA extraction and microarray analysis}

The first three fully expanded leaves from the top and fine roots $(<2 \mathrm{~mm}$ diameter $)$ of 59-day-old HP, MP and LP poplars (experiment 2) were harvested and immediately shock frozen in liquid nitrogen. Six plants per treatment (i.e. 18 plants in total) were used and the leaves respective roots of two individual poplars were pooled yielding three biological replicates per treatment. Frozen tissue was milled in liquid nitrogen and RNA was extracted from about $1 \mathrm{~g}$ of plant powder according to Chang et al. (1993) with modifications: no spermidine was used, $2 \% \quad \beta$-mercaptoethanol was added separately from the extraction buffer and phenol:chloroform:isoamyl alcohol (Roti ${ }^{\circledR}$ Aqua PCI, 25:24:1, Roth, Karlsruhe, Germany) was used instead of chloroform:isoamyl alcohol. RNA concentrations and purity were determined spectrophotometrically via the absorptions at 260 and $280 \mathrm{~nm}$ (BioPhotometer, Eppendorf, Hamburg, Germany). RNA integrity was determined with Agilent BioAnalyzer 2100 capillary electrophoresis at the Microarray Facility (MFT Services, Tübingen, Germany). Hybridization on the GeneChip ${ }^{\circledR}$ Poplar Genome Array (Affymetrix, Santa Clara, CA), washing, staining and scanning were conducted at the Microarray Facility (MFT Services, Tübingen, Germany). Raw and normalized data were uploaded into the EMBL-EBI ArrayExpress database (Kolesnikov et al., 2015) under E-MTAB-3934.

Statistical analyses of the raw data were performed as described in Janz et al. (2010) using the free statistic software R (version 2.14.2; $R$ Development Core Team, 2012). Only transcripts that had a detection call of "present" ("mas5calls" function with default settings for tau (0.015), alpha1 (0.04) and alpha2 (0.06)) on all replicate chips of at least one condition were used. For annotation of the microarray probe-set, the best gene model from the annotation file of the Aspen Data Base (Tsai et al., 2011) was used. When several probe sets represented one gene, the mean value of the $\log _{2}$-expression data was used for further analysis. The $\log _{2}$-expression values $\mathrm{x}_{\mathrm{i}}$ for each gene $\mathrm{i}$ of interest were normalized using $\mathrm{z}$-transformation resulting in $\mathrm{x}_{\mathrm{i}}{ }^{\prime}$ :

$\mathrm{x}_{\mathrm{i}}{ }^{\prime}=\frac{\mathrm{x}_{\mathrm{i}}-\overline{\mathrm{x}}}{\mathrm{s}}$ with

$\overline{\mathrm{X}}$ : arithmetic mean value of all $\log _{2}$-expression data for one gene,

s: standard deviation of all $\log _{2}$-expression data for one gene.

A heatmap of normalized expression values ("heatmap.2" function) was created using the R package "gplots" (Warnes, 2012). 
Here, the members of the putative PHT families 1, 2, 3, and 4 (according to Guo et al., 2008; Rausch and Bucher, 2002) were retrieved as genes of interest. To obtain the gene IDs and protein sequences for all putative poplar PHT genes, BlastP searches in the database Phytozome v9.1 (Goodstein et al., 2012) were conducted. The genome of Arabidopsis thaliana et al., 2012, https://phytozome.jgi.doe.gov/pz/portal.html\#!info?alias=Org_Athaliana) was searched with the keyword "pht" extracting the amino acid sequences of eighteen annotated PHT genes. These sequences were used for a BlastP search (e-value cutoff at e-20) against the Arabidopsis genome. The Pfam database was used to identify proteins with functional domains (Finn et al., 2014). Additional genes found by the BlastP search with the same domains (Mito_carr, MFS_1, Sugar_tr, Pfam-B_703, PHO4) that are present in the annotated proteins were added to the gene list. These protein sequences were used for BlastP searches against the Populus trichocarpa (Tuskan et al., 2006), the $\begin{array}{lllll}\text { Oryza sativa } \quad \text { (Ouyang 2007, } & \end{array}$ https://phytozome.jgi.doe.gov/pz/portal.html\#!info?alias=Org_Osativa) and the Zea mays genomes (Schnable et al., 2009, https://phytozome.jgi.doe.gov/pz/portal.html\#!info?alias=Org_Zmays). When the resulting proteins had similar domains as Arabidopsis PHTs, they were used for a second BlastP against the respective genome. The resulting sequences were added to the list when the protein domains were similar to the PHT Pfam domains or when the best BlastP hit against the Arabidopsis genome was a PHT.

The alignment was created with ClustalW2 on the EMBL-EBI webpages (Larkin et al., 2007, http://www.ebi.ac.uk/Tools/msa/clustalw2/) with default settings and the PHYLIP package (Felsenstein, 1993) was used to calculate a consensus (extended majority rule) neighbor joining phylogenetic tree using 500 replicates for bootstrapping and JonesTaylor-Thornton model for computing distance matrices. The phylogenetic tree was displayed with MEGA6 (Tamura et al., 2013, http://www.megasoftware.net). Based on the phylogeny, the poplar PHT2 to PHT4 genes were named. Gene IDs of the members of all putative PHTs were compiled in additional Table S3.1. The $1 \mathrm{~kb}$ upstream region of each poplar gene coding for a putative phosphate transporter was obtained from Phytozome using the BioMart tool on the Phytozome webpage (https://phytozome.jgi.doe.gov/biomart/martview) and used for a motif search with PLACE (Higo et al., 1999). 


\subsubsection{Quantitative Real Time PCR of $P$ transporter genes}

RNA samples from the same samples that had been used for microarray analyses (200 ng $\mu \mathrm{L}^{-1}$ in $25 \mu \mathrm{L}$ ) were treated with Ambion ${ }^{\circledR}$ Turbo DNA-free ${ }^{\mathrm{TM}}$ kit (Life Technologies, Carlsbad, CA, USA) two times according to the manual instructions and transcribed to cDNA $(0.5 \mu \mathrm{g})$ with the RevertAid First Strand cDNA Synthesis Kit and First Strand cDNA Synthesis Kit (Thermo Fisher Scientific, Braunschweig, Germany) using oligo(dT)-primers. For each gene, at least two technical replicates and three biological replicates were analyzed by quantitative Real Time PCR (qRT PCR) with a LightCycler $480^{\circledR}$ (Roche Diagnostics, Mannheim, Germany). The reaction volume (20 $\mu \mathrm{L}$ ) consisted of $10 \mu \mathrm{L}$ SYBR Green I Master kit (Roche Diagnostics, Mannheim, Germany), $2 \mu \mathrm{L}$ of the forward and reverse primers (10 $\mu \mathrm{M}$, additional Table S3.2 for detailed information), $1 \mu \mathrm{L}$ nucleic free water and $5 \mu \mathrm{L}$ cDNA-solution (1:10 dilution). After pre-incubation $\left(95^{\circ} \mathrm{C}, 5 \mathrm{~min}\right), 45$ or 55 cycles of amplification followed: $95^{\circ} \mathrm{C}$ for $10 \mathrm{~s}, 57^{\circ} \mathrm{C}\left(55^{\circ} \mathrm{C}\right.$ for PtPHT1;2) for $10 \mathrm{~s}$ and $72^{\circ} \mathrm{C}$ for $20 \mathrm{~s}$. Melting curve $\left(95^{\circ} \mathrm{C}\right.$ for $5 \mathrm{~s}, 65^{\circ} \mathrm{C}$ for $1 \mathrm{~min}$, then to $97^{\circ} \mathrm{C}$ at a rate of $0.11^{\circ} \mathrm{C} \mathrm{s}^{-1}$ ) analyses implemented in the LightCycler $480^{\circledR}$ software were used to assess primer specificity.

To calculate primer efficiency, raw data were converted using LC480 conversion (version

2014.1;

www.hartfaalcentrum.nl/index.php?main=files\&sub=LC480Conversion) and loaded into LinRegPCR (version 2016.0; Ruijter et al., 2009). The mean efficiency for each primer pair was calculated over all samples per gene after baseline subtraction. Cqvalues were calculated using the fluorescence threshold of 3.597. Relative expression values for each sample were calculated against two reference genes (Potri.001G309500 [Actin], Potri.001G047200 [PPR-repeat gene]):

Relative Expression $=\frac{\sqrt{E_{\left(\mathrm{Ref}_{1}\right)}^{\mathrm{Cq}} \times \mathrm{E}_{\left(\mathrm{Ref}_{2}\right)}^{\mathrm{Cq}}}}{\mathrm{E}_{(\mathrm{GOI})}^{\mathrm{Cq}}}$

E: efficiency of primer for gene

Cq: quantification cycle value of sample for gene

(GOI): gene of interest

( Ref $_{\mathrm{i}}$ ): reference gene i (Hellemans et al., 2007). 


\subsubsection{Statistical analyses}

R (versions 2.14 .2 and 3.0.2; $R$ Development Core Team, 2012) was used for all statistical analyses. Mean value \pm standard error were calculated. One- or Two-WayANOVA and Tukey's HSD were performed on original or transformed data. Residuals were tested visually for normal distribution and homogeneity of variance. Data were transformed logarithmically $\left(\log _{2}\right)$ or by square root, if needed. For statistical comparisons of single kinetic parameters, Welsh's $t$-test was performed using the output data of the models. For percentage data on ${ }^{33} \mathrm{P}$ recovery and $\mathrm{P}$ allocation, a general linear model with binomial distribution was fitted on underlying count data, and an analysis of deviance was used to calculate significant factor and interaction effects. A subsequent Tukey test was performed to determine the homogenous subsets. Means were considered to differ significantly between treatments, if $p \leq 0.05$. Differences between treatments are shown in the figures with different letters. The $p$-values calculated for gene expression data and $\mathrm{v}_{\max }$ for kinetic data were adjusted by Bonferroni correction. Two-Way-Repeated measurement-ANOVA with Tukey's HSD was performed for plant growth over time.

\subsection{Results}

\subsubsection{Plant performance, $P$ uptake and allocation in response to $P$ deficiency}

Pre-tests with five concentrations from 0.064 to $641 \mu \mathrm{M} \mathrm{PO}_{4}{ }^{3-}$ (further on called P) in the nutrient solution revealed a growth gradient for poplars with a strong decline in plant height and biomass between $\mathrm{P}$ concentration of 64 and $6.4 \mu \mathrm{M} \mathrm{P}$ (additional Figure S3.1). We selected 641 (HP), 6.4 (MP) and 0.064 (LP) $\mu \mathrm{M}$ P in the nutrient solution for further studies because these concentrations resulted in high, intermediate and almost no growth during long-term cultivation (Figure 3.1a) and because the highest $\mathrm{P}$ concentration is the typical P supply in nutrient solution (Müller et al., 2013), intermediate $\mathrm{P}$ is in the same range typically present in soil solutions and the lowest $\mathrm{P}$ concentration abolished growth entirely (Figure 3.1a). In comparison with HP plants, 
biomass production of MP and LP poplars was significantly inhibited (Figure 3.1b, additional Figure S3.1).
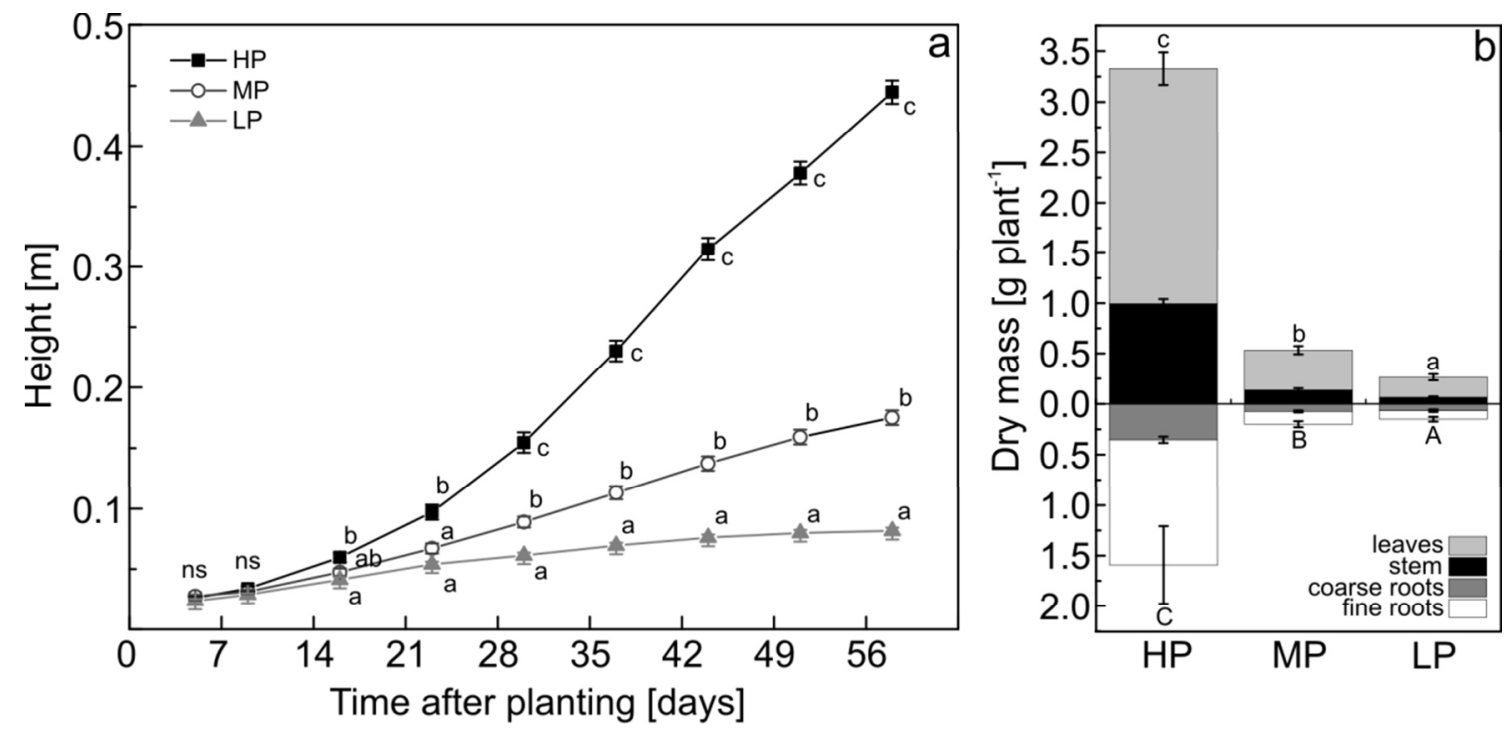

Figure 3.1. Growth characteristics of $\mathbf{P}$ deficient poplar. a) Height of poplar plants grown with high (HP: $641 \mu \mathrm{M}$ ), medium (MP: $6.4 \mu \mathrm{M}$ ) or low (LP: $0.064 \mu \mathrm{M}$ ) phosphate concentrations in the nutrient solution. Different letters indicate significant differences between treatments at each measuring day $(p \leq 0.05,2$-Way-repeated measurement-ANOVA and Tukey's honest significance test, $n=11-12$, mean \pm SE, ns: not significant). b) Dry mass of poplar tissues after 60 days of growth with HP, MP or LP phosphate in the nutrient solution. Different letters indicate significant differences between treatments in above- and belowground tissues $(p \leq 0.05$, ANOVA and Tukey's honest significance test, $\mathrm{n}=5$, mean $\pm \mathrm{SE}$ ).

HP plants exhibited the highest $\mathrm{P}$ concentrations, MP plants intermediate and LP plants the lowest $\mathrm{P}$ concentrations in all tissues (Table 3.1). Because our nutrient regime also resulted in growth decline, the whole-plant $\mathrm{P}$ content was about 30 times higher in HP plants than in MP and 50 times higher in HP compared with LP plants (Table 3.1). The relative allocation of $\mathrm{P}$ in above- to belowground material was significantly affected by $\mathrm{P}$ starvation with a higher fraction of P belowground after MP (about $50 \%$ ) and LP (43 $\%)$ than after HP treatments $(37 \%, p \leq 0.05)$. Exposure of HP, MP, and LP plants to ${ }^{33} \mathrm{P}$ in the nutrient solution showed the highest relative uptake for the MP plants. Within two days, they acquired $25 \%$ of the $\mathrm{P}$ in the labeling solution, while HP plants took up about $15 \%$ and LP only $2.5 \%$ of the new P (Table 3.1). It was notable that highest P 
recovery of MP and LP plants was found in roots, whereas that of HP plants was more evenly distributed between roots and leaves (Table 3.1).

The differences in distribution of the newly taken up ${ }^{33} \mathrm{P}$ were also qualitatively confirmed by whole plant imaging (Figure 3.2). While HP plants showed an almost even distribution across all tissues, MP plants showed a very high ${ }^{33} \mathrm{P}$ concentration in the uppermost leaf and nearly no newly taken up P in the oldest leaves (Figure 3.2). LP showed very little to no ${ }^{33} \mathrm{P}$ uptake in older leaves and the main aboveground allocation to the youngest leaf, while root uptake was high. All plants showed strong accumulation of ${ }^{33} \mathrm{P}$ in the roots, especially in parts adjacent to the root-stem junction (Figure 3.2). Because of the different $\mathrm{P}$ concentrations in the nutrient solutions the calculated total $\mathrm{P}$ uptake (taking into account different dilution factors for ${ }^{33} \mathrm{P}$ as detailed under materials and methods) corresponded to $95.7 \mathrm{nmol}$ in HP plants, 1.63 in MP and $1.94 \times 10^{-3} \mathrm{nmol}$ in LP plants (Table 3.1). The P use efficiency was highest in LP plants $(1.8 \pm 0.14 \mathrm{~g}$ dry mass $\left.\mathrm{mg}^{-1} \mathrm{P}\right)$, intermediate in MP plants $\left(1.0 \pm 0.10 \mathrm{~g}\right.$ dry mass $\left.\mathrm{mg}^{-1} \mathrm{P}\right)$ and least in HP plants $\left(0.14 \pm 0.01 \mathrm{~g}\right.$ dry mass $\mathrm{mg}^{-1} \mathrm{P}$ with $\left.p_{\text {(treatment) }} \leq 0.05\right)$. 
Table 3.1: In planta $P$ and $P$ uptake characteristics of $P$ deficient poplar.

\begin{tabular}{|c|c|c|c|c|c|}
\hline & & $\begin{array}{c}\text { total P } \\
\text { concentration } \\
{\left[\mathrm{mg} \mathrm{g}^{-1}\right]}\end{array}$ & $\begin{array}{l}\text { total P content } \\
{\left[\mathrm{mg} \mathrm{fraction}^{-1}\right]}\end{array}$ & $\begin{array}{l}{ }^{33} \mathrm{P} \text { recovery } \\
{\left[\% \text { fraction }^{-1}\right]}\end{array}$ & $\begin{array}{c}\text { P uptake } \\
{\left[\text { nmol fraction }^{-1}\right]}\end{array}$ \\
\hline HP & $\begin{array}{c}\text { Leaf } \\
\text { Stem } \\
\text { Fine Root } \\
\text { Coarse Root }\end{array}$ & $\begin{array}{l}6.80 \pm 0.51^{\mathrm{de}} \\
4.92 \pm 0.55^{\mathrm{d}} \\
11.27 \pm 1.40^{\mathrm{e}} \\
6.98 \pm 1.41^{\mathrm{de}}\end{array}$ & $\begin{array}{l}8.55 \pm 0.33^{\mathrm{e}} \\
2.56 \pm 0.20^{\mathrm{d}} \\
4.79 \pm 1.49^{\mathrm{de}} \\
1.92 \pm 0.32^{\mathrm{d}}\end{array}$ & $\begin{array}{l}6.79 \pm 0.29^{\mathrm{j}} \\
1.35 \pm 0.15^{\mathrm{e}} \\
5.79 \pm 0.97^{\mathrm{i}} \\
1.04 \pm 0.10^{\mathrm{d}}\end{array}$ & $\begin{array}{c}43.4 \pm 1.82^{\mathrm{g}} \\
8.64 \pm 0.96^{\mathrm{f}} \\
37.01 \pm 6.20^{\mathrm{g}} \\
6.65 \pm 0.65^{\mathrm{f}}\end{array}$ \\
\hline MP & $\begin{array}{c}\text { Leaf } \\
\text { Stem } \\
\text { Fine Root } \\
\text { Coarse Root }\end{array}$ & $\begin{array}{l}1.25 \pm 0.10^{\mathrm{c}} \\
1.11 \pm 0.11^{\mathrm{bc}} \\
0.67 \pm 0.12^{\mathrm{abc}} \\
1.03 \pm 0.15^{\mathrm{bc}}\end{array}$ & $\begin{array}{c}0.19 \pm 0.03^{\mathrm{bc}} \\
0.11 \pm 0.02^{\mathrm{abc}} \\
0.08 \pm 0.02^{\mathrm{ab}} \\
0.23 \pm 0.03^{\mathrm{c}}\end{array}$ & $\begin{array}{c}4.51 \pm 0.38^{\mathrm{h}} \\
7.22 \pm 0.79^{\mathrm{k}} \\
10.07 \pm 0.69^{1} \\
3.73 \pm 0.79^{\mathrm{g}}\end{array}$ & $\begin{array}{c}0.29 \pm 0.02^{\mathrm{d}} \\
0.46 \pm 0.05^{\mathrm{de}} \\
0.64 \pm 0.04^{\mathrm{e}} \\
0.24 \pm 0.05^{\mathrm{d}}\end{array}$ \\
\hline LP & $\begin{array}{c}\text { Leaf } \\
\text { Stem } \\
\text { Fine Root } \\
\text { Coarse Root }\end{array}$ & $\begin{array}{c}0.69 \pm 0.03^{\mathrm{abc}} \\
0.62 \pm 0.17^{\mathrm{ab}} \\
0.41 \pm 0.10^{\mathrm{a}} \\
0.49 \pm 0.03^{\mathrm{ab}}\end{array}$ & $\begin{array}{c}0.15 \pm 0.03^{\mathrm{bc}} \\
0.05 \pm 0.02^{\mathrm{a}} \\
0.05 \pm 0.01^{\mathrm{a}} \\
0.10 \pm 0.01^{\mathrm{abc}}\end{array}$ & $\begin{array}{l}0.08 \pm 0.02^{\mathrm{a}} \\
0.12 \pm 0.03^{\mathrm{b}} \\
1.94 \pm 0.47^{\mathrm{f}} \\
0.41 \pm 0.19^{\mathrm{c}}\end{array}$ & $\begin{aligned} 0.059 & \times 10^{-3} \pm 0.001 \times 10^{-3} \mathrm{a} \\
0.088 & \times 10^{-3} \pm 0.003 \times 10^{-3} \mathrm{a} \\
1.48 & \times 10^{-3} \pm 0.35 \times 10^{-3} \mathrm{c} \\
0.32 & \times 10^{-3} \pm 0.15 \times 10^{-3} \mathrm{~b}\end{aligned}$ \\
\hline $\begin{array}{l}p \text {-value } \\
p \text {-value } \\
p \text {-value }\end{array}$ & $\begin{array}{c}p_{\text {(treatment) }} \\
p_{\text {(fraction) }} \\
p_{\text {(treatment } \times \text { fraction) }}\end{array}$ & $\begin{array}{c}<0.001 \\
0.225 \\
<0.01\end{array}$ & $\begin{array}{l}<0.001 \\
<0.001 \\
<0.001\end{array}$ & $\begin{array}{l}<0.001 \\
<0.001 \\
<0.001\end{array}$ & $\begin{array}{l}<0.001 \\
<0.001 \\
<0.001\end{array}$ \\
\hline $\begin{array}{c}\text { HP } \\
\text { MP } \\
\text { LP } \\
p \text {-value }\end{array}$ & $\begin{array}{l}\text { whole plant } \\
\text { whole plant } \\
\text { whole plant }\end{array}$ & $\begin{array}{l}7.10 \pm 0.58^{\mathrm{C}} \\
1.03 \pm 0.11^{\mathrm{B}} \\
0.56 \pm 0.04^{\mathrm{A}} \\
\quad<0.001\end{array}$ & $\begin{array}{l}17.82 \pm 1.38^{\mathrm{C}} \\
0.61 \pm 0.05^{\mathrm{B}} \\
0.34 \pm 0.06^{\mathrm{A}} \\
<0.001\end{array}$ & $\begin{array}{l}14.98 \pm 1.36^{\mathrm{B}} \\
25.52 \pm 1.84^{\mathrm{C}} \\
2.55 \pm 0.64^{\mathrm{A}} \\
\quad<0.001\end{array}$ & $\begin{array}{c}95.69 \pm 8.71^{\mathrm{C}} \\
1.63 \pm 0.12^{\mathrm{B}} \\
1.94 \times 10^{-3} \pm 0.49 \times 10^{-3} \mathrm{~A} \\
<0.001\end{array}$ \\
\hline
\end{tabular}

Total P concentration and total P content per dry mass, ${ }^{33} \mathrm{P}$ recovery and calculated uptake of P after 2 days in tissues of and whole poplar plants grown with one of three different $\mathrm{P}$ concentrations in the nutrient solution in sand (HP: $641 \mu \mathrm{M}, \mathrm{MP}: 6.4 \mu \mathrm{M}, \mathrm{LP}: 0.064 \mu \mathrm{M}$ ). Different letters indicate significant differences ( $p \leq 0.05$, Two-Way-ANOVA and Tukey's honest significance test, mean \pm SE, $n=4-5)$. 


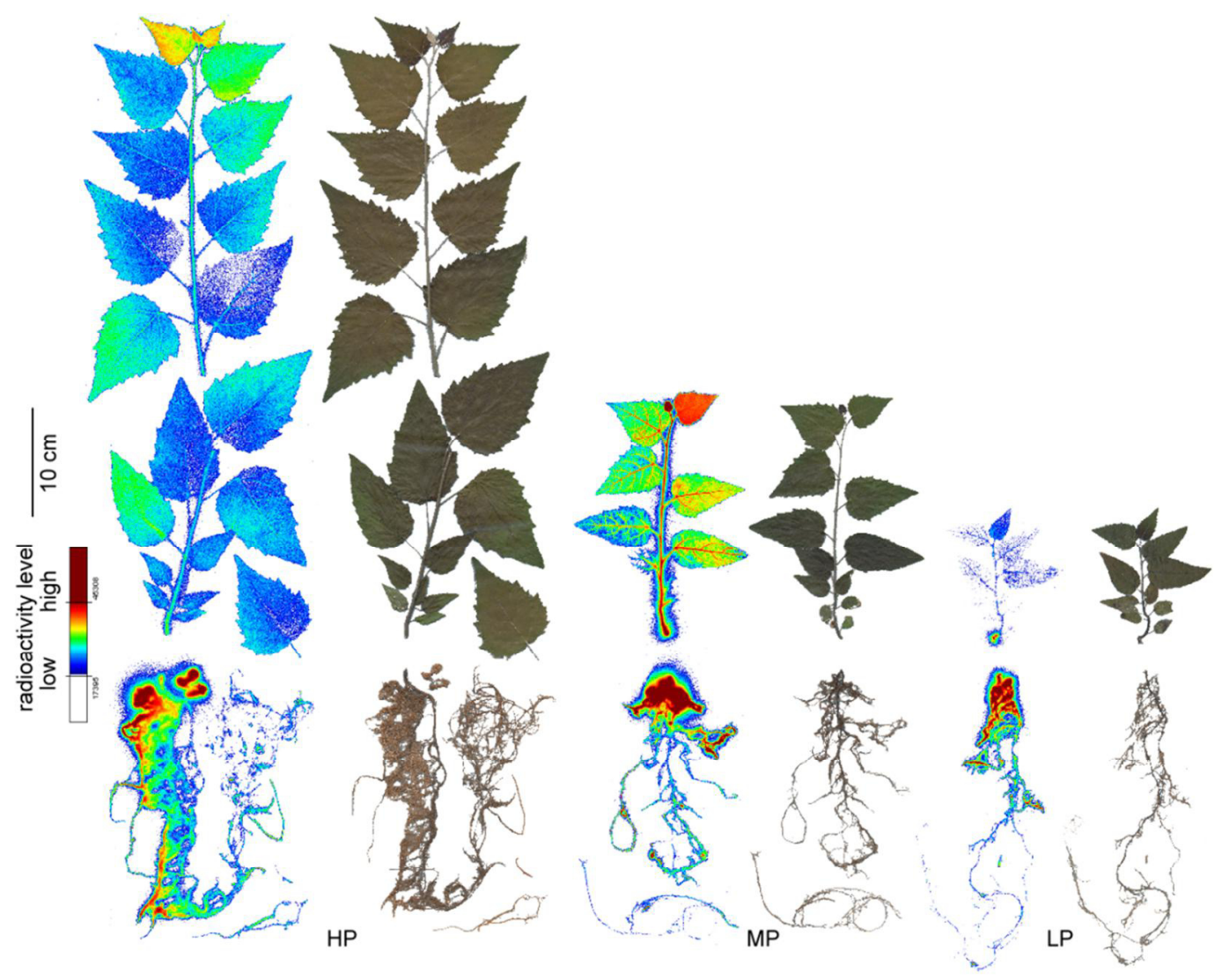

Figure 3.2. ${ }^{33} \mathbf{P}$ allocation in $\mathbf{P}$ deficient poplar. Autoradiographs of the ${ }^{33} \mathbf{P}$ distribution in poplars grown with different $\mathrm{P}$ concentrations in the nutrient solution (HP: $641 \mu \mathrm{M}, \mathrm{MP}: 6.4 \mu \mathrm{M}$, LP: $0.064 \mu \mathrm{M}$ ) and scans of the corresponding plants. Autoradiographs were taken of whole plants 2 days after exposure to ${ }^{33} \mathrm{P}$ as described under materials and methods. Uptake intensity is indicated by false color images with red indicating high and blue low radioactivity.

\subsection{2 $P$ uptake is not energy limited}

Because LP plants showed lower relative P uptake than MP or HP plants, we tested whether P uptake was inhibited by energy depletion. For this purpose, the growth medium was supplemented with glucose before adding the ${ }^{33} \mathrm{P}$-labeled nutrient solution. There was no difference in $\mathrm{P}$ uptake between the glucose-fed and the non-fed control plants. As before, MP plants showed the highest, HP intermediate and LP plants the lowest $\mathrm{P}$ recovery (Figure 3.3a), but the overall levels were lower because we used only $14 \mathrm{~h}$ exposure time instead of $48 \mathrm{~h}$ to avoid confounding effects of microbial growth. The soluble carbohydrate concentrations in fine roots were unaffected by glucose treatment (Figure 3.3b). The concentration of soluble carbohydrates was about 4-fold higher in the fine roots of P-depleted poplars (MP, LP) than in HP plants (Figure 3.3b). 

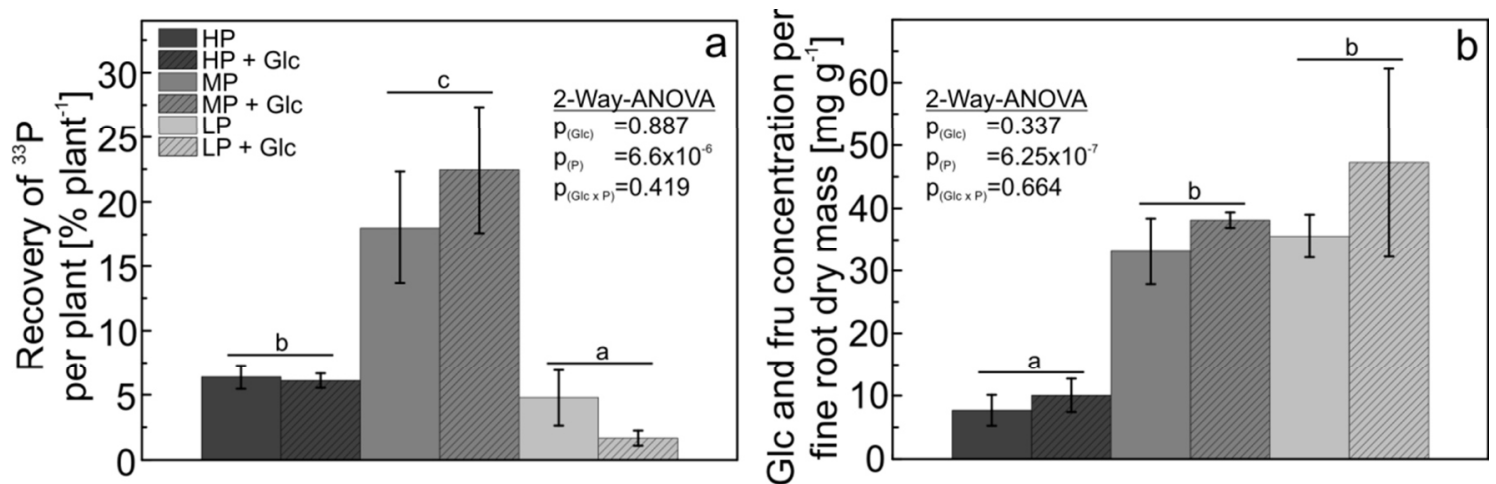

Figure 3.3. ${ }^{33} \mathbf{P}$ uptake and carbohydrate concentrations in $\mathbf{P}$ deficient poplar supplied with glucose in the nutrient solution. a) The recovery of ${ }^{33} \mathrm{P}$ in whole plants relative to the total amount of ${ }^{33} \mathrm{P}$ added to the nutrient solution. b) Soluble carbohydrate concentrations as the sum of fructose and glucose in roots of poplars. The plants were grown with three different phosphate concentrations in the nutrient solutions (HP: 641 $\mu \mathrm{M}$, MP: $6.4 \mu \mathrm{M}$, LP: $0.064 \mu \mathrm{M}$ ) that were supplemented with $400 \mathrm{mM}$ glucose for $2 \mathrm{~h}$ before adding $1 \mathrm{~mL}{ }^{33} \mathrm{P}$ labeled nutrient solution. Controls received no glucose. Different letters indicate significant differences between treatments ( $p \leq 0.05$, Two-WayANOVA and Tukey's honest significance test, $n=5$, mean $\pm \mathrm{SE}$ ).

\subsubsection{Low $P$ concentrations in the nutrient solution limit $P$ uptake}

To investigate plant acclimation to decreasing $\mathrm{P}$ availabilities in the nutrient solution, $\mathrm{P}$ uptake kinetics of HP, MP, and LP plants were determined. The modeled MichaelisMenten-curves for the P uptake of LP and MP plants showed a steep increase of the P uptake rate at low $\mathrm{P}$ concentrations in the nutrient solution and leveled off to different maximum uptake rates (Figure 3.4, Table 3.2). The highest $\mathrm{P}$ uptake rate was found in MP plants and was similar to that of the LP plants (Table 3.2). The maximum P uptake rate was more than 13 times higher in LP plants than in the HP plants (Table 3.2, Figure 3.4). The $\mathrm{K}_{\mathrm{m}}$ was $25.9( \pm 9.9) \mu \mathrm{M}$ in the MP and $19.9( \pm 8.1) \mu \mathrm{M}$ in the LP plants. The minimum concentration $\mathrm{C}_{\min }$, at which net uptake took place, was reached at $1.1 \mu \mathrm{M}$ (Figure 3.4, insert) and was similar for LP and MP poplars. HP plants exhibited very slow $\mathrm{P}$ uptake kinetics and therefore determination of $\mathrm{K}_{\mathrm{m}}$ and $\mathrm{C}_{\min }$ was not possible under our experimental conditions, where the maximum P concentration tested was 200 $\mu \mathrm{M}$. 


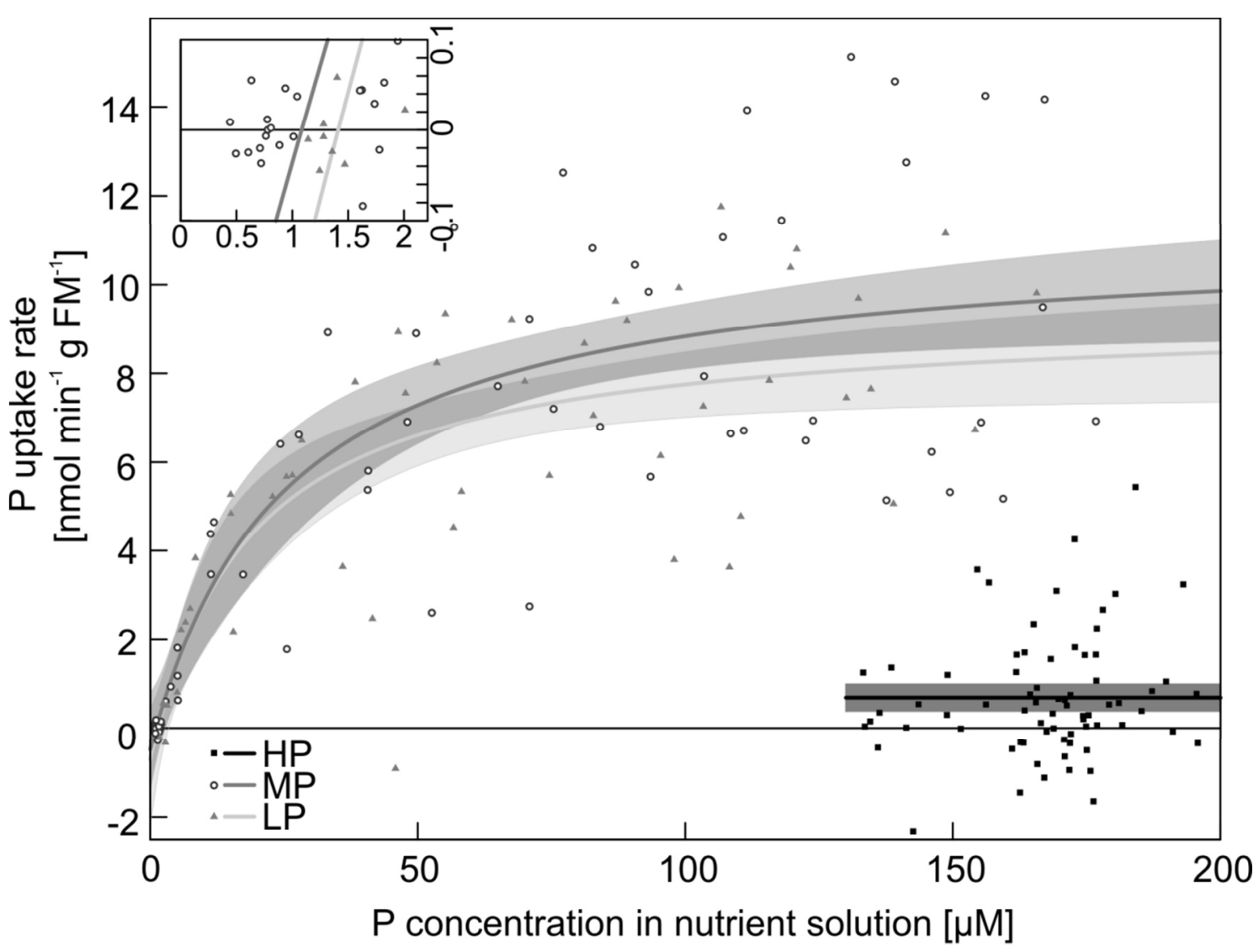

Figure 3.4. Model of kinetic parameters for $P$ uptake of $P$ deficient poplars at different $\mathbf{P}$ concentrations. $P$ uptake rate per gram of fine root mass of plants grown with different $\mathrm{P}$ concentrations in the nutrient solution (black squares: HP, $641 \mu \mathrm{M}$; open circles: MP, $6.4 \mu \mathrm{M}$; grey triangles: $\mathrm{LP}, 0.064 \mu \mathrm{M})$ during exposure to different $\mathrm{P}$ concentrations. Data points from six different plants per treatment. Modeled curves (HP: black, MP: dark grey, LP: light grey) with parameters from Table 3.2 and 95\%prediction interval in grey. The insert shows an enlargement of the curves at intermediate and low $\mathrm{P}$ concentrations around the concentration of $\mathrm{C}_{\mathrm{min}}$.

Table 3.2: Kinetic parameters for $P$ uptake of $P$ deficient poplar.

\begin{tabular}{llll}
\hline & HP & MP & LP \\
\hline $\mathrm{V}_{\max }\left[\mathrm{nmol} \mathrm{min}{ }^{-1} \mathrm{~g}^{-1}\right]$ & $0.689( \pm 0.164)^{\mathrm{a}}$ & $11.140( \pm 1.065)^{\mathrm{b}}$ & $9.311( \pm 0.908)^{\mathrm{b}}$ \\
$\mathrm{K}_{\mathrm{m}}[\mu \mathrm{M}]$ & n.d. & $25.87( \pm 9.87)^{\mathrm{ns}}$ & $19.85( \pm 8.11)^{\mathrm{ns}}$ \\
$\mathrm{C}_{\min }[\mu \mathrm{M}]$ & n.d. & $1.08( \pm 0.91)^{\mathrm{ns}}$ & $1.41( \pm 1.19)^{\mathrm{ns}}$ \\
\hline
\end{tabular}

Kinetic parameters (estimate \pm standard error) for the uptake of $\mathrm{P}$ in plants grown with one of three different P concentrations in the nutrient solution in sand (HP: $641 \mu \mathrm{M}$, MP: $6.4 \mu \mathrm{M}$, LP: $0.064 \mu \mathrm{M}$ ). Model calculated with data from 6 different plants per treatment. Different letters in rows indicate significant differences at $p \leq 0.05$. $\mathrm{V}_{\max }$ : maximum uptake rate, $\mathrm{K}_{\mathrm{m}}$ : Michaelis-Menten constant, $\mathrm{C}_{\min }$ : minimal concentration needed for uptake, n.d.: not determined 


\subsubsection{Low $P$ availabilities lead to differential regulation of $P$ transporters}

As the pre-requisite to analyze the response of poplar $\mathrm{P}$ transporters from different families, we annotated all putative PHTs in the poplar genome based on homology searches using Arabidopsis, rice and maize (additional Figure S3.2, Table S3.1). We found a total of 36 genes in poplar belonging to 4 different clades, of which 31 had probe sets on Affymetrix microarrays. Among those genes, 21 were expressed in roots and leaves (Figure 3.5a, additional Table S3.1, Table S3.3). We selected four genes for validation of their expression in different tissues and in response to different $\mathrm{P}$ supply (Figure 3.5b) and found a strong correlation between qRT PCR and microarray data (additional Figure S3.3).

The expression pattern of the 21 PHT genes clearly distinguished roots and leaves (Figure 3.5a). PtPHT1;1, PtPHT1;2, PtPHT1;4, PtPHT1;7, PtPHT1;9, PtPHT1;12, PtPHT3;1, PtPHT3;2, PtPHT3;6, PtPHT4;6, PtPHT4;7 and PtPHT4;8 exhibited generally higher transcript levels in roots than in leaves (Figure 3.5a). In leaves, the transcript abundances of PtPHT1;3, PtPHT2;1, PtPHT2;2, PtPHT3;5, PtPHT4;1, PtPHT4;2, PtPHT4;3, PtPHT4;4 and PtPHT4;5 were generally higher than in roots (Figure 3.5a). It was notable that among the putative plasma membrane $\mathrm{P}$ transporters only PtPHT1;3 was higher expressed in leaves than in roots and with almost 10-fold higher transcript abundance than in roots (Figure 3.5b). The expression of PtPHT1;1 and PtPHT1;2 was root-specific because we could not detect any signal in leaves with specific primers in the qRT PCR analysis (Figure 3.5b) and on microarrays the measured transcript abundance of these genes in leaves were classified with the expression probability "absent (for the definition, see materials and methos). The putative chloroplastic $\mathrm{P}$ transporters (PtPHT2;1, PtPHT2;2) showed higher expression levels in leaves than in roots.

The transcript levels of most PHTs, which had been classified into the "root" group showed strong responsiveness to $\mathrm{P}$ starvation in both tissues, roots and leaves, whereas the PHT members classified into the "leaf" group did not respond to variation in P supply, with few exceptions (PtPHT1;3, PtPHT4;2, PtPHT4;5) (Figure 3.5a). It is also important to note that the PHT members PtPHT1;4, PtPHT1;7, PtPHT1;9, and 
PtPHT3;6 showed the highest transcript abundances in roots under MP and in leaves under LP conditions (Figure 3.5a).
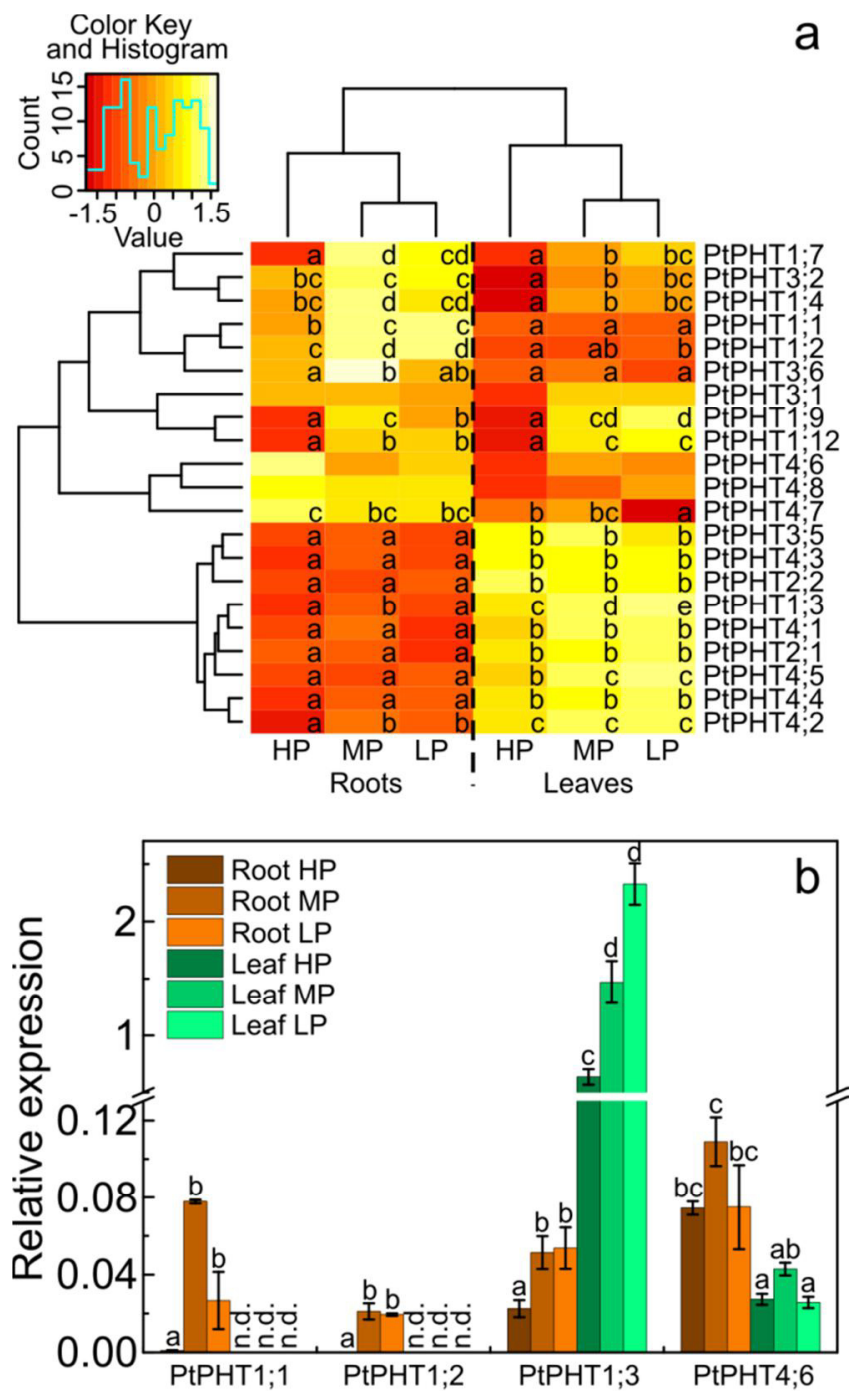

Figure 3.5. Expression of phosphate transporters in $\mathbf{P}$ deficient poplars. a) Heatmap of the relative expression of putative phosphate transporters in the three uppermost leaves and fine roots of poplar plants grown with different $\mathrm{P}$ concentrations in the nutrient solution (HP: $641 \mu \mathrm{M}$, MP: $6.4 \mu \mathrm{M}$, LP: $0.064 \mu \mathrm{M}$ ). Red colors indicate lower and yellow to white color higher values after z-transformation of the transcript abundances of each gene across all analyzed tissues and $\mathrm{P}$ conditions. b) Relative expression of selected PtPHTs measured by qRT PCR (mean \pm SE). Values were normalized to the expression of two reference genes (Actin, PPR-repeat) in the samples. Different letters indicate significant differences in expression of each gene (adj. $p \leq 0.05$, ANOVA and Tukey's honest significance test, $n=3$ ). 
Our annotation of the PHT family members also uncovered P1BS (PHR1 binding sequence) elements, known to be involved in the P response (Bustos et al., 2010) in the upstream regions of the genes (additional Table S3.1). P1BS elements were mainly present in PHT1 promoters (additional Table S3.1). Among the P starvation responsive genes in family 1 PtPHT1;1, PtPHT1;4, PtPHT1;7 and PtPHT1;9 had a P1BS element in the $1 \mathrm{~kb}$ promoter region and in family PHT4 it was present in the promoter region of PtPHT4;5. However, the P1BS element was not found in the $1 \mathrm{~kb}$ upstream region of other $\mathrm{P}$ starvation responsive genes of the PHT1, 3 and 4 families: PtPHT1;2, PtPHT1;3, PtPHT1;12, PtPHT3;2, PtPHT3;6 and PtPHT4;2, while it was present in PtPHT3;1, a gene, which showed no $\mathrm{P}$ starvation response under our experimental conditions.

\subsection{Discussion}

\subsubsection{P uptake and allocation}

Here, we characterized the uptake, allocation and PHT expression levels of Populus $\times$ canescens grown under different $\mathrm{P}$ availabilities. Similar as in P. tremuloides (Desai et al., 2014), we found that $\mathrm{P}$ availabilities below $60 \mu \mathrm{M}$ resulted in strong reduction in height growth and biomass. These reductions were accompanied by a strong decline in tissue phosphorus concentrations, with the strongest decline in fine roots. The phosphorus concentrations found in leaves and fine roots of MP poplars in our study were similar to those found in conventional poplar plantations, as reported for example by Ge et al. (2015). Poplar plantations are often established on marginal sites and therefore information on the uptake characteristics and allocation in the trees is an essential pre-requisite for sustainable management (Ge et al., 2015). Values indicating sufficient P supply of young Populus $\times$ canescens leaves range from 1.7 to $2.7 \mathrm{mg} \mathrm{g}^{-1}$ dry mass (Burg, 1985). According to these values, the MP and LP poplars in our study suffered from strong and very strong deficiency, whereas the P concentrations in the HP poplars indicate luxurious $\mathrm{P}$ supply. Luxurious $\mathrm{P}$ concentrations cannot be used for growth and consequently, PUE of $P . \times$ canescens increased when the $\mathrm{P}$ availability declined as was also shown for other poplar species and crops (Akhtar et al., 2007; Gan et al., 2016; Huang et al., 2011). It is further notable that the allocation pattern of newly 
taken up P was shifted towards leaves in the MP compared with LP or HP poplars. While usually the young leaves were the predominant aboveground sink, our imaging analyses showed that in MP plants also older leaves exhibited significant uptake of newly acquired $\mathrm{P}$, resulting in an allocation shift. Nevertheless, no measurable newly acquired $\mathrm{P}$ was allocated to the oldest leaves. Belowground, the new P was mainly concentrated in those parts of root system that were close to the root-shoot junction, regardless of the $\mathrm{P}$ supply. This finding was surprising because under severe $\mathrm{P}$ limitation one may have expected preferentially allocation of $\mathrm{P}$ to growing tissues such as the fine root tips and the shoot apex. The observed $\mathrm{P}$ accumulation suggests that the root-shoot junction constitutes an obstacle to $\mathrm{P}$ below-aboveground translocation. Studies on heavy metal transport (cadmium, zinc) suggested that the root-shoot junction serves as a control barrier for translocation of those elements into the shoot probably due to changes in the anatomical structure of the xylem at transition from root to shoot xylem (Martinka et al., 2014). The molecular and cellular basis for the supposed control function is unknown and must be addressed in future research. Our data suggest that an improved allocation from roots to the shoot could perhaps contribute to enhance PUE. This suggestion is currently speculative, but worthwhile to be addressed in future studies.

Under P starvation, the poplars showed not only differences in allocation and an increased $\mathrm{P}$ use but also higher uptake efficiency than the well-supplied trees, as indicated by the increased recovery of ${ }^{33} \mathrm{P}$ from the nutrient solution in MP compared with HP plants. While this finding is in agreement with crops and Arabidopsis (Bhadoria et al., 2004; Cogliatti and Clarkson, 1983; Dong et al., 1999; Jungk et al., 1990; Lee, 1982), severely P-starved poplars were not able to increase the relative $\mathrm{P}$ uptake compared with that of HP plants and even exhibited a significant decline in uptake efficiency. We considered whether energy limitation might have resulted in the reduction of $\mathrm{P}$ uptake efficiency. Because phosphorus occurs in the environment often in bound forms, P-starved poplars enhance the production and exudation of organic acids to increase the mobilization of external P (Desai et al., 2014). Consequently, large amounts of photo-assimilates are lost when the plants attempt to counteract $\mathrm{P}$ deficiency. Furthermore, P-starved plants accumulate carbohydrates in chloroplasts because the export of the carbon skeletons into the cytosol is inhibited (Hammond and White, 2008). Nevertheless, for some plants an increased carbohydrate translocation to 
the roots and even an accumulation in roots was shown under P deprivation (Hammond and White, 2008). Also here, an accumulation of carbohydrates in roots of both MP and LP compared with HP plants was found and exposure to additional glucose could not stimulate $\mathrm{P}$ uptake under any of the tested $\mathrm{P}$ concentrations in the growth medium. It is known that glucose is taken up by plants from the medium via monosaccharide transporters (Yamada et al., 2011) into the cytoplasm of root cells, i.e., the same compartment into which sugars from source tissues are unloaded (Lemoine et al., 2013). Therefore, the availability of sugar taken up from the medium does not differ from plant-derived sugar and thus, we could exclude energy limitation as the reason for the decrease in ${ }^{33} \mathrm{P}$-recovery of severely P-stressed poplars.

P uptake is further governed by the kinetic properties of the uptake systems. We found a threshold concentration of $1 \mu \mathrm{M}$ in the medium required for net $\mathrm{P}$ uptake. One reason for such a threshold could be the efflux of newly acquired ${ }^{33} \mathrm{P}$ from the roots back into the medium at very low external P concentrations because of the steep concentration

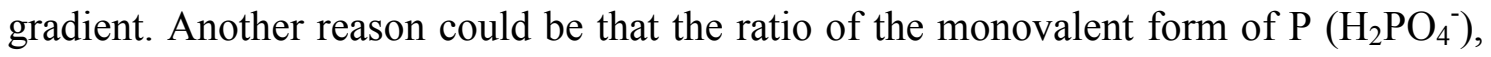
which is taken up by plants (Schachtman et al., 1998), was shifted to the acid form at the membrane due to an excess of protons under very low external $\mathrm{P}$ concentrations (Poirier and Bucher, 2002) and then was not available for plant uptake.

Here, we showed that the $\mathrm{K}_{\mathrm{m}}$ for $\mathrm{P}$ uptake of the root system of MP poplars did not decrease significantly when the phosphate concentration in the nutrient solution was further decreased.. This finding suggests that the uptake systems operate at their limits under these conditions. Desai et al. (2014) found a similar $\mathrm{K}_{\mathrm{m}}$ value of about $30 \mu \mathrm{M}$ for $\mathrm{P}$ accumulation in $P$. tremuloides across a range of low $\mathrm{P}$ concentrations. The apparent $\mathrm{K}_{\mathrm{m}}$ values for $\mathrm{P}$ uptake of P-starved poplars are, however, higher than phosphate concentrations in soil solutions in many non-fertilized ecosystems, for instance $5 \mu \mathrm{M}$ in forests beneath the organic layer (Asano et al., 2006; Fitzhugh et al., 2001; Ranger et al., 2001; van Hees et al., 2003). These soil concentrations are too low for sufficient $\mathrm{P}$ nutrition and the up-regulation of uptake systems would only ensure net uptake that occurred above the threshold concentration of $1 \mu \mathrm{M}$ P. Thus, neither decreases in $\mathrm{K}_{\mathrm{m}}$ values nor increases in $\mathrm{V}_{\max }$ by up-regulation of phosphate transporters would be sufficient to combat $\mathrm{P}$ deficiency in natural environments (Lambers et al., 2006). Under field conditions poplar roots are colonized by mycorrhizal fungi with different abilities for P acquisition (Baum and Makeschin, 2000; Danielsen et al., 2013, 2012; Gehring et 
al., 2006; Seven and Polle, 2014). Mycorrhizal roots usually show lower $\mathrm{K}_{\mathrm{m}}$ values for $\mathrm{P}$ uptake (Cress et al., 1979; Van Tichelen and Colpaert, 2000) and higher tissue P concentrations than non-mycorrhizal roots (Danielsen and Polle, 2014). In poplar the reduction in $\mathrm{K}_{\mathrm{m}}$ of $\mathrm{P}$ accumulation after colonization with the mycorrhizal fungus Laccaria bicolor was moderate (about $6 \mu \mathrm{M}$ instead of $30 \mu \mathrm{M}$ (Desai et al., 2014)). In Pinus sylvestris, mycorrhizal colonization decreased not only the $\mathrm{K}_{\mathrm{m}}$ from $12.1 \mu \mathrm{M}$ to $3.5 \mu \mathrm{M}$, but also the minimum threshold concentration for net $\mathrm{P}$ uptake of $2 \mu \mathrm{M}$ to 0.2 $\mu \mathrm{M}$ (Van Tichelen and Colpaert, 2000). Altogether, these finding underpin that without the help of microbes, $\mathrm{P}$ nutrition of poplars is critical in nature and may often fall below the threshold for net uptake.

\subsubsection{Regulation of the poplar PHT families in response to $P$ starvation}

$\mathrm{P}$ uptake and intracellular distribution is achieved by four $\mathrm{P}$ transporter families, with different number of genes in different plant species. Our in silico annotation of the PHTs of poplars showed that the PHT1 family was the largest with 12 members, followed by PHT4 with 9 members, while PHT3 and PHT2 contained 6 and 2 members respectively. These findings demonstrate that not only poplar PHT1 (Loth-Pereda et al., 2011), but also the other families exhibit an expansion compared to Arabidopsis (Guo et al., 2008; Poirier and Bucher, 2002). The PHT2, PHT3 and PHT4 families contain organelle membrane located transporters, which assure together photosynthetic and respiration processes (López-Arredondo et al., 2014). The presence of the putative $\mathrm{P}$ responsive element P1BS in the $1 \mathrm{~kb}$ upstream region was confirmed for PHT1 family members and was further demonstrated for some members of the PHT3 and PHT4 families, but was unrelated to $\mathrm{P}$ starvation responsiveness as reports previously for the poplar PHT1 (Loth-Pereda et al., 2011).

Here, the putative chloroplastic P transporters PtPHT2;1 and PtPHT2;2 exhibited low transcript abundance in roots and high in leaves, but were not responsive to $\mathrm{P}$ starvation. Similar results have been reported for the only member AtPHT2;1 in Arabidopsis (Versaw and Harrison, 2002) suggesting that the functional properties have been maintained. The results for the mitochondrial PHTs are more divergent because AtPHT3; 1 was unresponsive to P starvation, whereas its homologs in poplar (PtPHT3;1 and PtPHT3;2) showed increased transcript levels (this study; Morcuende et al., 2007). 
Poplar PtPHT3;5, an ortholog to the mitochondrial Arabidopsis AtPHT3;3 was unresponsive to P deprivation in both plant species (this study; Morcuende et al., 2007). The PHT4 family showed an interesting clustering with PtPHT4;6, PtPHT4;7 and PtPHT4;8, the orthologs of AtPHT4;6, AtPHT4;2 and AtPHT4;3, respectively, exhibiting higher transcript levels in roots than in leaves, and higher transcript abundances in leaves than in roots for PtPHT4;1, PtPHT4;2, PtPHT4;3, PtPHT4;4 and PtPHT4;5, which are the orthologs to AtPHT4;1, AtPHT4;4 and AtPHT4;5. An expression pattern similar to that in poplar was reported for Arabidopsis with higher transcript levels in roots for AtPHT4;6, and AtPHT4;2 and higher levels in leaves for AtPHT4;1, AtPHT4;4 and AtPHT4;5 (Guo et al., 2008). The latter transporters were localized to chloroplasts, while AtPHT4;6 was localized in the Golgi membrane (Guo et al., 2008). In poplar, the members of PHT4 were not or only little regulated by $\mathrm{P}$ starvation. Still, they have important function for intracellular trafficking of P. For example, deletion of the Golgi-membrane localized AtPHT4;6 leads to severe growth impairment and symptoms of $\mathrm{P}$ starvation, despite normal tissue $\mathrm{P}$ concentrations (Hassler et al., 2012). Altogether, similar tissue-specific expression pattern and $\mathrm{P}$ responsiveness of many organelle-related $\mathrm{P}$ transporters suggest that their functions are conserved in Arabidopsis and poplar.

The members of PHT1 family are localized to the plasma membrane and catalyze P uptake from the soil and long distance transport in plants (Nussaume et al., 2011; Poirier and Bucher, 2002; Poirier and Jung, 2015). Each of the nine Arabidopsis and all analyzed poplar PHT1 members show increased transcript abundance after exposure to low P supply (this study; Loth-Pereda et al., 2011; Morcuende et al., 2007), although some genotype-related exception were found (Loth-Pereda et al., 2011). While three of the nine Arabidopsis PHT1 genes (AtPHT1;3, AtPHT1;5, AtPHT1;6) exhibited higher expression in leaves than in roots (Morcuende et al., 2007), in poplar, only PtPHT1;3 showed this pattern. PtPHT1;3 was phylogenetically related to AtPHT1;4 and AtPHT1;7, but showed a higher distance to these Arabidopsis genes than the poplar genes PtPHT1;4, PtPHT1;5 and PtPHT1;7. This observation suggests that PtPHT1;3 may have evolved more rapidly and already acquired additional functions compared to the Arabidopsis genes.

The expression patterns of poplar PtPHT1;9 and PtPHT1;12 were similar in roots and in leaves with activation in response to P deficiency. Their orthologs in Arabidopsis 
(AtPHT1;9 and AtPHT1;8 for PtPHT1;9) mediated high-affinity $\mathrm{P}$ uptake in roots (Remy et al., 2012) and AtPHT1;5 (for PtPHT1;12) was located in the vascular system (Mudge et al., 2002) suggesting important roles for uptake and long-distance transport under P starvation. The expression of these transporters was most strongly stimulated by P deficiency in P. trichocarpa (Loth-Pereda et al., 2011). In contrast to those results, we found the strongest responsiveness to $\mathrm{P}$ starvation for PtPHT1;1, PtPHT1;2, PtPHT1;12 and PtPHT1;7, which underline genotype-related differences in the expression patterns. In Arabidopsis, AtPHT1;1 and AtPHT1;4, orthologs to those poplar genes, are expressed in the epidermal layer of roots and mediate high-affinity root uptake (Misson et al., 2004; Mudge et al., 2002; Shin et al., 2004). The pre-dominant expression of those poplar transporters in roots and their strong root-specific upregulation upon $\mathrm{P}$ limitation, suggests that these functions are conserved in $P . \times$ canescens and Arabidopsis thaliana.

\subsubsection{Conclusions}

Here, we annotated the four PHT families in poplar and demonstrated tissue-specific expression patterns in response to $\mathrm{P}$ starvation. $\mathrm{P}$ transporters that were higher expressed in young leaves than in fine roots belonged to the organelle-related families and showed no response to P starvation, with the exception of PtPHT1;3. The transcript abundance of the latter transporter in leaves was high under high $\mathrm{P}$ supply, but further increased massively under $\mathrm{P}$ starvation suggesting an important role of this gene for foliar P supply in accordance with highest allocations to the youngest leaves. Other members of the PHT1 family also showed strong up-regulation in response to P starvation, but were generally higher expressed in roots than in leaves underpinning their role in $\mathrm{P}$ uptake from the environment. The root-specific increment in PtPHT1;1 and PtPHT1;2 expression suggests a major role for these transporters in combating $\mathrm{P}$ deficiency in poplar. In accordance with the enhanced expression of PHT members in roots, $\mathrm{P}$ uptake efficiency was enhanced at the intermediate $\mathrm{P}$ level which represents a concentration that can occur in soil solution. Furthermore, P starved poplars showed the highest allocation of newly acquired $\mathrm{P}$ to fine roots, suggesting that these organs were preferentially supplied with $P$ to maintain their physiological activities. 
We found that the threshold for net P uptake was about $1 \mu \mathrm{M}$ and the apparent $\mathrm{K}_{\mathrm{m}}$ for the whole-root system about $26 \mu \mathrm{M}$. These findings indicate that under low $\mathrm{P}$ availabilities, which occur often in soil solutions, bare-rooted poplars are prone to suffer from P limitations. Mycorrhizal colonization of the roots can increase net $\mathrm{P}$ uptake (Casieri et al., 2013), but which fungal species are the most useful to combat $\mathrm{P}$ deficiency is an open question, which needs to be addressed for sustainable poplar plantation management.

\subsection{Acknowledgements}

We are grateful to Gabriele Lehmann, Bernd Kopka, Thomas Klein (Labor für RadioIsotope, LARI, Georg-August Universität Göttingen), and Christine Kettner for expert technical assistance. We thank Dennis Janz for introducing statistical and microarray analyses in $\mathrm{R}$ to $\mathrm{MK}$.

The Georg-August University of Göttingen funded the $\mathrm{PhD}$ position of MK. The Deutsche Forschungsgemeinschaft (DFG), Priority Program SPP 1685 "Ecosystem Nutrition" provided financial support for this research project under grant number Po362/22-2. The publication fund of the University of Göttingen and the Deutsche Forschungsgemeinschaft supported open access publication of this article. The funders had no role in the design of the study, the collection, analysis, and interpretation of data and in writing the manuscript. 


\subsection{References}

Ai, P., Sun, S., Zhao, J., Fan, X., Xin, W., Guo, Q., Yu, L., Shen, Q., Wu, P., Miller, A.J., $X u, G$. (2009): Two rice phosphate transporters, OsPht1;2 and OsPht1;6, have different functions and kinetic properties in uptake and translocation. Plant J. 57, 798-809.

Akhtar, M.S., Oki, Y., Adachi, T., Murata, Y., Khan, M.H.R. (2007): Relative phosphorus utilization efficiency, growth response, and phosphorus uptake kinetics of Brassica cultivars under a phosphorus stress environment. Commun. Soil Sci. Plant Anal. 38, 1061-1085.

Asano, Y., Compton, J.E., Church, M.R. (2006): Hydrologic flowpaths influence inorganic and organic nutrient leaching in a forest soil. Biogeochemistry 81, 191-204.

Baker, A., Ceasar, S.A., Palmer, A.J., Paterson, J.B., Qi, W., Muench, S.P., Baldwin, S.A. (2015): Replace, reuse, recycle: improving the sustainable use of phosphorus by plants. J. Exp. Bot. 66, 3523-3540.

Baum, C., Makeschin, F. (2000): Effects of nitrogen and phosphorus fertilization on mycorrhizal formation of two poplar clones (Populus trichocarpa and P. tremula $\mathrm{x}$ tremuloides). J. Plant Nutr. Soil Sci. 163, 491-497.

Bhadoria, P.S., Dessougi, H.E., Liebersbach, H., Claassen, N. (2004): Phosphorus uptake kinetics, size of root system and growth of maize and groundnut in solution culture. Plant Soil 262, 327-336.

Bieleski, R.L. (1973): Phosphate pools, phosphate transport, and phosphate availability. Annu. Rev. Plant Physiol. 24, 225-252.

Bolker, B. (2013): emdbook: Ecological Models and Data in R. R package version 1.3.4.

Burg, J. van den (1985): Foliar analysis for determination of tree nutrient status- a compilation of literature data. Rapp. Rijksinst. Voor Onderz. Bos- En Landschapsbouw Dorschkamp Neth.

Bustos, R., Castrillo, G., Linhares, F., Puga, M.I., Rubio, V., Pérez-Pérez, J., Solano, R., Leyva, A., Paz-Ares, J. (2010): A central regulatory system largely controls transcriptional activation and repression responses to phosphate starvation in Arabidopsis. PLoS Genet 6, e1001102.

Casieri, L., Lahmidi, N.A., Doidy, J., Veneault-Fourrey, C., Migeon, A., Bonneau, L., Courty, P.-E., Garcia, K., Charbonnier, M., Delteil, A., Brun, A., Zimmermann, S., Plassard, C., Wipf, D. (2013): Biotrophic transportome in mutualistic plant-fungal interactions. Mycorrhiza 23, 597-625. 
Chang, S., Puryear, J., Cairney, J. (1993): A simple and efficient method for isolating RNA from pine trees. Plant Mol. Biol. Report. 11, 113-116.

Claassen, N., Barber, S.A. (1974): A method for characterizing the relation between nutrient concentration and flux into roots of intact plants. Plant Physiol. 54, 564-568.

Cogliatti, D.H., Clarkson, D.T. (1983): Physiological changes in, and phosphate uptake by potato plants during development of, and recovery from phosphate deficiency. Physiol. Plant. 58, 287-294.

Cress, W.A., Throneberry, G.O., Lindsey, D.L. (1979): Kinetics of phosphorus absorption by mycorrhizal and nonmycorrhizal tomato roots. Plant Physiol. 64, 484487.

Danielsen, L., Lohaus, G., Sirrenberg, A., Karlovsky, P., Bastien, C., Pilate, G., Polle, $A$. (2013): Ectomycorrhizal colonization and diversity in relation to tree biomass and nutrition in a plantation of transgenic poplars with modified lignin biosynthesis. PLOS ONE 8, e59207.

Danielsen, L., Polle, A. (2014): Poplar nutrition under drought as affected by ectomycorrhizal colonization. Environ. Exp. Bot. 108, 89-98.

Danielsen, L., Thürmer, A., Meinicke, P., Buée, M., Morin, E., Martin, F., Pilate, G., Daniel, R., Polle, A., Reich, M. (2012): Fungal soil communities in a young transgenic poplar plantation form a rich reservoir for fungal root communities. Ecol. Evol. 2, 1935-1948.

Daram, P., Brunner, S., Rausch, C., Steiner, C., Amrhein, N., Bucher, M. (1999): Pht2;1 encodes a low-affinity phosphate transporter from Arabidopsis. Plant Cell Online 11, 2153-2166.

Desai, S., Naik, D., Cumming, J.R. (2014): The influence of phosphorus availability and Laccaria bicolor symbiosis on phosphate acquisition, antioxidant enzyme activity, and rhizospheric carbon flux in Populus tremuloides. Mycorrhiza 24, 369-382.

Dong, B., Ryan, P.R., Rengel, Z., Delhaize, E. (1999): Phosphate uptake in Arabidopsis thaliana: dependence of uptake on the expression of transporter genes and internal phosphate concentrations. Plant Cell Environ. 22, 1455-1461.

Felsenstein, J. (1993): PHYLIP (Phylogeny Inference Package) version 3.5c. Distributed by the author. Department of Genetics, University of Washington, Seattle.

Finn, R.D., Bateman, A., Clements, J., Coggill, P., Eberhardt, R.Y., Eddy, S.R., Heger, A., Hetherington, K., Holm, L., Mistry, J., Sonnhammer, E.L.L., Tate, J., Punta, M. (2014): Pfam: the protein families database. Nucleic Acids Res. 42, D222-D230. 
Fitzhugh, R.D., Driscoll, C.T., Groffman, P.M., Tierney, G.L., Fahey, T.J., Hardy, J.P. (2001): Effects of soil freezing disturbance on soil solution nitrogen, phosphorus, and carbon chemistry in a northern hardwood ecosystem. Biogeochemistry 56, 215-238.

Gan, H., Jiao, Y., Jia, J., Wang, X., Li, H., Shi, W., Peng, C., Polle, A., Luo, Z.-B. (2016): Phosphorus and nitrogen physiology of two contrasting poplar genotypes when exposed to phosphorus and/or nitrogen starvation. Tree Physiol. 36, 22-38.

Ge, X., Tian, Y., Tang, L. (2015): Nutrient distribution indicated whole-tree harvesting as a possible factor restricting the sustainable productivity of a poplar plantation system in China. PLOS ONE 10, e0125303.

Gehring, C.A., Mueller, R.C., Whitham, T.G. (2006): Environmental and genetic effects on the formation of ectomycorrhizal and arbuscular mycorrhizal associations in cottonwoods. Oecologia 149, 158-164.

Goodstein, D.M., Shu, S., Howson, R., Neupane, R., Hayes, R.D., Fazo, J., Mitros, T., Dirks, W., Hellsten, U., Putnam, N., Rokhsar, D.S. (2012): Phytozome: a comparative platform for green plant genomics. Nucleic Acids Res. 40, D1178-D1186.

Guo, B., Jin, Y., Wussler, C., Blancaflor, E.B., Motes, C.M., Versaw, W.K. (2008): Functional analysis of the Arabidopsis PHT4 family of intracellular phosphate transporters. New Phytol. 177, 889-898.

Hammond, J.P., White, P.J. (2008): Sucrose transport in the phloem: integrating root responses to phosphorus starvation. J. Exp. Bot. 59, 93-109.

Hassler, S., Lemke, L., Jung, B., Möhlmann, T., Krüger, F., Schumacher, K., Espen, L., Martinoia, E., Neuhaus, H.E. (2012): Lack of the Golgi phosphate transporter PHT4;6 causes strong developmental defects, constitutively activated disease resistance mechanisms and altered intracellular phosphate compartmentation in Arabidopsis. Plant J. 72, 732-744.

Heinrichs, H., Brumsack, H.-J., Loftfield, N., König, N. (1986): Verbessertes Druckaufschlußsystem für biologische und anorganische Materialien. Z. Für Pflanzenernähr. Bodenkd. 149, 350-353.

Hellemans, J., Mortier, G., De Paepe, A., Speleman, F., Vandesompele, J. (2007): qBase relative quantification framework and software for management and automated analysis of real-time quantitative PCR data. Genome Biol. 8, R19.

Hewitt, E.J., Smith, T.A. (1974): Plant Mineral Nutrition. English University Press, London, p. 298 pp.

Higo, K., Ugawa, Y., Iwamoto, M., Korenaga, T. (1999): Plant cis-acting regulatory DNA elements (PLACE) database: 1999. Nucleic Acids Res. 27, 297-300. 
Holford, I.C.R. (1997): Soil phosphorus: its measurement, and its uptake by plants. Soil Res. 35, 227-240.

Huang, C.Y., Shirley, N., Genc, Y., Shi, B., Langridge, P. (2011): Phosphate utilization efficiency correlates with expression of low-affinity phosphate transporters and noncoding RNA, IPS1, in barley. Plant Physiol. 156, 1217-1229.

Janz, D., Behnke, K., Schnitzler, J.-P., Kanawati, B., Schmitt-Kopplin, P., Polle, A. (2010): Pathway analysis of the transcriptome and metabolome of salt sensitive and tolerant poplar species reveals evolutionary adaption of stress tolerance mechanisms. BMC Plant Biol. 10, 150.

Jentschke, G., Brandes, B., Heinzemann, J., Marschner, P., Godbold, D.L. (1999): Sand culture of mycorrhizal plants. J. Plant Nutr. Soil Sci. 162, 107-112.

Jungk, A., Asher, C.J., Edwards, D.G., Meyer, D. (1990): Influence of phosphate status on phosphate uptake kinetics of maize (Zea mays) and soybean (Glycine max). Plant Soil 124, 175-182.

Kolesnikov, N., Hastings, E., Keays, M., Melnichuk, O., Tang, Y.A., Williams, E., Dylag, M., Kurbatova, N., Brandizi, M., Burdett, T., Megy, K., Pilicheva, E., Rustici, G., Tikhonov, A., Parkinson, H., Petryszak, R., Sarkans, U., Brazma, A. (2015): ArrayExpress update--simplifying data submissions. Nucleic Acids Res. 43, D1113D1116.

Lambers, H., Shane, M.W., Cramer, M.D., Pearse, S.J., Veneklaas, E.J. (2006): Root structure and functioning for efficient acquisition of phosphorus: Matching morphological and physiological traits. Ann. Bot. 98, 693-713.

Lamesch, P., Berardini, T.Z., Li, D., Swarbreck, D., Wilks, C., Sasidharan, R., Muller, R., Dreher, K., Alexander, D.L., Garcia-Hernandez, M., Karthikeyan, A.S., Lee, C.H., Nelson, W.D., Ploetz, L., Singh, S., Wensel, A., Huala, E. (2012): The Arabidopsis Information Resource (TAIR): improved gene annotation and new tools. Nucleic Acids Res. 40, D1202-D1210.

Larkin, M.A., Blackshields, G., Brown, N.P., Chenna, R., McGettigan, P.A., McWilliam, H., Valentin, F., Wallace, I.M., Wilm, A., Lopez, R., Thompson, J.D., Gibson, T.J., Higgins, D.G. (2007): Clustal W and Clustal X version 2.0. Bioinformatics 23, $2947-$ 2948.

Lee, R.B. (1982): Selectivity and kinetics of ion uptake by barley plants following nutrient deficiency. Ann. Bot. 50, 429-449.

Lemoine, R., Camera, S.L., Atanassova, R., Dédaldéchamp, F., Allario, T., Pourtau, N., Bonnemain, J.-L., Laloi, M., Coutos-Thévenot, P., Maurousset, L., Faucher, M., Girousse, C., Lemonnier, P., Parrilla, J., Durand, M. (2013): Source-to-sink transport of sugar and regulation by environmental factors. Front. Plant Sci. 4, 272. 
Leple, J.C., Brasileiro, A.C.M., Michel, M.F., Delmotte, F., Jouanin, L. (1992): Transgenic poplars: expression of chimeric genes using four different constructs. Plant Cell Rep. 11, 137-141.

López-Arredondo, D.L., Leyva-González, M.A., González-Morales, S.I., López-Bucio, J., Herrera-Estrella, L. (2014): Phosphate nutrition: Improving low-phosphate tolerance in crops. Annu. Rev. Plant Biol. 65, 95-123.

Loth-Pereda, V., Orsini, E., Courty, P.-E., Lota, F., Kohler, A., Diss, L., Blaudez, D., Chalot, M., Nehls, U., Bucher, M., Martin, F. (2011): Structure and expression profile of the phosphate Pht1 transporter gene family in mycorrhizal Populus trichocarpa. Plant Physiol. 156, 2141-2154.

Martinka, M., Vaculik, M., Lux, A. (2014): Plant cell responses to cadmium and zinc, in: Nick, P., Opatrny, Z. (eds.): Applied plant cell biology. Springer Berlin Heidelberg, Berlin, Heidelberg, pp. 209-246.

Misson, J., Thibaud, M.-C., Bechtold, N., Raghothama, K., Nussaume, L. (2004): Transcriptional regulation and functional properties of Arabidopsis Pht1;4, a high affinity transporter contributing greatly to phosphate uptake in phosphate deprived plants. Plant Mol. Biol. 55, 727-741.

Mitsukawa, N., Okumura, S., Shirano, Y., Sato, S., Kato, T., Harashima, S., Shibata, D. (1997): Overexpression of an Arabidopsis thaliana high-affinity phosphate transporter gene in tobacco cultured cells enhances cell growth under phosphate-limited conditions. Proc. Natl. Acad. Sci. U. S. A. 94, 7098-7102.

Morcuende, R., Bari, R., Gibon, Y., Zheng, W., Pant, B.D., Bläsing, O., Usadel, B., Czechowski, T., Udvardi, M.K., Stitt, M., Scheible, W.-R. (2007): Genome-wide reprogramming of metabolism and regulatory networks of Arabidopsis in response to phosphorus. Plant Cell Environ. 30, 85-112.

Mudge, S.R., Rae, A.L., Diatloff, E., Smith, F.W. (2002): Expression analysis suggests novel roles for members of the Pht1 family of phosphate transporters in Arabidopsis. Plant J. 31, 341-353.

Müller, A., Volmer, K., Mishra-Knyrim, M., Polle, A. (2013): Growing poplars for research with and without mycorrhizas. Front. Plant Sci. 4, 332.

Nussaume, L., Kanno, S., Javot, H., Marin, E., Pochon, N., Ayadi, A., Nakanishi, T.M., Thibaud, M.-C. (2011): Phosphate import in plants: Focus on the PHT1 transporters. Front. Plant Sci. 2, 83.

Ouyang, S., Zhu, W., Hamilton, J., Lin, H., Campbell, M., Childs, K., Thibaud-Nissen, F., Malek, R.L., Lee, Y., Zheng, L., Orvis, J., Haas, B., Wortman, J., Buell, C.R. (2007): The TIGR rice genome annotation resource: improvements and new features. Nucleic Acids Res. 35, D883-D887. 
Pinheiro, J.C., Bates, D.M., DebRoy, S., the R Development Core Team (2012): The R Core Team nlme: Linear and Nonlinear Mixed Effects Models. R package version 3.1103.

Poirier, Y., Bucher, M. (2002): Phosphate transport and homeostasis in Arabidopsis. Arab. Book e0024.

Poirier, Y., Jung, J.-Y. (2015): Phosphate transporters, in: Plaxton, W.C., Lambers, H. (eds.): Annual Plant Reviews Volume 48. John Wiley \& Sons, Inc., Hoboken, NJ, USA, pp. 125-158.

Polle, A., Chen, S. (2015): On the salty side of life: molecular, physiological and anatomical adaptation and acclimation of trees to extreme habitats. Plant Cell Environ. $38,1794-1816$.

Polle, A., Janz, D., Teichmann, T., Lipka, V. (2013): Poplar genetic engineering: promoting desirable wood characteristics and pest resistance. Appl. Microbiol. Biotechnol. 97, 5669-5679.

$R$ Development Core Team (2012): R: a language and environment for statistical computing. R Foundation for Statistical Computing, Vienna, Austria.

Rae, A.L., Cybinski, D.H., Jarmey, J.M., Smith, F.W. (2003): Characterization of two phosphate transporters from barley; evidence for diverse function and kinetic properties among members of the Pht1 family. Plant Mol. Biol. 53, 27-36.

Ranger, J., Marques, R., Jussy, J.-H. (2001): Forest soil dynamics during stand development assessed by lysimeter and centrifuge solutions. For. Ecol. Manag. 144, $129-145$.

Rausch, C., Bucher, M. (2002): Molecular mechanisms of phosphate transport in plants. Planta 216, 23-37.

Remy, E., Cabrito, T.R., Batista, R.A., Teixeira, M.C., Sá-Correia, I., Duque, P. (2012): The Pht1;9 and Pht1;8 transporters mediate inorganic phosphate acquisition by the Arabidopsis thaliana root during phosphorus starvation. New Phytol. 195, 356-371.

Ruijter, J.M., Ramakers, C., Hoogaars, W.M.H., Karlen, Y., Bakker, O., Hoff, M.J.B. van den, Moorman, A.F.M. (2009): Amplification efficiency: linking baseline and bias in the analysis of quantitative PCR data. Nucleic Acids Res. 37, e45-e45.

Schachtman, D.P., Reid, R.J., Ayling, S.M. (1998): Phosphorus uptake by plants: from soil to cell. Plant Physiol. 116, 447-453.

Schnable, P.S., Ware, D., Fulton, R.S., Stein, J.C., Wei, F., Pasternak, S., Liang, C., Zhang, J., Fulton, L., Graves, T.A., Minx, P., Reily, A.D., Courtney, L., Kruchowski, S.S., Tomlinson, C., Strong, C., Delehaunty, K., Fronick, C., Courtney, B., Rock, S.M., 
Belter, E., Du, F., Kim, K., Abbott, R.M., Cotton, M., Levy, A., Marchetto, P., Ochoa, K., Jackson, S.M., Gillam, B., Chen, W., Yan, L., Higginbotham, J., Cardenas, M., Waligorski, J., Applebaum, E., Phelps, L., Falcone, J., Kanchi, K., Thane, T., Scimone, A., Thane, N., Henke, J., Wang, T., Ruppert, J., Shah, N., Rotter, K., Hodges, J., Ingenthron, E., Cordes, M., Kohlberg, S., Sgro, J., Delgado, B., Mead, K., Chinwalla, A., Leonard, S., Crouse, K., Collura, K., Kudrna, D., Currie, J., He, R., Angelova, A., Rajasekar, S., Mueller, T., Lomeli, R., Scara, G., Ko, A., Delaney, K., Wissotski, M., Lopez, G., Campos, D., Braidotti, M., Ashley, E., Golser, W., Kim, H., Lee, S., Lin, J., Dujmic, Z., Kim, W., Talag, J., Zuccolo, A., Fan, C., Sebastian, A., Kramer, M., Spiegel, L., Nascimento, L., Zutavern, T., Miller, B., Ambroise, C., Muller, S., Spooner, W., Narechania, A., Ren, L., Wei, S., Kumari, S., Faga, B., Levy, M.J., McMahan, L., Buren, P.V., Vaughn, M.W., Ying, K., Yeh, C.-T., Emrich, S.J., Jia, Y., Kalyanaraman, A., Hsia, A.-P., Barbazuk, W.B., Baucom, R.S., Brutnell, T.P., Carpita, N.C., Chaparro, C., Chia, J.-M., Deragon, J.-M., Estill, J.C., Fu, Y., Jeddeloh, J.A., Han, Y., Lee, H., Li, P., Lisch, D.R., Liu, S., Liu, Z., Nagel, D.H., McCann, M.C., SanMiguel, P., Myers, A.M., Nettleton, D., Nguyen, J., Penning, B.W., Ponnala, L., Schneider, K.L., Schwartz, D.C., Sharma, A., Soderlund, C., Springer, N.M., Sun, Q., Wang, H., Waterman, M., Westerman, R., Wolfgruber, T.K., Yang, L., Yu, Y., Zhang, L., Zhou, S., Zhu, Q., Bennetzen, J.L., Dawe, R.K., Jiang, J., Jiang, N., Presting, G.G., Wessler, S.R., Aluru, S., Martienssen, R.A., Clifton, S.W., McCombie, W.R., Wing, R.A., Wilson, R.K. (2009): The B73 maize genome: Complexity, diversity, and dynamics. Science 326, 1112-1115.

Seven, J., Polle, A. (2014): Subcellular nutrient element localization and enrichment in ecto- and arbuscular mycorrhizas of field-grown beech and ash trees indicate functional differences. PLOS ONE 9, e114672.

Shin, H., Shin, H.-S., Dewbre, G.R., Harrison, M.J. (2004): Phosphate transport in Arabidopsis: Pht1;1 and Pht1;4 play a major role in phosphate acquisition from both low- and high-phosphate environments. Plant J. 39, 629-642.

Takabatake, R., Hata, S., Taniguchi, M., Kouchi, H., Sugiyama, T., Izui, K. (1999): Isolation and characterization of cDNAs encoding mitochondrial phosphate transporters in soybean, maize, rice, and Arabidopsis. Plant Mol. Biol. 40, 479-486.

Tamura, K., Stecher, G., Peterson, D., Filipski, A., Kumar, S. (2013): MEGA6: Molecular Evolutionary Genetics Analysis Version 6.0. Mol. Biol. Evol. 30, 2725-2729.

Tsai, C.-J., Ranjan, P., DiFazio, S., Tuskan, G., Johnson, V. (2011): Poplar genome microarrays, in: Joshi, C., DiFazio, S., Kole, C. (eds.): Genetics, genomics and breeding of poplars. Science Publishers, Enfield, NH, pp. 112-127.

Tuskan, G.A., DiFazio, S., Jansson, S., Bohlmann, J., Grigoriev, I., Hellsten, U., Putnam, N., Ralph, S., Rombauts, S., Salamov, A., Schein, J., Sterck, L., Aerts, A., Bhalerao, R.R., Bhalerao, R.P., Blaudez, D., Boerjan, W., Brun, A., Brunner, A., Busov, V., Campbell, M., Carlson, J., Chalot, M., Chapman, J., Chen, G.-L., Cooper, D., 
Coutinho, P.M., Couturier, J., Covert, S., Cronk, Q., Cunningham, R., Davis, J., Degroeve, S., Déjardin, A., dePamphilis, C., Detter, J., Dirks, B., Dubchak, I., Duplessis, S., Ehlting, J., Ellis, B., Gendler, K., Goodstein, D., Gribskov, M., Grimwood, J., Groover, A., Gunter, L., Hamberger, B., Heinze, B., Helariutta, Y., Henrissat, B., Holligan, D., Holt, R., Huang, W., Islam-Faridi, N., Jones, S., JonesRhoades, M., Jorgensen, R., Joshi, C., Kangasjärvi, J., Karlsson, J., Kelleher, C., Kirkpatrick, R., Kirst, M., Kohler, A., Kalluri, U., Larimer, F., Leebens-Mack, J., Leplé, J.-C., Locascio, P., Lou, Y., Lucas, S., Martin, F., Montanini, B., Napoli, C., Nelson, D.R., Nelson, C., Nieminen, K., Nilsson, O., Pereda, V., Peter, G., Philippe, R., Pilate, G., Poliakov, A., Razumovskaya, J., Richardson, P., Rinaldi, C., Ritland, K., Rouzé, P., Ryaboy, D., Schmutz, J., Schrader, J., Segerman, B., Shin, H., Siddiqui, A., Sterky, F., Terry, A., Tsai, C.-J., Uberbacher, E., Unneberg, P., Vahala, J., Wall, K., Wessler, S., Yang, G., Yin, T., Douglas, C., Marra, M., Sandberg, G., Peer, Y.V. de, Rokhsar, D. (2006): The genome of black cottonwood, Populus trichocarpa (Torr. \& Gray). Science $313,1596-1604$.

van Hees, P.A.W., Vinogradoff, S.I., Edwards, A.C., Godbold, D.L., Jones, D.L. (2003): Low molecular weight organic acid adsorption in forest soils: effects on soil solution concentrations and biodegradation rates. Soil Biol. Biochem. 35, 1015-1026.

Van Tichelen, K.K., Colpaert, J.V. (2000): Kinetics of phosphate absorption by mycorrhizal and non-mycorrhizal Scots pine seedlings. Physiol. Plant. 110, 96-103.

Versaw, W.K., Harrison, M.J. (2002): A chloroplast phosphate transporter, PHT2;1, influences allocation of phosphate within the plant and phosphate-starvation responses. Plant Cell Online 14, 1751-1766.

Warnes, G.R. (2012): gplots: Various R programming tools for plotting data. R package version 2.11.0.

Yamada, K., Kanai, M., Osakabe, Y., Ohiraki, H., Shinozaki, K., Yamaguchi-Shinozaki, K. (2011): Monosaccharide absorption activity of Arabidopsis roots depends on expression profiles of transporter genes under high salinity conditions. J. Biol. Chem. 286, 43577-43586.

Zhang, Z., Liao, H., Lucas, W.J. (2014): Molecular mechanisms underlying phosphate sensing, signaling, and adaptation in plants: Phosphate sensing and signaling in plants. J. Integr. Plant Biol. 56, 192-220. 


\subsection{Supporting information}

Table S3.1: In silico analyses of putative poplar phosphate transporters.

Table S3.2: Primers used for qRT PCR of putative P transporter genes.

Table S3.3: Transcript abundances of phosphate transporter genes

Figure S3.1. Biomass and performance of poplar grown with five different $P$ concentrations.

Figure S3.2. Neighbor-Joining tree (Jones-Taylor-Thornton model, 500 bootstraps) of the amino acid sequences for inorganic phosphate transporters in poplar.

Figure S3.3. Correlations of absolute microarray expression data ( $\log _{2}$-value) and qRT PCR relative expression values $\left(\log _{2}\right)$ for PtPHTs. 
Table S3.1: In silico analyses of putative poplar phosphate transporters.

\begin{tabular}{|c|c|c|c|c|c|}
\hline GeneID & $\begin{array}{l}\text { Gene } \\
\text { name or } \\
\text { Family }\end{array}$ & $\begin{array}{l}\text { PLACE } \\
\text { P1BS- } \\
\text { Local- } \\
\text { ization }\end{array}$ & Affy IDs & $\begin{array}{l}\text { Com- } \\
\text { ments }\end{array}$ & $\begin{array}{l}\text { Ath protein } \\
\text { homolog (\% } \\
\text { identity) }\end{array}$ \\
\hline Potri.010G072000 & PtPHT1;1 & 54 & $\begin{array}{l}\text { PtpAffx.215047.1.S1_s_at } \\
\text { PtpAffx.208712.1.S1_at } \\
\text { PtpAffx.219484.1.S1_s_at }\end{array}$ & & AtPHT1;5 (77.5) \\
\hline Potri.010G071700 & PtPHT1;2 & & PtpAffx.219485.1.S1_s_at & & AtPHT1;5 (78.7) \\
\hline Potri.010G071500 & PtPHT1;3 & & PtpAffx.54440.1.A1_at & & $\begin{array}{l}\text { AtPHT1;4 (82.5), } \\
\text { AtPHT1;7 (82.0) }\end{array}$ \\
\hline Potri.005G223500 & PtPHT1;4 & 404 & $\begin{array}{l}\text { PtpAffx.141538.1.S1_s_at } \\
\text { Ptp.5181.2.S1_at } \\
\text { PtpAffx.69535.1.A1_s_at }\end{array}$ & & $\begin{array}{l}\text { AtPHT1;4 (83.0), } \\
\text { AtPHT1;7 (84.7) }\end{array}$ \\
\hline Potri.002G038900 & PtPHT1;5 & 169 & & NA & $\begin{array}{l}\text { AtPHT1;4 (84.5), } \\
\text { AtPHT1;7 (83.6) }\end{array}$ \\
\hline Potri.005G175500 & PtPHT1;6 & & PtpAffx.223352.1.S1_s_at & n.d. & $\begin{array}{l}\text { AtPHT1;6 (64.5), } \\
\text { At4G08895 (53.3) }\end{array}$ \\
\hline Potri.005G223600 & PtPHT1;7 & 911 & $\begin{array}{l}\text { PtpAffx.205756.1.S1_x_at } \\
\text { PtpAffx.205756.1.S1_at } \\
\text { PtpAffx.69535.2.A1_s_at }\end{array}$ & n.d. & $\begin{array}{l}\text { AtPHT1;4 (85.9), } \\
\text { AtPHT1;7 (86.9) }\end{array}$ \\
\hline Potri.019G061900 & PtPHT1;8 & & $\begin{array}{l}\text { PtpAffx.215592.1.S1_at } \\
\text { PtpAffx.223434.1.S1_at } \\
\text { PtpAffx.223434.1.S1_s_at }\end{array}$ & $\begin{array}{l}\text { n.d. } \\
\text { n.d. } \\
\text { n.d. }\end{array}$ & - \\
\hline Potri.002G005500 & PtPHT1;9 & 334 & PtpAffx.62481.1.A1_s_at & & $\begin{array}{l}\text { AtPHT1;8 (60.4), } \\
\text { AtPHT1.9 (62 9) }\end{array}$ \\
\hline Potri.015G022800 & PtPHT1;10 & $\begin{array}{l}489 \\
581 \\
826\end{array}$ & $\begin{array}{l}\text { PtpAffx.201523.1.S1_at } \\
\text { PtpAffx.218285.1.S1_at }\end{array}$ & $\begin{array}{l}\text { n.d. } \\
\text { n.d. }\end{array}$ & $\begin{array}{l}\text { AtPHT1;9 (62.9) } \\
-\end{array}$ \\
\hline Potri.005G256100 & PtPHT1;11 & 514 & & NA & $\begin{array}{l}\text { AtPHT1;8 (61.0), } \\
\text { AtPHT1;9 (64.2) }\end{array}$ \\
\hline Potri.001G318500 & PtPHT1;12 & & PtpAffx.201089.1.S1_at & & AtPHT1;5 (78.9) \\
\hline Potri.005G175700 & Fam. 1 & & PtpAffx.205527.1.S1_at & n.d. & $\begin{array}{l}\text { AtPHT1;6 (66.5), } \\
\text { At4G08895 (53.3) }\end{array}$ \\
\hline Potri.005G223700 & Fam. 1 & & PtpAffx.205757.1.S1_at & n.d., tr. & - \\
\hline Potri.006G109800 & Fam. 4 & 434 & PtpAffx.206360.1.S1_at & n.d., tr. & - \\
\hline Potri.010G071600 & Fam. 1 & & & NA & AtPHT1;5 (78.9) \\
\hline Potri.013G089800 & Fam. 1 & $\begin{array}{l}449 \\
472\end{array}$ & & NA, tr. & - \\
\hline Potri.008G186600 & PtPHT2;1 & & PtpAffx.208289.1.S1_at & & AtPHT2;1 (81.7) \\
\hline Potri.010G046300 & PtPHT2;2 & & PtpAffx.208671.1.S1_at & & AtPHT2;1 (73.3) \\
\hline
\end{tabular}


Table S3.1 (continued)

\begin{tabular}{|c|c|c|c|c|c|}
\hline GeneID & $\begin{array}{l}\text { Gene } \\
\text { name or } \\
\text { Family }\end{array}$ & $\begin{array}{l}\text { PLACE } \\
\text { P1BS- } \\
\text { Local- } \\
\text { ization }\end{array}$ & Affy IDs & $\begin{array}{l}\text { Com- } \\
\text { ments }\end{array}$ & $\begin{array}{l}\text { Ath protein } \\
\text { homolog (\% } \\
\text { identity) }\end{array}$ \\
\hline Potri.017G060800 & PtPHT3;1 & 305 & $\begin{array}{l}\text { PtpAffx.223426.1.S1_at } \\
\text { PtpAffx.51641.2.S1_at }\end{array}$ & n.d. & AtPHT3;1 (88.3) \\
\hline Potri.001G322300 & PtPHT3;2 & & $\begin{array}{l}\text { PtpAffx.7845.1.A1_s_at } \\
\text { Ptp.2106.1.A1_s_at } \\
\text { PtpAffx.51641.1.S1_s_at } \\
\text { PtpAffx.201077.1.S1_at }\end{array}$ & & AtPHT3;1 (88.8) \\
\hline Potri.012G105100 & PtPHT3;3 & & & NA & - \\
\hline Potri.015G104400 & PtPHT3;4 & 277 & Ptp.6141.1.S1_at & n.d. & - \\
\hline Potri.004G207200 & PtPHT3;5 & & $\begin{array}{l}\text { PtpAffx.172.1.S1_at } \\
\text { PtpAffx.222497.1.S1_s_at }\end{array}$ & & AtPHT3;3 (75.2) \\
\hline Potri.005G098800 & РtPHT3;6 & & $\begin{array}{l}\text { PtpAffx.205286.1.S1_at } \\
\text { PtpAffx.13003.1.S1_at }\end{array}$ & & AtPHT3;3 (72.7) \\
\hline Potri.006G062300 & PtPHT4;1 & & $\begin{array}{l}\text { PtpAffx.216795.1.S1_at } \\
\text { Ptp.850.1.S1_at }\end{array}$ & n.d. & AtPHT4;5 (71.7) \\
\hline Potri.018G121600 & PtPHT4;2 & & $\begin{array}{l}\text { PtpAffx.214529.1.S1_at } \\
\text { PtpAffx.214529.1.S1_x_at } \\
\text { PtpAffx.157223.1.S1_at } \\
\text { Ptp.6820.1.S1_at }\end{array}$ & & AtPHT4;5 (67.0) \\
\hline Potri.001G249800 & PtPHT4;3 & & Ptp.7586.1.S1_at & & AtPHT4;1 (75.6) \\
\hline Potri.009G043800 & PtPHT4;4 & & PtpAffx.95515.1.S1_at & & AtPHT4;1 (75.4) \\
\hline Potri.014G085700 & PtPHT4;5 & 958 & PtpAffx.59699.2.A1_a_at & & AtPHT4;4 (73.8) \\
\hline Potri.009G168200 & PtPHT4;6 & & $\begin{array}{l}\text { PtpAffx.147587.1.A1_at } \\
\text { PtpAffx.204370.1.S1_at }\end{array}$ & n.d. & AtPHT4;6 (78.7) \\
\hline Potri.016G111000 & PtPHT4;7 & & Ptp.5773.1.S1_at & & AtPHT4;2 (73.8) \\
\hline Potri.001G248200 & PtPHT4;8 & & $\begin{array}{l}\text { PtpAffx.107855.1.A1_a_at } \\
\text { PtpAffx.112006.1.S1_s_at } \\
\text { PtpAffx.107855.1.A1_at } \\
\text { PtpAffx.200753.1.S1_at } \\
\text { PtpAffx.112006.1.S1_at } \\
\text { PtpAffx.204925.1.S1_at }\end{array}$ & $\begin{array}{l}\text { n.d. } \\
\text { n.d. }\end{array}$ & AtPHT4;3 (77.0) \\
\hline $\begin{array}{l}\text { Potri.004G061400 } \\
\text { Potri.013G095600 }\end{array}$ & $\begin{array}{l}\text { uncl. } \\
\text { uncl. }\end{array}$ & & $\begin{array}{l}\text { PtpAffx.203816.1.S1_at } \\
\text { PtpAffx.211244.1.S1_at }\end{array}$ & $\begin{array}{l}\text { n.d. } \\
\text { n.d., tr. }\end{array}$ & - \\
\hline
\end{tabular}

GeneID: Poplar gene IDs in genome annotation version v3, PLACE P1BS-Localization: location of P1BS-motif(s) in $1 \mathrm{~kb}$ upstream region of the gene, Affy IDs: probe names on annotated for the gene by Tsai et al. (2011), Ath protein homolog: closest Arabidopsis protein homolog after Figure S1 and its identity (\%) with the poplar protein, n.d.: expression not detected on microarray, NA: gene is not on array, tr.: truncated; uncl: unclustered. 
Table S3.2: Primers used for qRT PCR of putative $P$ transporter genes.

\begin{tabular}{|c|c|c|c|c|c|}
\hline Potri.ID & Affy IDs & Primer name & Primer sequence (5'-3') & Design & Reference \\
\hline $\begin{array}{l}\text { Potri.010G072000 } \\
\text { (PtPHT1;1) }\end{array}$ & $\begin{array}{l}\text { PtpAffx.215047.1.S1_s_at } \\
\text { PtpAffx.208712.1.S1_at } \\
\text { PtpAffx.219484.1.S1_s_at }\end{array}$ & $\begin{array}{l}\text { PtPH1f } \\
\text { PtPH1r }\end{array}$ & $\begin{array}{l}\text { GCGATTCACGAGGTTTTTCA } \\
\text { GGCGAAGAAAAAGGTCAACG }\end{array}$ & & $\begin{array}{l}\text { Loth-Pereda et } \\
\text { al. (2011) }\end{array}$ \\
\hline $\begin{array}{l}\text { Potri.010G071700 } \\
\text { (PtPHT1;2) }\end{array}$ & PtpAffx.219485.1.S1_s_at & $\begin{array}{l}\text { PcPHT1;2_fw } \\
\text { PcPHT1;2_rev2 }\end{array}$ & $\begin{array}{l}\text { CACAGACCGAACGAAGACTG } \\
\text { ATCACACTGAAGCCATCCTAGG }\end{array}$ & & $\begin{array}{l}\text { (after) Loth- } \\
\text { Pereda et al. } \\
\text { (2011) }\end{array}$ \\
\hline $\begin{array}{l}\text { Potri.010G071500 } \\
\text { (PtPHT1;3) }\end{array}$ & PtpAffx.54440.1.A1_at & $\begin{array}{l}\text { PcPHT1;3_fw } \\
\text { PcPHT1;3_rev }\end{array}$ & $\begin{array}{l}\text { CGACAACCGAATTGGCTTCG } \\
\text { CAAGTGGACCTCAGTCTCG }\end{array}$ & $\begin{array}{l}\text { intron } \\
\text { spanning }\end{array}$ & $\begin{array}{l}\text { after Loth- } \\
\text { Pereda et al. } \\
\text { (2011) }\end{array}$ \\
\hline $\begin{array}{l}\text { Potri.009G168200 } \\
\text { (PtPHT4;6) } \\
\text { Potri.001G047200 } \\
\text { (PPR-repeat as } \\
\text { reference gene) }\end{array}$ & $\begin{array}{l}\text { PtpAffx.147587.1.A1_at } \\
\text { PtpAffx.204370.1.S1_at } \\
\text { PtpAffx.200189.1.S1_at }\end{array}$ & $\begin{array}{l}\text { PcPHT4;6_fw } \\
\text { PcPHT4;6_rev } \\
\text { Pc001G047200_fw } \\
\text { Pc001G047200_rev }\end{array}$ & $\begin{array}{l}\text { CGCTCGCTGCCAATCTTAC } \\
\text { GTCTAGGGATGTTCCACCC } \\
\text { GGCTGAGGAATGTCGAATGG } \\
\text { AGAACGCAACATCATGGAAACC }\end{array}$ & $\begin{array}{l}\text { intron } \\
\text { spanning } \\
\text { Exon- } \\
\text { Exon } \\
\text { junction }\end{array}$ & \\
\hline $\begin{array}{l}\text { Potri.001G309500 } \\
\text { (Actin as } \\
\text { reference gene) }\end{array}$ & $\begin{array}{l}\text { Ptp.6486.1.S1_s_at } \\
\text { PtpAffx.1258.1.S1_s_at } \\
\text { PtpAffx.1258.4.S1_s_at }\end{array}$ & $\begin{array}{l}\text { Aktin9_fw } \\
\text { Aktin9_rev }\end{array}$ & $\begin{array}{l}\text { TGGTGGTTCCACTATGTTCC } \\
\text { TGGAAATCCACATCTGCTGG }\end{array}$ & $\begin{array}{l}\text { Exon- } \\
\text { Exon } \\
\text { junction }\end{array}$ & Janz et al. (2012) \\
\hline
\end{tabular}


Table S3.3: Transcript abundances of phosphate transporter genes.

Raw expression values for the PHT genes on microarrays (means of $n=3$ ) used for $z$ normalization to construct the heatmap shown in Figure 5a. Poplar plants were grown with nutrient solutions differing in phosphate concentration (641 $\mu \mathrm{M} \mathrm{P}$ (HP), $6.4 \mu \mathrm{M} \mathrm{P}$ (MP), $0.064 \mu \mathrm{M}$ P (LP)).

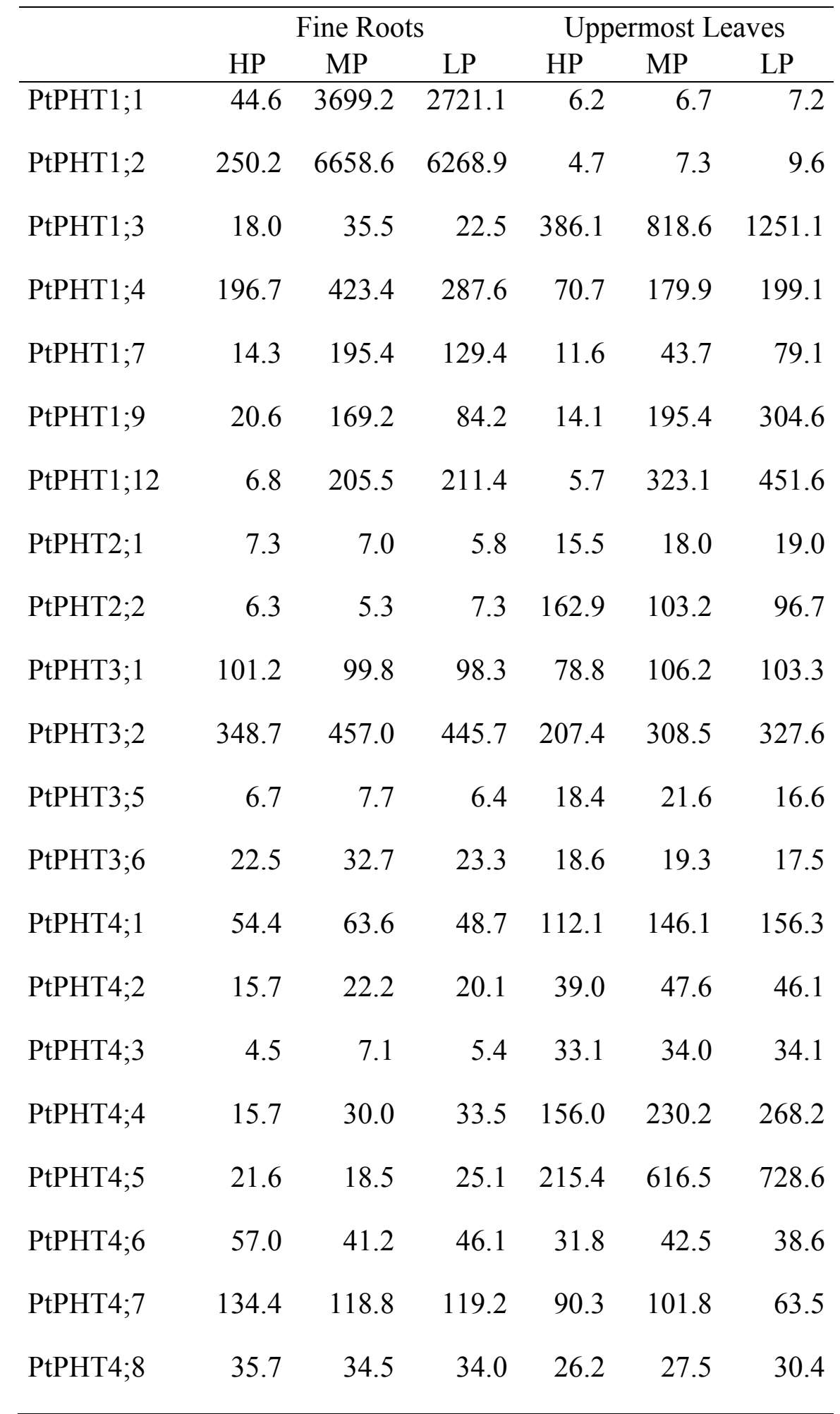




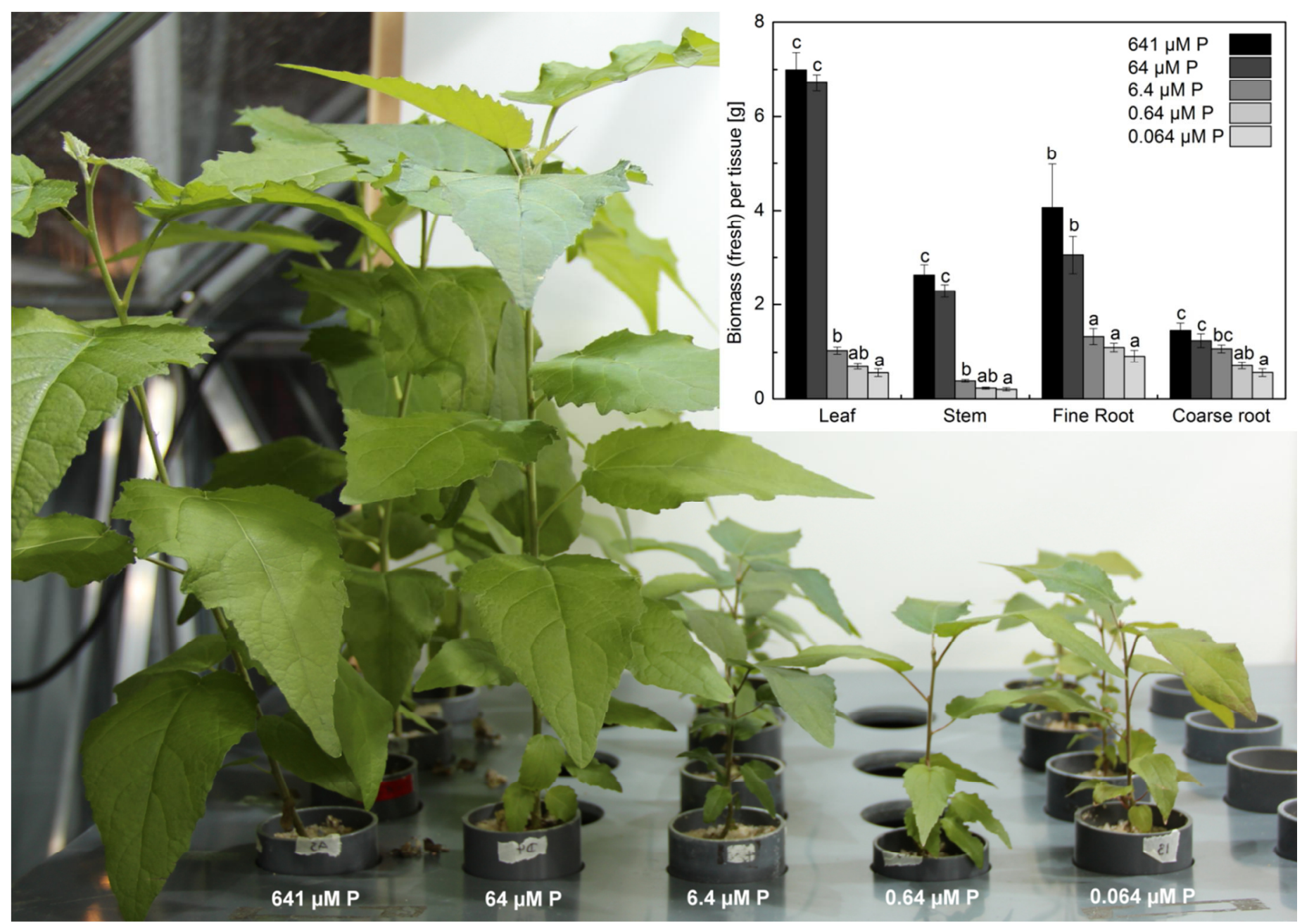

Figure S3.1. Biomass and performance of poplar grown with five different $\mathbf{P}$ concentrations. Populus $\times$ canescens plants were grown for about 2 months in nutrient solutions differing in phosphate concentrations (641 $\mu \mathrm{M} \mathrm{P}(\mathrm{HP}), 64 \mu \mathrm{M} \mathrm{P}, 6.4 \mu \mathrm{M} \mathrm{P}(\mathrm{MP}), 0.64 \mu \mathrm{M}$ P, $0.064 \mu \mathrm{M} \mathrm{P}$ (LP)). Biomass data are means for $\mathrm{n}=11-12( \pm \mathrm{SE})$. 


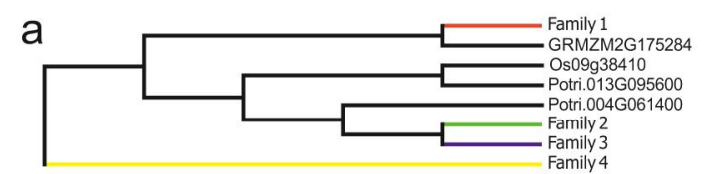

b

b $100{ }^{64} \square^{0502939750}$

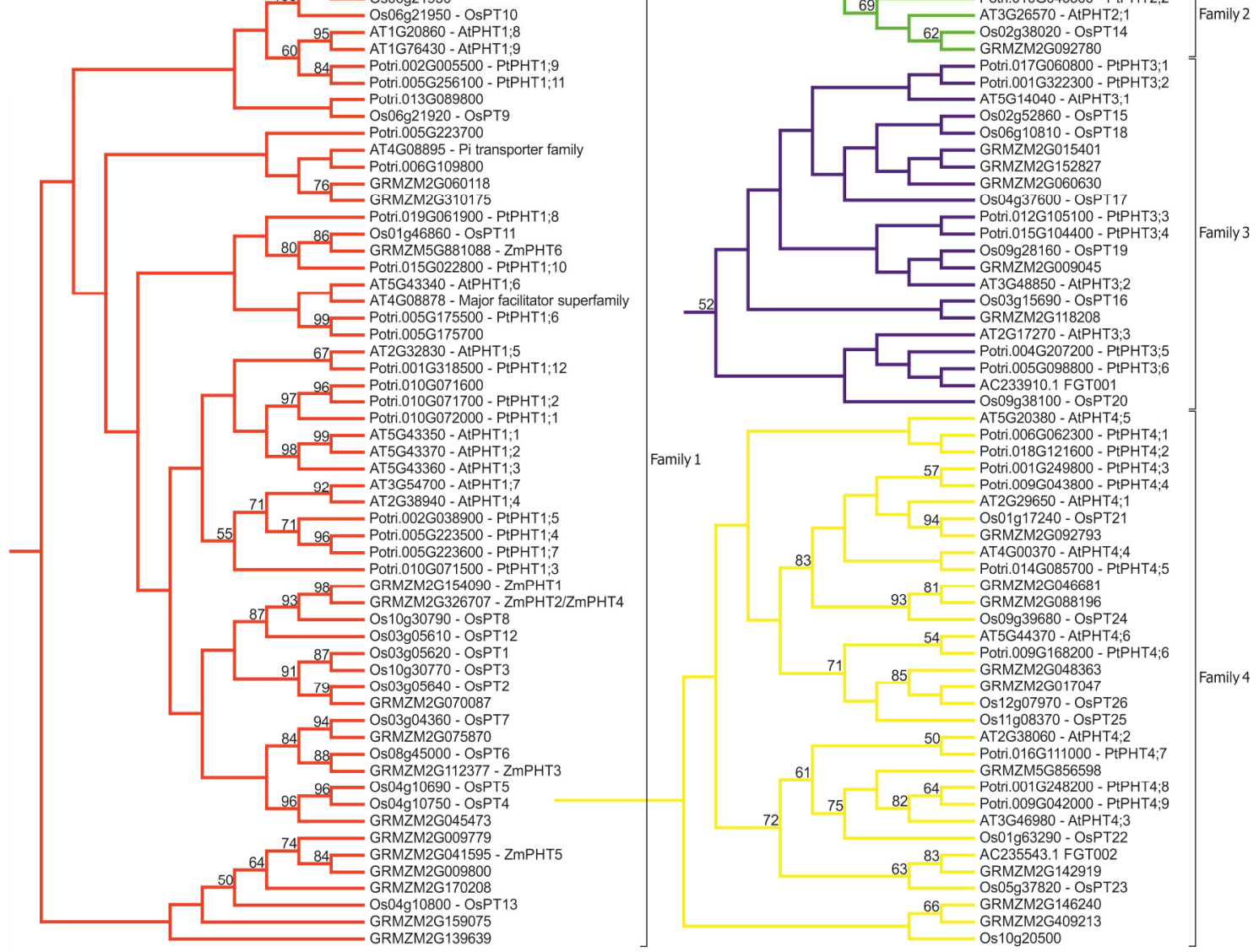

Figure S3.2. Neighbor-Joining tree (Jones-Taylor-Thornton model, 500 bootstraps) of the amino acid sequences for inorganic phosphate transporters in poplar. Poplar (Potri), Arabidopsis (AT), rice (Os) and maize (GRMZM and AC) sequences were used; A: unrooted compressed phylogenetic tree; B: expanded view of the four families, names according to Fan et al. (2013), Liu et al. (2011) and Phytozome, names for newly annotated poplar genes according to tree structure. Only bootstrap values $\geq 50$ are displayed. 


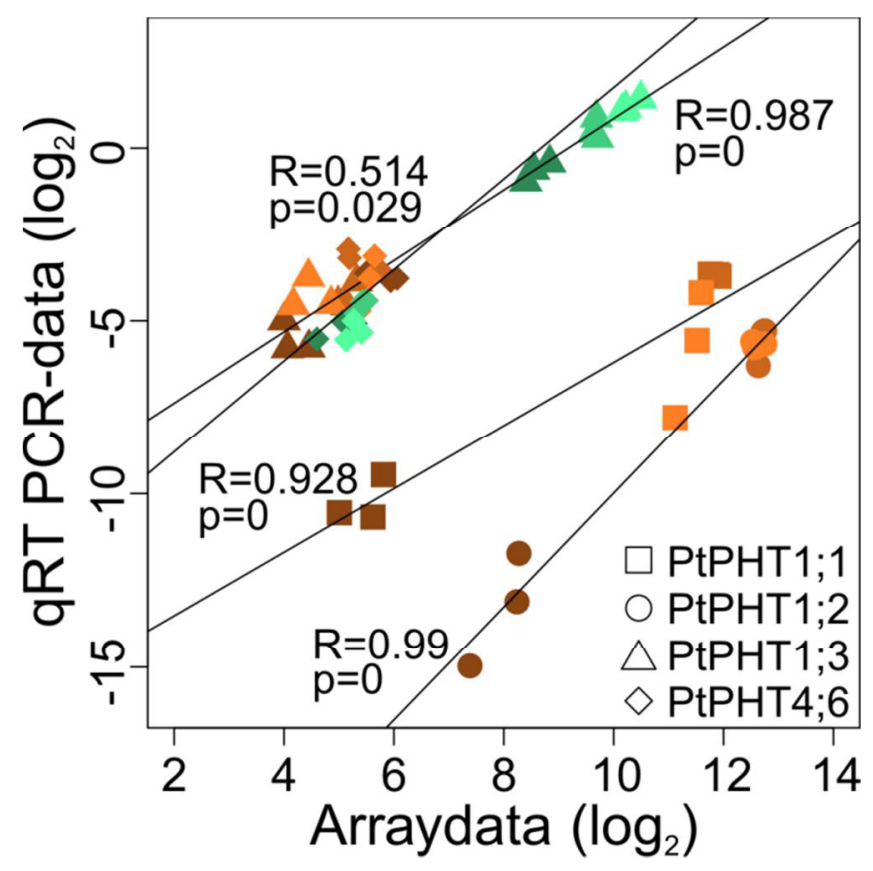

Figure S3.3. Correlations of absolute microarray expression data $\left(\log _{2}\right.$-value) and qRT PCR relative expression values $\left(\log _{2}\right)$ for PtPHTs. P-value and R-value of correlation ( $\mathrm{R}$ function cor.test) are given, red: root samples, green: leaf samples, dark: HP, middle: MP, light: LP; expression of PtPHT1;1 and PtPHT1;2 could not be detected by qRT PCR in leaves. Absolute expression values are given for the microarray data and relative expression values to two reference genes (Actin, PPRrepeat) for qRT PCR data. 


\section{References for supplements Chapter 3}

Fan, C., Wang, X., Hu, R., Wang, Y., Xiao, C., Jiang, Y., Zhang, X., Zheng, C., Fu, Y.-F. (2013): The pattern of Phosphate transporter 1 genes evolutionary divergence in Glycine max L. BMC Plant Biol. 13, 48.

Janz, D., Lautner, S., Wildhagen, H., Behnke, K., Schnitzler, J.-P., Rennenberg, H., Fromm, J., Polle, A. (2012): Salt stress induces the formation of a novel type of "pressure wood" in two Populus species. New Phytol. 194, 129-141.

Liu, F., Chang, X.-J., Ye, Y., Xie, W.-B., Wu, P., Lian, X.-M. (2011): Comprehensive sequence and whole-life-cycle expression profile analysis of the phosphate transporter gene family in rice. Mol. Plant 4, 1105-1122.

Loth-Pereda, V., Orsini, E., Courty, P.-E., Lota, F., Kohler, A., Diss, L., Blaudez, D., Chalot, M., Nehls, U., Bucher, M., Martin, F. (2011): Structure and expression profile of the phosphate Pht1 transporter gene family in mycorrhizal Populus trichocarpa. Plant Physiol. 156, 2141-2154.

Tsai, C.-J., Ranjan, P., DiFazio, S., Tuskan, G., Johnson, V. (2011): Poplar genome microarrays, in: Joshi, C., DiFazio, S., Kole, C. (eds.): Genetics, genomics and breeding of poplars. Science Publishers, Enfield, NH, pp. 112-127. 


\subsection{Authors' contributions}

MK conducted experiments, analyzed data and wrote the manuscript. AP designed the experiments, analyzed data and wrote the manuscript. Both authors read and approved the final manuscript.

\subsection{Declaration}

The following data shown in this chapter have been provided:

- ICP-OES and calculations were conducted by members of the Department of Plant Ecology and Ecosystems Research (Albrecht-von-Haller-Institute for Plant Sciences, Georg-August University Göttingen).

- All laboratory steps for microarray analyses (from RNA quality determinations to raw data) were provided by the Microarray Facility (MFT Services, Tübingen, Germany). 


\section{Chapter 4}

\section{Phosphate acquisition by poplar: Phylogeny, tissue- specific expression, and activity of root secreted purple acid phosphatases}

\subsection{Introduction}

Plants take up phosphorus (P) only in the inorganic form, phosphate (Schachtman et al., 1998). But phosphate is present in soil solutions in only low concentrations of below 10 $\mu \mathrm{M}$ (Bieleski, 1973). Therefore, the inorganic phosphate pool has to be replenished constantly from other phosphorus pools. Up to $80 \%$ of the total soil P sources is bound in organic P compounds (Schachtman et al., 1998). Enzymes that cleave inorganic phosphate from organic $\mathrm{P}$ are phosphatases. The largest group of phosphatases, the purple acid phosphatases (PAPs) (Olczak et al., 2003) have a $\mathrm{pH}$ optimum in acidic conditions present in most soils. PAPs have a purple color in concentrated solutions due to a ferric ligand in the active center of the enzyme (Vincent and Averill, 1990).

Most PAPs have a broad substrate spectrum (Olczak et al., 2003). They acquire phosphate from organic $\mathrm{P}$ in the soil but also from internal $\mathrm{P}$ sources (Duff et al., 1994). Zhu et al. (2005) found that 16 of 29 Arabidopsis PAPs were expressed in roots, seven AtPAPs were solely expressed in flowers, highlighting the role of PAPs for other functions than phosphate acquisition from soil.

The acid phosphatase activities in the whole plant are enhanced under $\mathrm{P}$ deprivation as was shown for Arabidopsis (Del Pozo et al., 1999; Wang et al., 2014), poplar (Gan et al., 2016), and Carpinus pubescens and Eurycorymbus cavalerei (Zhang et al., 2015). AtPAP17 is one of the acid phosphatases with highest activity increment under low P (Del Pozo et al., 1999). It was shown that the expression of AtPAP17 is induced not only by $\mathrm{P}$ starvation but also by senescence, salt stress, abscisic acid and hydrogen peroxide suggesting a role in P mobilization in response to those stresses (Del Pozo et al., 1999). An enhanced acid phosphatase activity on roots under $\mathrm{P}$ limited conditions was shown for Arabidopsis (Wang et al., 2014) and tomato (Bozzo et al., 2006). Experiments with Arabidopsis mutants have shown that AtPAP12 and AtPAP26 are the 
main secreted phosphatases and responsible for most of the phosphatase activity in the medium under low $\mathrm{P}$ conditions, whereas AtPAP10 is the main root-associated phosphatase under low P conditions (Wang et al., 2014).

The transcript levels of most, but not all PAPs are induced by P starvation (e.g. in soybean (Li et al., 2012), maize (González-Muñoz et al., 2015), rice (Zhang et al., 2011) and Arabidopsis (Li et al., 2002; Lohrasebi et al., 2007)). In poplar (Populus. simonii and P. $\times$ euramericana), the expression of one PAP (Potri.010G158400) was studied and found to be increased upon $\mathrm{P}$ starvation in roots and leaves in congruence with enhanced acid phosphatase activity in these tissues (Gan et al., 2016). But it is not known, which phosphatases contribute to root derived soil phosphatase activity in low $\mathrm{P}$ conditions of poplar.

The main goals of this study were to investigate acid phosphatase activities of poplar (Populus $\times$ canescens) roots under low $\mathrm{P}$ conditions and to reveal which phosphatases, that might acquire $\mathrm{P}$ from organic $\mathrm{P}$ sources, are released into the growth medium under control and low $\mathrm{P}$ conditions. To achieve this, transcriptome and proteome analyses were combined with phosphatase activity assays. Additionally, changes in root morphology in response to low $\mathrm{P}$ availabilities as method for increased root surface and therefore PAP secretion area were assessed.

\subsection{Materials and Methods}

\subsubsection{Measurement of root-associated acid phosphatase activity in vivo}

Populus $\times$ canescens (INRA717 1-B4) was micropropagated and rooted on MS-medium as described in Müller et al. (2013). For -P plants, potassium dihydrogenphosphate was substituted by equimolar concentration of potassium chloride in the MS-medium. Phosphatase activities on the roots were measured by two methods essentially after Wang et al. (2011) with modifications: For measurements with 4-nitrophenyl phosphate disodium salt (pNPP; Sigma-Aldrich Chemie, Munich, Germany), the plants (height about $5 \mathrm{~cm}$ ) were transferred after three weeks to $1.5 \mathrm{~mL}$ Long Ashton nutrient solution with or without $\mathrm{P}_{\mathrm{i}}$ in an $2 \mathrm{~mL}$ tube and adapted to laboratory conditions under slight mixing (130 rpm, GFL 3018, Gesellschaft für Labortechnik, Burgwedel, Germany). 
Nutrient solution was refilled to $1.5 \mathrm{~mL}$ regularly. Air humidity was maintained by covering each plant with a $50 \mathrm{~mL}$ tube (Figure 4.1).

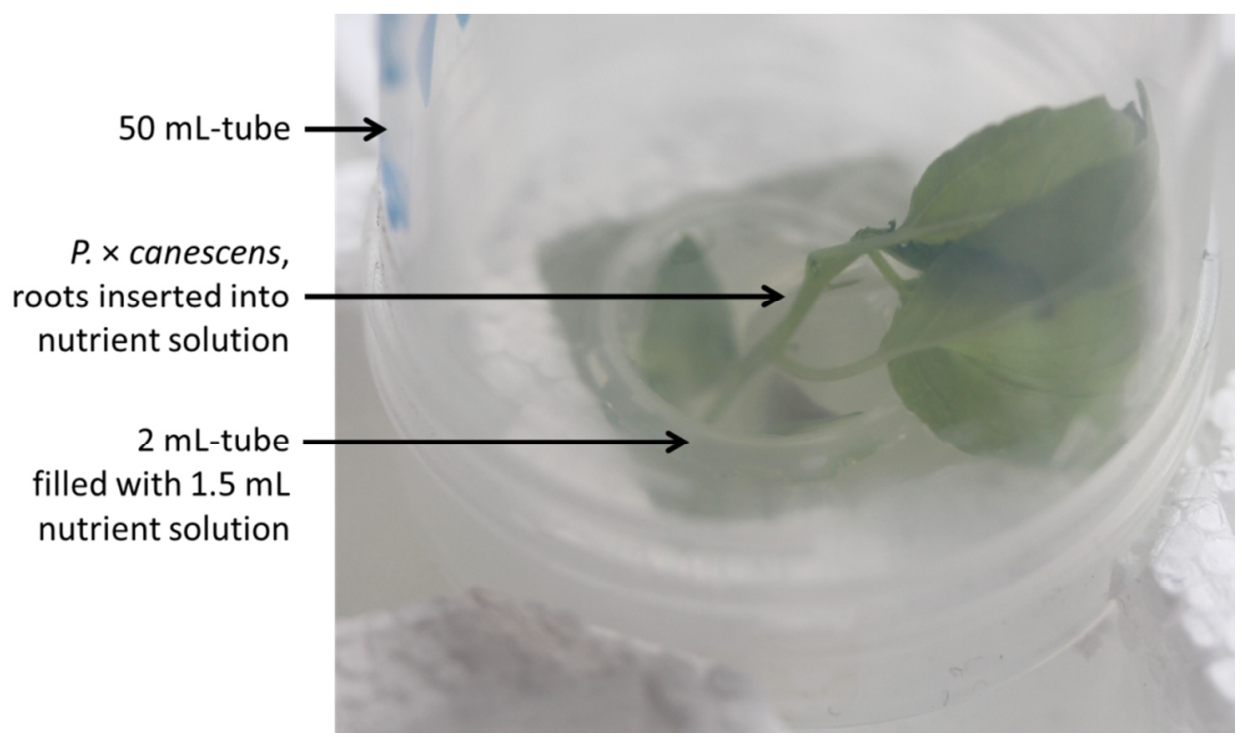

Figure 4.1. Experimental setup for measurement of root-associated acid phosphatase activity in vivo

After two days, the plants were transferred to fresh Long Ashton solution $(1.5 \mathrm{~mL}$, without $\mathrm{P}_{\mathrm{i}}$ for $-\mathrm{P}$ plants and with or without $\mathrm{P}_{\mathrm{i}}$ for $+\mathrm{P}$ plants to distinguish between activity capacity and possible inhibition by P) and $200 \mu \mathrm{L}$ pNPP $\left(1 \mathrm{mg} \mathrm{mL}^{-1}\right)$. After $1 \mathrm{~h}$ with slight shaking the plants were removed and $300 \mu \mathrm{L} 0.4 \mathrm{M} \mathrm{NaOH}$ were added to the solution. This solution $(500 \mu \mathrm{L})$ was measured in three technical replicates photometrically at $410 \mathrm{~nm}$. A calibration curve with 4-nitrophenol (FLUKA, SigmaAldrich Chemie, Munich, Germany) was prepared for calculation of phosphatase activity. 4-nitrophenol was diluted to different amounts $(0,0.00575,0.0115,0.023$, $0.046,0.092,0.184 \mathrm{nmol}$ ) per $1.7 \mathrm{~mL}$ sample with $+\mathrm{P}$ or $-\mathrm{P}$ nutrient solution (as for the plant roots) and treated in the same way. Calibration curves did not differ between $+P$ and -P solution.

For measurement of acid phosphatase activity with 5-bromo-4-chloro-3-indolyl phosphate disodium salt (BCIP; Carl Roth, Karlsruhe, Germany), the micropropagated and to laboratory conditions adapted plants in nutrient solution were transferred to fresh Long Ashton solution (1.5 mL) containing $4 \mathrm{mM}$ BCIP. After $1 \mathrm{~h}$ with slight shaking the plants were removed. From the solution, $0.6 \mathrm{~mL}$ were taken and $1 \mathrm{~mL} \mathrm{HCl}(1 \mathrm{M})$ was added (two technical replicates per sample). The samples were mixed, incubation 
for $25 \mathrm{~min}$ at room temperature and centrifuged for $5 \mathrm{~min}$ at $10000 \mathrm{~g}$. The supernatant was discarded. The pellet was diluted in $1 \mathrm{~mL}$ dimethyl sulfoxide. Two technical replicates of this solution $(500 \mu \mathrm{L})$ were measured photometrically at $635 \mathrm{~nm}$. Acid phosphatase activity was recorded in 4-nitrophenol produced [nmol] per hour per gram fresh mass of root or per $\mathrm{cm}^{2}$ of root surface (for measurement with pNPP) or as absorption at $635 \mathrm{~nm}\left(\mathrm{~A}_{635}\right.$, for measurement with $\left.\mathrm{BCIP}\right)$ per hour per gram fresh mass of root or per $\mathrm{cm}^{2}$ of root surface, measured as described below.

For staining of phosphatase activity on the roots, micropropagated and rooted $-\mathrm{P}$ and $+\mathrm{P}$ poplars were planted into MS-medium without phosphate by placing the roots into warm but still liquid medium (about $50^{\circ} \mathrm{C}$ ), containing $0.01 \%$ BCIP and $0.5 \%$ agar (Micro-Agar, Duchefa Biochemie, Haarlem, The Netherlands) in Petri dishes (12 cm x $12 \mathrm{~cm}$; Greiner Bio-One, Frickenhausen, Germany) and scanned after $4 \mathrm{~h}$ (HP Scanjet G4050, Hewlett-Packard, Böblingen, Germany).

\subsubsection{Purple acid phosphatases in apoplastic washing fluid (AWF)}

Poplar plants (micropropagated and grown for three weeks on MS-medium, $n=8$ ) were cultivated in Long Ashton nutrient solution with $641 \mu \mathrm{M}$ or with $0.064 \mu \mathrm{M}$ P (missing $\mathrm{K}$ added as $\mathrm{KCl}$ ) for 3 months (for medium see Kavka and Polle, 2016). AWF was collected after Floerl et al. (2008) with modifications: Roots were washed with tap water and infiltrated with cold $100 \mathrm{mM} \mathrm{KCl} \mathrm{(20} \mathrm{kPa} \mathrm{for} 15 \mathrm{~min})$. Roots were patted dry, rolled into plastic foil and placed vertically into centrifuge tubes $\left(4^{\circ} \mathrm{C}, 950 \mathrm{~g}, 8 \mathrm{~min}\right)$. AWF was collected and stored at $-80^{\circ} \mathrm{C}$ until further analyzes. Four biological samples were pooled to result in two biological replicates per treatment. Per replicate, two samples of up to $1 \mathrm{~mL}$ were lyophilized at $-80^{\circ} \mathrm{C}$. One of these samples was used for a proteomic approach and one for protein gel electrophoresis.

For the gel electrophoresis, the lyophilized sample was dissolved in $20 \mu \mathrm{L}$ solution containing $50 \mathrm{mM}$ sodium acetate $(\mathrm{pH} 4.9)$ and $10 \mathrm{mM} \mathrm{MgCl}_{2}$. Two $\mu \mathrm{L}$ were used for measuring the protein concentration in a micro Bradford assay (Coomassie plus reagent, Thermo Scientific, Waltham, MA, USA) following the instructions manual. The protein concentration was calculated against a bovine serum albumin standard curve $(12.5,25$, 50,100 and $200 \mu \mathrm{g} \mathrm{mL}^{-1}$ ). For the in-gel assay of acid phosphatase activity, the method of Wang et al. (2011) was used with modifications: The same amount of protein 
$(0.3 \mu \mathrm{g})$ for each sample was diluted in $13 \mu \mathrm{l}$ solution as above, mixed with $13 \mu \mathrm{l}$ sample buffer without SDS (0.06 M Tris-(hydroxymethyl)-aminomethanhydrochlorid $\mathrm{HCl}, 10 \%$ glycerol, $0.025 \%$ bromphenol blue (w:v)) and loaded on a Amersham $\mathrm{ECL}^{\mathrm{TM}}$ Gel $12 \%$ (GE Healthcare Life Sciences, Freiburg, Germany). The gel was run as indicated in the manual instructions for $1.25 \mathrm{~h}$, cooled on ice. The gel was washed in cold distilled water (6 times $10 \mathrm{~min}$ at about $50 \mathrm{rpm}$ ) and then in $50 \mathrm{mM}$ sodium acetate (pH 4.9), $10 \mathrm{mM} \mathrm{MgCl}_{2}$ (2 times $15 \mathrm{~min}$ at about $50 \mathrm{rpm}$ ). The gel was stained with 100 $\mathrm{mL} 50 \mathrm{mM}$ sodium acetate $(\mathrm{pH} 4.9), 10 \mathrm{mM} \mathrm{MgCl}_{2}$ solution containing $15 \mathrm{mg} 2-$ naphtyl phosphate sodium salt (Sigma-Aldrich Chemie, Munich, Germany) and $75 \mathrm{mg}$ Fast Black K salt (Serva, Heidelberg, Germany) at $37^{\circ} \mathrm{C}$ overnight with slight shaking (about $50 \mathrm{rpm}$ ) and scanned.

For the proteomic approach with Liquid-Chromatography Electrospray-Ionization Mass Spectrometer (LC-ESI-MS), the second aliquot of the lyophilized samples was dissolved in $80 \mu \mathrm{l} 20 \mathrm{mM}$ ammonium bicarbonate, $80 \mathrm{mM}$ D-1,4-dithiothreitol and centrifuged at $2000 \mathrm{rpm}$ for $3 \mathrm{~min}$. $75 \mu \mathrm{l}$ of 2,2,2-trifluoroethanol was added to $75 \mu \mathrm{l}$ sample, shaken for $15 \mathrm{~min}$ by using a Vortex mixer, sonicated for $5 \mathrm{~min}$ (RK $100 \mathrm{H}$, Bandelin electronic, Berlin, Germany), shaken again for 15 min and incubated for 30 $\min$ at $60^{\circ} \mathrm{C}$. After centrifugation $(10 \mathrm{~min}, 16000 \mathrm{~g}), 100 \mu \mathrm{l}$ supernatant was collected into a $1.5 \mathrm{ml}$ LoBind tube (Eppendorf, Hamburg, Germany). Proteins were alkylated by adding $5 \mu 1500 \mathrm{mM}$ iodoacetamide and incubated for $30 \mathrm{~min}$ in dark and thereafter diluted with $50 \mu 1$ water.

Proteins were purified according to Wessel and Flügge (1984) using chloroform/methanol precipitation. In short, methanol was added to the protein sample, mixed and centrifuged, and then chloroform was added, the sample mixed and centrifuged. Proteins precipitate in the interphase. The upper phase with methanol was removed and the sample again washed with methanol and centrifuged. The supernatant was removed and the protein pellet dried. Precipitates were suspended in $50 \mu 1$ Tris(hydroxymethyl)-aminomethanhydrochlorid (100 mM, pH 8.0) by sonication (RK 100 $\mathrm{H}$, Bandelin electronic, Berlin, Germany) for about $3 \mathrm{~min}$. Proteins in the samples were digested overnight at $37^{\circ} \mathrm{C}$ in a water bath after adding $5 \mu$ trypsin solution $(100 \mathrm{ng} / \mu 1$ in $10 \mathrm{mM} \mathrm{HCl}$ (MS grade, Promega)). The digestion was stopped by adding $20 \mu 1$ ammonium formate (20 mM, pH 10). Samples were mixed and centrifuged (20 min, 16000 g). $60 \mu \mathrm{l}$ of sample were immediately purified by using StageTips (Stop-and-go- 
extraction tips) (Rappsilber et al., 2007) prepared from three layers of Empore 3M-C18 filter (3M, USA) and conditioned with ammonium formate $(20 \mathrm{mM}, \mathrm{pH} 10)$. The peptides were eluted from the tips with $60 \%$ acetonitrile (Ultima LC-MS grade, Fisher Scientific) in ammonium formate $(20 \mathrm{mM})$. After drying for $10 \mathrm{~min}$ in a vacuum concentrator (Concentrator 5301, Eppendorf, Hamburg, Germany) peptides were stored at $-20^{\circ} \mathrm{C}$. Peptides were dissolved in $5 \mu 12 \%$ acetonitrile in water with $0.1 \%$ formic acid (all solvents in Ultima LC-MS quality) and analyzed by "trap \& elute" mode (Eksigent 420, Sciex, USA) using a $2.5 \mathrm{~cm} 100 \mu \mathrm{m}$ id pre-column packed with $5 \mu \mathrm{m}$ Reprosil-Pur C18-AQ (Dr. Maisch GmbH, Ammerbuch, Germany) and $30 \mathrm{~cm} 50 \mu \mathrm{m}$ id analytical column packed with $3 \mu \mathrm{m}$ Reprosil-Gold C18. Samples were separated in a gradient mode at $260 \mathrm{~nL} \mathrm{~min}^{-1}$ solvent flow with solvent A (100\% water with $0.1 \%$ formic acid in water (Optima Gold quality, Thermo Fisher Scientific, Braunschweig, Germany). Solvent B consisted of $0.1 \%$ formic acid in acetonitrile (Optima Gold quality, Thermo Fisher Scientific, Braunschweig, Germany) and served as the eluent in the following gradient: initially $5 \%, 100 \min$ to $35 \%, 20 \min$ to $50 \%$ and $2 \min$ to 95 $\%$. The mass spectrometry system consisted of Hybrid Quadrupole-TOF LC/MS/MS Mass Spectrometer TripleTOF 5600+ (Sciex, USA), nano-spray source Nanospray III (Sciex) and Analyst 1.7 software. MS spectra in the positive mode were detected in a range of 300 to $2000 \mathrm{Da}$ and 30 most intensive ions with charge $2+$ to $5+$ were fragmented in the MS/MS mode. Analyses of MS spectra and protein identification were performed by ProteinPilot 5.0 (Sciex, Darmstadt, Germany). The protein identification database consisted of Populus trichocarpa protein sequences (JGI; Tuskan et al., 2006) combined with a common contaminants dataset (Sciex, Darmstadt, Germany). Carbamidomethylation of cysteine and trypsin cleavage were set as fixed modifications. Searches were performed in "false discovery rate" mode with thorough settings including biological modifications and amino acid substitutions. Results were filtered for at least two peptides per protein and an unused score of at least four to exclude proteins from the results that were not sufficiently supported by peptide sequences. 


\subsubsection{Gene expression analysis}

The microarrays with the accession number E-MTAB-3934 (Kavka and Polle, 2016) from the EMBL-EBI ArrayExpress database (http://www.ebi.ac.uk/arrayexpress/) were used: In this experiment, poplar plants were grown in sand culture irrigated with Long Ashton nutrient solution containing three different phosphate concentrations (641 $\mu \mathrm{M}$ HP, $6.4 \mu \mathrm{M}$ - MP, $0.064 \mu \mathrm{M}$ - LP) with three biological replicates per treatment with uppermost leaves and fine roots as samples. For annotation of the Affy probe set IDs to gene model IDs, the best hit in the annotation file of the AspenDB (Tsai et al., 2011) was used. For each purple acid phosphatase, the mean expression value of the three replicates was calculated. When there were more than one probe set per gene, the mean value of all probe sets were calculated. The $\log _{2}$-expression values for each gene were z-transformed across all arrays. Heatmap of normalized expression values was created using "heatmap.2" function implemented in the R ( $R$ Development Core Team, 2012) package "gplots" (Warnes, 2012).

\subsubsection{Quantitative Real Time PCR}

To remove contaminating DNA, an aliquot of the RNA samples that were also used for microarray analyses $\left(200 \mathrm{ng} \mu \mathrm{L}^{-1}\right.$ in $\left.25 \mu \mathrm{l}\right)$ were treated with Ambion ${ }^{\circledR}$ Turbo DNAfree $^{\mathrm{TM}}$ kit (Life Technologies, Carlsbad, CA, USA) two times according to the manual instructions and transcribed to cDNA $(0.5 \mu \mathrm{g})$ with the RevertAid First Strand cDNA Synthesis Kit and First Strand cDNA Synthesis Kit (Thermo Fisher Scientific, Braunschweig, Germany) using oligo(dT)-primers. To validate the microarray, four genes were chosen (PtPAP1 (Potri.005G233400), PtPAP30 (Potri.012G042200), Potri.013G005700, Potri.007G089000) with different expression patterns over all samples on the microarrays. Primers used for quantitative Real Time PCR (qRT PCR) were described in Janz et al. (2012; Potri.013G005700, Potri.007G089000, Potri.001G309500) or designed using OligoExplorer 1.5 and checked with OligoAnalyzer 1.5 (both Gene Link, Hawthorne, NY, USA, Table 4.1 for detailed information). At least one primer for each gene was designed to cross an exon-exon junction. For each gene and sample (three biological replicates per treatment, fine roots and leaves), at least two technical replicates were analyzed by qRT PCR with 
LightCycler 480® (Roche Diagnostics, Mannheim, Germany). The reaction volume of $20 \mu \mathrm{l}$ consisted of $10 \mu \mathrm{l}$ SYBR Green I Master kit (Roche Diagnostics, Mannheim, Germany), $2 \mu 1$ of forward and reverse primer $(10 \mu \mathrm{M}), 1 \mu 1$ nucleic free water and $5 \mu 1$ cDNA-solution (1:10 dilution). After pre-incubation $\left(95^{\circ} \mathrm{C}, 5 \mathrm{~min}\right), 45$ or 55 cycles of amplification followed: $95^{\circ} \mathrm{C}$ for $10 \mathrm{~s}, 57^{\circ} \mathrm{C}$ for $10 \mathrm{~s}$ and $72^{\circ} \mathrm{C}$ for $20 \mathrm{~s}$. Melting curve $\left(95^{\circ} \mathrm{C} 5 \mathrm{~s}, 65^{\circ} \mathrm{C} 1 \mathrm{~min}\right.$ to $97^{\circ} \mathrm{C}$ with $\left.0.11^{\circ} \mathrm{C} / \mathrm{s}\right)$ analyses implemented in the LightCycler $480 \AA$ software were used to assess primer specificity.

To calculate efficiency, raw data were converted using LC480 conversion (version 2014.1; www.hartfaalcentrum.nl/index.php?main=files\&sub=LC480Conversion) and loaded into LinRegPCR (version 2016.0; Ruijter et al., 2009). The mean efficiency for each primer pair was calculated over all samples after baseline subtraction and given in Table 1. Quantification cycle-values were calculated using the fluorescence threshold of 3.597 (lowest threshold of all genes). Relative expressions for each sample were calculated against two reference genes using the formula

Relative Expression $=\frac{\sqrt{\mathrm{E}_{\left(\mathrm{Ref}_{1}\right)}^{\mathrm{Cq}} \times \mathrm{E}_{\left(\mathrm{Ref}_{2}\right)}^{\mathrm{Cq}}}}{\mathrm{E}_{(\mathrm{GOI})}^{\mathrm{Cq}}}$

E: efficiency of primer for gene

Cq: quantification cycle value

(GOI): efficiency and $\mathrm{Cq}$ for gene of interest

$\left(\right.$ Ref $_{\mathrm{i}}$ ): efficiency and $\mathrm{Cq}$ for reference gene $\mathrm{i}$ (Hellemans et al., 2007). 
Table 4.1: Primers used for qRT PCR.

\begin{tabular}{|c|c|c|c|c|}
\hline Potri.ID & Affy IDs & Primer name & Primer sequence $\left(5^{\prime}-3^{\prime}\right)$ & $\begin{array}{l}\text { Primer } \\
\text { efficiency }\end{array}$ \\
\hline Potri.005G233400 & PtpAffx.33535.1.A1_at & Pc005_fw & GTTGCATACAACATCGTGAACG & 1.870 \\
\hline (PtPAP1) & PtpAffx.33535.3.S1_at & Pc005 rev & CTGTCATGCTGGTCACTAATC & \\
\hline Potri.012G042200 & Ptp.6082.1.S1_at & Pc012_fw & AGCACAAGTTAAGCCTTCACC & 1.924 \\
\hline (PtPAP30) & & Pc012_rev & TTCAGCCAATTCAGCATCGAC & \\
\hline Potri.013G005700 & Ptp.3948.1.S1_at & Pc013G005700_fw & CCACAAAGAATCATTTTCTCTG & 1.836 \\
\hline (Xyloglucan Endotransglucosylase) & $\begin{array}{l}\text { PtpAffx.102427.1.A1_at } \\
\text { PtpAffx.102427.1.A1_s_at }\end{array}$ & Pc013G005700_rev & AAACTAGAGTAAATTCTCATTGG & \\
\hline $\begin{array}{l}\text { Potri.007G089000 } \\
\text { (Myo-Inositol-1-Phosphate Synthase) }\end{array}$ & $\begin{array}{l}\text { PtpAffx.249.474.S1_at } \\
\text { PtpAffx.249.570.S1_a_at } \\
\text { PtpAffx.249.570.S1_at } \\
\text { PtpAffx.36446.1.A1_at }\end{array}$ & $\begin{array}{l}\text { Pc007G089000_fw } \\
\text { Pc007G089000_rev }\end{array}$ & $\begin{array}{l}\text { CCCATGGTGAACCCAGATG } \\
\text { TCAGGGTCGTAAATTCCAGG }\end{array}$ & 1.874 \\
\hline $\begin{array}{l}\text { Potri.001G047200 } \\
\text { (PPR-repeat as reference gene) }\end{array}$ & PtpAffx.200189.1.S1_at & $\begin{array}{l}\text { Pc001G047200_fw } \\
\text { Pc001G047200_rev }\end{array}$ & $\begin{array}{l}\text { GGCTGAGGAATGTCGAATGG } \\
\text { AGAACGCAACATCATGGAAACC }\end{array}$ & 1.908 \\
\hline $\begin{array}{l}\text { Potri.001G309500 } \\
\text { (Actin as reference gene) }\end{array}$ & $\begin{array}{l}\text { Ptp.6486.1.S1_s_at } \\
\text { PtpAffx.1258.1.S1_s_at } \\
\text { PtpAffx.1258.4.S1_s_at }\end{array}$ & $\begin{array}{l}\text { Aktin9_fw } \\
\text { Aktin9_rev }\end{array}$ & $\begin{array}{l}\text { TGGTGGTTCCACTATGTTCC } \\
\text { TGGAAATCCACATCTGCTGG }\end{array}$ & 1.876 \\
\hline
\end{tabular}

Corresponding Potri.IDs and Affy IDs for probe sets on microarray and primer efficiency calculated by LinRegPCR are given; primers for Potri.013G005700, Potri.007G089000 and Potri.001G309500 were obtained from Janz et al. (2012). 


\subsubsection{Assessment of root morphological parameters}

For measuring the root surface and root length in different width classes, roots were scanned (HP Scanjet G4050, Hewlett-Packard, Böblingen, Germany) before drying and analyzed with WinRhizo (version 2012b, Regent Instruments Inc., Ottawa, Canada). To get optimal scans, following parameters for a transmitted-light-scan were set: scanning resolution of $300 \mathrm{dpi}$, greyscale, middle tone: -30 , bright image areas: -100 , shadows: 100, gamma: 1.0 .

Roots from acid phosphatase activity measurements were scanned directly after the experiment.

HP, MP and LP fine roots were taken from another plant set and washed before scanning. In the case of HP roots only an aliquot was scanned.

Photos of root hairs were taken in water with a digital camera (DFC420 C, Leica Microsystems Ltd., Germany) attached to a stereomicroscope (M205 FA, Leica Microsystems Ltd., Wetzlar, Germany).

\subsubsection{Phylogeny of PAPs in poplar compared with Arabidopsis, rice and maize}

All protein sequences and gene IDs were obtained from Phytozome v9.1 (www.phytozome.net, Goodstein et al., 2012). For domain comparisons the Pfam database (pfam.xfam.org) was used. All annotated (Wang et al., 2014) Arabidopsis PAP protein

sequences (http://phytozome.jgi.doe.gov/pz/portal.html\#!info?alias=Org_Athaliana) were used for a BlastP search (e-value cutoff at $\mathrm{e}^{-20}$ ) against the Populus trichocarpa, Oryza sativa (http://phytozome.jgi.doe.gov/pz/portal.html\#!info?alias=Org_Osativa) and Zea mays proteomes (http://phytozome.jgi.doe.gov/pz/portal.html\#!info?alias=Org_Zmays), but only proteins with a Metallophos or Metallophos $\mathrm{C}$ domain were kept, as these were present in every Arabidopsis PAP. The alignment was performed using the online tool ClustalW2 (www.ebi.ac.uk/Tools/msa/clustalw2/) with default settings. The PHYLIP package (Felsenstein, 1993) was used to calculate a consensus (extended majority rule) neighbor joining phylogenetic tree using 500 replicates for bootstrapping and Jones- 
Taylor-Thornton model for computing distance matrices. MEGA6 (Tamura et al., 2013) was used to display and edit the phylogenetic trees. Phylogenetic subgroups were named after Li et al. (2002). Poplar PAPs were named according to their position in the phylogenetic tree, rice PAP names are according to Zhang et al. (2011), maize PAP names according to González-Muñoz et al. (2015) and Arabidopsis PAP names according to Li et al. (2002). The $1 \mathrm{~kb}$ upstream region of each poplar gene coding for a putative PAP was obtained from Phytozome using the BioMart tool (http://phytozome.jgi.doe.gov/biomart/martview/16e565cddceb03f127d3e5b55e576a6f) and used for a motif search with PLACE (Higo et al., 1999). Protein sequences were used for prediction of the subcellular locations of the proteins with TargetP v. 1.1 (http://www.cbs.dtu.dk/services/TargetP/; Emanuelsson et al., 2000).

\subsubsection{Statistical analyses}

R (versions 2.14.2 and 3.0.2, $R$ Development Core Team, 2012, www.r-project.org) was used for statistical analyses. One-Way-ANOVA and Tukey's HSD were performed on original or transformed data. Residuals were checked visually for normal distribution and homogeneity of variance and transformed logarithmically $\left(\log _{2}\right)$ or by square root if needed. Means were considered to differ significantly between treatments, if $\mathrm{P} \leq 0.05$. The P-value was Bonferroni adjusted for ANOVAs on gene expression data. Figures show mean value \pm standard error.

\subsection{Results}

\subsubsection{Phylogeny of PAPs}

The PAPs proteins of poplar clustered into the three main clades (I, II and III) known from Arabidopsis (Figure 4.2A) with three subclades in cluster I (Ia with Ia-1 to Ia-3 and five unclustered maize and rice PAPs, Ib-1 and Ib-2), three subclades in cluster II (IIa to IIc) and two subclades (IIIa and IIIb) in cluster III (Figure 4.2B). We found 33 poplar PAPs, compared with the 29 PAPs known from Arabidopsis. Our search revealed 30 rice PAPs: the 26 PAPs found by Zhang et al. (2011) and four additional 
ones (Figure 4.2). Of the 33 maize PAPs found by González-Muñoz et al. (2015) not all were retrieved because ZmPAP7c and ZmPAP28b were not found by our approach. As expected, the nearest homologs of poplar PAPs were Arabidopsis PAPs (Figure 4.2B). In the PAP clusters Ib-1, Ib-2 and IIIa, there was a direct orthologous group of poplar and Arabidopsis proteins for each group of rice and maize proteins (Figure 4.2B). In all other clusters, there was mostly one branch each with monocot and dicot proteins (Figure 4.2B). Cluster Ia-1 consisted of only Arabidopsis proteins, in cluster IIc no Arabidopsis proteins but two poplar proteins were present. Four poplar proteins were orthologous to the two Arabidopsis proteins AtPAP10 and AtPAP12, one rice protein (OsPAP10a) and one maize protein (ZmPAP10); three poplar proteins were orthologous to AtPAP26, OsPAP26 and ZmPAP26. Additionally multiplicated poplar genes were found for AtPAP1, AtPAP17, and AtPAP14 compared with Arabidopsis, rice and maize.

Among the 33 poplar PAPs 28 were targeted to the secretion pathway; one member of cluster Ia-2 (Potri.004G160100) to mitochondria and four had no distinct target sequence (Table 4.2).

P1BS elements, which are known to play a role in the up-regulation of gene expression in response to phosphate starvation (Bustos et al., 2010), were present in the $1 \mathrm{~kb}$ upstream sequence of ten poplar PAP genes from clusters I and III. 


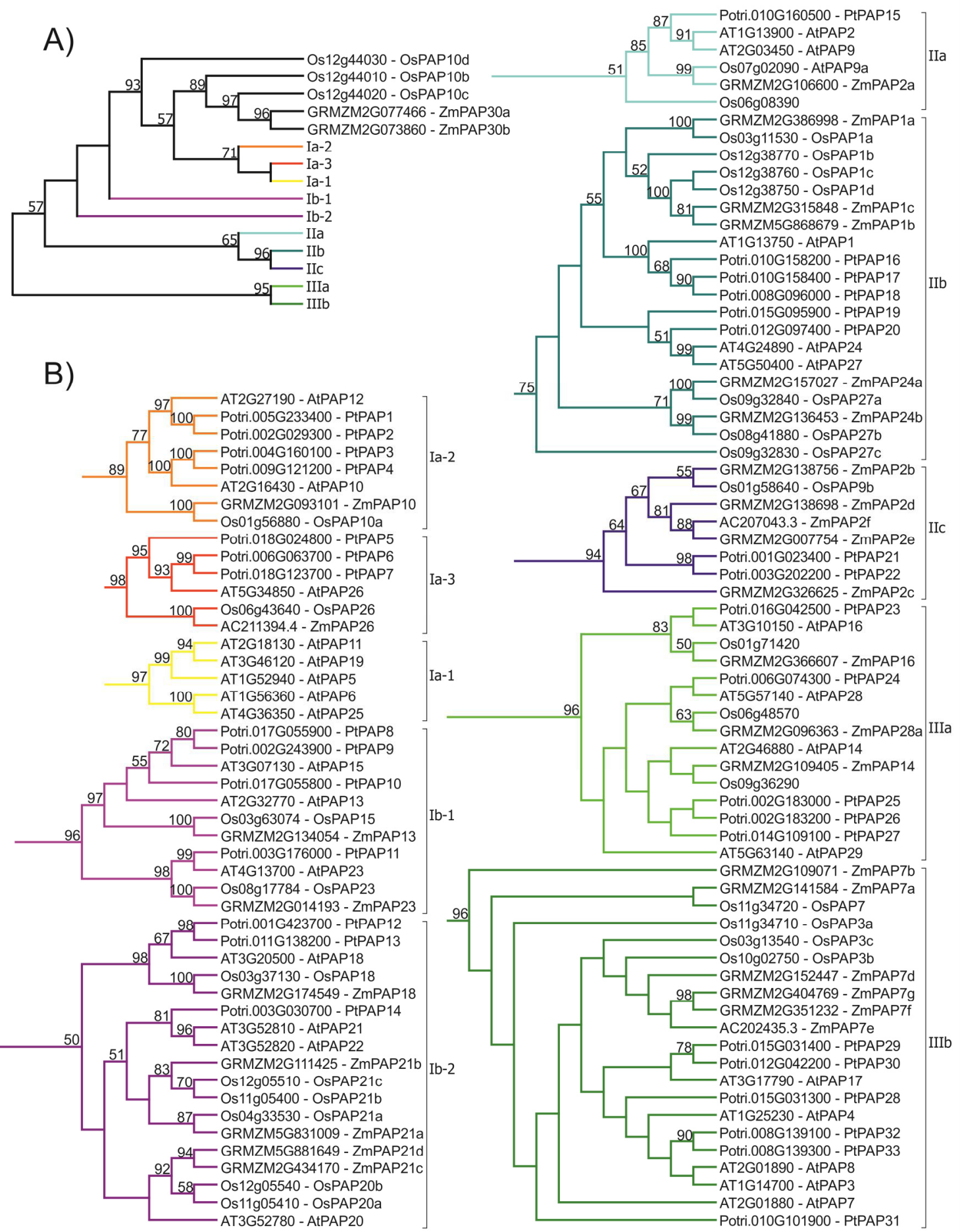

Figure 4.2. Neighbor-Joining tree (Jones-Taylor-Thornton model, 500 bootstraps) of the amino acid sequences for purple acid phosphatases in poplar. Poplar (Potri), Arabidopsis (AT), rice (Os) and maize (GRMZM and AC); A: unrooted compressed phylogenetic tree; B: expanded view of the clusters, names of clusters modified after Li et al. (2002), names for OsPAPs from Zhang et al. (2011), names for ZmPAPs from González-Muñoz et al. (2015). Only bootstrap values $\geq 50$ are displayed. 
Table 4.2: Summary of in silico analyses for poplar purple acid phosphatases.

\begin{tabular}{|c|c|c|c|c|c|c|}
\hline 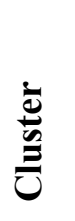 & GeneID & $\begin{array}{l}\text { Gene } \\
\text { name }\end{array}$ & 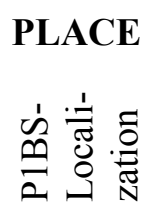 & 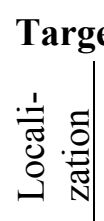 & $\underset{\simeq}{U}$ & Affy IDs \\
\hline Ia-2 & $\begin{array}{l}\text { Potri.002G029300 } \\
\text { Potri.004G160100 } \\
\text { Potri.005G233400 } \\
\text { Potri.009G121200 }\end{array}$ & $\begin{array}{l}\text { PtPAP2 } \\
\text { PtPAP3 } \\
\text { PtPAP1 } \\
\text { PtPAP4 }\end{array}$ & 603 & $\begin{array}{l}M \\
S\end{array}$ & $\begin{array}{l}4 \\
5 \\
1\end{array}$ & $\begin{array}{l}\text { PtpAffx.33535.2.A1_at } \\
\text { PtpAffx.662.1.A1_at } \\
\text { PtpAffx.33535.3.S1_at } \\
\text { PtpAffx.33535.1.A1_at } \\
\text { PtpAffx.662.3.A1_at (n.d.) }\end{array}$ \\
\hline Ia-3 & $\begin{array}{l}\text { Potri.006G063700 } \\
\text { Potri.018G024800 } \\
\text { Potri.018G123700 }\end{array}$ & $\begin{array}{l}\text { PtPAP6 } \\
\text { PtPAP5 } \\
\text { PtPAP7 }\end{array}$ & $\begin{array}{l}927 \\
635\end{array}$ & $\mathrm{~S}$ & 1 & $\begin{array}{l}\text { PtpAffx.38937.2.A1_at (n.d.) } \\
\text { PtpAffx.45845.1.S1_at } \\
\text { PtpAffx.125017.1.S1_at (n.d.) } \\
\text { PtpAffx.125017.1.S1_s_at (n.d.) } \\
\text { Ptp.1772.1.A1_at } \\
\text { PtpAffx.214211.1.S1_at } \\
\text { NA }\end{array}$ \\
\hline $\mathrm{Ib}-1$ & $\begin{array}{l}\text { Potri.002G243900 } \\
\text { Potri.003G176000 } \\
\text { Potri.017G055800 } \\
\text { Potri.017G055900 }\end{array}$ & $\begin{array}{l}\text { PtPAP9 } \\
\text { PtPAP11 } \\
\text { PtPAP10 } \\
\text { PtPAP8 }\end{array}$ & 449 & $\bar{S}$ & $\begin{array}{l}3 \\
1\end{array}$ & $\begin{array}{l}\text { Ptp.5137.1.S1_at } \\
\text { PtpAffx.66415.1.A1_s_at } \\
\text { PtpAffx.203446.1.S1_at } \\
\text { PtpAffx.94885.1.S1_s_at (n.d.) } \\
\text { PtpAffx.213843.1.S1_at (n.d.) } \\
\text { PtpAffx.121479.1.A1_at } \\
\text { PtpAffx.213844.1.S1_at (n.d.) }\end{array}$ \\
\hline $\mathrm{Ib}-2$ & $\begin{array}{l}\text { Potri.001G423700 } \\
\text { Potri.003G030700 } \\
\text { Potri.011G138200 }\end{array}$ & $\begin{array}{l}\text { PtPAP12 } \\
\text { PtPAP14 } \\
\text { PtPAP13 }\end{array}$ & 544 & $\mathrm{~S}$ & 1 & $\begin{array}{l}\text { PtpAffx.145701.1.S1_s_at } \\
\text { PtpAffx.211221.1.S1_at } \\
\text { PtpAffx.160811.1.S1_s_at } \\
\text { PtpAffx.221489.1.S1_at } \\
\text { PtpAffx.221491.1.S1_at } \\
\text { PtpAffx.160811.2.S1_at } \\
\text { PtpAffx.145392.1.A1_at }\end{array}$ \\
\hline IIa & Potri.010G160500 & PtPAP15 & & $\mathrm{S}$ & 1 & PtpAffx.77953.1.S1_at \\
\hline $\mathrm{IIb}$ & $\begin{array}{l}\text { Potri.010G158200 } \\
\text { Potri.010G158400 } \\
\text { Potri.012G097400 }\end{array}$ & $\begin{array}{l}\text { PtPAP18 } \\
\text { PtPAP16 } \\
\text { PtPAP17 } \\
\text { PtPAP20 }\end{array}$ & & $\begin{array}{l}S \\
S\end{array}$ & $\begin{array}{l}1 \\
2\end{array}$ & $\begin{array}{l}\text { PtpAffx.124035.1.S1_s_at } \\
\text { PtpAffx.207897.1.S1_at (n.d.) } \\
\text { PtpAffx.101405.1.A1_at (n.d.) } \\
\text { PtpAffx.35988.1.A1_at } \\
\text { PtpAffx.35988.4.A1_aat } \\
\text { PtpAffx.140167.1.A1_at } \\
\text { PtpAffx.143041.1.S1_s_at } \\
\text { PtpAffx.138433.1.S1_s_at (n.d.) } \\
\text { Ptp.2985.1.S1_at } \\
\text { PtpAffx.210647.1.S1_s_at } \\
\text { PtpAffx.212872.1.S1_s_at }\end{array}$ \\
\hline
\end{tabular}


Table 4.2 (continued)

\begin{tabular}{|c|c|c|c|c|c|c|}
\hline 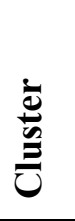 & GeneID & $\begin{array}{l}\text { Gene } \\
\text { name }\end{array}$ & 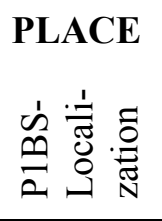 & 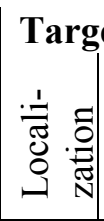 & $\underset{\simeq}{U}$ & Affy IDs \\
\hline IIc & $\begin{array}{l}\text { Potri.001G023400 } \\
\text { Potri.003G202200 }\end{array}$ & $\begin{array}{l}\text { PtPAP21 } \\
\text { PtPAP22 }\end{array}$ & & S & 1 & $\begin{array}{l}\text { PtpAffx.200148.1.S1_at (n.d.) } \\
\text { PtpAffx.34917.2.S1_a_at } \\
\text { PtpAffx.34917.1.S1_at } \\
\text { PtpAffx.203537.1.S1_at (n.d.) }\end{array}$ \\
\hline IIIa & $\begin{array}{l}\text { Potri.002G183000 } \\
\text { Potri.002G183200 } \\
\text { Potri.006G074300 } \\
\text { Potri.014G109100 } \\
\text { Potri.016G042500 }\end{array}$ & $\begin{array}{l}\text { PtPAP25 } \\
\text { PtPAP26 } \\
\text { PtPAP24 } \\
\text { PtPAP27 } \\
\text { PtPAP23 }\end{array}$ & 676 & $\begin{array}{l}\mathrm{S} \\
\mathrm{S} \\
\mathrm{S} \\
\mathrm{S} \\
\mathrm{S}\end{array}$ & $\begin{array}{l}3 \\
3 \\
1 \\
2 \\
1\end{array}$ & $\begin{array}{l}\text { PtpAffx.3736.1.S1_at } \\
\text { NA } \\
\text { NA } \\
\text { NA } \\
\text { PtpAffx.213280.1.S1_at }\end{array}$ \\
\hline IIIb & $\begin{array}{l}\text { Potri.008G139100 } \\
\text { Potri.008G139300 } \\
\text { Potri.010G101900 } \\
\text { Potri.012G042200 } \\
\\
\text { Potri.015G031300 } \\
\text { Potri.015G031400 }\end{array}$ & $\begin{array}{l}\text { PtPAP32 } \\
\text { PtPAP33 } \\
\text { PtPAP31 } \\
\text { PtPAP30 } \\
\text { PtPAP28 } \\
\text { PtPAP29 }\end{array}$ & $\begin{array}{l}477,523, \\
531\end{array}$ & $\begin{array}{l}S \\
S \\
S \\
S\end{array}$ & $\begin{array}{l}1 \\
1 \\
5 \\
2\end{array}$ & $\begin{array}{l}\text { PtpAffx.95224.1.A1_at } \\
\text { NA } \\
\text { PtpAffx.208843.1.S1_at (n.d.) } \\
\text { Ptp.6082.1.S1_at } \\
\text { NA } \\
\text { PtpAffx.7937.1.A1_at }\end{array}$ \\
\hline
\end{tabular}

GeneID: Poplar gene IDs in genome v3; PLACE P1BS-Localization: location of P1BSmotif(s) in $1 \mathrm{~kb}$ upstream region of the gene; TargetP Localization: predicted localization of protein $(\mathrm{M}$ : mitochondria, S: secreted, : none of above and not chloroplast and cytoplasm, RC: Reliability Class (best 1 to 5); Affy IDs: probe names on annotated for the gene by Tsai et al. (2011), n.d.: expression not detected, NA: gene is not on array

\subsubsection{Expression of poplar PAPs is enhanced under phosphate deprivation in roots and leaves}

Six of the poplar PAPs present in the phylogenetic tree were not present as probe sets on the Affymetrix microarray (PtPAP7, PtPAP24, PtPAP26-28, PtPAP33). Four PAPs (PtPAP4, PtPAP8, PtPAP22, PtPAP31) could neither be detected under control conditions nor under phosphate deprivation regardless the tissue analyzed (Table 4.2). The genes had no truncated sequence compared with sequences of expressed genes. Therefore, they may be expressed in tissues or conditions not analyzed here.

The microarray data were validated by qRT PCR for two PAPs (PtPAP1, PtPAP30) with strong increase under $\mathrm{P}$ limitation and two genes with opposing expression patterns (Potri.013G005700 (xyloglucan endotransglucosylase), Potri.007G089000 (myo- 
inositol-1-phosphate synthase)). qRT PCR and transcript abundance data of the microarray showed a strong correlation (Figure 4.3).
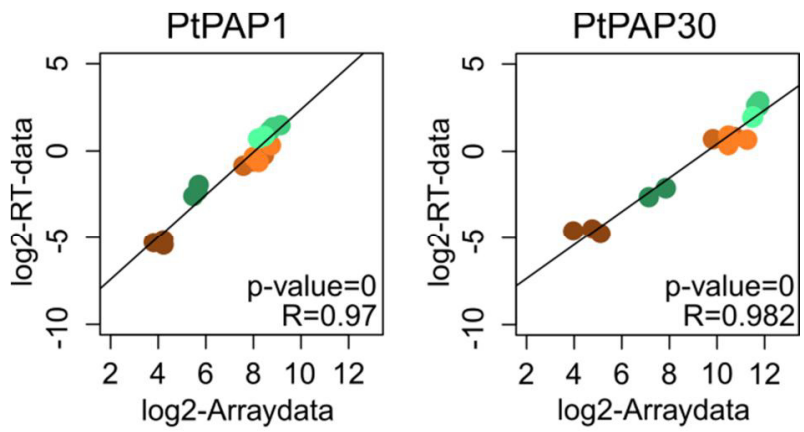

Xyloclucan

Myo-Inositol-1-
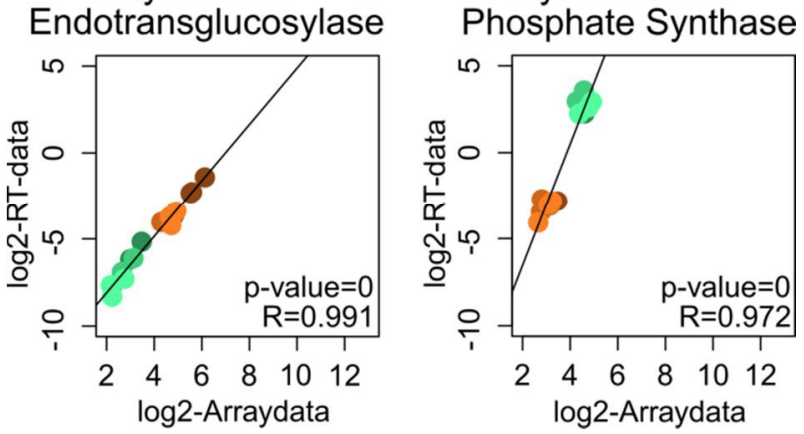

Figure 4.3. Verification of array data by qRT PCR. Red: root samples, green: leaf samples, dark: HP, middle: MP, light: LP; $\log 2$-value for expression with p-value and $\mathrm{R}$-value of correlation ( $\mathrm{R}$ function cor.test)

Based on their z-transformed expression values under control (HP) and low P (MP, LP) the PAPs of poplar could be divided into three groups (Figure 4.4). The first group consisted of PAPs that are upregulated under P deprivation in both roots and leaves. Among them, PtPAP17, PtPAP18 and PtPAP32 exhibited a higher expression in roots than in leaves, PtPAP1, PtPAP16, PtPAP21, PtPAP29 and PtPAP30 a higher expression in leaves than in roots, while the expression of PtPAP9 and PtPAP14 did not differ between roots and leaves (Figure 4.4).

The second group contained four genes with highest expression under HP conditions that were unresponsive to or showed lower transcript abundance in low $\mathrm{P}$ conditions (Figure 4.4). These genes were all from cluster I: PtPAP3, PtPAP5, PtPAP6 and PtPAP12.

The third group was formed by genes with higher expressions in leaves than in roots only under low $\mathrm{P}$ conditions (PtPAP11, PtPAP15 and PtPAP23), and genes with generally higher transcript levels in leaves (PtPAP2, PtPAP19, PtPAP25). PtPAP10 had 
the highest transcript level in HP leaves and PtPAP13 and PtPAP20 exhibited no significant differences in expression (Figure 4.4).

The presence of a P1BS-element in the $1 \mathrm{~kb}$ promoter sequence had no clear influence on the expression under $\mathrm{P}$ deprivation, because half of the eight genes containing a P1BS-element in the promoter on the array that were analyzed here did not show any up-regulation in low $\mathrm{P}_{\mathrm{i}}($ PtPAP2, PtPAP5, PtPAP6, PtPAP12). The other four genes were upregulated in roots and leaves (PtPAP14, and PtPAP30 with three P1BS elements) or only in leaves (PtPAP11, PtPAP23) under low $\mathrm{P}_{\mathrm{i}}$ availability.

Based on the expression values of the PAP family the tissues were clustered into one group with HP tissues and one group containing the clusters MP and LP roots and MP and LP leaves (Figure 4.4). Only PtPAP5 had different expression between MP and LP with lower expression in LP leaves compared to MP and also HP leaves.

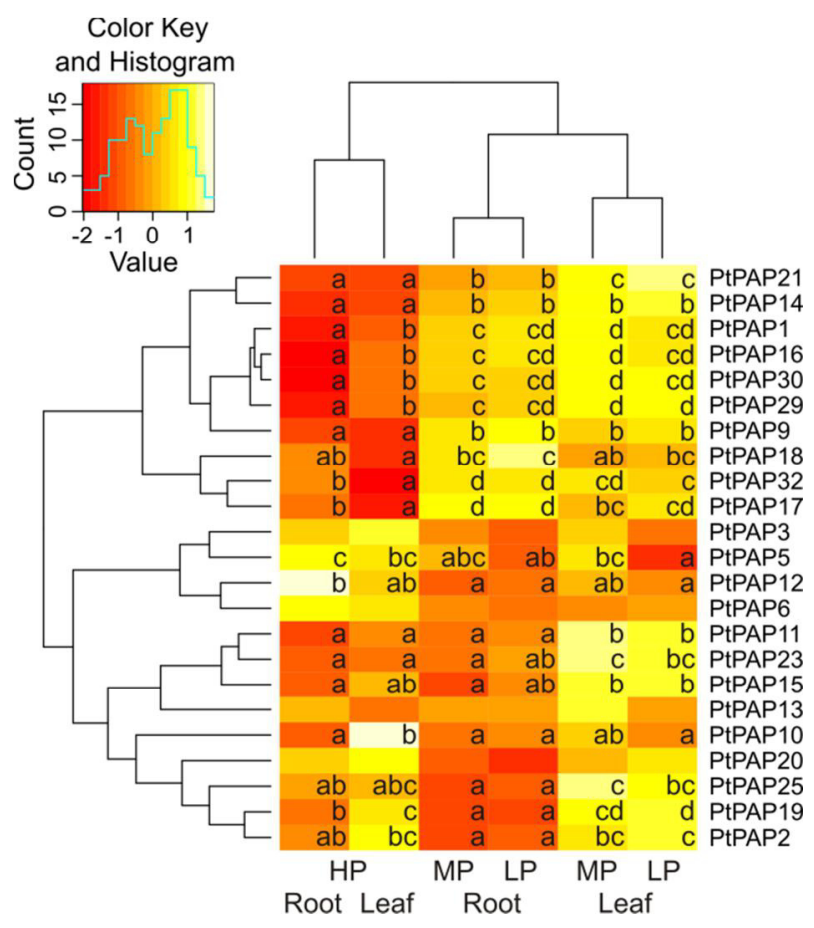

Figure 4.4. Expression of purple acid phosphatases in $\mathbf{P}$ deficient poplars. Heatmap of the relative expression of putative purple acid phosphatases in the three uppermost leaves and fine roots of poplar plants grown with different $\mathrm{P}$ concentrations in the nutrient solution (HP: $641 \mu \mathrm{M}$, MP: $6.4 \mu \mathrm{M}$, LP: $0.064 \mu \mathrm{M}$ ). Red colors indicate lower and yellow to white color higher values after $z$-transformation of the transcript abundances of each gene across all analyzed tissues and $\mathrm{P}$ conditions. Different letters indicate significant differences in expression of each gene (adj. $\mathrm{P} \leq 0.05$, ANOVA and Tukey's honest significance test, $n=3$, mean of normalized expression for each gene is color coded). 


\subsubsection{Roots of $P$ deprived poplar have altered root morphology and higher acid phosphatase activity}

Changes in root morphology of three-week-old micropropagated poplars in vitro grown in agar medium were visible upon $\mathrm{P}$ deprivation (Figure 4.5A). Plants grown with 625 $\mu \mathrm{M} \mathrm{P}$ had a rounded root tip with a distinct root cap (Figure 4.5B), whereas plants grown without $\mathrm{P}$ developed long peaked root tips (Figure 4.5C). Root hairs were longer and in greater number in $-\mathrm{P}$ plants (Figure 4.5C). Mean root diameter was higher in $-\mathrm{P}$ plants than in $+\mathrm{P}$ plants (Figure 4.6A). This change was also detected in fine root morphology after growth in sand culture. Only in HP plants very fine roots with less than $2 \mathrm{~mm}$ diameter were present in high numbers (Figure 4.6B). The roots of MP and LP plants had longer and more root hairs than roots of HP plants (Figure 4.7).

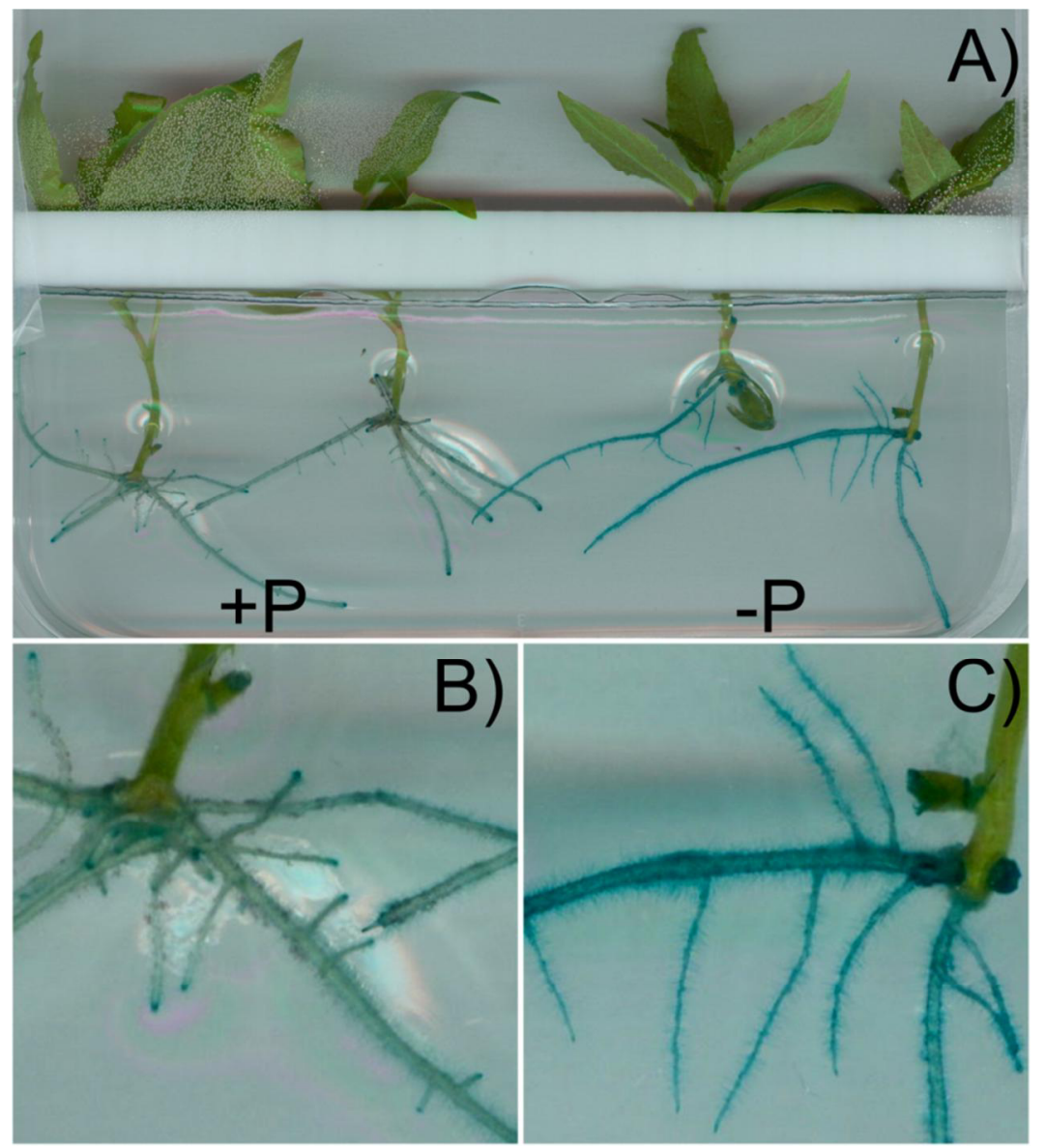

Figure 4.5. Poplar roots grown with or without Pi stained for acid phosphatase activity. $0.01 \%$ BCIP in medium, staining for $4 \mathrm{~h}$. Blue color indicates phosphatase activity, A) side length of picture: $12 \mathrm{~cm}$, zoom on roots of $+P(B),-P(C)$ plants, zoomed picture side length: $1.5 \mathrm{~cm}$ 

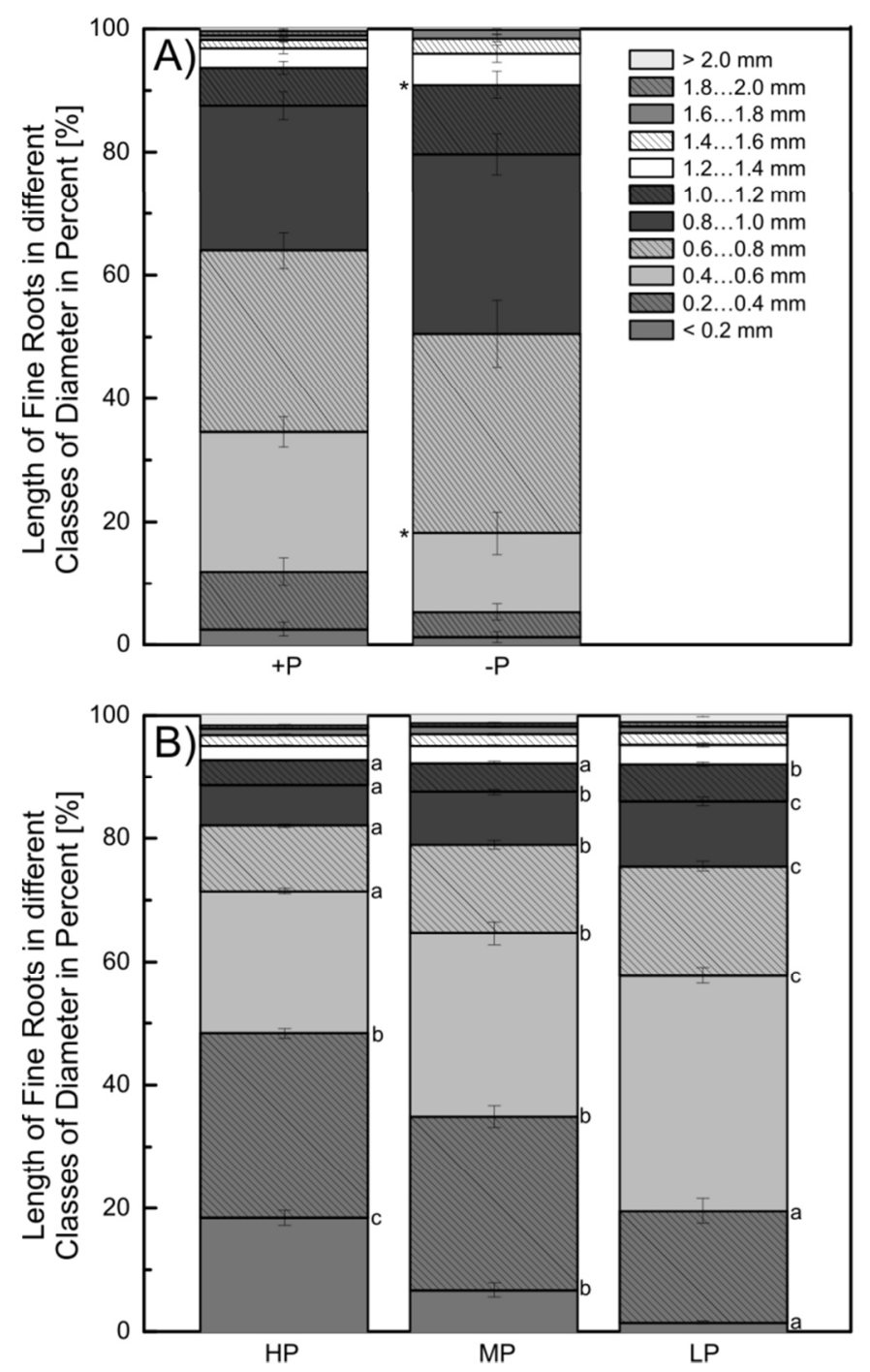

Figure 4.6. Length of roots in different root diameter classes in percent of total root length. A) micopropagated plants from measurement of acid phosphatase activity in vivo $(\mathrm{n}=24$ for $+\mathrm{P}, \mathrm{n}=12$ for $-\mathrm{P})$, and $\mathrm{B}) \mathrm{HP}$, MP and LP plants $(\mathrm{n}=8)$. Stars and different letters indicate significant differences at $\mathrm{P} \leq 0.05$, ANOVA and Tukey's honest significance test. 

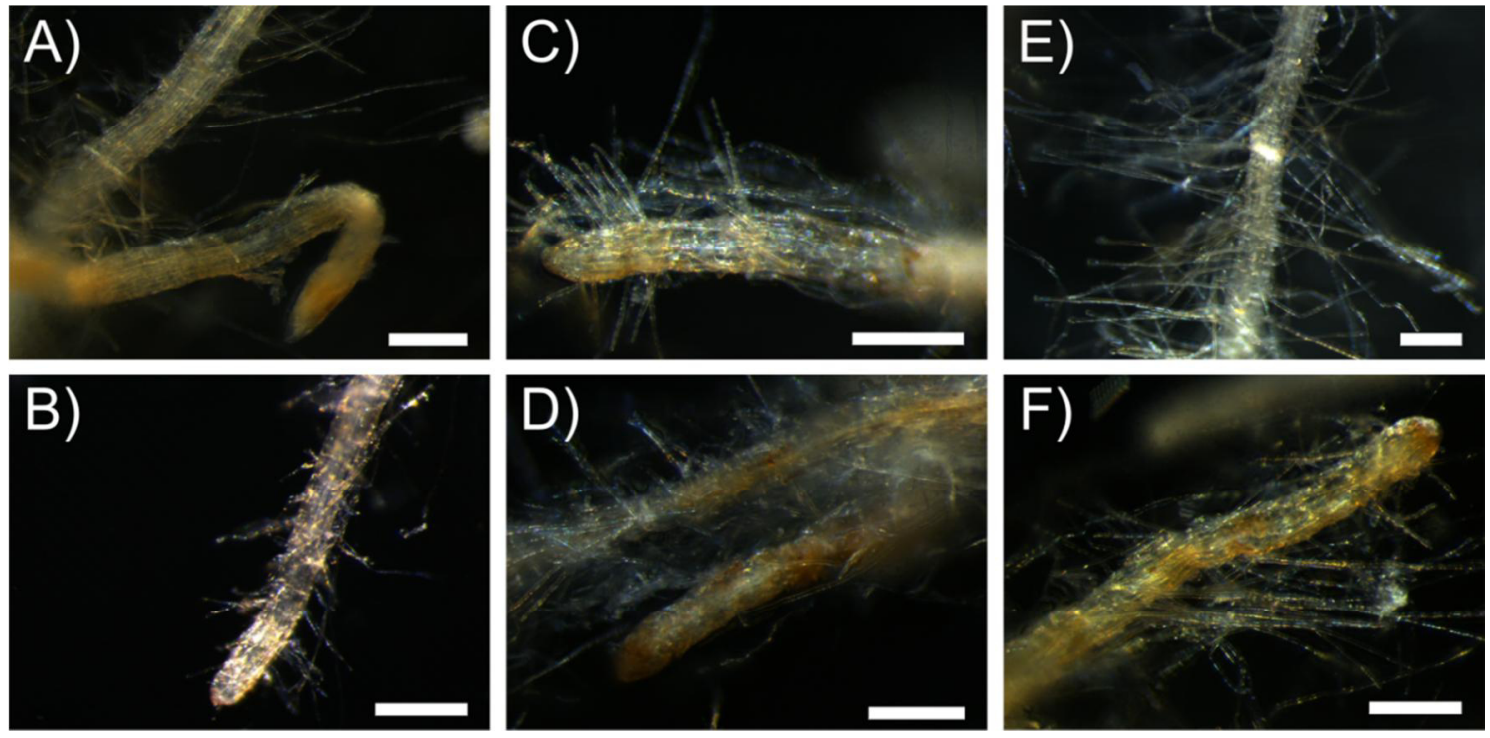

Figure 4.7. Roots hairs of poplars grown with different $P$ availabilities. A,B) HP, C,D) MP, E,F) LP plants, scale bar $=200 \mu \mathrm{m}$.

Roots of $-\mathrm{P}$ poplar showed higher root-associated PAP activity than those of $+\mathrm{P}$ plants grown with $625 \mu \mathrm{M}$ P (Figure $4.5 \mathrm{~A}$ ). In $+\mathrm{P}$ roots, the PAP activity was high in root caps and in small patches across the root surface, but otherwise negligible (Figure 4.5B). Strong PAP activity was distributed across root surface and root hairs of $-\mathrm{P}$ roots (Figure 4.5C). These results were also confirmed for Arabidopsis (Supplemental materials). To test which AtPAP contribute to root-associated PAP activity, roots of different Arabidopsis mutants were stained for PAP activity. But only in the pap10mutant PAP staining was suppressed (Supplemental material).

The two tests (BCIP and pNPP) for quantification of PAP activity of poplar roots grown in agar medium showed consistently a higher PAP activity for $-\mathrm{P}$ roots than for $+\mathrm{P}$ roots (Figure 4.8). Because PAP activity was shown to be inhibited by $\mathrm{P}$, the root PAP activity of $+\mathrm{P}$ plants was tested for two reaction media: with P (PAP activity of roots in growth medium) and without P (possible PAP activity of roots). The PAP activity was slightly but not significantly inhibited in $\mathrm{P}_{\mathrm{i}}$ consisting medium (Figure 4.8). 

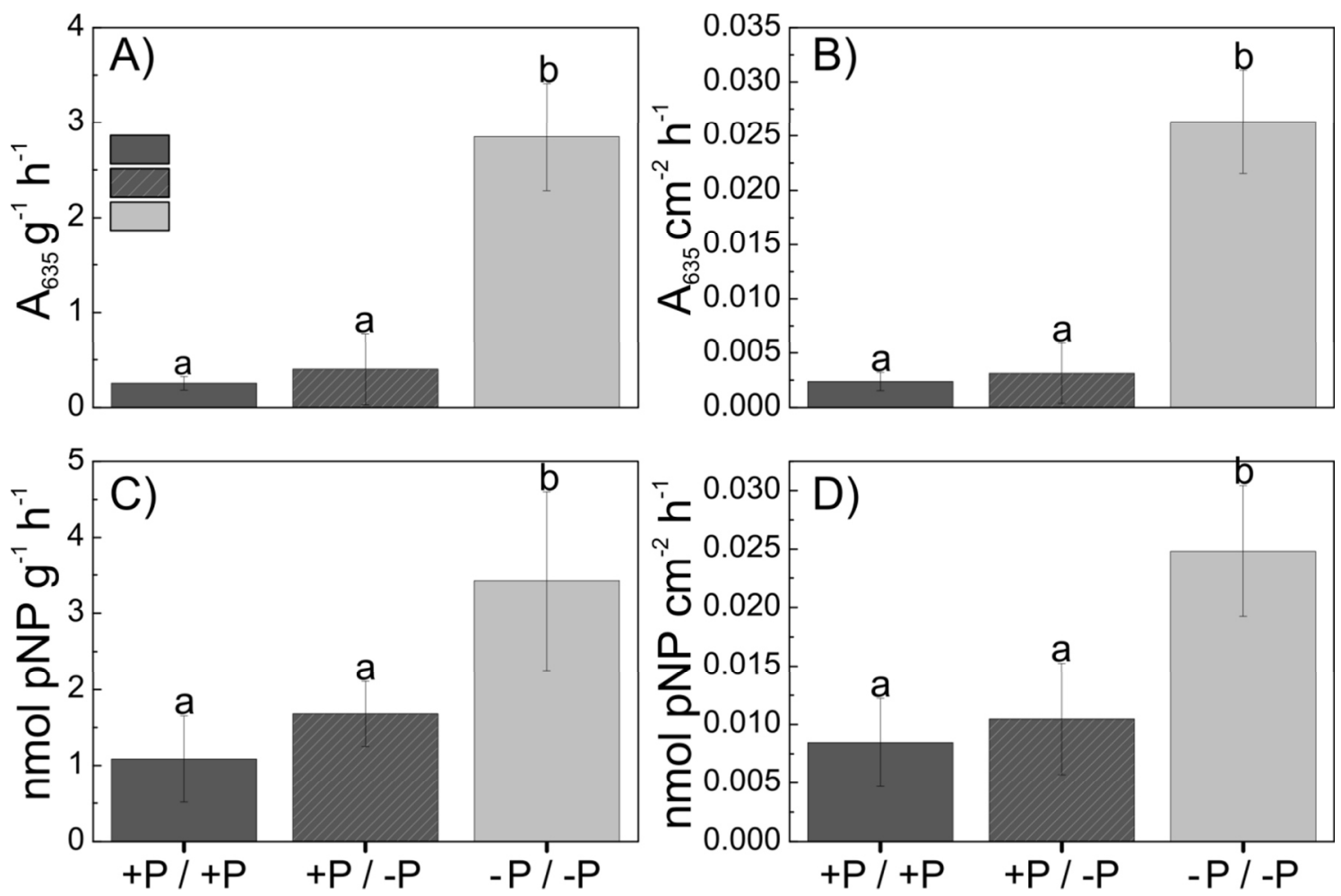

Figure 4.8. Root associated acid phosphatase activity of poplar. Poplar grown with phosphate and measured in solution with phosphate $(+\mathrm{P} /+\mathrm{P})$, measured in solution without phosphate $(+\mathrm{P} /-\mathrm{P})$ and grown and measured in solution without phosphate $(-\mathrm{P} /-$ P). A), B) measured with BCIP as substrate, C), D) measured with pNPP as substrate, activity calculated A), C) per gram root fresh mass, B), D) per $\mathrm{cm} 2$ root surface

\subsubsection{Roots of $P$ deprived poplar secrete additionally PtPAP1}

PAP staining of native gels revealed one PAP band for AWFs of HP poplars and two bands for those of LP poplars (Figure 4.9). The staining showed a higher PAP activity in LP PAPs than in HP PAPs (Figure 4.9). In proteins of HP and LP AWFs was one isoform with slow running behavior (E1) that was stained only slightly. A second isoform (E2) only seen in the LP samples had a slightly faster running behavior and was stained stronger than the slower isoform. 


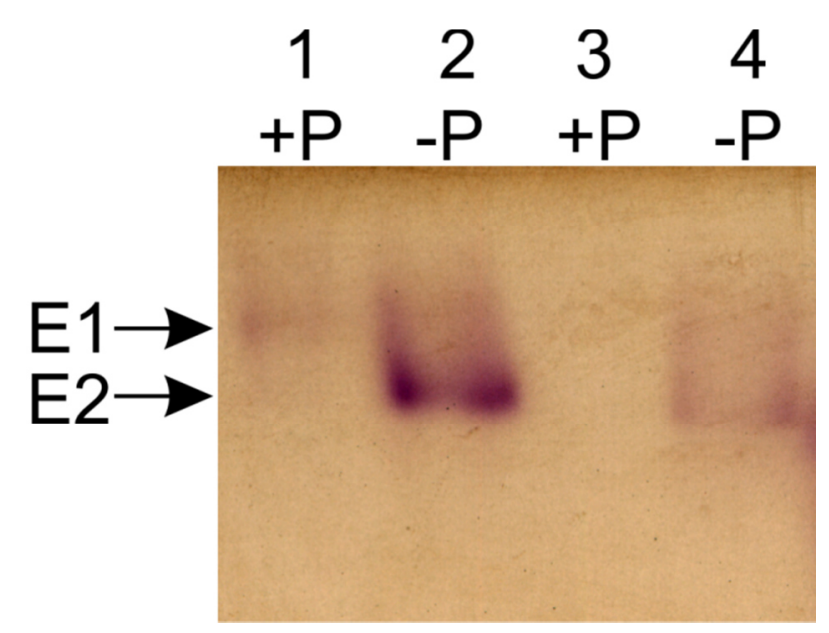

Figure 4.9. In gel-assay of acid phosphatase activity from poplar root AWF. Poplars were grown with $(+\mathrm{P})$ or without phosphate $(-\mathrm{P}), \mathrm{E} 1$ and E2: phosphatase isoforms

To identify the PAPs present in the apoplast, proteomic analyses were conducted. In general, AWFs from LP roots contained a lower number of proteins than those from HP roots (Table S4.1). In the AWF of HP plants, we detected PtPAP4 and PtPAP17 or the homologous PtPAP18 with PtPAP4 being most abundant. Of these PAPs, PtPAP4 had no secretion signal (Table 4.2). Although there were less total protein numbers present, PtPAP1 was found only in LP samples. This PAP was not present in HP AWF.

To test whether PtPAP1 could rescue PAP staining of the atpap10-mutant at low $\mathrm{P}$ conditions, the PtPAPI coding sequence was transformed into the Arabidopsis pap10mutant (Supplemental material). Cloning and transformation of PtPAP1 was successful, but expression in Arabidopsis was not yet successful (Supplemental material).

\subsection{Discussion}

Here, the complete phylogeny of the purple acid phosphatase family in poplar is presented in comparison with the model plant Arabidopsis and the model monocotyledonous crop plants rice and maize. Although the total numbers of sequences found for PAPs in poplar were similar to those of Arabidopsis, rice and maize, phylogenetic clustering suggested evolutionary differences. For example, sub-cluster Ia1 consisted of only Arabidopsis PAPs implying evolvement of these proteins in Arabidopsis. AtPAP5 of this cluster plays a role in resistance to pathogens and is 
upregulated during the early stages of pathogen defense (Ravichandran et al., 2013). For other Arabidopsis PAPs, duplicated or multiplicated genes were found in poplar. Relatively fast substitutions in the Arabidopsis genome and genome duplication events in the evolution of poplar (Van de Peer et al., 2009) led to this phylogenetic clustering. The four poplar PAPs that were not detected under our conditions at expression level in roots and leaves are duplicated genes compared to Arabidopsis. Therefore, these genes may have already lost their function or they may be expressed under different conditions or in different tissues than those in this study. Other poplar PAPs may have gained functional diversification during duplication. For example the closely related PtPAP1 and PtPAP2 have different expression patterns: PtPAP1 was transcriptionally upregulated during $\mathrm{P}$ starvation in both roots and leaves whereas PtPAP2 had the highest transcript abundances in leaves and was unresponsive to $\mathrm{P}$ starvation.

In this study, enhanced acid phosphatase activity of poplar roots during P starvation was shown for $P . \times$ canescens. This was shown before for different $\mathrm{P}$ deficient poplar species (P. tremuloides, P. simonii, P. × euramericana; Desai et al., 2014; Gan et al., 2016) without knowledge of the participating enzymes. In this study, two PAP isoforms were detected by in-gel PAP staining of AWF proteins. Low activity of one phosphatase isoform was detected in AFW proteins from LP and HP plants. One isoform with high activity was found only in LP samples.

The expression levels of PtPAP17, PtPAP18 and PtPAP32 were higher in roots than in leaves. Other PAPs (PtPAP1, PtPAP9, PtPAP14, PtPAP16, PtPAP21, PtPAP29, PtPAP30) exhibited up-regulation in roots under $\mathrm{P}$ deprivation. These PAPs may play a role in $\mathrm{P}$ acquisition from soil and the latter ones in the enhanced PAP activities on roots of P starved poplar. In Arabidopsis, AtPAP12 and AtPAP26 are the main secreted PAPs under low P conditions, whereas AtPAP10 is primarily associated with the root cell-walls (Wang et al., 2014). AtPAP10 and AtPAP12 are homologous to PtPAP1 to PtPAP4, AtPAP26 to PtPAP5 to PtPAP7. The detection of PtPAP4 and PtPAP1 proteins in the AWF of poplar roots suggested a conserved function for these enzymes with Arabidopsis AtPAP12. Especially PtPAP1 may be responsible for the enhanced PAP activity of poplar roots under low P conditions as this PAP was found only in AWF of $\mathrm{P}$ starved poplar roots and is transcriptionally upregulated. Whether another poplar PAP is bound to root cell-walls and could therefore not detected in the AWF, remains open. Further tests have to reveal whether PtPAP1 is a suitable candidate gene 
to engineer $-\mathrm{P}$ tolerant poplars for natural soils with organic $\mathrm{P}$ sources. Firstly, it has to be tested, whether the acid phosphatase isoform with high activity in AWF of poplar roots grown under low P conditions is PtPAP1. Further, it should be tested, whether enhanced expression of PtPAP1 leads to enhanced P acquisition from organic P sources and better plant performance under low phosphate conditions. First experiments with transient expression in Arabidopsis have been initiated (Supplemental materials) but were not yet successful. Overexpression in poplar would be a further step.

Additionally to their function in soil $\mathrm{P}$ acquisition, PAPs release $\mathrm{P}$ from internal stores (Duff et al., 1994). As newly taken up $\mathrm{P}$ in poplar is mainly transported to the youngest, growing leaves (Kavka and Polle, 2016), a recycling of $\mathrm{P}$ from storage pools in older leaves is likely, especially in P starved plants. PtPAPs highly expressed or up-regulated in leaves upon $\mathrm{P}$ starvation may have a role in plant internal P recycling (e.g. PtPAP2, PtPAP11, PtPAP15, PtPAP23).

Besides the enzymatic changes towards higher $\mathrm{P}$ acquisition and $\mathrm{P}$ recycling in the plant, plants also have to alter their root system and morphology to increase the access to phosphate in soil (Lambers and Plaxton, 2015). Increased root hair length and density is an early and specific response to P deprivation (Niu et al., 2013) and could be seen in very young as well as in long term P stressed poplars in this study. Poplars also changed the root morphology towards longer exploring root tips as was seen in maize. Maize roots show a reduced root diameter in the apical region (Mollier and Pellerin, 1999) which was also detected in poplar. Reduced root diameter as in Arabidopsis Col-0 is not a universal response to reduced $P$ availability in plants (Lambers et al., 2006). In poplar, the root diameter distribution changed from thin to more thick roots under $\mathrm{P}$ deprivation.

In this study, it was shown that $\mathrm{P}$ starved $P . \times$ canescens roots had higher PAP activity than well P-supplied plants. PtPAP4 was secreted into the growth medium under high and low P conditions, whereas PtPAP1 was secreted into the growth medium only under low $\mathrm{P}$ conditions. Therefore, PtPAP1 may play a role in enhanced $\mathrm{P}$ acquisition of $\mathrm{P}$ starved poplars. Additionally, P deprived poplars increased their root surface by increasing the number and length of root hairs, which allows them to explore a greater soil volume in search for P sources. 


\subsection{References}

Bieleski, R.L. (1973): Phosphate pools, phosphate transport, and phosphate availability. Annu. Rev. Plant Physiol. 24, 225-252.

Bozzo, G.G., Dunn, E.L., Plaxton, W.C. (2006): Differential synthesis of phosphatestarvation inducible purple acid phosphatase isozymes in tomato (Lycopersicon esculentum) suspension cells and seedlings. Plant Cell Environ. 29, 303-313.

Bustos, R., Castrillo, G., Linhares, F., Puga, M.I., Rubio, V., Pérez-Pérez, J., Solano, R., Leyva, A., Paz-Ares, J. (2010): A central regulatory system largely controls transcriptional activation and repression responses to phosphate starvation in Arabidopsis. PLoS Genet 6, e1001102.

Del Pozo, J.C., Allona, I., Rubio, V., Leyva, A., De La Peña, A., Aragoncillo, C., PazAres, J. (1999): A type 5 acid phosphatase gene from Arabidopsis thaliana is induced by phosphate starvation and by some other types of phosphate mobilising/oxidative stress conditions. Plant J. 19, 579-589.

Desai, S., Naik, D., Cumming, J.R. (2014): The influence of phosphorus availability and Laccaria bicolor symbiosis on phosphate acquisition, antioxidant enzyme activity, and rhizospheric carbon flux in Populus tremuloides. Mycorrhiza 24, 369-382.

Duff, S.M., Sarath, G., Plaxton, W.C. (1994): The role of acid phosphatases in plant phosphorus metabolism. Physiol. Plant. 90, 791-800.

Emanuelsson, O., Nielsen, H., Brunak, S., von Heijne, G. (2000): Predicting subcellular localization of proteins based on their N-terminal amino acid sequence. J. Mol. Biol. 300, 1005-1016.

Felsenstein, J. (1993): PHYLIP (Phylogeny Inference Package) version 3.5c. Distributed by the author. Department of Genetics, University of Washington, Seattle.

Floerl, S., Druebert, C., Majcherczyk, A., Karlovsky, P., Kües, U., Polle, A. (2008): Defence reactions in the apoplastic proteome of oilseed rape (Brassica napus var. napus) attenuate Verticillium longisporum growth but not disease symptoms. BMC Plant Biol. 8, 129.

Gan, H., Jiao, Y., Jia, J., Wang, X., Li, H., Shi, W., Peng, C., Polle, A., Luo, Z.-B. (2016): Phosphorus and nitrogen physiology of two contrasting poplar genotypes when exposed to phosphorus and/or nitrogen starvation. Tree Physiol. 36, 22-38.

González-Muñoz, E., Avendaño-Vázquez, A.-O., Montes, R.A.C., de Folter, S., AndrésHernández, L., Abreu-Goodger, C., Sawers, R.J.H. (2015): The maize (Zea mays ssp. mays var. B73) genome encodes 33 members of the purple acid phosphatase family. Front. Plant Sci. 6, 341. 
Goodstein, D.M., Shu, S., Howson, R., Neupane, R., Hayes, R.D., Fazo, J., Mitros, T., Dirks, W., Hellsten, U., Putnam, N., Rokhsar, D.S. (2012): Phytozome: a comparative platform for green plant genomics. Nucleic Acids Res. 40, D1178-D1186.

Hellemans, J., Mortier, G., De Paepe, A., Speleman, F., Vandesompele, J. (2007): qBase relative quantification framework and software for management and automated analysis of real-time quantitative PCR data. Genome Biol. 8, R19.

Higo, K., Ugawa, Y., Iwamoto, M., Korenaga, T. (1999): Plant cis-acting regulatory DNA elements (PLACE) database: 1999. Nucleic Acids Res. 27, 297-300.

Janz, D., Lautner, S., Wildhagen, H., Behnke, K., Schnitzler, J.-P., Rennenberg, H., Fromm, J., Polle, A. (2012): Salt stress induces the formation of a novel type of "pressure wood" in two Populus species. New Phytol. 194, 129-141.

Kavka, M., Polle, A. (2016): Phosphate uptake kinetics and tissue-specific transporter expression profiles in poplar (Populus $\times$ canescens) at different phosphorus availabilities. BMC Plant Biol. 16, 206.

Lambers, H., Plaxton, W.C. (2015): Phosphorus: Back to the roots, in: Plaxton, W.C., Lambers, H. (eds.): Annual Plant Reviews Volume 48. John Wiley \& Sons, Inc., Hoboken, NJ, USA, pp. 1-22.

Lambers, H., Shane, M.W., Cramer, M.D., Pearse, S.J., Veneklaas, E.J. (2006): Root structure and functioning for efficient acquisition of phosphorus: Matching morphological and physiological traits. Ann. Bot. 98, 693-713.

Li, C., Gui, S., Yang, T., Walk, T., Wang, X., Liao, H. (2012): Identification of soybean purple acid phosphatase genes and their expression responses to phosphorus availability and symbiosis. Ann. Bot. 109, 275-285.

Li, D., Zhu, H., Liu, K., Liu, X., Leggewie, G., Udvardi, M., Wang, D. (2002): Purple acid phosphatases of Arabidopsis thaliana, comparative analysis and differential regulation by phosphate deprivation. J. Biol. Chem. 277, 27772-27781.

Lohrasebi, T., Malboobi, M.A., Samaeian, A., Sanei, V. (2007): Differential expression of Arabidopsis thaliana acid phosphatases in response to abiotic stresses. Iran. J. Biotechnol. 5, 130-39.

Mollier, A., Pellerin, S. (1999): Maize root system growth and development as influenced by phosphorus deficiency. J. Exp. Bot. 50, 487-497.

Müller, A., Volmer, K., Mishra-Knyrim, M., Polle, A. (2013): Growing poplars for research with and without mycorrhizas. Front. Plant Sci. 4, 332. 
Niu, Y.F., Chai, R.S., Jin, G.L., Wang, H., Tang, C.X., Zhang, Y.S. (2013): Responses of root architecture development to low phosphorus availability: a review. Ann. Bot. 112, 391-408.

Olczak, M., Morawiecka, B., Watorek, W. (2003): Plant purple acid phosphatases genes, structures and biological function. Acta Biochim. Pol. 50, 1245-1256.

$R$ Development Core Team (2012): R: a language and environment for statistical computing. R Foundation for Statistical Computing, Vienna, Austria.

Rappsilber, J., Mann, M., Ishihama, Y. (2007): Protocol for micro-purification, enrichment, pre-fractionation and storage of peptides for proteomics using StageTips. Nat. Protoc. 2, 1896-1906.

Ravichandran, S., Stone, S.L., Benkel, B., Prithiviraj, B. (2013): Purple Acid Phosphatase 5 is required for maintaining basal resistance against Pseudomonas syringae in Arabidopsis. BMC Plant Biol. 13, 107.

Ruijter, J.M., Ramakers, C., Hoogaars, W.M.H., Karlen, Y., Bakker, O., Hoff, M.J.B. van den, Moorman, A.F.M. (2009): Amplification efficiency: linking baseline and bias in the analysis of quantitative PCR data. Nucleic Acids Res. 37, e45.

Schachtman, D.P., Reid, R.J., Ayling, S.M. (1998): Phosphorus uptake by plants: from soil to cell. Plant Physiol. 116, 447-453.

Tamura, K., Stecher, G., Peterson, D., Filipski, A., Kumar, S. (2013): MEGA6: Molecular Evolutionary Genetics Analysis Version 6.0. Mol. Biol. Evol. 30, 2725-2729.

Tsai, C.-J., Ranjan, P., DiFazio, S., Tuskan, G., Johnson, V. (2011): Poplar genome microarrays, in: Joshi, C., DiFazio, S., Kole, C. (eds.): Genetics, genomics and breeding of poplars. Science Publishers, Enfield, NH, pp. 112-127.

Tuskan, G.A., DiFazio, S., Jansson, S., Bohlmann, J., Grigoriev, I., Hellsten, U., Putnam, N., Ralph, S., Rombauts, S., Salamov, A., Schein, J., Sterck, L., Aerts, A., Bhalerao, R.R., Bhalerao, R.P., Blaudez, D., Boerjan, W., Brun, A., Brunner, A., Busov, V., Campbell, M., Carlson, J., Chalot, M., Chapman, J., Chen, G.-L., Cooper, D., Coutinho, P.M., Couturier, J., Covert, S., Cronk, Q., Cunningham, R., Davis, J., Degroeve, S., Déjardin, A., dePamphilis, C., Detter, J., Dirks, B., Dubchak, I., Duplessis, S., Ehlting, J., Ellis, B., Gendler, K., Goodstein, D., Gribskov, M., Grimwood, J., Groover, A., Gunter, L., Hamberger, B., Heinze, B., Helariutta, Y., Henrissat, B., Holligan, D., Holt, R., Huang, W., Islam-Faridi, N., Jones, S., JonesRhoades, M., Jorgensen, R., Joshi, C., Kangasjärvi, J., Karlsson, J., Kelleher, C., Kirkpatrick, R., Kirst, M., Kohler, A., Kalluri, U., Larimer, F., Leebens-Mack, J., Leplé, J.-C., Locascio, P., Lou, Y., Lucas, S., Martin, F., Montanini, B., Napoli, C., Nelson, D.R., Nelson, C., Nieminen, K., Nilsson, O., Pereda, V., Peter, G., Philippe, R., Pilate, G., Poliakov, A., Razumovskaya, J., Richardson, P., Rinaldi, C., Ritland, K., Rouzé, P., 
Ryaboy, D., Schmutz, J., Schrader, J., Segerman, B., Shin, H., Siddiqui, A., Sterky, F., Terry, A., Tsai, C.-J., Uberbacher, E., Unneberg, P., Vahala, J., Wall, K., Wessler, S., Yang, G., Yin, T., Douglas, C., Marra, M., Sandberg, G., Peer, Y.V. de, Rokhsar, D. (2006): The genome of black cottonwood, Populus trichocarpa (Torr. \& Gray). Science 313, 1596-1604.

Van de Peer, Y., Fawcett, J.A., Proost, S., Sterck, L., Vandepoele, K. (2009): The flowering world: a tale of duplications. Trends Plant Sci. 14, 680-688.

Vincent, J.B., Averill, B.A. (1990): An enzyme with a double identity: purple acid phosphatase and tartrate-resistant acid phosphatase. FASEB J. 4, 3009-3014.

Wang, L., Li, Z., Qian, W., Guo, W., Gao, X., Huang, L., Wang, H., Zhu, H., Wu, J.-W., Wang, D., Liu, D. (2011): The Arabidopsis purple acid phosphatase AtPAP10 is predominantly associated with the root surface and plays an important role in plant tolerance to phosphate limitation. Plant Physiol. 157, 1283-1299.

Wang, L., Lu, S., Zhang, Y., Li, Z., Du, X., Liu, D. (2014): Comparative genetic analysis of Arabidopsis purple acid phosphatases AtPAP10, AtPAP12, and AtPAP26 provides new insights into their roles in plant adaptation to phosphate deprivation: Comparative analysis of three Arabidopsis APases. J. Integr. Plant Biol. 56, 299-314.

Warnes, G.R. (2012): gplots: Various R programming tools for plotting data. R package version 2.11.0.

Wessel, D., Flügge, U.I. (1984): A method for the quantitative recovery of protein in dilute solution in the presence of detergents and lipids. Anal. Biochem. 138, 141-143.

Zhang, Q., Wang, C., Tian, J., Li, K., Shou, H. (2011): Identification of rice purple acid phosphatases related to posphate starvation signalling. Plant Biol. 13, 7-15.

Zhang, X.M., Hong, K., Yi, Y. (2015): Effect of short-term phosphate starvation on acid phosphatase activity of Carpinus pubescens and Eurycorymbus cavalerei. Russ. J. Plant Physiol. 62, 57-64.

Zhu, H., Qian, W., Lu, X., Li, D., Liu, X., Liu, K., Wang, D. (2005): Expression patterns of purple acid phosphatase genes in Arabidopsis organs and functional analysis of AtPAP23 predominantly transcribed in flower. Plant Mol. Biol. 59, 581-594. 


\subsection{Supporting information}

Table S4.1: Proteins in the AWF of P starved poplar (on data CD)

Additional file: Establishment of Arabidopsis pap-mutant lines for functional analyses of poplar purple acid phosphatases 


\section{Additional file: Establishment of Arabidopsis pap-mutant lines for functional analyses of poplar purple acid phosphatases}

\section{Introduction}

The purple acid phosphatase PtaPAP1 was additionally secreted under low phosphate conditions by poplar (Populus $\times$ canescens) roots. It was found in the apoplastic washing fluid (AWF) of only $\mathrm{P}$ starved poplar roots and not under control conditions. Furthermore, PtaPAPl was highly upregulated under low $\mathrm{P}$ conditions and belonged to the highest regulated genes. PtaPAPl expression pattern was correlated with the $\mathrm{P}$ concentration in the plant tissues (Chapter 1). Luo et al. (2009) found PtaPAP1, together with four other purple acid phosphatases (PtaPAP16, PtaPAP29, PtaPAP30, PtaPAP32) downregulated in mycorrhizal poplar roots with higher phosphorus concentrations. These phosphatases were upregulated under phosphate deprivation in roots in this study.

The goal of this study was to test, whether PtaPAP1 takes part in the P acquisition under low $\mathrm{P}$ conditions in poplar.

The homolog of PtPAP1 in Arabidopsis is AtPAP10 (Table S4.1). The atpap10-mutant has reduced root-associated acid phosphatase activity (Wang et al., 2011), in contrast to mutants of other PAP homologs (Figure S4.1) that are also highly upregulated in poplar upon $\mathrm{P}$ starvation. Therefore, this mutant is a promising system to test, whether the poplar PtaPAP1 is a major root-associated PAP that is able to rescue the atpap10mutant phenotype.
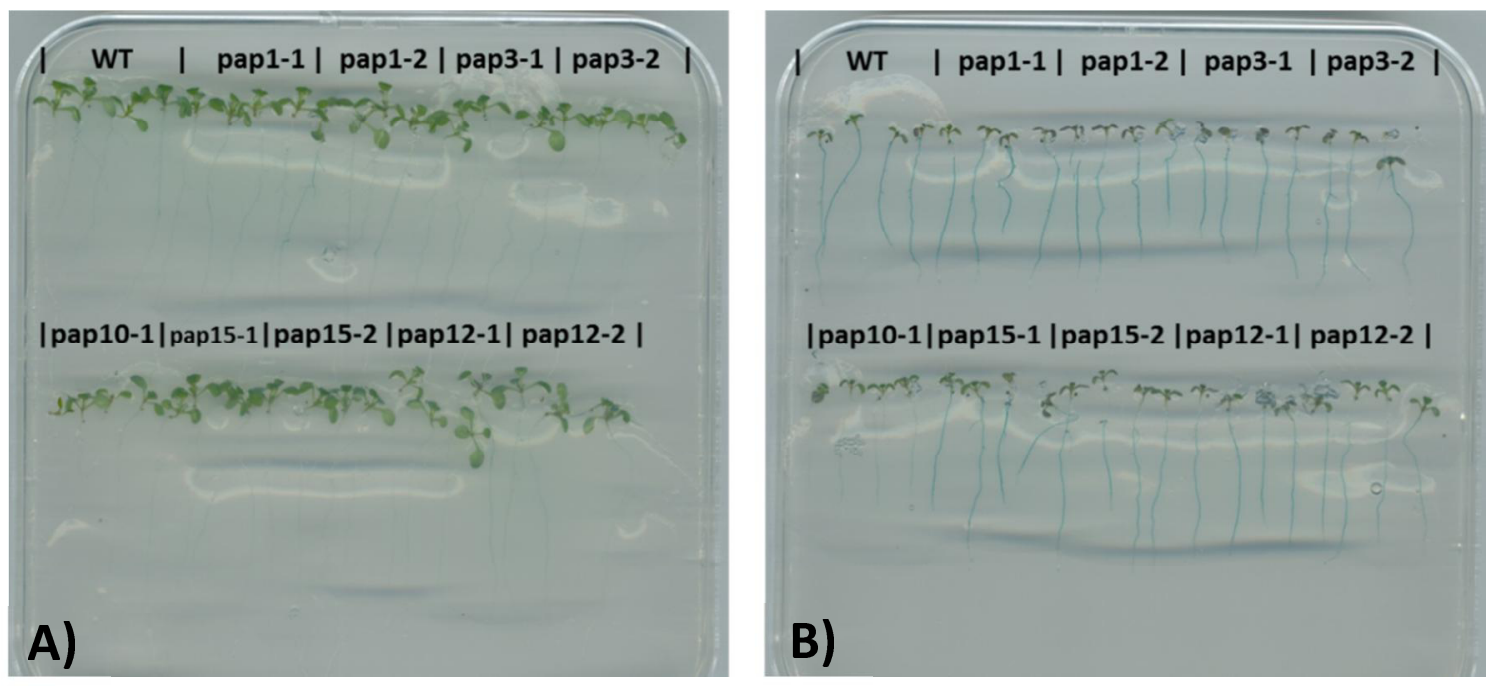

Figure S4.1: BCIP-staining of Arabidopsis roots for acid phosphatase activity. Arabidopsis plants (for lines refer to Table 1) were grown vertically on $1 / 2 \mathrm{MS}$-medium for $8 \mathrm{~d}$ with (A) and without (B) P, overlaid with $0.01 \%$ BCIP- $0.8 \%$ Agar-medium and scanned after $17 \mathrm{~h}$. 


\section{atpap mutant lines}

The Arabidopsis pap-mutant lines were purchased from the European Arabidopsis Stock Centre (NASC). These lines are T-DNA insertion lines: A short DNA fragment (T-DNA) is inserted into the genome of Arabidopsis. The insertion site is random but known after sequencing. If the insert is positioned inside an important part of a gene sequence, the gene cannot be (fully) expressed.

Whether the insertion was homozygous (on both alleles), heterozygous (on one allele) or crossed out (two wild type alleles), was tested by PCR. In this PCR, one primer pair was positioned on the left and on the right side of the T-DNA insert (LP and RP primer, Figure S4.2A). The sequence between them could only be amplified without insert (wild type allele). A second primer pair consisted of the primer on the right side of the T-DNA insert (RP) and a primer binding to the T-DNA. The latter one could only bind if there was an insert present. This amplified sequence was chosen to be shorter than the previous one. The mutations were tested on leaf DNA extracts in two different PCRs or in one PCR with all three primers, resulting in exemplified gel pictures seen in Figure S4.2B for wild type (WT), heterozygous (HZ) and homozygous (HM) plants. Results of the PCRs are seen in Figure S4.3.

All selected mutations were in the Col-0 background.
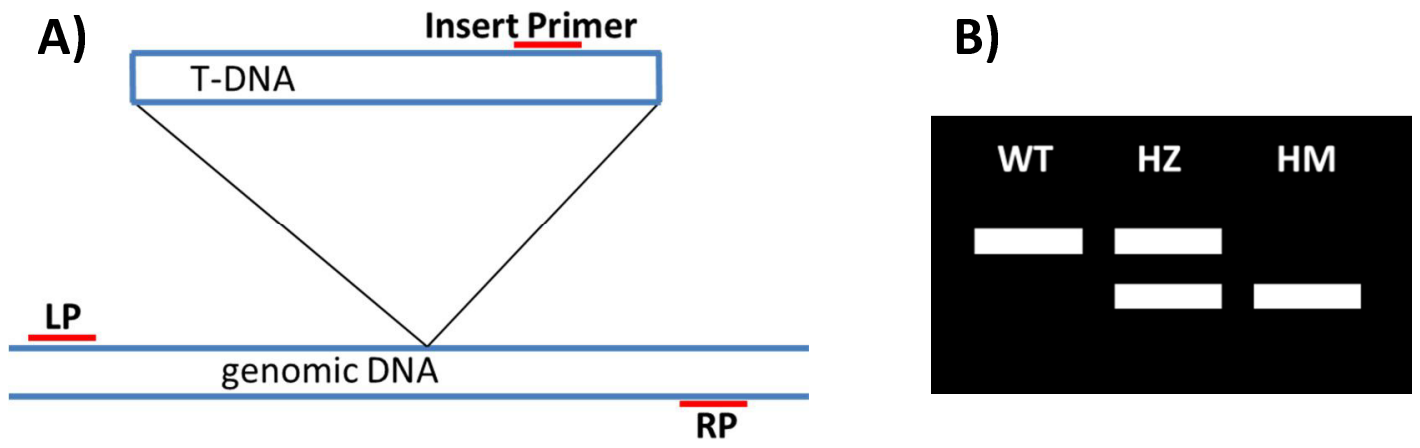

Figure S4.2: A) Scheme of the primer position in T-DNA insertion lines, B) schematic picture of the resulting gel after PCR with all three primers for T-DNA insertion lines (WT: wild type, HZ: heterozygous, HM: homozygous). 


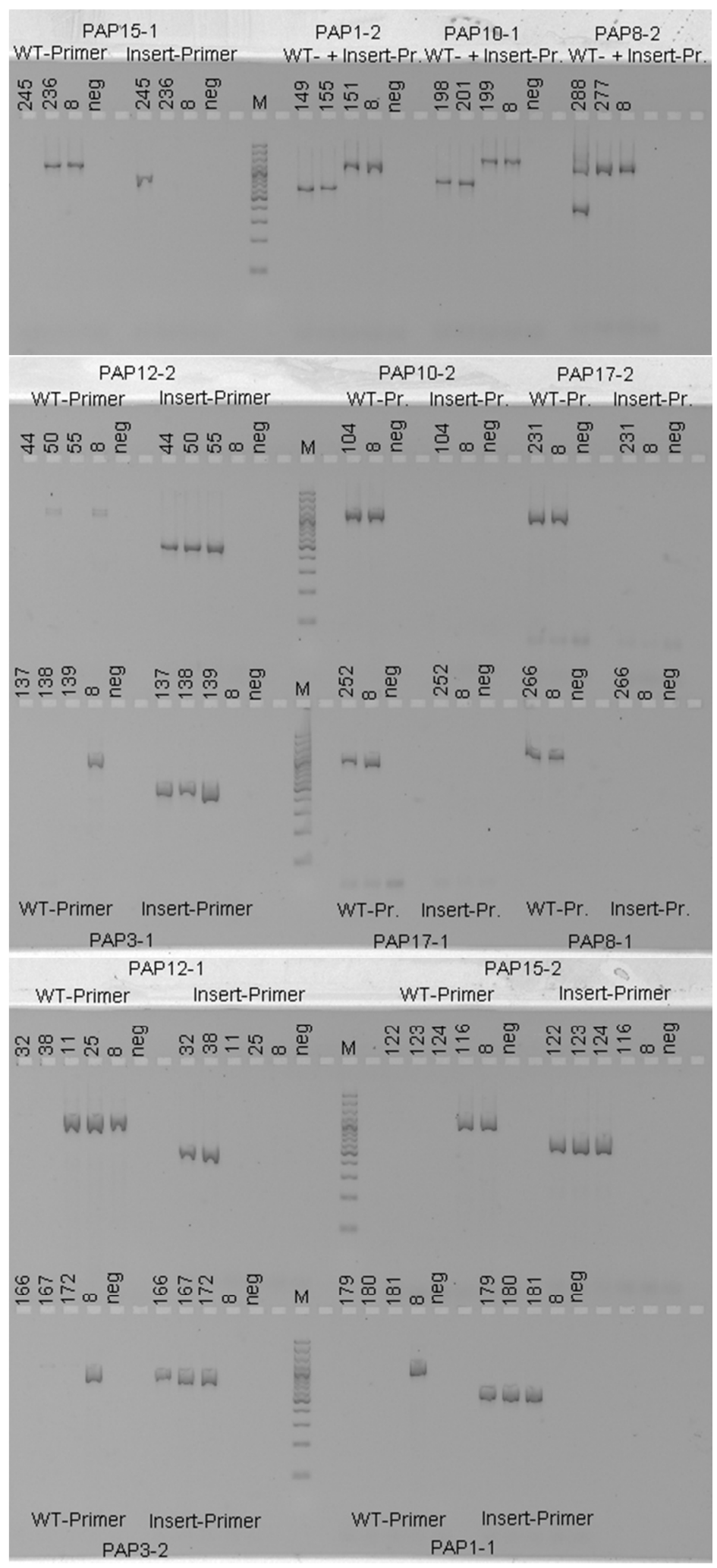

Figure S4.3: Results of PCR for insert testing of plants of the mutant lines. WT-Primer: LP and RP primer, Insert-Primer: Insert-primer and RP primer, M: marker (GeneRuler $100 \mathrm{bp}$ Plus DNA ladder (Thermo Fisher Scientific, Waltham, MA, USA), see Figure S4.4 for DNA fragment sizes). Numbers are individual plants from the mutant lines, 8 : wild type, neg: water. Colors are inverted. $1 \mu 1$ PCR-product, $2 \%$ agarose gel. 


\section{0 bp Plus}

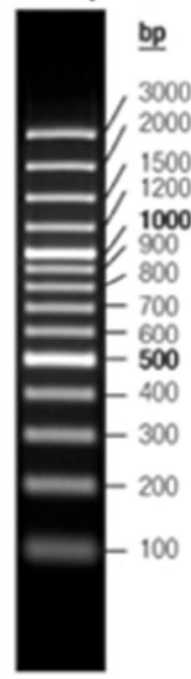

$1.7 \%$ agarose

Figure S4.4: Fragment sizes of GeneRuler 100 bp Plus DNA ladder (Thermo Fisher Scientific, Waltham, MA, USA). Source: https://www.thermofisher.com/us/en/home/brands/thermo-scientific/molecularbiology/thermo-scientific-nucleic-acid-electrophoresis-purification/dna-electrophoresisthermo-scientific/dna-ladders-thermo-scientific/generuler-dna-ladders.html 
Table S4.1: Poplar PAP and homologous Arabidopsis PAP, Arabidopsis mutant lines with position of insert and primers used for confirmation of homozygosity of mutation.

\begin{tabular}{|c|c|c|c|c|c|}
\hline $\begin{array}{l}\text { Poplar } \\
\text { PAP }\end{array}$ & $\begin{array}{l}\text { homolog- } \\
\text { ous } \\
\text { AtPAP }\end{array}$ & Ath mutant line & $\begin{array}{l}\text { position of } \\
\text { Insert }\end{array}$ & Primers & Comments \\
\hline PtPAP1 & $\begin{array}{l}\text { AtPAP10 } \\
\text { and } \\
\text { AtPAP12 }\end{array}$ & $\begin{array}{l}\text { PAP10-1 } \\
(\text { SALK_122362(BV)) } \\
\text { PAP10-2 } \\
\text { (SAIL_1234_D05) } \\
\text { PAP12-1 } \\
(\text { GK-151C09) } \\
\text { PAP12-2 } \\
(\text { GK-662B07) }\end{array}$ & $\begin{array}{l}\text { 300-UTR5 } \\
\text { Exon } \\
\text { Exon } \\
\text { 300-UTR5 }\end{array}$ & $\begin{array}{l}\text { SALK_122362_LP: CTTTTGCTTCTTGTGTCACCC } \\
\text { SALK_122362_RP: TTTCTTGGCACTCCACAAAAC } \\
\text { SAIL_1234_D05_LP: ACCCTCATTGTTTCACCTTCC } \\
\text { SAIL_1234_D05_RP: TAGCACCAAAAAGCACAAAGC } \\
\text { GABI_151C09_LP: AAAGCTAGCTTCTCGAAACGC } \\
\text { GABI_151C09_RP: ATGAGATGAATCCGGGAAAAG } \\
\text { GABI_662B07_LP2: AATGACTAAACGAATAACAAAGG } \\
\text { GABI_662B07_RP: CTGTTGCTTCTGCTTGTTTCC }\end{array}$ & no homozygous found \\
\hline PtPAP16 & AtPAP1 & $\begin{array}{l}\text { PAP1-1 } \\
(\text { SALK_038756C) } \\
\text { PAP1-2 } \\
\text { (SALK_067586C) }\end{array}$ & $\begin{array}{l}\text { 300-UTR5 } \\
\text { Exon }\end{array}$ & $\begin{array}{l}\text { SALK_038756_LP: AAGCTTCAAGGAACCAGTTCC } \\
\text { SALK_038756_RP: CCAAAAGCATTGACACTTTGG } \\
\text { SALK_067586_LP: CGGTGGATAGGAAAGGAAAAG } \\
\text { SALK_067586_RP: TCACCGTGTTCTCGGTTATTC }\end{array}$ & \\
\hline $\begin{array}{l}\text { PtPAP29 } \\
\text { and } \\
\text { PtPAP30 }\end{array}$ & AtPAP17 & $\begin{array}{l}\text { PAP17-1 } \\
(\text { SALK_046977 (AI)) } \\
\text { PAP17-2 } \\
\text { (SALK_097938) }\end{array}$ & Exon & $\begin{array}{l}\text { SALK_046977_LP: GCCTACCTAGCCTGCAATAGG } \\
\text { SALK_046977_RP: CTCGTTGCTTATCAGGTTTGG } \\
\text { SALK_097938_LP: GCCTACCTAGCCTGCAATAGG } \\
\text { SALK_097938_RP: CTCGTTGCTTATCAGGTTTGG }\end{array}$ & no homozygous found \\
\hline
\end{tabular}


Table S4.1 (continued)

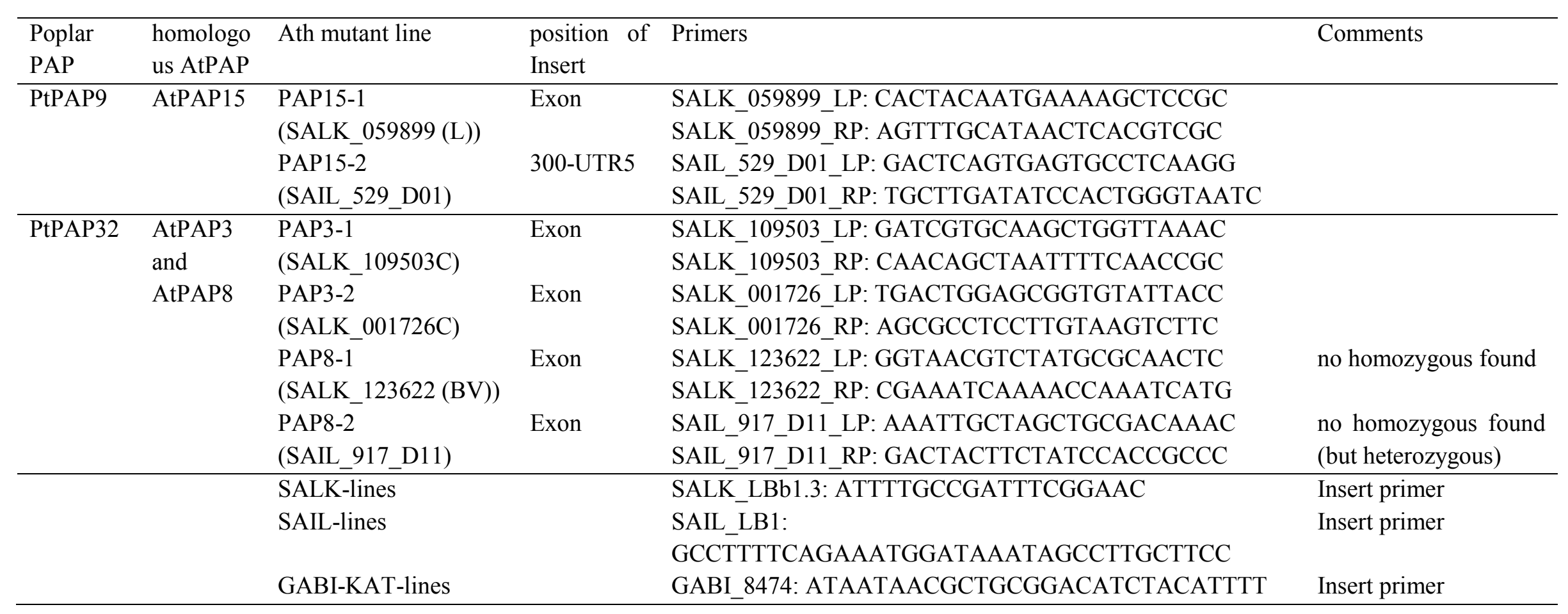




\section{The Gateway system}

To try whether PtaPAP1 can functional complement the atpap10-mutation in Arabidopsis, PtaPAP1 coding sequence was cloned into a vector containing a CamV35S-promoter for overexpressing by using the Gateway system.

Each Gateway vector has a "death gene" $(c c d \mathrm{~B})$ between two cloning sites (att-sites) lethal for E. coli-cells. During cloning reaction, this "death gene" is substituted by the DNA-sequence of interest (Figure S4.5A). Additionally, these vectors contain an antibiotics resistance gene. After transformation into E. coli, during following selection, only those cells survive that were transformed with the vector with DNA-sequence of interest.

The cloning is performed in two steps: Firstly, the DNA-sequence of interest (PCRproduct) is cloned into a donor vector (pDONR201) via the BP-reaction forming the entry vector. Secondly, the DNA-sequence of interest is cloned from the entry vector into the destination vector (here pGWB2) (LR-reaction). These reactions are oriented and cannot be undone in the same reaction, because the required att-sites are changed with each reaction (Figure S4.5B).

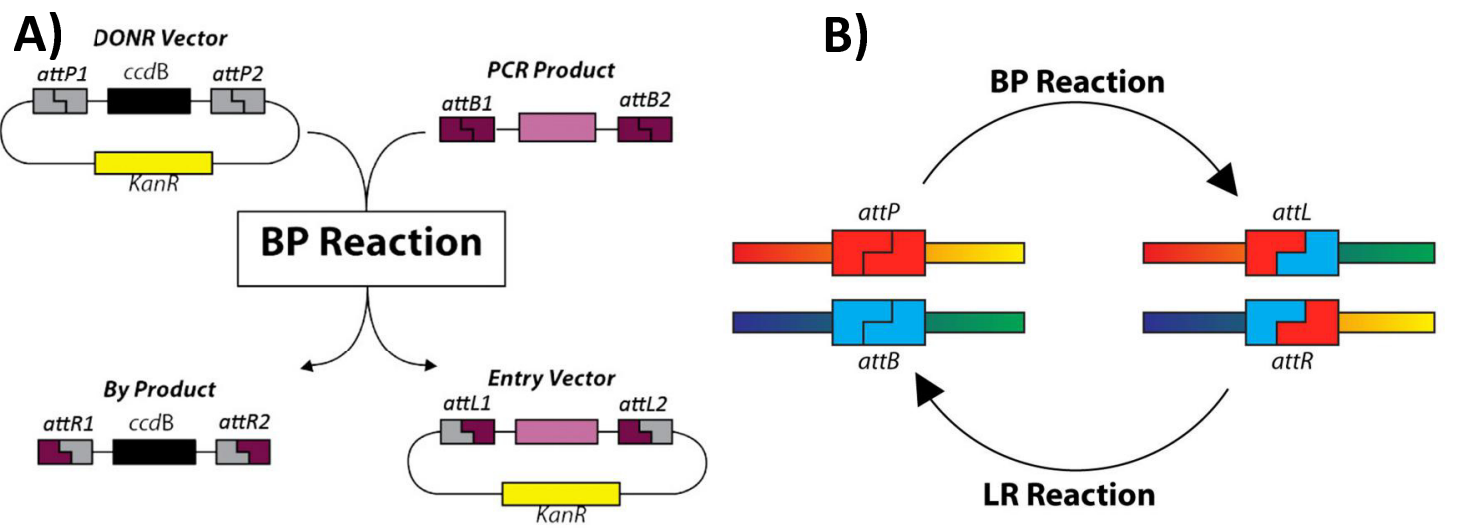

Figure S4.5: Scheme of cloning reactions with the Gateway system. Source: https://www.google.de/url? sa $=\mathrm{t} \& \mathrm{rct}=\mathrm{j} \& \mathrm{q}=\& \mathrm{esrc}=\mathrm{s} \&$ source $=$ web\&cd $=1 \& \mathrm{ved}=0$ ahUKE wjjvJjngc_MAhUhEJoKHSoDC40QFggqMAA\&url=https\%3A\%2F\%2Fsecuiqhdks.fil es.wordpress.com $\% 2 \mathrm{~F} 2015 \% 2 \mathrm{~F} 01 \% 2 \mathrm{Ftest} 2$.docx\&usg=AFQjCNH0a87zB0nxUVECPz hePLs2c9OILw\&cad=rja

\section{Cloning-Protocol}

Additionally to the poplar gene PtaPAPl, the Arabidopsis gene AtPAP10 was used as positive control for functional complementation of the atpap10-mutant. AtPAP10 has two gene models with only one expressed gene (AT2G16430.2) (TAIR, Wang et al. 2011). The coding sequence of this gene from start until the stop codon ( $\sim 1500 \mathrm{bp})$ was amplified from cDNA and simultaneously, att-sites for cloning were added. 
PtaPAP1 has three gene models in P. trichocarpa with Potri.005G233400.1 as primary transcript. The differences in the two other transcripts are: longer UTRs in Potri.005G233400.2 (no difference in coding sequence), and a shorter coding sequence for Potri.005G233400.3 at the 5'-end. For transformation, the coding sequence of Potri.005G233400.1 from start until the stop codon ( $1500 \mathrm{bp})$ was amplified from cDNA of Populus $\times$ canescens and simultaneously, the att-sites for cloning were added. For that PCR reactions, following primers were used (black for att-site addition, red for gene): $\quad$ attB1_AtPAP10_fw GGGGACAAGTTTGTACAAAAAAGCAGGCTTCACCATGGGTCGTGTCCGA-3') and attB2_At_rev

GGGGACCACTTTGTACAAGAAAGCTGGGTCTCAAGAATTACAAGAAGGAGA ATC-3') for AtPAP10 and attB1_Pc005_fw (5'GGGGACAAGTTTGTACAAAAAAGCAGGCTTCACCATGGAAGTGAGATGGG ACTC-3') and attB2_rev+Gen (5'GGGGACCACTTTGTACAAGAAAGCTGGGTCTCATAACGCAGCCACGG-3') for PtaPAP1. The PCR settings are summarized in Table S4.2.

Table S4.2: PCR settings for amplification of AtPAP10 and PtaPAPI coding sequence with addition of att-sites for Gateway-cloning.

\begin{tabular}{|c|c|c|c|c|}
\hline Solutions & $\mu l$ & Programm & Hot Start / L & \\
\hline 5X Phusion Buffer & 10 & & $105^{\circ} \mathrm{C}$ & \\
\hline dNTP Mix (10 mM of each) & 1 & Step & Temperature & Time \\
\hline Primer fw $(10 \mu \mathrm{M})$ & 2.5 & 1 & $98^{\circ} \mathrm{C}$ & hold \\
\hline Primer rev $(10 \mu \mathrm{M})$ & 2.5 & 2 & $98^{\circ} \mathrm{C}$ & $30 \mathrm{sec}$ \\
\hline Phusion-Polymerase $(2 \mathrm{U} / \mu \mathrm{l})$ & 0.5 & 3 & $98^{\circ} \mathrm{C}$ & $10 \mathrm{sec}$ \\
\hline Water (Nuklease free) & 31.5 & 4 & $60^{\circ} \mathrm{C}$ & $30 \mathrm{sec}$ \\
\hline cDNA-Extract & 2 & 5 & $72^{\circ} \mathrm{C}$ & $45 \mathrm{sec}$ \\
\hline \multirow[t]{3}{*}{ total volumen } & 50 & 6 & Go to 3 / Rep 35 & \\
\hline & & 7 & $72^{\circ} \mathrm{C}$ & $5 \mathrm{~min}$ \\
\hline & & 8 & Hold $4^{\circ} \mathrm{C} /$ Enter & \\
\hline
\end{tabular}

After amplification, the PCR-product was purified with innuPREP PCRpure Kit (Analytik Jena, Jena, Germany) after manual instructions and eluted with $25 \mu 1$ nuclease-free water. Afterwards, it was extracted from an agarose gel (1.2\% agarose, $50 \mathrm{ml}$ gel volume, $\sim 3 \mathrm{~h}, 35 \mathrm{~mA}$ ) with the QIAquick Gel Extraction Kit (Qiagen, Hilden, Germany) after manual instructions.

The resulting DNA products (Figure S4.6) had DNA-concentrations (Biophotometer, Eppendorf, Hamburg, Germany) of $14.5 \mathrm{ng} / \mu 1$ for Arabidopsis gene and $19.5 \mathrm{ng} / \mu \mathrm{l}$ for poplar gene. 


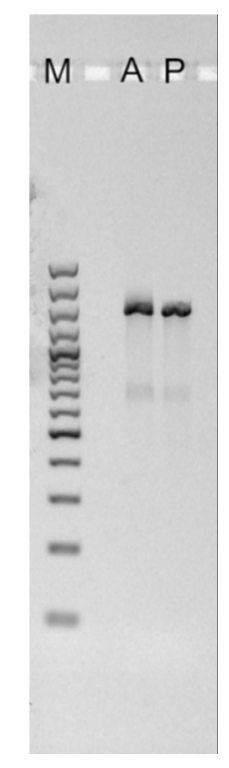

Figure S4.6: Purified PCR-products (M: GeneRuler 100 bp plus, see Figure S4.4), A: Arabidopsis, P: poplar gene. Colors are inverted. $2 \mu \mathrm{l}$ PCR product, $1.2 \%$ agarose gel.

\section{BP-Reaction}

Afterwards, the BP-reaction was set up. As donor vector, pDONR201 with kanamycin resistance (Figure 7) was used in equimolar concentration with the PCR-product (Table S4.3).

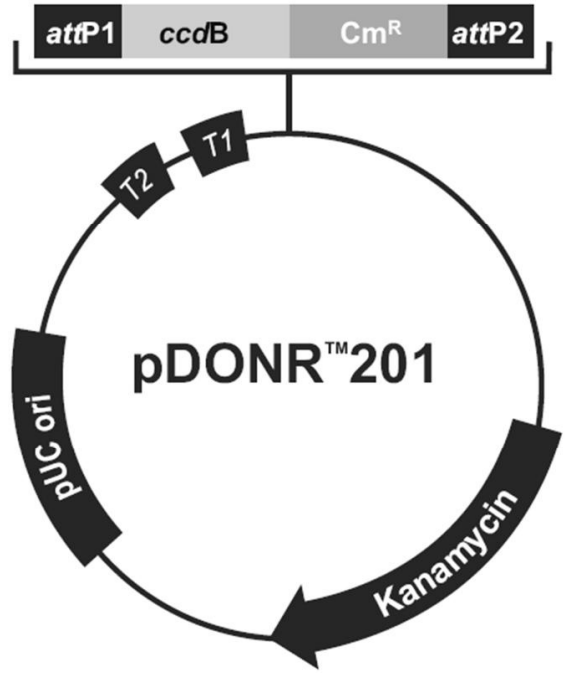

Figure S4.7: Map of important elements of the donor vector pDONR201. Source: http://www.biofeng.com.img.800cdn.com/uploads/\%E8\%BD\%BD\%E4\%BD\%93\%E5 $\% 9 \mathrm{~B} \% \mathrm{BE} \% \mathrm{E} 8 \% \mathrm{~B} 0 \% \mathrm{~B} 1 / \mathrm{pDONR} 201 \% \mathrm{E} 8 \% \mathrm{BD} \% \mathrm{BD} \% \mathrm{E} 4 \% \mathrm{BD} \% 93 \% \mathrm{E} 5 \% 9 \mathrm{~B} \% \mathrm{BE} \% \mathrm{E}$ $8 \% \mathrm{~B} 0 \% \mathrm{~B} 1 . \mathrm{gif}$ 
Table S4.3: Settings for BP-reaction

\begin{tabular}{llll}
\hline & for Ath & for Pta & for positive control \\
& in $\mu \mathrm{l}$ & in $\mu \mathrm{l}$ & in $\mu \mathrm{l}$ \\
\hline pDONR201 $(150 \mathrm{ng} / \mu \mathrm{l})$ & 0.5 & 0.5 & 0.5 \\
PCR-product/pos. control & 1.7 & 1.3 & 1 \\
$\mathrm{H}_{2} \mathrm{O}$ & 1.8 & 2.2 & 2.5 \\
$\mathrm{BP}-\mathrm{Clonase} \mathrm{II}$ & 1 & 1 & 1 \\
\hline room temperature over night & & \\
\hline Proteinase $\mathrm{K}$ & 0.5 & 0.5 & 0.5 \\
\hline $37^{\circ} \mathrm{C}$ for 10 min & &
\end{tabular}

\section{Transformation of $E$. coli}

Forty $\mu 1$ of electro competent E. coli TOP10 cells (generated by Invitrogen but own culture) were transformed with $2 \mu \mathrm{l}$ of BP-reaction products by using an electro shock of $1.8 \mathrm{kV}$. Afterwards, the cells were slightly shaken for about $1.5 \mathrm{~h}$ at $37^{\circ} \mathrm{C}$ in $1 \mathrm{ml}$ SOC medium.

Two hundred $\mu 1$ and $500 \mu 1$ of the cell suspension were streaked on LB-medium with kanamycin or tetracyclin (for control insert) and cultivated at $37^{\circ} \mathrm{C}$ overnight.

A colony PCR (PCR settings in Table S4.4) was performed to assess the success of the transformation (for the two genes). Single colonies were picked with a previously sterilized tooth stick and streaked on LB-medium with kanamycin to grow further. The tooth stick tip with the rest of the colony was swirled inside the PCR-mix. If not differently stated, nuclease free water was used for negative controls. For the Arabidopsis gene, pAtPAP10_S7At_fw (5'-CCGTTTAAGCCGTTCACGC-3') and pDONR_rev (5'-GTGCAATGTAACATCAGAGAT-3') were used as primers to amplify a product of about $820 \mathrm{bp}$. For the poplar gene pAtPAP10_S7_fw (5'TGTCCCATATAGAGCATCAG-3') and pDONR_rev were used to amplify a product of about 800 bp (Figure S4.8). 
Table S4.4: Settings for PCR-reaction of colony PCR after transformation of BPreaction

\begin{tabular}{|c|c|c|c|c|}
\hline Solutions & $\mu \mathrm{l}$ & \multirow[t]{2}{*}{ Programm } & \multicolumn{2}{|c|}{ Hot Start / Lid } \\
\hline 10x PCR Buffer $\left(\mathrm{NH}_{4}\right)_{2} \mathrm{SO}_{4}$ & 2.0 & & $105^{\circ} \mathrm{C}$ & \\
\hline $25 \mathrm{mM} \mathrm{MgCl}_{2}$ & 1.6 & Step & Temperature & time \\
\hline dNTP Mix (10 mM of each) & 0.4 & 1 & $95^{\circ} \mathrm{C}$ & hold \\
\hline Primer LP $(10 \mu \mathrm{M})$ & 1.0 & 2 & $95^{\circ} \mathrm{C}$ & $60 \mathrm{sec}$ \\
\hline Primer RP $(10 \mu \mathrm{M})$ & 1.0 & 3 & $94^{\circ} \mathrm{C}$ & $15 \mathrm{sec}$ \\
\hline Taq-Polymerase $(5 \mathrm{U} / \mu \mathrm{l})$ & 0.1 & 4 & $57^{\circ} \mathrm{C}$ & $30 \mathrm{sec}$ \\
\hline Water (nuclease free) & 12.9 & 5 & $72^{\circ} \mathrm{C}$ & $60 \mathrm{sec}$ \\
\hline Colony & $\sim 1 \mu 1$ & 6 & Go to 3 / Rep 35 & \\
\hline total volume & 20.0 & 7 & $72^{\circ} \mathrm{C}$ & $5 \mathrm{~min}$ \\
\hline & & 8 & Hold $4^{\circ} \mathrm{C} /$ Enter & \\
\hline
\end{tabular}

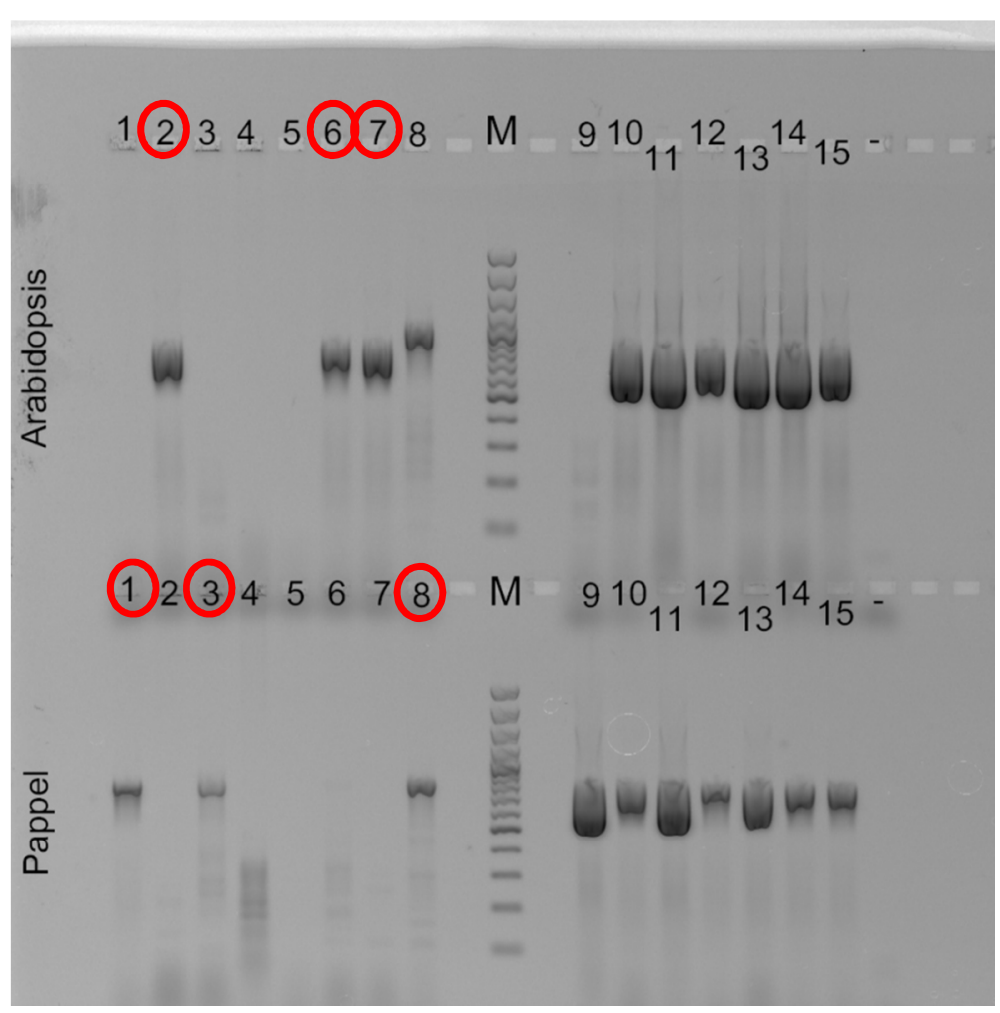

Figure S4.8: Results of colony PCR for transformation testing. M: marker (GeneRuler 100 bp Plus, see Figure S4.4). Numbers are individual colonies. First row: for Arabidopsis gene, second row: for poplar gene, -: water. Colors are inverted. $4 \mu 1$ PCRproduct, $1.2 \%$ agarose gel. Red circles mark chosen colonies for next steps.

\section{Plasmid-extraction and sequencing}

Colonies of A2, A6, A7, P1, P3 and P8 were grown in liquid LB medium and kanamycin overnight at $37^{\circ} \mathrm{C}$. The plasmids were extracted as given in the manual of the innuPREP Plasmid Mini Kit (Analytik Jena, Jena, Germany) for high-copy plasmids. The DNA concentrations were determined (A2: $421 \mathrm{ng} / \mu 1, \mathrm{~A} 6: 387 \mathrm{ng} / \mu 1, \mathrm{~A} 7$ : 
$360 \mathrm{ng} / \mu 1, \mathrm{P} 1: 204 \mathrm{ng} / \mu 1, \mathrm{P} 3: 262 \mathrm{ng} / \mu 1, \mathrm{P} 8: 195 \mathrm{ng} / \mu \mathrm{l})$ and a PCR conducted with the plasmids as template DNA and the same conditions as for the colony PCR (Table S4.4, results: Figure S4.9).

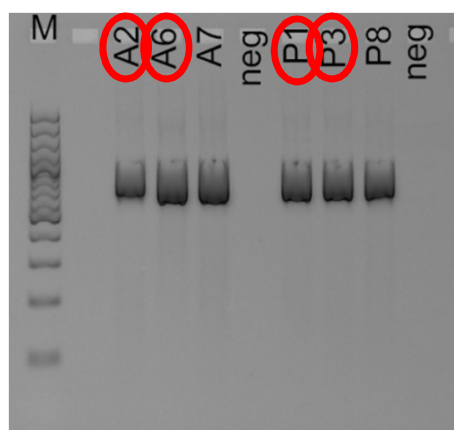

Figure S4.9: Results of plasmid PCR. M: marker (GeneRuler 100 bp Plus, see Figure S4.4). Numbers were individual colonies (A: for Arabidopsis gene, P: for poplar gene, neg: water). Colors are inverted. $1 \mu 1$ PCR-product, $2 \%$ agarose gel. Red circles mark chosen colonies for next steps.

The plasmids A2, A6, P1 and P3 were sequenced at the Seqlab Sequence Laboratories (Göttingen, Germany) with the primers pDONR_fw (5'TAACGCTAGCATGGATCTC-3') and pDONR_rev (5'GTGCAATGTAACATCAGAGAT-3') for both genes and pAtPAP10_AtS6_fw (5'TCATGGGTGACACAAGAAGC-3') for AtPAP1 and pAtPAP10_S6_fw (5'TGGGCTGAAAATAGTGAGC-3') for PtaPAP1.

Plasmid A6 had no differences to the coding sequence at Phytozome (Figure S4.10). Plasmid P1 had one T-to-C transition at $600 \mathrm{bp}$ that does not change the protein sequence. There were no further differences to the sequence at AspenDB (Xue et al., 2015) or to the aligned sequence of PtaPAPl in the RNA sequencing results of Anna Müller (Figure S4.11). 
$\begin{array}{llllllllll}340 & 350 & 360 & 370 & 380 & 390 & 400 & 410 & 420 & 430\end{array}$ pDoNR201-AtPAP10 CAAATAATGA TTPTATTTTG ACTGATAGT ACCTGTCGT TGCAACAAAT TGATGAGCAA TGCTTTTTA TAATGCCAAG TTTGTACAAA AAAGCAGGC TCACCATGG 1 Seq_pDONR_fw

2Seq_Ats6_tw

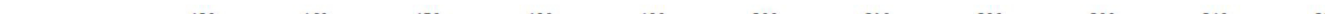

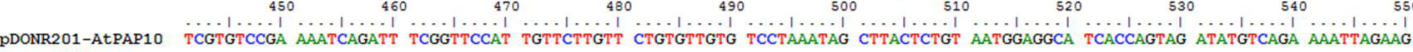
1 Seq_pDONR_fw

2Seq_Ats6_f $\mathrm{f} w$

3Seq_pDoNR_rev

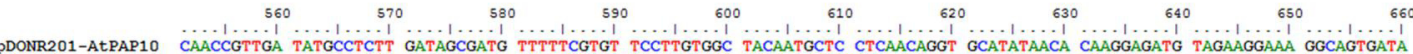
1Seq_pDoNR_ ${ }_{2}$ 3Seq_pDoNR_rev

$\begin{array}{llllllllll}670 & 680 & 690 & 700 & 710 & 720 & 730 & 740 & 750 & 760\end{array}$

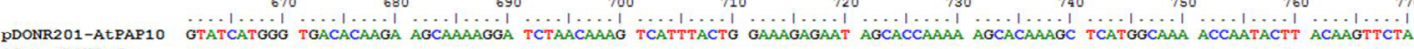
1 Seq_pDONR_fw 3Sec pDONR re

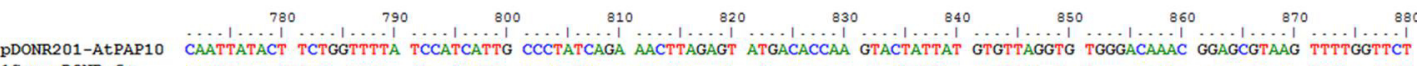
1 Seq_pDONR_fw

3Seq_pDoNR_rev

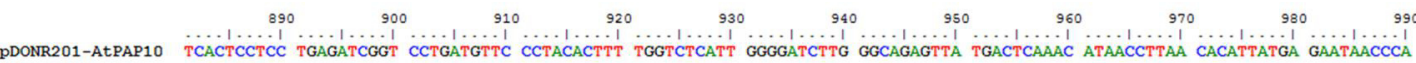
1 Seq_pDONR_fw

2Seq_AtS6_ $\bar{f} w$

3Seq_pDONR_rev

$\begin{array}{llllllllll}1000 & 1010 & 1020 & 1030 & 1040 & 1050 & 1060 & 1070 & 1080 & 1090\end{array}$ pDoNR201-AtPAP10 ACAAAGGGC AAGCGGTTT GTTCGTCGGC GATATCTCAT ACGCTGATAC TTATCCGGAT CATGACAATA GGAGATGGGA CAGTTGGGA AGATTTGCTG AAAGAGCAC 1Seq_pDONR fw

2Seq_atsG_f

3Seq_pDONR_rev

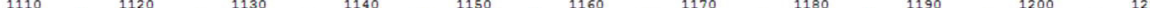

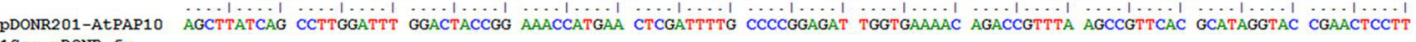
1 Seq_pDONR_fw 3Sec pDoNR rev PDONR201-AtPAP10 ACCGATCATC AGGCAGCACC GAACCATTCT GGTACTCGAT AAAGAGAGG CCGGCTTACA TAATCGTGCT AGCTTCATAT TCAGCATATG GAAATACAC ACCACAGTAC $1 \mathrm{Seq} \_\mathrm{pDONR} \mathrm{fw}$

3Seq_pDONR_rev

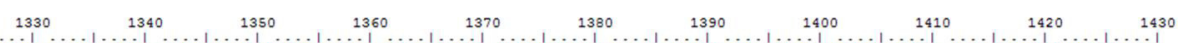

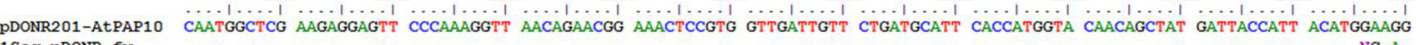
1Seq_pDONR_fw

2Seq_AtS6_f $\mathrm{f} w$

3Seq_pDONR_rev

$\begin{array}{llllllllll}1440 & 1450 & 1460 & 1470 & 1480 & 1490 & 1500 & 1510 & 1520 & 1530\end{array}$

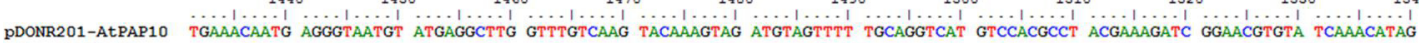
pDDNR201-AtPAP10 TGAAACAATG AGGGTAATGT ATGAGGCTTG GTTTGTCAAG TACAAAGTAG ATGTAGTTTT TGCAGGTCAT GTCCACGCCT ACGAAAGATC GGAACGTGTA TCAAACATAG
1 Seq_pDONR_fw 1Seq_pDONR_ $-\bar{f}$.

3Seq_pDoNR_re

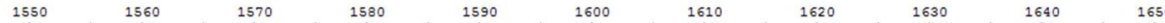
pDonR201-AtPAP10 CTTACAATGT TGTTACGGC ATTTGCACTC CAGTCAAAGA TCAATCAGCT CCAGTCTATA TCACCATTGG TGATGGAGGC AATATTGAGG GCTTGGCTAC CAAAATGACT 1Seq_pDONR_fw

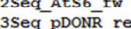

$\begin{array}{llllllllllll}1660 & 1670 & 1680 & 1690 & 1700 & 1710 & 1720 & 1730 & 1740 & 1750 & 1760\end{array}$ pDoNR201-AtPAP10 GAGCCTCAGC CTAAGTACTC TGCCTTTAGA GAAGCAAGCT TCGGCATGC TATATTCTCG ATAAAGAACA GGACGCATGC TCACTATGGA TGGCATAGGA ACCATGATGG 1 Seq_pDONR_fw

2Seq_Ats6_fw

3Seq_pDonR_rev

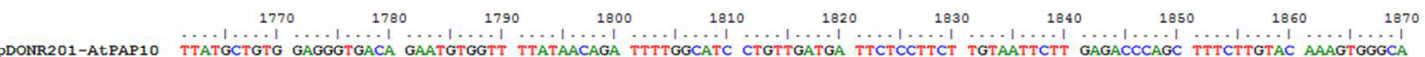

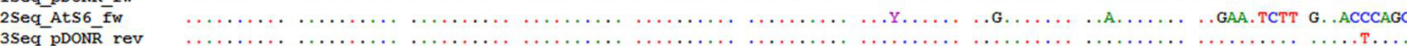
$\begin{array}{llllllllll}1880 & 1890 & 1900 & 1910 & 1920 & 1930 & 1940 & 1950 & 1960 & 1970 \quad 1980\end{array}$ pDonR201-AtPAP10 TTATAAGAA GCATTGCTTA TCAATTTGTT GCAACGACA GGTCACTATC AGTCAAAATA AAATCATTAT TTGCCATCCA GCTGCAGCTC TGGCCCGTG CTCAAAATCT 1Seq_pDONR_fw

2Seq_Ats6_fw

Figure S4.10: Alignment of the AtPAP10 plasmid sequences (1Seq to 3Seq) with the sequence of pDONR201 with inserted AtPAP10 coding sequence (pDONR201AtPAP10). 


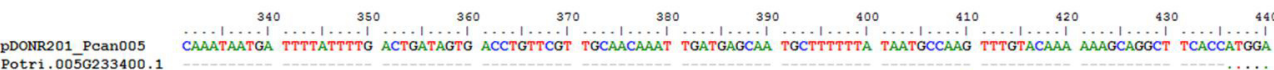

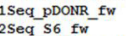
3Seq_pDONR_rev

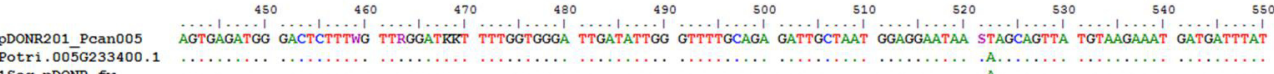
1Seq_pDONR $\mathrm{fw}$ 2 Seq_S6_fw

DDoNR201 Pcan005 PDONR201_Pcan005 1Seq_pDONR_fw

Thor

pDoNR201_PCan005
Potri.005G233400.1 1Seq_pDoNR_fw $2 S e q$ S6 fw
3 Seq_pDoNR_rev

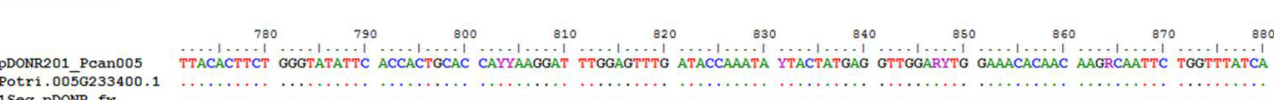
1Seq_pDONR_fw

pDONR201_Pcan005
Potri.005G233400.1
1Seq pDONR fw 1 Seq pDoNR $\mathrm{fw}_{2}$

3Seq_pDoNR_rev

pDoNR201_Pcan005 1509 Dors $f \times$ 15eq_pDOAR_Ev 3Seq_pDONR_rev

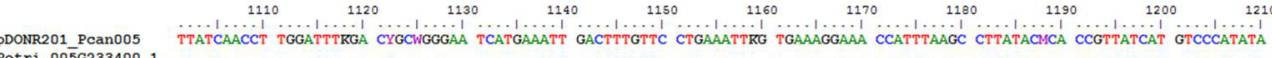
Potri.005G233400.

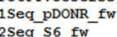
2Seq_S6_fw

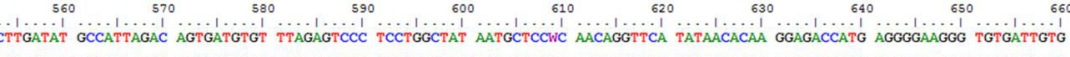
$\begin{array}{cccccccccccc}670 & 600 & 690 & 700 & 710 & 720 & 730 & 740 & 750 & 760 & 770 \\ \text { TCTTGGGTTA CACCAGATGA GCSTGGTTCA ACGACAGTGC } & \text { TTTACTGGGC TGAAAATAGT GAGCTAAAAA ATTCTGCAGA TGGCTTTATT TTGAAKTATA GATACTTCAA }\end{array}$

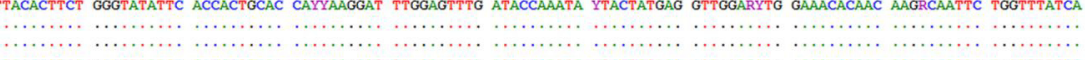

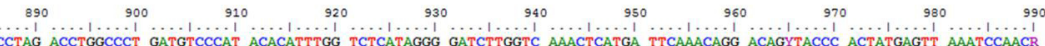

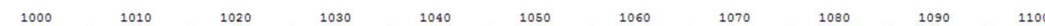

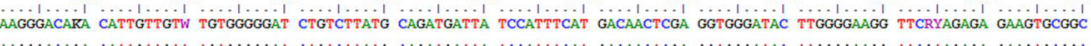

$\begin{array}{llllllllll}1220 & 1230 & 1240 & 1250 & 1260 & 1270 & 1280 & 1290 & 1300 & 1310\end{array}$ pDonR201_Pcano05 GAGCATCAGG GAGCACATCR CMGATGTGG ACTCCATCAA GAGAGCTTCR GCATACATSA TTGTCTTGTC CTCYTACTCA GCTTATGGAA AATACACTCC TCAATACARA 1Seq_pDoNR_fw

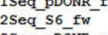

pDoNR201_Pcan005
Potri.005 2333400.1 1Seq_pDONR_fw 3Seq_pDONR_rev pDonr201_Poano05
Potri.005G233400.1
1Seq_pDONR_fw 3Seq_pDONR_rev

pDONR201_Pcan005 1 Seq_pDONR_fw $2 \mathrm{Seq} \mathrm{S}_{-} \mathrm{IW}^{-}$ 3Seq_pDONR_rev

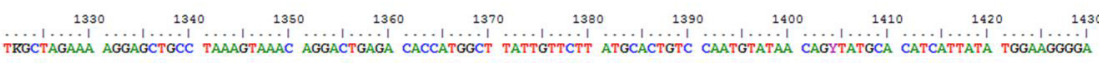

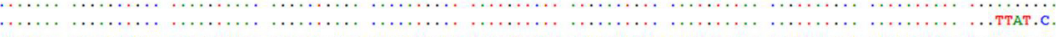

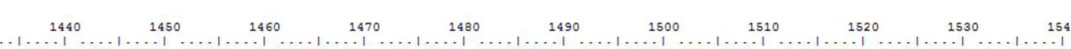

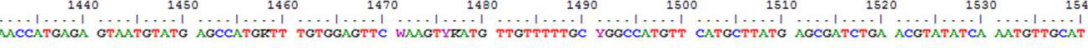

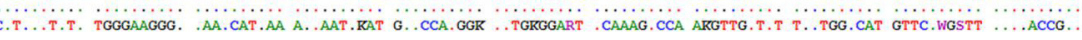

$$
\begin{array}{lllllllllll}
1550 & 1560 & 1570 & 1580 & 1590 & 1600 & 1610 & 1620 & 1630 & 1640 & 1650
\end{array}
$$
ACAACATCGT GAAYGGTTG TGCRCTCCCA TAAGAGATMA ATCYGCCCCC ATTTACATAA CCATTGGAGA YGGAGGAÄ CTAGAAGGAT TAGTGACMÁ CATGACAGAG CYGGA.GGR. WTY.ApDoNR201_Pcan005
Potri.005G233400.1
1Seq_pDONR_w
2Sec_S6_fw 3Seq_pDONR_rev

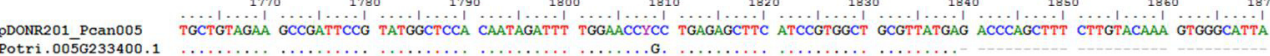
1Seq_pDonR_fw 2Seq_S6_fw 3Seq_ pDoNR rev

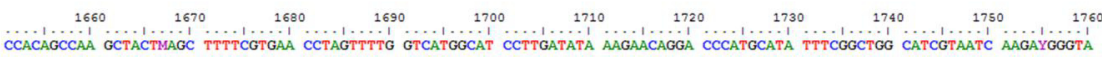

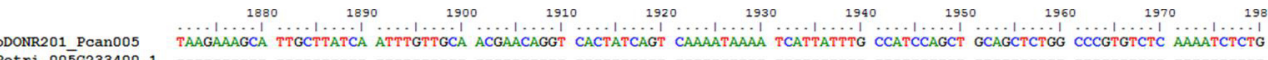
1 1Seq_pDonR_fw 2Seq_S6_fw

3Seq_pDôR_ rev

Figure S4.11: Alignment of the PtaPAP1 plasmid sequences (1Seq to 3Seq) with the sequence of pDONR201 with inserted PtaPAPl coding sequence of Anna Müller's data (pDONR201_Pcan005) and the data of AspenDB (Potri.005G233400.1). 


\section{LR-Reaction}

The vector pGWB2 has the sequence of a 35S-promoter, and kanamycin and hygromycin resistance genes for bacteria and plants (Figure S4.12). Also for the LRreaction, entry-vector and destination-vector were used in equimolar concentrations. Therefore, A6 and P1 were diluted to $11 \mathrm{ng} / \mu 1$.

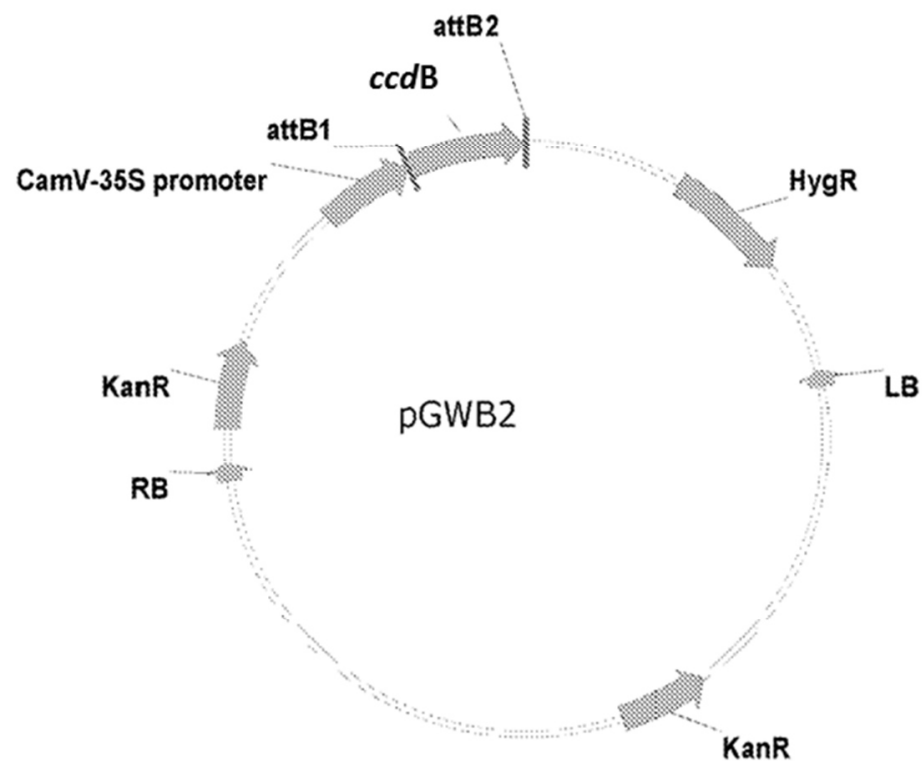

Figure S4.12: Map of important elements of the destination vector pGWB2. Source: www.google.com/patents/EP2357239A1?cl=en (mod.)

Table 5: Settings for LR-reaction

\begin{tabular}{ll}
\hline solution & amount in $\mu 1$ \\
\hline pGWB2 (50 ng/ $\mathrm{l})$ & 1 \\
pENTR (pDONR201 with AtPAP10 or PtaPAP1 & 1 \\
or pENTR-gus as positive control) & \\
$\mathrm{H}_{2} \mathrm{O}$ & 2 \\
LR-Clonase II & 1 \\
\hline room temperature over night & \\
\hline Proteinase $\mathrm{K}$ & 0.5 \\
\hline $37^{\circ} \mathrm{C}$ for $10 \mathrm{~min}$ &
\end{tabular}

Transformation of $E$. coli TOP10 cells with the LR-reaction products was as described above for the BP-reaction products.

Selection of clones was done on LB-medium with kanamycin and hygromycin addition.

Colony-PCR for each 6 colonies for the Arabidopsis and poplar gene was performed with conditions described in Table S4.6 with following primers for AtPAP10: 
SALK_122362_LP (5'-CTTTTGCTTCTTGTGTCACCC-3') and pGWB2_fw (5'catttggagagaacacggggg-3') resulting in a product of $411 \mathrm{bp}$; and primers Pc005G233400_rev (5'-CCCAAGACACAATCACACCC-3') and pGWB2_fw for PtaPAP1 resulting in a product of 390 bp (Figure S4.13).

Table S4.6: Settings for PCR-reaction of colony PCR after transformation of LRreaction

\begin{tabular}{|c|c|c|c|c|}
\hline solutions & $\mu l$ & & & \\
\hline 10x PCR Puffer $\left(\mathrm{NH}_{4}\right)_{2} \mathrm{SO}_{4}$ & 2.0 & Programm & Hot Start / I & \\
\hline $25 \mathrm{mM} \mathrm{MgCl}_{2}$ & 1.6 & & $105^{\circ} \mathrm{C}$ & \\
\hline dNTP Mix (10 mM of each) & 0.4 & Step & Temperature & Time \\
\hline Primer LP $(10 \mu \mathrm{M})$ & 1.0 & 1 & $95^{\circ} \mathrm{C}$ & hold \\
\hline Primer RP $\quad(10 \mu \mathrm{M})$ & 1.0 & 2 & $95^{\circ} \mathrm{C}$ & $60 \mathrm{sec}$ \\
\hline Taq-Polymerase $(5 \mathrm{U} / \mu \mathrm{l})$ & 0.1 & 3 & $94^{\circ} \mathrm{C}$ & $15 \mathrm{sec}$ \\
\hline Water (nuclease free) & 12.9 & 4 & $54^{\circ} \mathrm{C}$ & $30 \mathrm{sec}$ \\
\hline Colony & $\sim 1 \mu 1$ & 5 & $72^{\circ} \mathrm{C}$ & $30 \mathrm{sec}$ \\
\hline \multirow[t]{3}{*}{ total volume } & 20.0 & 6 & Go to 3 / Rep 35 & \\
\hline & & 7 & $72^{\circ} \mathrm{C}$ & $5 \mathrm{~min}$ \\
\hline & & 8 & Hold $4^{\circ} \mathrm{C} /$ Enter & \\
\hline
\end{tabular}

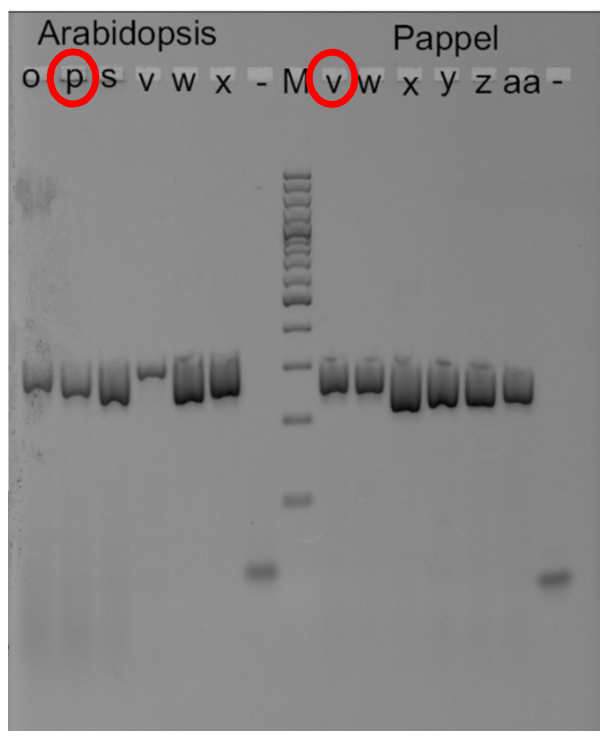

Figure S4.13: Results of colony PCR. M: marker (GeneRuler 100 bp Plus, see Figure S4.4). Letters were individual colonies (Arabidopsis: for Arabidopsis gene, Pappel: for poplar gene, -: water). Colors are inverted. $2 \mu \mathrm{l}$ PCR-product, $2 \%$ agarose gel. Red circles mark chosen colonies for next steps. 
Plasmid extraction from overnight cultures of A6p and P1v was performed as described above resulting in plamid extracts with concentrations of $18.7 \mathrm{ng} / \mu 1$ for A6p and 14.3 $\mathrm{ng} / \mu \mathrm{l}$ for P1v.

A control-PCR of plasmids as in Table S4.6 with 1:100 dilution of plasmid extract and controls was performed (Figure 14). Enzyme digestion of the plasmids with BsrGI and NcoI in two separate reactions was performed with following conditions as control:

$4 \mu 1$ Plasmid

$4.75 \mu 1$ Water

$1 \mu 1$ Tango-Buffer

$0.25 \mu 1 \mathrm{BsrGI} / \mathrm{NcoI}$

$37^{\circ} \mathrm{C}, 3-4 \mathrm{~h}$

Expectations for BsrGI:

pGWB2 (empty): 402 bp, 1295 bp, 15539 bp

pGWB2 + Ath-Gene: 1443 bp, 15539 bp

pGWB2 + Pta-Gene: 1440 bp, 15539 bp

Expectations for NcoI:

pGWB2 (empty): 528 bp, 1310 bp, 1879 bp, 2250 bp, 3058 bp, 3398 bp, 4813 bp

pGWB2 + Ath-Gene: 528 bp, 579 bp, 959 bp, 1879 bp, 2250 bp, 2576 bp, 3405 bp, 4813 bp

pGWB2 + Pta-Gene: 90 bp, 528 bp, 579 bp, 929 bp, 1879 bp, 2250 bp, 2513 bp, 3405 bp, 4813 bp

The results of the enzyme digestions (Figure S4.14) shows that the bands $3405 \mathrm{bp}$ and $4813 \mathrm{bp}$ for NcoI were not divided. 


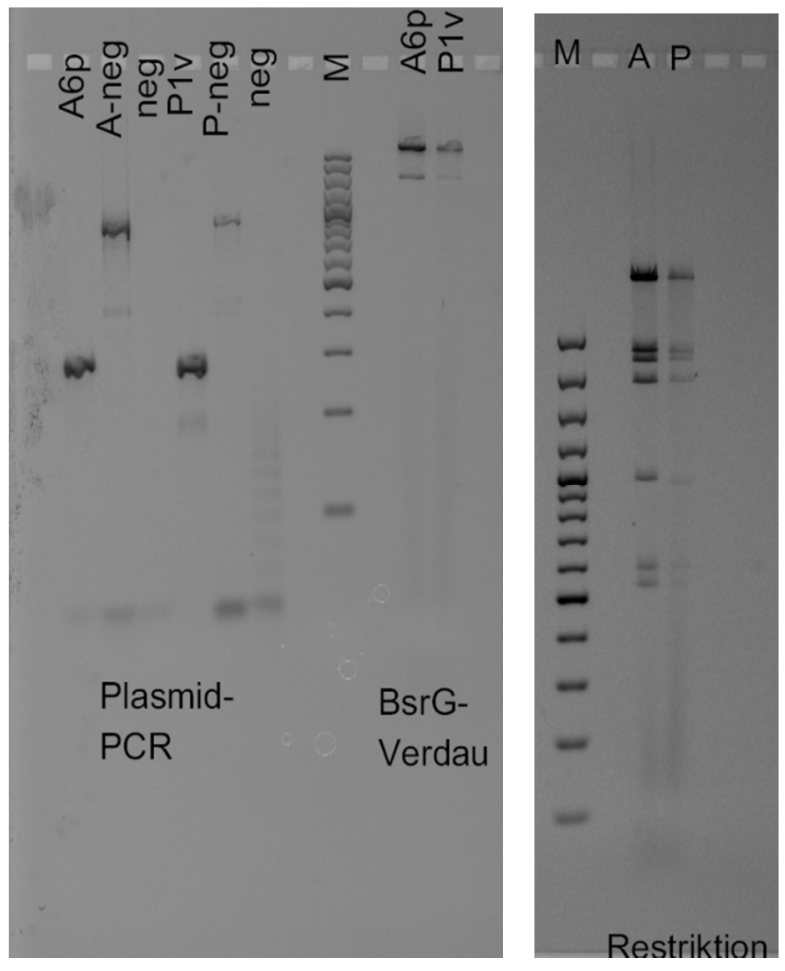

Figure S4.14: Results of plasmid PCR (Plasmid-PCR) and digestions with BsrGI (BsrG-Verdau) and NcoI (Restriktion). M: marker (GeneRuler 100 bp Plus, see Figure S4.4). Letters were individual colonies (A-neg/P-neg: plasmids with negative PCR results for $A t P A P 10$ and $P t a P A P 1$, neg: water). Colors are inverted.

Plasmids of overnight cultures of A6p and P1v ( $>$ A6p1 and P1v1) were extracted and sequenced. The sequences were identical to the sequences above (Figures S4.10 and S4.11).

These plasmids were (re)transformed into E. coli TOP10 cells and, after positive colony PCR (colonies number A6p1f and P1v1f) extracted by midi-plasmid extraction (Macherey-Nagel Düren, Germany) for low copy plasmids as described in the manual, and digested with NcoI (same result as above). The concentrations were $104 \mathrm{ng} / \mu \mathrm{l}$ for A6p1f and $88.5 \mathrm{ng} / \mu 1$ for P1v1f.

The pGWB2-gus-plasmid was extracted from an overnight culture (Midi-Prep with column (1,2), Midi-Prep without column (3)) resulting in concentrations of $22.5 \mathrm{ng} / \mu 1$ (1, concentrated to $69 \mathrm{ng} / \mu \mathrm{l}$ at $50^{\circ} \mathrm{C}$ in SpeedVac), $10 \mathrm{ng} / \mu \mathrm{l}(2)$ and $1145 \mathrm{ng} / \mu \mathrm{l}(3)$ and digested with NcoI.

\section{Agrobacteria-Transformation}

Agrobacterium tumefaciens (GV3101pMP90RK) was transformed with about $3 \mu \mathrm{g}$ plasmid. $200 \mu \mathrm{l}$ competent agrobacteria were mixed with the plasmid (Ath: $29 \mu 1$, Pta: $34 \mu 1$, for gus-control: $32 \mu 1$ of 1) $+0,7 \mu 1$ of 3)) and cooled on ice for 30 min with 
occasional slight mixing, frozen for $2 \mathrm{~min}$ in liquid nitrogen and heated for $5 \mathrm{~min}$ at $37^{\circ} \mathrm{C}$ in a heating block. $800 \mu \mathrm{l}$ YEB-Medium were added and the sample was slightly shaked at $28^{\circ} \mathrm{C}$ for about $4 \mathrm{~h}$.

Two hundred and $400 \mu \mathrm{l}$ cell suspension were streaked on YEB medium with kanamycin, hygromycin and gentamycin. After $2 \mathrm{~d}$ at $28^{\circ} \mathrm{C}$ each two colonies were grown as overnight cultures $\left(2 \mathrm{~d}, 28^{\circ} \mathrm{C}\right)$. Glycerol stocks (A1, A2 for AtPAP10 and P1, P2 for PtaPAP1) were set up and the plasmids extracted with NcoI (results as above).

\section{Arabidopsis transformation}

Flowering Arabidopsis wild type and mutants (pap10-1, SALK_122362) were transformed.

Agrobacteria from stocks A1 and P1 were streaked on plates and three colonies each were used to inoculate the floral dip mix (20 ml YEB medium with kanamycin and hygromycin). Two times $400 \mathrm{ml}$ YEB medium with antibiotics were inoculated with this mix and grown to an OD of 0.8 . The inoculated medium was centrifuged (5000 rpm for $15 \mathrm{~min}$ ) and the pellet resuspended in 10 to $20 \mathrm{ml} 5 \%$ saccharose solution, again centrifuged (5000 rpm for $15 \mathrm{~min}$ ) and the pellet resuspended in $200 \mathrm{ml} 5 \%$ saccharose solution and cooled on ice. $100 \mu$ Silwett was added and Arabidopsis flowers were swiveled inside for 5 to $10 \mathrm{sec}$. The Arabidopsis plants were left overnight in the laboratory with hood and then put again in the climate cabinet. One week later the transformation procedure was repeated.

\section{Arabidopsis selection}

Seeds of the transformed Arabidopsis-flowers were sowed on $1 / 2$ MS-medium with kanamycin and hygromycin. Plants which grew longer hypocotyls (Figure S4.15) were placed on $1 / 2$ MS-medium without antibiotics for about one week and then on soil.

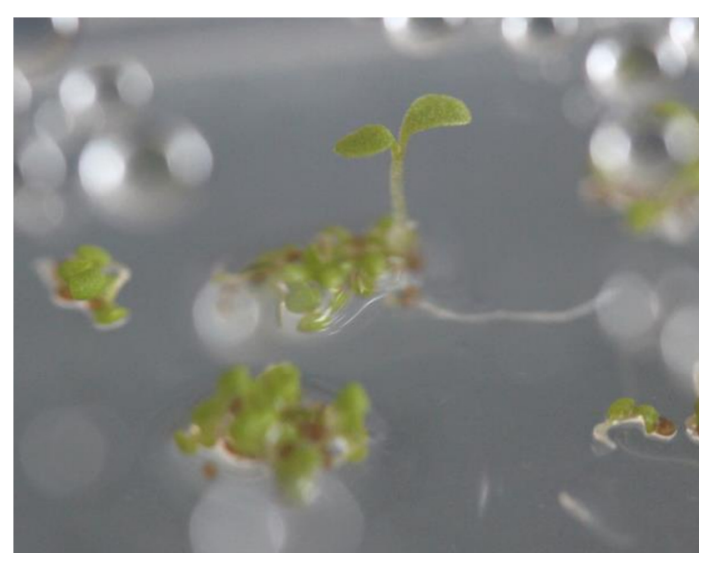

Figure S4.15: Germinated Arabidopsis seeds of plants after flower dip on selection medium. To differentiate are plants with long hypocotyl (with antibiotic resistance gene) and with short hypocotyl (transformation not successful). 
A control PCR was conducted with DNA from leaves with the primers SALK_122362_LP or Pc005G233400_rev or gus_rev (5'GATTATTGACCCACACTTTGCC-3') and pGWB2_fw as above.

Although the successful transformation of Arabidopsis was demonstrated by PCR, a functional complementation could be achieved neither by the AtPAP10 positive control nor by the PtaPAPl gene (Figure S4.16). Further work (semi-quantitative PCR) could not detect any expression of PtaPAPl in the transformed Arabidopsis plants and only low expression of AtPAP10 in the pap10-mutant plants (also in non-transformed pap10plants) (U. Lipka, personal communication).

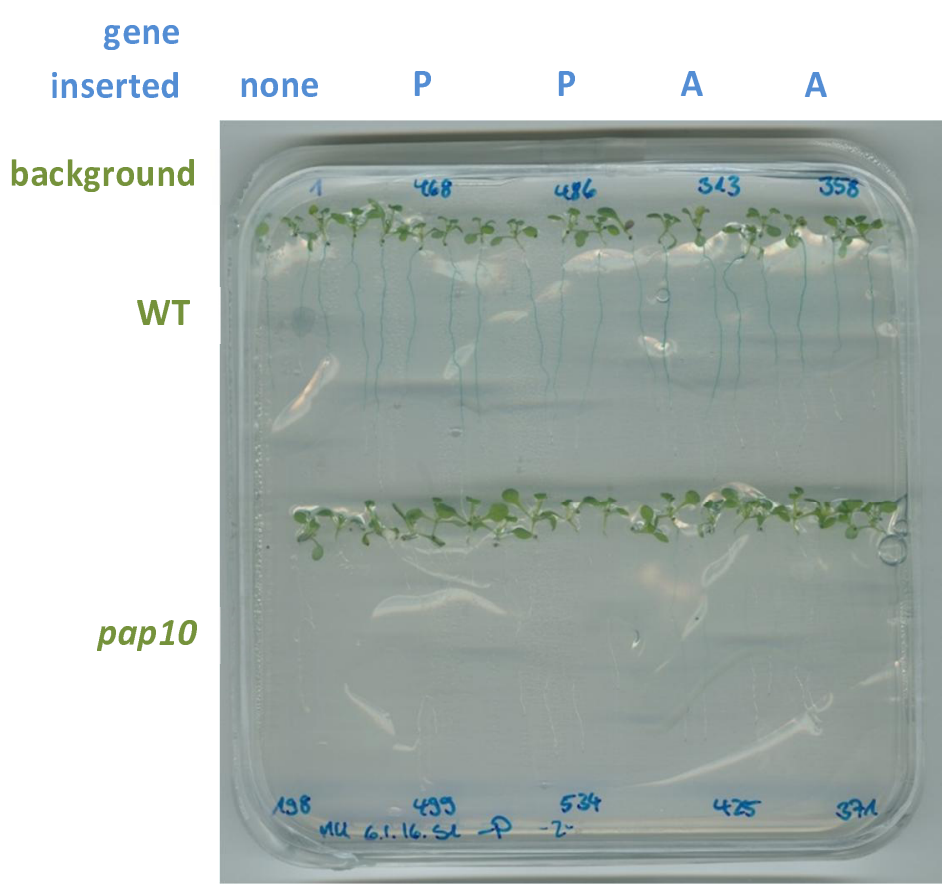

Figure S4.16: BCIP-staining of Arabidopsis roots for acid phosphatase activity. Arabidopsis plants (seeds of wild type (WT), pap10 and the plants positively tested for transformation with AtPAP10 (A) or PtaPAP1 (P) by PCR) were grown vertically on $1 / 2$ MS-medium for $8 \mathrm{~d}$ without $\mathrm{P}$, overlaid with $0.01 \%$ BCIP- $0.8 \%$ Agar-medium and scanned after $4 \mathrm{~d}$.

\section{Possible faults and suggestions for improvement}

Possible reasons for this lack of expression could be a fault of the vector (e.g. wrong labeling in the stocks that would also explain the one missing enzyme restriction site). Also gene silencing due to the 35S-promoter and possible multiple insertion sites in the genome is possible. A requirement of the UTR-sites for expression or the expression of other transcripts in wild type plants might be another possibility. 
Therefore, I suggest using a different vector and a different promoter (e.g. root specific, ubiquitin promoter, AtPAP10-promoter, PtaPAP1-promoter) for future studies. Furthermore, codon optimization is a tool for improved transient expression. By using the genomic sequence or the whole transcript sequence including untranslated regions, any required additional information for expression is included.

In addition, it would be worth to transform poplar for PtaPAPI overexpression lines to validate PAP secretion due to PtaPAP1 under low phosphate conditions. 


\section{Media and protocols}

\section{$1 / 2$ Murashige and Skoog (MS) medium for Arabidopsis with and without $P$}

$\begin{array}{ll}\text { Macro solution } & \mathrm{g} / 500 \mathrm{ml} \\ \mathrm{NH}_{4} \mathrm{NO}_{3} & 8.25 \\ \mathrm{KNO}_{3} & 9.5 \\ \mathrm{CaCl}_{2} \times 2 \mathrm{H}_{2} \mathrm{O} & 2.2 \\ \mathrm{MgSO}_{4} \times 7 \mathrm{H}_{2} \mathrm{O} & 1.85 \\ \mathrm{KCl} \text { or } \mathrm{KH}_{2} \mathrm{PO}_{4} & 0.465 \text { or } 0.85 \\ & \\ \mathrm{Micro} \mathrm{solution} & \mathrm{mg} / 100 \mathrm{ml} \\ \mathrm{H}_{3} \mathrm{BO}_{3} & 620 \\ \mathrm{MnSO}_{4} \times \mathrm{H}_{2} \mathrm{O} & 1000 \\ \mathrm{ZnSO}_{2} \times 7 \mathrm{H}_{2} \mathrm{O} & 860 \\ \mathrm{KJ} & 83 \\ \mathrm{Na}_{2} \mathrm{MoO}_{4} \times 2 \mathrm{H} \mathrm{O} & 25 \\ \mathrm{CuSO}_{4} 5 \mathrm{H}_{2} \mathrm{O} & 2.5 \\ \mathrm{CoCl}_{2} \times 6 \mathrm{H}_{2} \mathrm{O} & 2.5 \mathrm{mg}\end{array}$

Vitamin solution $\mathrm{mg} / 100 \mathrm{ml}$

Nicotinacid $\quad 50$

Pyridoxin- $\mathrm{HCl} \quad 50$

Thiamin- $\mathrm{HCl} \quad 10$

\begin{tabular}{ll} 
Glycin solution & $\mathrm{mg} / 100 \mathrm{ml}$ \\
\hline Glycin & 200
\end{tabular}

$\begin{array}{ll}\text { Inosit solution } & \mathrm{g} / 250 \mathrm{ml}\end{array}$

Iron solution $\quad \mathrm{g} / 250 \mathrm{ml}$

$\mathrm{C}_{10} \mathrm{H}_{12} \mathrm{FeN}_{2} \mathrm{NaO}_{8} \quad 1.835$

$50 \mathrm{ml}$ Macro solution, $0.5 \mathrm{ml}$ Micro solution, $0.5 \mathrm{ml}$ Vitamin solution, $0.5 \mathrm{ml}$ Glycin solution, $2.5 \mathrm{ml}$ Iron solution and $2.5 \mathrm{ml}$ Inosit solution are mixed with $10 \mathrm{~g}$ saccharose, $0.5 \mathrm{~g}$ MES and $8 \mathrm{~g}$ Agar and water added to 11 (pH 5.7).

autoclaving 


\section{LB medium}

5 g yeast extract

$10 \mathrm{~g}$ trypton

$10 \mathrm{~g} \mathrm{NaCl}$

(15 g Agar)

ad 11 water, $\mathrm{pH} 7$

autoclaving

\section{YEB medium}

$5 \mathrm{~g}$ beef extract

$1 \mathrm{~g}$ yeast extract

5 g peptone

5 g saccharose

$493 \mathrm{mg} \mathrm{MgSO}_{4}$ × $7 \mathrm{H}_{2} \mathrm{O}$

(15 g Agar)

ad 11 water, $\mathrm{pH} 7.2$

autoclaving

\section{SOB medium}

20 g trypton

$5 \mathrm{~g}$ yeast extract

$0.6 \mathrm{~g} \mathrm{NaCl}$

$0.2 \mathrm{~g} \mathrm{KCl}$

$990 \mathrm{ml} \mathrm{H}_{2} \mathrm{O}$

autoclaving

$10 \mathrm{ml}$ sterile $\mathrm{MgCl}_{2} / \mathrm{MgSO}_{4}$ x $7 \mathrm{H}_{2} \mathrm{O}$ solution

$\mathrm{MgCl}_{2} / \mathrm{MgSO}_{4}$ × $7 \mathrm{H}_{2} \mathrm{O}$ solution

$20.331 \mathrm{~g} \mathrm{MgCl}_{2}$

$24.64 \mathrm{~g} \mathrm{MgSO}_{4}$ × $7 \mathrm{H}_{2} \mathrm{O}$

$100 \mathrm{ml} \mathrm{H}_{2} \mathrm{O}$

autoclaving

\section{SOC medium}

SOB medium with $20 \mathrm{mM}$ glucose 
Table S4.7: Antibiotics concentrations

\begin{tabular}{lccc}
\hline Antibiotics & $\begin{array}{c}\text { E. coli } \\
{\left[\mu \mathrm{g} \mathrm{m}^{-1}\right]}\end{array}$ & $\begin{array}{c}\text { A. tumefaciens } \\
{\left[\mu \mathrm{g} \mathrm{ml}^{-1}\right]}\end{array}$ & $\begin{array}{c}\text { A. thaliana } \\
{\left[\mu \mathrm{g} \mathrm{m}^{-1}\right]}\end{array}$ \\
\hline Kanamycin & 100 & 100 & 50 \\
Hygromycin & 50 & 50 & 25 \\
Ampicillin & 100 & & \\
Tetracyclin & 20 & & \\
Streptinomycin & 100 & 25 & \\
Gentamycin & & 150 & \\
Rifampicin & & & \\
\hline
\end{tabular}

\section{Electrocompetent $E$. coli TOP10}

One colony of $E$. coli TOP10 cells was used to inoculate $50 \mathrm{ml}$ SOB-medium with streptomycin. Five $\mathrm{ml}$ of this culture grown over night at $37^{\circ} \mathrm{C}$ was used to inoculate $500 \mathrm{ml} \mathrm{SOB}$-medium without antibiotics and grown at $37^{\circ} \mathrm{C}$ until an optical density at $578 \mathrm{~nm}$ of $0.46-0.48$. The culture was cautiously swirled on ice for $10 \mathrm{~min}$, centrifuged at $5400 \mathrm{~g}$ for $10 \mathrm{~min}$ at $4^{\circ} \mathrm{C}$, and the pellet two times washed with cold deionized water (about $250 \mathrm{ml}$, then about $125 \mathrm{ml}$ with centrifuging as above). The pellet was resuspended in $12.5 \mathrm{ml} 10 \%$ glycerol (sterile, cold) and centrifuged again as above. The pellet of $500 \mathrm{ml}$ culture was resuspended in $2 \mathrm{ml} 10 \%$ glycerol and aliquots of $40 \mu \mathrm{l}$ frozen in liquid nitrogen and stored at $-80^{\circ} \mathrm{C}$.

\section{Electrocompetent $A$. tumefaciens GV3101pMP90RK}

One colony of A. tumefaciens (GV3101pMP90RK) cells was used to inoculate $50 \mathrm{ml}$ YEB-medium with gentamycin, rifampicin and kanamycin and grown for 2 days at $28^{\circ} \mathrm{C}$. Two $\mathrm{ml}$ of this culture were used to inoculate $50 \mathrm{ml}$ YEB-medium without antibiotics and grown until an optical density at $600 \mathrm{~nm}$ of 0.5 and centrifuged for $5 \mathrm{~min}$ at $4^{\circ} \mathrm{C}$ with $5000 \mathrm{rpm}$ (Minifuge RF, Heraeus, Hanau, Germany). The pellet was resuspended in $10 \mathrm{ml} 0.15 \mathrm{M} \mathrm{NaCl}$ (cold) and again centrifuged as above. The pellet of $50 \mathrm{ml}$ culture was resuspended in $1 \mathrm{ml} 75 \mathrm{mM} \mathrm{CaCl}$ (cold) and aliquots of $200 \mu \mathrm{l}$ frozen in liquid nitrogen and stored at $-80^{\circ} \mathrm{C}$. 


\section{References for supplements Chapter 4}

Luo, Z.-B., Janz, D., Jiang, X., Göbel, C., Wildhagen, H., Tan, Y., Rennenberg, H., Feussner, I., Polle, A. (2009): Upgrading root physiology for stress tolerance by ectomycorrhizas: Insights from metabolite and transcriptional profiling into reprogramming for stress anticipation. Plant Physiol. 151, 1902-1917.

Wang, L., Li, Z., Qian, W., Guo, W., Gao, X., Huang, L., Wang, H., Zhu, H., Wu, J.-W., Wang, D., Liu, D. (2011): The Arabidopsis purple acid phosphatase AtPAP10 is predominantly associated with the root surface and plays an important role in plant tolerance to phosphate limitation. Plant Physiol. 157, 1283-1299.

Xue, L.-J., Alabady, M.S., Mohebbi, M., Tsai, C.-J. (2015): Exploiting genome variation to improve next-generation sequencing data analysis and genome editing efficiency in Populus tremula $\times$ alba 717-1B4. Tree Genet. Genomes 11, 82. 


\subsection{Declaration}

The following data shown in this chapter have been provided:

- All laboratory steps for microarray analyses (from RNA quality determinations to raw data) were provided by the Microarray Facility (MFT Services, Tübingen, Germany).

- Proteomic analyses (from AWF to annotated proteins) were conducted by Dr. Andrzej Majcherczyk (Molecular Wood Biotechnology and Technical Mycology, Büsgen-Institute, Georg-August University of Göttingen). 


\section{Discussion}

\subsection{Discussion}

Phosphorus $(\mathrm{P})$ is needed in high amounts by plants but $\mathrm{P}$ is one of the least available nutrients in the soil. In this thesis it was studied how young poplar trees react to phosphate deprivation on transcriptional level and how these changes reflect on growth, phosphate uptake from soil and the phosphate acquisition potential from the soil.

The growth of Populus $\times$ canescens was decreased at P availabilities below $64 \mu \mathrm{M}$ similar as reported for $P$. tremuloides (Desai et al., 2014). In the present study, the phosphorus concentrations in the tissues of plants grown with $\mathrm{P}$ availabilities of $6.4 \mu \mathrm{M}$ were similar to those in poplars grown in plantations (Ge et al., 2015). Van den Burg (1985) found that foliar $\mathrm{P}$ concentrations between $1.7 \mathrm{mg} \mathrm{g}^{-1}$ and $2.7 \mathrm{mg} \mathrm{g}^{-1}$ were sufficient for growth of young $P . \times$ canescens. Therefore, the foliar $\mathrm{P}$ concentrations $1.25 \mathrm{mg} \mathrm{g}^{-1}$ and $0.69 \mathrm{mg} \mathrm{g}^{-1}$ dry mass in leaves of plants grown with intermediate and low $\mathrm{P}$ availability, respectively, seemed to suggest deficiency, whereas the $\mathrm{P}$ concentration for control plants $\left(6.8 \mathrm{mg} \mathrm{g}^{-1}\right)$ can be considered as luxurious.

Most of the other measured nutrient concentrations in the plant tissues were also changed upon lower $\mathrm{P}$ availabilities, however not as strong as the $\mathrm{P}$ concentration. Decreased concentrations in nutrients other than $\mathrm{P}$ in the poplar tissues were still above the deficiency thresholds (Burg, 1985). That implies that deficiency symptoms were solely based on the decreased $\mathrm{P}$ concentrations or disturbed nutrient rates. Changes in nutrient concentrations were also shown in P starved Arabidopsis (Kellermeier et al., 2014; Misson et al., 2005; Ward et al., 2008). For example, reduced potassium, calcium and magnesium concentrations in poplar leaves were also detected in $\mathrm{P}$ starved Arabidopsis (Kellermeier et al., 2014; Misson et al., 2005; Ward et al., 2008). A reduction in manganese concentration (Kellermeier et al., 2014; Ward et al., 2008) and a strong increase in iron concentration as in P starved Arabidopsis leaves (Gruber et al., 2013; Hirsch et al., 2006; Kellermeier et al., 2014; Rai et al., 2015) could not be detected in P starved poplar. 
Here, it was demonstrated for a tree, poplar, that a massive transcriptomic reprogramming had taken place upon P starvation. But only a small part of the regulated genes were directly correlated with the total tissue $\mathrm{P}$ concentrations. This observation suggests an indirect regulation by the total $\mathrm{P}$ concentration, by free phosphate concentrations or by co-occurring changes in e.g. other nutrient concentrations. Among the genes related to the $\mathrm{P}$ concentration were known $\mathrm{P}$ responsive genes that were also strongly regulated in Arabidopsis (e.g. SPX, PAP, SQD) (Lan et al., 2015). In poplar, genes involved in membrane lipid remodeling were found in the P-responsive gene module. They were also reported in a "core gene"-set (Lan et al., 2015) of P starvation response in Arabidopsis. This finding suggests similar transcriptional alterations in poplar and Arabidopsis.

Upon P starvation in leaves and roots PtPHT1;9 and PtPHT1;12 were upregulated in $P$. $\times$ canescens in this study. Their $\mathrm{P}$ responsiveness was also reported in P. trichocarpa roots (Loth-Pereda et al., 2011). The homologous Arabidopsis proteins take up P in the roots (AtPHT1;8, AtPHT1;9) (Remy et al., 2012) and are located in the vascular system (AtPHT1;12) (Mudge et al., 2002). Therefore the strong induction of PtPHT1;9 and PtPHT1;12 gene expression suggests a role in $\mathrm{P}$ uptake and long-distance transport in poplar. In this study, PtPHT1;1 and PtPHT1;2 were highly upregulated upon $\mathrm{P}$ starvation specifically in roots of $P . \times$ canescens. High up-regulation was shown for PtPHT1;2 also in P starved P. simonii roots (Zhang et al., 2016). The transporters PtPHT1;1 and PtPHT1;2 may have functions in P uptake under low P conditions, because in Arabidopsis, the closely related AtPHT1;1, AtPHT1;2, AtPHT1;3 and AtPHT1;4 take up together more than $80 \%$ of $\mathrm{P}$ from the medium (Ayadi et al., 2015). In this study, PtPHT1;3 was highly expressed in leaves and further up-regulated upon $\mathrm{P}$ starvation. This observation suggests an important role in $\mathrm{P}$ distribution inside the plant in accordance with the observed high $\mathrm{P}$ allocation to the young leaves in $\mathrm{P}$ starved poplar. The up-regulation of $\mathrm{P}$ transporters led to a higher uptake capacity of $\mathrm{P}$ starved poplars. The $\mathrm{K}_{\mathrm{m}}$-values for $\mathrm{P}$ uptake for $\mathrm{P}$ starved $P . \times$ canescens was comparable with the $\mathrm{K}_{\mathrm{m}}$-value for $\mathrm{P}$ accumulation in roots of $\mathrm{P}$ starved P. deltoides (Desai et al., 2014). The present analysis showed that a minimal $\mathrm{P}$ concentration of $1 \mu \mathrm{M}$ in the growth medium was required for net $\mathrm{P}$ uptake. Otherwise, $\mathrm{P}$ uptake was prevented at very low concentrations. Since the free P concentration is low in most ecosystems (e.g. $5 \mu \mathrm{M}$ in 
forests beneath the organic layer (Asano et al., 2006; Fitzhugh et al., 2001; Ranger et al., 2001; van Hees et al., 2003) forest trees must have evolved further mechanisms to combat $\mathrm{P}$ deficiency.

One of the mechanisms to cope with low $\mathrm{P}$ concentrations is the production and secretion of purple acid phosphatases, which make organic P sources in the soil plant available by the release of inorganic phosphate. PAPs that were upregulated in leaves and roots upon P starvation (e.g. PtPAP1, PtPAP16, PtPAP29, PtPAP30) have probably a function in internal P mobilization. The homolog of PtPAP29 and PtPAP30 in Arabidopsis is AtPAP17. AtPAP17 was the first plant PAP purified and plays an role in $\mathrm{P}$ recycling e.g. during senescence (Del Pozo et al., 1999).

In accordance with the up-regulation of PAPs in roots, the root-associated acid phosphatase activity in $\mathrm{P}$ starved $P . \times$ canescens increased. This agrees with other studies, in which an enhanced phosphatase activity was shown for other poplar species under low P conditions ( $P$. tremuloides, $P$. simonii, $P . \times$ euramericana) (Desai et al., 2014; Gan et al., 2016). In Arabidopsis, AtPAP10, AtPAP12 and AtPAP26 are responsible for $70 \%$ of the root-associated acid phosphatase activity under low $\mathrm{P}$ conditions (Wang et al., 2014). In poplar, PtPAP4 was secreted by roots under high and low P availabilities. PtPAP1 was detected only under low P availability in the apoplastic washing fluid. Both are homologous to AtPAP10 and AtPAP12. These findings suggest a conserved function for the Arabidopsis and poplar proteins.

Based on these results, I propose following model (Figure 5.1) for the contributions of PHTs and PAPs in P uptake and P acquisition: PtPAP4 is secreted into the soil by poplar roots making phosphate available from organic $\mathrm{P}$ sources. Upon low $\mathrm{P}$ concentrations in the plant, PtPAP1 is additionally secreted. Consequently, the plant root-associated phosphatase activity increases. Because of their transcriptional upregulation, I suggest that PtPAPs like PtPAP1, PtPAP16, PtPAP29 and PtPAP30 respond to the plant $\mathrm{P}$ status and have a role in $\mathrm{P}$ acquisition in soil and $\mathrm{P}$ mobilization inside the plant. PtPHT1;9 and PtPHT1;12 take up P from the soil into the plant. With low P availability, PtPHT1;1 and PtPHT1;2 take part in the overall increased uptake activity. $\mathrm{P}$ is transported up to the leaves and re-allocated by PtPHT1;3, PtPHT1;9 and PtPHT1;12 inside the plant. 


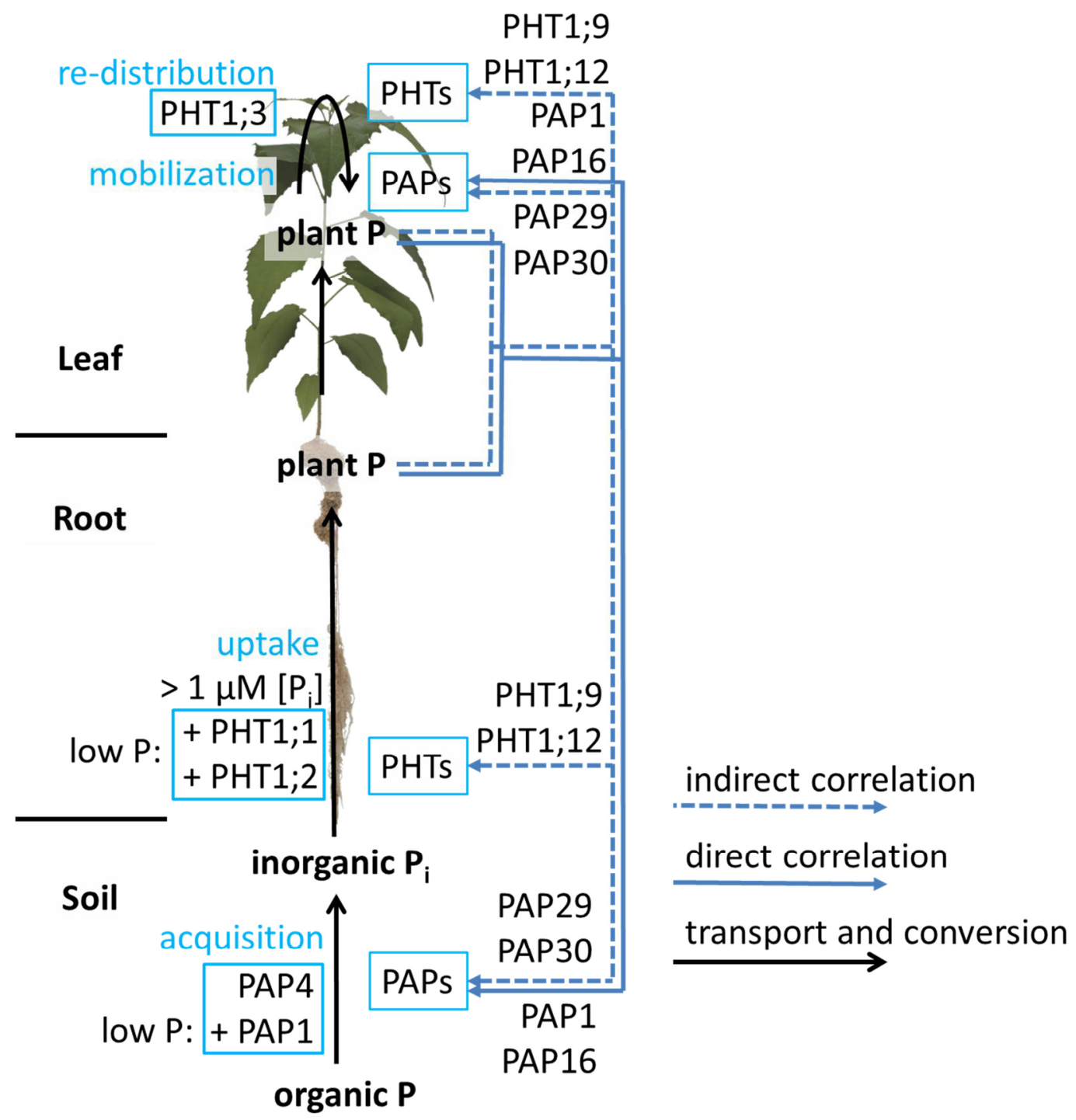

Figure 5.1. Model for the possible contributions of PAPs and PHTs in $P$ acquisition and $P$ uptake in poplar $(P . \times$ canescens $)$.

\subsection{Outlook}

Here, PtPHT1;1 and PtPHT1;2 were proposed to contribute to the P uptake in P starved poplar, but what amount of $\mathrm{P}$ they transport into the poplar and the contributions of other transporters to the enhanced $\mathrm{P}$ uptake efficiency remains open. Also, whether PtPAP1 is not only secreted but also cell-wall associated in poplar roots remains open. Further tests have to reveal the organic phosphate source preferences of poplars. 
Under natural conditions, poplar roots are colonized by mycorrhizal fungi with different abilities for P acquisition (Baum and Makeschin, 2000; Danielsen et al., 2013, 2012; Gehring et al., 2006; Seven and Polle, 2014). Ectomycorrhiza reduce the $\mathrm{K}_{\mathrm{m}}$ for plant $\mathrm{P}$ uptake, P accumulation (Cress et al., 1979; Desai et al., 2014; Van Tichelen and Colpaert, 2000) and the threshold concentration for $\mathrm{P}$ uptake (Van Tichelen and Colpaert, 2000). Loth-Pereda et al. (2011) studied the transcriptional regulation of phosphate transporters in mycorrhizal and non-mycorrhizal $P . \times$ canescens roots and found especially PtPHT1;9 and PtPHT1;12 to be upregulated upon colonization with ectomycorrhizal and arbuscular mycorrhizal fungi. But the regulation of $\mathrm{P}$ transporters in P starved mycorrhizal poplar roots and which fungal species are the most useful for enhanced $\mathrm{P}$ nutrition remains to be studied for sustainable poplar plantation management.

Timonen and Sen (1998) found enhanced acid phosphatase activity in proteins of mycorrhizal compared with non-mycorrhizal roots. Courty et al. (2010) found two poplar and no Laccaria PAP genes induced whereas Luo et al. (2009) found decreased expression for poplar PAPs upon mycorrhization probably due to increased tissue $\mathrm{P}$ concentrations. Whether fungal or plant PAPs enhance the root-associated phosphatase activity in mycorrhizal plants is not known.

These considerations indicate that poplar P nutrition cannot be fully understood when the contributions of interacting organisms are not considered. Therefore, further studies should focus on the influence of microorganisms on the P nutrition of poplar, especially since the contributions and abilities of bare-rooted poplars have been unraveled in this study. 


\subsection{References}

Asano, Y., Compton, J.E., Church, M.R. (2006): Hydrologic flowpaths influence inorganic and organic nutrient leaching in a forest soil. Biogeochemistry 81, 191-204.

Ayadi, A., David, P., Arrighi, J.-F., Chiarenza, S., Thibaud, M.-C., Nussaume, L., Marin, E. (2015): Reducing the genetic redundancy of Arabidopsis PHOSPHATE TRANSPORTER1 transporters to study phosphate uptake and signaling. Plant Physiol. $167,1511-1526$.

Baum, C., Makeschin, F. (2000): Effects of nitrogen and phosphorus fertilization on mycorrhizal formation of two poplar clones (Populus trichocarpa and P. tremula $\mathrm{x}$ tremuloides). J. Plant Nutr. Soil Sci. 163, 491-497.

Burg, J. van den (1985): Foliar analysis for determination of tree nutrient status- a compilation of literature data. Rapp. Rijksinst. Voor Onderz. Bos- En Landschapsbouw Dorschkamp Neth.

Courty, P.E., Labbé, J., Kohler, A., Marçais, B., Bastien, C., Churin, J.L., Garbaye, J., Tacon, F.L. (2010): Effect of poplar genotypes on mycorrhizal infection and secreted enzyme activities in mycorrhizal and non-mycorrhizal roots. J. Exp. Bot. 62, 249-260.

Cress, W.A., Throneberry, G.O., Lindsey, D.L. (1979): Kinetics of phosphorus absorption by mycorrhizal and nonmycorrhizal tomato roots. Plant Physiol. 64, 484487.

Danielsen, L., Lohaus, G., Sirrenberg, A., Karlovsky, P., Bastien, C., Pilate, G., Polle, $A$. (2013): Ectomycorrhizal colonization and diversity in relation to tree biomass and nutrition in a plantation of transgenic poplars with modified lignin biosynthesis. PLOS ONE 8, e59207.

Danielsen, L., Thürmer, A., Meinicke, P., Buée, M., Morin, E., Martin, F., Pilate, G., Daniel, R., Polle, A., Reich, M. (2012): Fungal soil communities in a young transgenic poplar plantation form a rich reservoir for fungal root communities. Ecol. Evol. 2, 1935-1948.

Del Pozo, J.C., Allona, I., Rubio, V., Leyva, A., De La Peña, A., Aragoncillo, C., PazAres, J. (1999): A type 5 acid phosphatase gene from Arabidopsis thaliana is induced by phosphate starvation and by some other types of phosphate mobilising/oxidative stress conditions. Plant J. 19, 579-589.

Desai, S., Naik, D., Cumming, J.R. (2014): The influence of phosphorus availability and Laccaria bicolor symbiosis on phosphate acquisition, antioxidant enzyme activity, and rhizospheric carbon flux in Populus tremuloides. Mycorrhiza 24, 369-382. 
Fitzhugh, R.D., Driscoll, C.T., Groffman, P.M., Tierney, G.L., Fahey, T.J., Hardy, J.P. (2001): Effects of soil freezing disturbance on soil solution nitrogen, phosphorus, and carbon chemistry in a northern hardwood ecosystem. Biogeochemistry 56, 215-238.

Gan, H., Jiao, Y., Jia, J., Wang, X., Li, H., Shi, W., Peng, C., Polle, A., Luo, Z.-B. (2016): Phosphorus and nitrogen physiology of two contrasting poplar genotypes when exposed to phosphorus and/or nitrogen starvation. Tree Physiol. 36, 22-38.

Ge, X., Tian, Y., Tang, L. (2015): Nutrient distribution indicated whole-tree harvesting as a possible factor restricting the sustainable productivity of a poplar plantation system in China. PLOS ONE 10, e0125303.

Gehring, C.A., Mueller, R.C., Whitham, T.G. (2006): Environmental and genetic effects on the formation of ectomycorrhizal and arbuscular mycorrhizal associations in cottonwoods. Oecologia 149, 158-164.

Gruber, B.D., Giehl, R.F.H., Friedel, S., Wirén, N. von (2013): Plasticity of the Arabidopsis root system under nutrient deficiencies. Plant Physiol. 163, 161-179.

Hirsch, J., Marin, E., Floriani, M., Chiarenza, S., Richaud, P., Nussaume, L., Thibaud, M.C. (2006): Phosphate deficiency promotes modification of iron distribution in Arabidopsis plants. Biochimie 88, 1767-1771.

Kellermeier, F., Armengaud, P., Seditas, T.J., Danku, J., Salt, D.E., Amtmann, A. (2014): Analysis of the root system architecture of Arabidopsis provides a quantitative readout of crosstalk between nutritional signals. Plant Cell 26, 1480-1496.

Lan, P., Li, W., Schmidt, W. (2015): “Omics" approaches towards understanding plant phosphorus acquisition and use, in: Plaxton, W.C., Lambers, H. (eds.): Annual Plant Reviews Volume 48. John Wiley \& Sons, Inc., Hoboken, NJ, USA, pp. 65-97.

Loth-Pereda, V., Orsini, E., Courty, P.-E., Lota, F., Kohler, A., Diss, L., Blaudez, D., Chalot, M., Nehls, U., Bucher, M., Martin, F. (2011): Structure and expression profile of the phosphate Pht1 transporter gene family in mycorrhizal Populus trichocarpa. Plant Physiol. 156, 2141-2154.

Luo, Z.-B., Janz, D., Jiang, X., Göbel, C., Wildhagen, H., Tan, Y., Rennenberg, H., Feussner, I., Polle, A. (2009): Upgrading root physiology for stress tolerance by ectomycorrhizas: Insights from metabolite and transcriptional profiling into reprogramming for stress anticipation. Plant Physiol. 151, 1902-1917.

Misson, J., Raghothama, K.G., Jain, A., Jouhet, J., Block, M.A., Bligny, R., Ortet, P., Creff, A., Somerville, S., Rolland, N., Doumas, P., Nacry, P., Herrerra-Estrella, L., Nussaume, L., Thibaud, M.-C. (2005): A genome-wide transcriptional analysis using Arabidopsis thaliana Affymetrix gene chips determined plant responses to phosphate deprivation. Proc. Natl. Acad. Sci. U. S. A. 102, 11934-11939. 
Mudge, S.R., Rae, A.L., Diatloff, E., Smith, F.W. (2002): Expression analysis suggests novel roles for members of the Pht1 family of phosphate transporters in Arabidopsis. Plant J. 31, 341-353.

Rai, V., Sanagala, R., Sinilal, B., Yadav, S., Sarkar, A.K., Dantu, P.K., Jain, A. (2015): Iron availability affects phosphate deficiency-mediated responses, and evidence of cross-talk with auxin and zinc in Arabidopsis. Plant Cell Physiol. 56, 1107-1123.

Ranger, J., Marques, R., Jussy, J.-H. (2001): Forest soil dynamics during stand development assessed by lysimeter and centrifuge solutions. For. Ecol. Manag. 144, 129-145.

Remy, E., Cabrito, T.R., Batista, R.A., Teixeira, M.C., Sá-Correia, I., Duque, P. (2012): The Pht1;9 and Pht1;8 transporters mediate inorganic phosphate acquisition by the Arabidopsis thaliana root during phosphorus starvation. New Phytol. 195, 356-371.

Seven, J., Polle, A. (2014): Subcellular nutrient element localization and enrichment in ecto- and arbuscular mycorrhizas of field-grown beech and ash trees indicate functional differences. PLOS ONE 9, e114672.

Timonen, S., Sen, $R$. (1998): Heterogeneity of fungal and plant enzyme expression in intact Scots pine-Suillus bovinus and-Paxillus involutus mycorrhizospheres developed in natural forest humus. New Phytol. 138, 355-366.

van Hees, P.A.W., Vinogradoff, S.I., Edwards, A.C., Godbold, D.L., Jones, D.L. (2003): Low molecular weight organic acid adsorption in forest soils: effects on soil solution concentrations and biodegradation rates. Soil Biol. Biochem. 35, 1015-1026.

Van Tichelen, K.K., Colpaert, J.V. (2000): Kinetics of phosphate absorption by mycorrhizal and non-mycorrhizal Scots pine seedlings. Physiol. Plant. 110, 96-103.

Wang, L., Lu, S., Zhang, Y., Li, Z., Du, X., Liu, D. (2014): Comparative genetic analysis of Arabidopsis purple acid phosphatases AtPAP10, AtPAP12, and AtPAP26 provides new insights into their roles in plant adaptation to phosphate deprivation: Comparative analysis of three Arabidopsis APases. J. Integr. Plant Biol. 56, 299-314.

Ward, J.T., Lahner, B., Yakubova, E., Salt, D.E., Raghothama, K.G. (2008): The effect of iron on the primary root elongation of Arabidopsis during phosphate deficiency. PLANT Physiol. 147, 1181-1191.

Zhang, C., Meng, S., Li, M., Zhao, Z. (2016): Genomic identification and expression analysis of the phosphate transporter gene family in poplar. Front. Plant Sci. 7, 1398. 


\section{Acknowledgements}

This work was done in the Department of Forest Botany and Tree Physiology and the associated Laboratory for Radio-Isotopes (LARI) and I would like to express my gratitude to many people for their help and support.

I am grateful to my supervisor Prof. Dr. Andrea Polle, for the possibility to work on this interesting project, for her support, suggestions and ideas during experiments, analysis and writing.

I thank Prof. Dr. Elvira Hörandl for being in my thesis committee and being the coreferee, and Prof. Dr. Ivo Feußner, PD Dr. Thomas Teichmann, Prof. Dr. Konstantin Krutovsky and Prof. Dr. Christian Ammer for being part of the examination committee. I also thank the University of Göttingen/LARI for funding my position and the Deutsche Forschungsgemeinschaft (DFG), Priority Program SPP 1685 "Ecosystem Nutrition" for financial support for this research project under grant number Po362/222.

I would like to thank Dr. Andrzej Majcherczyk from the Department of Molecular Wood Biotechnology and Technical Mycology for the proteomic analysis and his explanations and the late Karin Lange for her help during protein analysis. I thank Dr. Merlin Muhr from the Department of Plant Cell Biology for the vectors and experience in working with Gateway systems.

Thanks to all the LARI members for their great help, especially Gabriele Lehmann for helping me during all experiments involving radioactivity and for producing the phosphoimager pictures, Thomas Klein for his advice regarding molecular work, and Bernd Kopka who shared his enthusiasm for radioactivity, fixed every computer problem, and gave encouragement.

I would like to thank the people of the Forest Botany: all technicians for their help during harvests and laboratory experiments, especially Christine Kettner, who provided micropropagated poplars whenever needed and did the pressure extraction for element 
analysis, Marianne Smiatacz, and Gisbert Langer-Kettner, who measured C/N for me. I give many thanks to Dr. Dennis Janz who showed me how to analyze my data in R and gave many recommendations. I thank Prof. Dr. Henning Wildhagen for his suggestions especially regarding array analyses and Dr. Stephanie Werner for help with Arabidopsis, cloning and transformation.

Furthermore, I thank my former and current colleagues for the nice working atmosphere, inspiring discussions and becoming friends. I like to thank especially Dr. Anna Schmidt, Dr. Kristina Schröter, Dr. Bettina Otto, Lisa Kins, Gerrit-Jan Strijkstra, Shanty Paul, and Dade Yu. Finally, I especially thank my family and friends for their support and encouragement. 


\section{Eidesstattliche Erklärung}

Hiermit erkläre ich, dass ich die vorliegende Arbeit selbständig und ohne unzulässige Hilfe oder Benutzung anderer als der angegebenen Quellen und Hilfsmittel angefertigt habe. Es wurden alle Personen genannt, die direkt und indirekt an der Entstehung der vorliegenden Arbeit beteiligt waren. Alle Textstellen, die wörtlich oder sinngemäß aus veröffentlichten oder nichtveröffentlichten Schriften entnommen sind, wurden als solche kenntlich gemacht.

Die vorgelegte Arbeit wurde weder im Inland noch im Ausland in gleicher oder ähnlicher Form einer anderen Prüfungsbehörde zum Zweck einer Promotion oder eines anderen Prüfungsverfahrens vorgelegt.

Göttingen, Oktober 2016 


\section{Curriculum vitae}

\section{Persönliche Daten}

$\begin{array}{ll}\text { Name } & \text { Mareike Jana Kavka } \\ \text { Geburtsdatum } & 10.01 .1988 \\ \text { Geburtsort } & \text { Hamburg } \\ \text { Nationalität } & \text { deutsch }\end{array}$

\section{Ausbildung und wissenschaftlicher Werdegang}

10/2012-03/2016 Wissenschaftliche Mitarbeiterin zur Promotion

Georg-August Universität Göttingen

Abteilung Forstbotanik und Pflanzenphysiologie, Labor für Radioisotope

Titel der Dissertation: „Phosphorus nutrition of poplar“

10/2010-09/2012 Studium MSc. Diversität und Evolution

Universität Rostock

Titel der Masterarbeit: „Diatomeenentwicklung vs. Klimaschwankungen der letzten ca. 80 Jahre - Untersuchungen an laminierten Sedimenten des Woseriner Sees in MecklenburgVorpommern"

10/2007-09/2010 Studium BSc. Biowissenschaften

Universität Rostock

Titel der Bachelorarbeit: „Erarbeitung einer Artenliste pro- und eukaryonter Algen in Gewässern des Botanischen Gartens Rostock im Frühjahr 2010"

1998-2007 Gymnasium Glinde

1994-1998 Grundschule Willinghusen 